\title{
Der Sacre und die Theaterreform
}

Es ist kein Geheimnis, dass zwischen dem ersten Entwurf des Sacre du printemps (1910) - damals noch Великая Жертва (Das große Opfer) genannt - und dem schließlich 1913 im Théâtre des Champs-Élysées in Paris uraufgeführten Werk wesentliche Unterschiede bestehen: Ursprünglich war die Intention gewesen, ein Ballett zu schaffen, das auf archäologischen Untersuchungen gründete. Stravinskij hatte nämlich den Ehrgeiz entwickelt, das ästhetische Ideal der Ballets Russes erstmals in die Tat umzusetzen: Das große Opfer sollte ein veritables "neonationalist ,Gesamtkunstwerk “ werden ein antiliterarisches Musiktheater, bei dem alle drei beteiligten Kunstformen gleichberechtigt nebeneinander wirkten; das verwendete Sujet - und das ist für das vorliegende Kapitel zentral - sollte in der russischen Kultur bzw. auf „authentischen“256 Erkenntnissen fußen (Kapitel II.). Gemeinsam mit dem Archäologen und Bühnenbildner Nikolaj Rerich, der sich zu der Zeit in Sankt Petersburg wie kein anderer mit den archaisch gedachten Riten und Bräuchen des vorzeitlichen Russland auskannte, entwickelte Stravinskij also einen ersten Entwurf für sein neues Ballett. ${ }^{257}$ Taruskin beschreibt ausführlich, wie Stravinskij und Rerich hierfür akribisch ausgewählte folkloristische Vorbilder für Libretto und Musik verwendeten, und Garafola und Hudson weisen unter anderem darauf hin, dass sich auch Nižinskij bei der Erarbeitung seiner Choreografie von diesen Vorbildern beeinflussen ließ. ${ }^{258}$

256 Ich beziehe mich bei der Verwendung des schwierigen Begriffs „authentisch“ auf Taruskin, der unter anderem auch im Hinblick auf Libretto und Komposition des Sacre und das darin verwendete folkloristische Material von "archeological authenticity“ spricht. Er identifiziert im Streben nach „Authentizität“ ein zentrales Moment des Gesamtkunstwerksideals der Ballets Russes. Vgl. insbesondere die Teilkapitel "Archeological Authenticity“ und „The Musical Sources“ in: Taruskin, Stravinsky and the Russian Traditions, Bd. 1, S. 881-933. Dass im Sacre aber beispielsweise gerade für das Menschenopfer ein „authentisches“ Vorbild fehlt, machte jüngst Andreas Meyer noch einmal sehr deutlich. Vgl. Andreas Meyer: „Disrupted Structures. Rhythm, Melody, Harmony“, in: Avatar of Modernity, hg. von Danuser und Zimmermann, S. 102-129, hier S. 118.

257 Vgl. Taruskin, Stravinsky and the Russian Traditions, Bd. 1, S. 86o-966.

258 Vgl. unter anderem Taruskin, „Russian Folk Melodies in ,The Rite of Spring ““; Garafola, Diaghilev's Ballets Russes, S. 68. 
Im Sacre von 1913 waren diese Vorbilder nun aber gar nicht zu erkennen: Stravinskij hatte die ausgewählten Volksmelodien derart verarbeitet, dass sie beim bloßen Hören nicht identifizierbar waren. ${ }^{259}$ Und auch bezüglich der Choreografie sind - laut der Ballets-Russes-Expertin Claudia Jeschke - keine Rückgriffe auf bereits Vorhandenes festzustellen. ${ }^{260}$ Vergleicht man also den ursprünglichen Plan von 1910 mit dem tatsächlich realisierten Sacre von 1913, ist ein signifikanter qualitativer Sprung zu beobachten. Und so stellt sich die Frage: Wurde das zu Anfang (1910) für Das große Opfer intendierte archäologisch „Authentische“ bei der Realisierung des Sacre (1913) etwa bewusst verfälscht? Oder anders gefragt: Was fiel zwischen 1910 und 1913 vor, was Stravinskij von seinem hehren Ziel abbrachte, das „neonationalist“ Ideal der Ballets Russes in aller Konsequenz umzusetzen?

Nur wenigen Forschern scheint bewusst, dass die Mitarbeiter der Ballets Russes - allen voran Aleksandr Benua - mit Vetretern der um 1900 von Deutschland ausgehenden Theaterreformbewegung in Kontakt standen. In der Literatur findet der Austausch zwischen Ballets Russes und Theaterreformern kaum Erwähnung - entweder aufgrund von Unkenntnis oder aber, weil er bislang schlicht als bedeutungslos erachtet wurde. ${ }^{261}$ Wäre es also nicht denkbar, dass sich die Reformbewegung als ein wichtiger Schlüssel zum vollständigen Verständnis des Sacre erweist? Und könnte die Konfrontation der Ballets-Russes-Mitglieder mit jenem Reformgedankengut nicht vielleicht ein Auslöser für den dargelegten qualitativen Sprung in der Konzeption des Sacre gewesen sein?

259 Vgl. Hill, The Rite of Spring, S. 114. Vgl. hierzu auch Meyer, „Disrupted Structures“, S. 109-115. 26 o Vgl. Jeschke, „Russische Bildwelten in Bewegung. Bewegungstexte“, S. 77.

261 Am ausführlichsten berichtet darüber noch Scheijen, Diaghilev, S. 24of. In Garafolas Ballets-Russes-Studie findet sich der Name Georg Fuchs nur einmal, allerdings in einem anderen Kontext. Sie erwähnt Craig in ihrer Monografie zwar mehrfach, macht aber lediglich auf die Unterschiede von Craig- und Ballets-Russes-Ästhetik sowie auf Craigs Ballets-Russes-Kritik aufmerksam. Verbindungen benennt sie nicht. Vgl. Garafola, Diaghilev's Ballets Russes, S. 27, 46, 55, 87, 302 und 317f. In ihrem 2017 erschienenen Aufsatz „Harry Graf Kessler und die Ballets Russes. Nijinskys, Le Sacre du printemps' im Kontext der europäischen Moderne“ berichtet Gabriele Brandstetter von dem Tagebucheintrag Kesslers, in dem er beschreibt, wie sich Nižinskij und Gordon Craig über Marionetten austauschen, und weist auch darauf hin, dass Craig „der Schöpfer der ,Übermarionette“ sei. Die Theaterreform bleibt allerdings unerwähnt. Vgl. Gabriele BRANDSTETTE R: „Harry Graf Kessler und die Ballets Russes. Nijinskys ,Le Sacre du printemps' im Kontext der europäischen Moderne“, in: Sacre 1913/2013. Tanz, Opfer, Kultur, hg. von DIEs. und Katja SCHNEIDER, Freiburg i.Br., Berlin und Wien 2017, S. 227-252. Zu diesem Tagebucheintrag, Gordon Craig sowie den Verbindungen zwischen Nižinskij und Craig vgl. insbesondere Kapitel III.1.1.2. und III.1.2.2. 
Diesen Fragen soll im Folgenden nachgegangen werden, und zwar mit besonderem Augenmerk auf den Sommer 1911. Zu jenem Zeitpunkt wurde Stravinskijs zweites Ballett Pétrouchka in Paris uraufgeführt, für das er (auf Geheiß von Djagilev) intensiv mit Benua zusammengearbeitet und hierfür auch seine Arbeit am bereits 1910 skizzierten Ballett Das große Opfer unterbrochen hatte. Unmittelbar nach der Ballets-Russes-Saison 1911 nahm Stravinskij seine Arbeit an jenem Entwurf dann wieder auf, nahm gemeinsam mit Rerich markante Änderungen im Libretto vor und änderte unerwartet und radikal seine bis dato durchweg positive Einstellung gegenüber dem Choreografen Fokin. Es ist derselbe ereignisreiche Sommer, in dem Gordon Craig die Ballets Russes erstmals bezichtigt, seine Ideen gestohlen zu haben, und es ist derselbe Sommer, nach dessen Ausklang Stravinskij seinen langjährigen Sankt Petersburger Freund Andrej Rimskij-Korsakov dazu drängt, einen Artikel von Georg Fuchs zu lesen, der 1906 in Stuttgart erschienen war und 1910 in Sankt Petersburg in einer russischen Übersetzung.

\subsection{Ideentransfer: Von Deutschland über Russland nach Paris}

Die Ballets Russes gelten als die bekannteste und einflussreichste Ballettkompanie des 20. Jahrhunderts und ihr Initiator, Sergej Djagilev, als ihr Heros. ${ }^{262}$ Nach einem fulminanten Auftakt der Ballets-Russes-Saison in Paris 1909 und 1910 organisierte Djagilev erfolgreiche Tourneen in die europäischen Metropolen London, Rom, Wien und Berlin sowie binnen Kurzem in mehrere Städte in Nord- und Südamerika. Als wichtigste Innovation der Djagilev-Produktionen galt den Zeitgenossen „die Geschlossenheit der künstlerischen Konzeption und Ausführung ${ }^{\prime 263}$, bei der die Kritiker (spätestens seit der Mitwirkung Stravinskijs) neben Bühnengestaltung und Choreografie

262 Vgl. Garafola, Diaghilev's Ballets Russes, S. vii-xiii.

263 Monika Wortas: Leonide Massine. Choreograph zwischen Tradition und Avantgarde (Theatron. Studien zur Geschichte und Theorie der dramatischen Künste, Bd. 18), Tübingen 1996, S. 11. Woitas verweist hierbei auf Valerian Svetlov, der 1912 über die Ballets-Russes-Aufführungen Folgendes notiert: „Voilà comment, naguère, étaient mis sur pied les ballets. Il en va tout autrement avec le nouveau ballet, le ,ballet Diaghilew‘. Les artistes, peintres, compositeur, maître de ballet, littérateurs et autres personnes compétentes en matière d'art se réunissent et préparent ensemble le plan du prochain travail. Un sujet est proposé, élaboré en détail. L'un suggére tel ou tel trait qui lui vient à l'esprit, les autres approuvent ou non; par le fait, il devient difficile, étant donné ce travail collectif, de décider qui est le véritable auteur du livret. Naturellement, c'est celui qui en a eu l'idée première; mais le développement, les remaniements, les détails sont l'œuvre commune." Valerian Svetrov: Le Ballet Contemporain, hg. in Zusammenarbeit mit Lev BAKst, französische Übersetzung von Michel Dimitri Calvocoressi, Paris 1912, S. 56 f. 
auch den Bereich der Musik miteinschlossen. ${ }^{264}$ Heute noch werden der Gesamteindruck der Djagilev-Ballette sowie die darin betonte Visualität als erfolgsgenerierendes Moment gesehen. Und so lautet das Resümee des britischen Kunsthistorikers John Bowlt, das dieser zum hundertjährigen Ballets-Russes-Jubiläum formuliert, folgendermaßen:

Sergei Diaghilev's Ballets Russes exerted a lasting and profound effect on the culture of early twentieth century Russia, Europe and America not only because of the impaccable dancing $[\ldots]$, the skillful choreography $[. .$.$] and the radical music$ [...]. Some might argue, in fact, that the primary agent of influence was the visual resolution $-[. .$.$] and the costumes, sets and properties, no less then the dancer's$ leaps and bounds, were the real generators of movement in the Ballets Russes. ${ }^{265}$

In Anbetracht dieses (damals wie heute) flächendeckenden Elogiums lässt ein Dialog aufmerken, der unmittelbar nach der Londoner Ballets-Russes-Saison 1911 in der Augustausgabe der English Review erschien ${ }^{266}$ - ein wohl imaginäres Gespräch zwischen einer gewissen Lady Diana ${ }^{267}$ und einem unbekannten Theaterbesucher, aufgezeichnet von einem unbekannten Autor:

The Lady Diana, who was a grand person in Society, looked up the meaning of ,choreography' and took a party to the Russian Ballet. ,It's a new thing,' she said, ,choreography they call it; [...]'. [...] there was one occupant at her box who [answered] [...]. ,I know. That's it. You think this is a Russian discovery, don't you? You see this house chock-ful of people applauding what they consider to be some Moscovite revelation. In part it is. The dancing is Russian, the music is Russian, the splendid unity of design is Russian. But that beautiful blue hanging in Carnaval, the lighting and colour scheme of the stage that you liked so much in Pavillon d'Armide, in Igor, in Spectre de la Rose, where do you think the idea of that came from? From Paris? From St. Petersburg? [...] Let me tell you. Ten years ago the Russian ballet had no such thing. It is a new art, and, strange as it may seem to you, it came from England. [...] The man I am thinking of is the son of indubitably the greatest actress of our generation, Ellen Terry. [...] ,Oh, do go on! I simply must know his name. 'You shall. Dear Lady Diana,' said the man. ,You have seen the new choreographic art. It has conquered Russia, Berlin, Paris, and

264 Vgl. Dahms, Woitas, Oberzaucher-Schüller, Bröcker u.a., Art. ,Tanz', Sp. 329.

265 Bowlt, „Designing Dance“, S. 14.

266 Die erste Londoner Ballets-Russes-Saison fand vom 21. Juni bis zum 31. Juli 1911 im Königlichen Opernhaus in Covent Garden statt. Vgl. Scheijen, Diaghilev, S. 22 .

267 Lady Diana ist höchstwahrscheinlich eine Anspielung auf Lady Diana Cooper, geborene Diana Manners. Vgl. Garafola, Diaghilev's Ballets Russes, S. 302. Sie kann als eine berühmte und schillernde Persönlichkeit der Londoner Gesellschaft beschrieben werden, die sich in einflussreichen Kreisen bewegte. 
it is now conquering London. The man who gave that beautiful new stage art to Europe is, as I have said, an Englishman, and his name is Gordon Craig. ${ }^{268}$

Der namenlose Theaterbesucher bezweifelt 1911 genau das, was der zeitgenössischen Rezeption wie dem Gros der Wissenschaft als unbestritten gilt: Er behauptet, dass die eingangs genannte Innovation der Ballets Russes - das Gesamtkonzept, "the new choreographic art" bzw. „the new stage art" inklusive Wandbehängung, Licht- und Farbkonzept - gar nicht auf Djagilev und seine Ballets Russes zurückzuführen sei, sondern ihren Ursprung in England habe. Die einzelnen Bestandteile der Ballette - Tanz, Musik und Bühnenbild würden zwar aus Russland stammen, für Gesamtkonzeption und -eindruck aber sei jemand anderes verantwortlich: ebenjener erwähnte Engländer namens Gordon Craig. Zwei Monate später wird ein John Balance die Ballets Russes sogar der „kleptomania“ bezichtigen: Nicht nur die Ideen und Konzepte Gordon Craigs, sondern auch diejenigen anderer zeitgenössischer Künstler und Kunstströmungen glaubt dieser in den russischen Produktionen als „stolen“ wiederzuerkennen. ${ }^{269}$ Auch wenn es im Falle des anonymen Autors noch nicht belegt werden konnte, ist man sich heute einig darüber, wer hinter sowohl ihm als auch John Balance steckt - pikanterweise ist es dieselbe Person, die beide zu exponieren versuchen: nämlich der britische Schauspieler, Regisseur und Bühnenbildner Edward Gordon Craig selbst. ${ }^{270}$

Gordon Craig - darauf wurde bereits in Kapitel II verwiesen - gilt als einer der führenden Köpfe der Theaterreformbewegung zu Beginn des 20. Jahrhunderts. Er stammte aus einer angesehenen Schauspieler- und Theaterfamilie

268 Auszug aus: „Lady Diana goes to the Ballet“, in: The English Review 9 (1911), S. 167-169. Der Artikel wurde ohne Angabe eines Autors publiziert und ist ediert in: Gordon Craig on Movement and Dance, hg. von Arnold Reed, London 1977, S. 77-79. Zu Reaktionen britischer Autoren auf Djagilevs Ballets Russes allgemein vgl. Susan Jones: „Diaghilev and British Writing", in: Dance Research 27/1 (2009), S. 65-92.

269 Vgl. John Balance: „Kleptomania, or the Russian Theatre“, in: The Mask. A Quaterly Journal of the Art of the Theatre 4/2 (1911), S. 97-101, hier S. 98: „But the Russians have done one clever thing: they have increased the value of their [...] Ballet by adding to it a few tricks stolen from other lands and other arts."

270 Gemeinhin wird der zitierte Artikel Gordon Craig zugeschrieben. Vgl. unter anderem Garafola, Diaghilev's Ballets Russes, S. 470. Martha Vogeler mutmaßte 2008, dass womöglich auch Austin Harrison, der Herausgeber der English Review, den Artikel verfasst haben könnte, nachdem Craig sich bei ihm darüber beklagt habe, dass Djagilev ihm seine Ideen stehlen würde. Vgl. Martha S. Voge Le r: Austin Harrison and the ,English Review', Columbia und London 2008, S. 103. Ob nun von ihm selbst verfasst oder nicht, macht in diesem Fall allerdings keinen Unterschied. Craig hatte zu der Zeit offenbar das Gefühl, dass die Ballets Russes seine Ideen kopierten. 
des viktorianischen England und entwickelte bereits in seiner Adoleszenz eine Leidenschaft für das Theater. Zunächst tätig als Schauspieler, begann er bald Inszenierungsideen in Form von Skizzen und Zeichnungen festzuhalten und widmete sich Regiearbeiten sowie theoretischen Überlegungen zur Erneuerung des Theaters. ${ }^{271}$ Seine wichtigsten Schriften zur Schauspielkunst und zu einer Reform des Theaterwesens erschienen zwischen 1905 und 1910,272 und im oben zitierten Londoner Dialog sind es genau diese Reformideen, die Craig in den Produktionen der Ballets Russes wiederzuerkennen glaubt.

Craig vertrat schon früh die Auffassung, dass sich als Ausdrucksformen für die Bühne lediglich Tanz und Pantomime eigneten, ${ }^{273}$ und definierte 1905 ein Theaterkunstwerk als ein Zusammenspiel von „action, words, line, coulour, [and] rhythm“274, wobei er gleichzeitig betonte, dass die Bewegung darin "the most valuable part ${ }^{\text {“275 }}$ darstellen würde. Auch andere Reformtheoretiker der Zeit sahen in der Bewegung als solcher die Zukunft des modernen Theaters und forderten für den neuen Schauspielertypus eine Orientierung am Tänzer. ${ }^{276}$ Der deutsche Publizist und Regisseur Georg Fuchs beispielsweise hielt das Drama für "die höchst-vergeistigte und differenzierteste Anwendung der Tanzkunst“277 und konstatierte (ebenfalls 1905): „Das Drama ist möglich ohne Wort und ohne Ton, ohne Szene und ohne Gewand, rein als rhythmische Bewegung des menschlichen Körpers. ${ }^{\text {}}{ }^{278}$ Anders als Fuchs, der sich für die Ursprünglichkeit und Natürlichkeit des bewegten menschlichen Körpers interessierte und daher vom Schauspieler forderte, dass dieser aus seinem unbewussten

271 Vgl. Brauneck, Theater im 20. Jahrhundert, 2009, S. 210-213.

272 Ein großer Teil der Reformschriften Gordon Craigs, die zuvor an anderer Stelle publiziert worden sind, erschien $1911 \mathrm{im}$ Sammelband Edward Gordon CraIg (Hg.): On the Art of the Theatre, London 1911.

273 Vgl. Grund, Zwischen den Künsten, S. 127.

274 Edward Gordon Craig: „The Art of the Theatre“ (Berlin 1905), ediert in: On the Art of the Theatre, hg. von DERS., S. 137-181, hier S. 138.

275 Craig, "The Art of the Theatre“, S. 138.

276 Vgl. in diesem Kontext auch Gabriele Brandstetters Studie Tanz-Lektüren, in der sie anschaulich darstellt, inwiefern der Tanz Anfang des 20. Jahrhunderts als ein Symbol der Moderne begriffen werden kann. Vgl. Gabriele Brandstetten: Tanz-Lektüren. Körperbilder und Raumfiguren der Avantgarde, Frankfurt a.M. 1995, S. 336f. Friedrich Nietzsche und insbesondere sein Werk Also sprach Zarathustra waren an der Aufwertung des Tanzes um 1900 in starkem Maße beteiligt. Vgl. hierzu unter anderem auch die Ausführungen zu Friedrich Nietzsches Zarathustra als Tänzerfigur in Katrin Haf EmANn: Schamlose Tänze. Bewegungsszenen in Frank Wedekinds, Lulu'-Doppeltragödie und, Mine-Haha oder Über die körperliche Erziehung junger Mädchen', Würzburg 2010, S. 21-26.

277 Fuchs, „Der Tanz", S. 13.

278 Georg Fuchs: Die Schaubühne der Zukunft, Berlin und Leipzig 1905, S. 41. 
Inneren heraus agieren sollte, ${ }^{279}$ vertrat Craig die Ansicht, dass der Regisseur der seiner Ansicht nach einzig wahre Künstler des Theaterkunstwerks - seine Ideen von außen an die Schauspieler herantragen sollte. Einzige Aufgabe der Darsteller auf der Bühne sollte es somit sein, den Willen des Regisseurs umzusetzen. ${ }^{280}$ Zugunsten dieser übergeordneten Gestaltungsidee (oder auch Kontrolle) des Regisseurs forderte Craig schließlich (1908), den Schauspieler ganz von der Bühne zu verbannen und durch die „Über-Marionette“ zu ersetzen:281

The actor must go, and in his place comes the inanimate figure - the übermarionette we may cal[l] him [...]. Much has been written about the puppet - or marionette. To-day in his least happy period many people have come to regard him as rather a superior doll - and to think he has developed from the doll. This is incorrect. He is a descendant of the stone images of the old Temples - he is to-day a rather degenerate form of a God. [...] When anyone designs a puppet on paper, he draws a stiff and comic looking thing. Such a one has not even perceived what is contained in the idea which we now call the Marionette. [...] To that end we must study to remake these images - no longer content with a puppet, we must create an über-marionette. The über-marionette will not compete with Life - but will rather go beyond it. Its ideal will not be the flesh and blood but rather the body in Trance. ${ }^{282}$

Man könnte nun also vermuten, dass Craig 1911 neben seinen Überlegungen $\mathrm{zu}$ einer neuen szenischen Gestaltung im Theater auch sein Konzept der Über-Marionette in den Produktionen der Ballets Russes wiederzuerkennen glaubt. $^{283}$

279 Zu Georg Fuchs und dem von ihm für den Schauspieler oder Tänzer geforderten unbewussten Zustand vgl. Kapitel III.1.2.1.

280 Grund benutzt in diesem Kontext das Bild des Designers, um Craigs Gestaltungsidee zu verdeutlichen. Vgl. Grund, Zwischen den Künsten, S. 137.

281 Zu Idee und Begriff der Über-Marionette vgl. unter anderem Grund, Zwischen den Künsten, S. 118; Brauneck, Theater im 20.Jahrhundert, 2009, S. 214-218; ders., Die Welt als Bühne, Bd. 3, S. $858 \mathrm{f}$.

282 Edward Gordon Craig: „The Actor and the Über-Marionette“, in: The Mask. A Monthly Journal of the Art of the Theatre 1/2 (1908), S. 3-15, hier S. 11f. Das Wort über oder auch uber kann im Englischen unter anderem im Sinne von „superior, excellent“ verstanden werden und in dieser Bedeutung auf das deutsche über im Sinne des von Nietzsche gebrauchten Begriffs des Übermenschen zurückgeführt werden. Vgl. hierzu die Einträge zu uber und superman in: The American Heritage Dictionary of the English Language, hg. von Joseph PICKeTt, 5. Ausg., Boston 2011, S. 1749 und 1879.

283 Theaterwissenschaftler wie Olga Taxidou versuchen, Craigs Kritik und Anschuldigungen gegen die Ballets Russes unter anderem damit zu erklären, dass dem Engländer trotz ähnlicher Ziele nie ein solch durchschlagender Erfolg vergönnt war wie dem russischen 
Als zentrale Neuproduktion der Ballets Russes für die Pariser Saison 1911 kann Stravinskijs Ballett Pétrouchka gesehen werden, das am 13. Juni 1911 im Théâtre du Châtelet uraufgeführt wurde. In London pflegte Djagilev immer ein etwas konservatives Programm zu zeigen. ${ }^{284}$ Dieser Tatsache ist es wohl geschuldet, dass Pétrouchka - das aktuellste Ballett der Truppe - dort nicht auf dem Programm zu finden war. Da Craig allerdings einige Wochen in Paris verbrachte, bevor er am 16. Juli nach London zurückkehrte, ${ }^{285}$ ist nicht ganz auszuschließen, dass er Stravinskijs neuestes Ballett entweder gesehen oder aufgrund des durchschlagenden Erfolgs - zumindest davon gehört hatte.

Sollte Craig mit seiner Behauptung recht haben, dass die Produktionen der Ballets Russes auf seinen höchst eigenen Reformideen fußen, muss es zwischen diesen und Stravinskijs Pétrouchka evidente Zusammenhänge geben - und zwar in Libretto, Notentext und Choreografie.

\subsubsection{Die Kontrolle von Puppen und Publikum}

Stravinskijs Chroniques de ma vie ist zu entnehmen, dass er eigentlich ein Konzertstück für Klavier und Orchester schreiben wollte, als er sich an die Arbeit von Pétrouchka machte. Die zündende Idee für einen passenden Titel kam ihm erst nach langer Überlegung:286 Petruška, die Hauptfigur des russischen Puppentheaters - ein komischer Kauz und Unruhestifter mit Buckel, Hakennase und schriller Stimme, meist ausgestattet mit Knüppel, Glocke, einem spitzen Hut und ausgebeulter Hose. Ein eher tölpelhafter Charakter - ähnlich dem italienischen Pulcinella oder dem angelsächsischen Punch. ${ }^{287}$ Man kann davon ausgehen, dass Djagilev schon im Oktober 1910 jene Abschnitte von Stravinskijs neuer Komposition für Orchester und Klavier zu Ohren gekommen waren und den Komponisten anschließend davon überzeugte, aus jenen Versatzstücken ein neues Ballett zu machen. ${ }^{288}$ Für die Ausarbeitung des Librettos sollte sich Stravinskij mit Benua zusammentun, den er ja bereits durch seine vorherigen Arbeiten für die Ballets Russes kannte.

Impresario. Vgl. Olga Taxidou: The Mask. A Periodical Performance by Edward Gordon Craig (Contemporary Theatre Studies, Bd. 30), Amsterdam 1998, S. 63f.

284 Vgl. Scheijen, Diaghilev, S. 232.

285 Vgl. Lindsay Mary Newman (Hg.): The Correspondence of Edward Gordon Craig and Count Harry Kessler. 1903-1937, London 1995, S. 73.

286 Vgl. Strawinsky, Chroniques de ma vie, Bd. 1, S. 7 of.

287 Diese Petruška-Beschreibung orientiert sich an den pointierten Ausführungen von Elizabeth A. WARnen: The Russian Folk Theater, Den Haag 1977, S. 109-126, hier S. 114f.

288 Vgl. Taruskin, Stravinsky and the Russian Traditions, Bd. 1, S. 67 o. 
Benua wird maßgeblicher Einfluss bei der Entstehung des Ballettszenarios zugeschrieben. ${ }^{289}$ So geht beispielsweise auf ihn das Kuriosum zurück, dass die Figur des namensgebenden Tölpels Petruška, den Stravinskij in seinen Chroniques de ma vie beschreibt, im 1911 uraufgeführten Ballett gar nicht auftaucht. Die von den Ballets Russes präsentierte Figur erinnert vielmehr an den melancholischen Charakter des französischen Pierrot bzw. italienischen Pedrolino aus der Commedia dell'Arte. Der Pariser Bühne war Pierrot nicht neu: Die Trias Pierrot - Harlequin - Columbine, in Stravinskijs Ballett durch Petruška - Moor - Ballerina ersetzt, wurde in Westeuropa spätestens Ende des 19. Jahrhunderts zu einem beliebten Sujet für Theater, Literatur und Kunst. Auch in Russland, wo die Symbolisten im Commedia-dell'Arte-Trio schnell großes Potenzial erkannten, erschien der Pierrot Anfang des 2o. Jahrhunderts immer häufiger in Ballett und Theater. ${ }^{290}$

Tanz- bzw. Musikwissenschaftler wie Jordan, Walsh und Taruskin verweisen im Kontext der Pétrouchka-Handlung auf Stravinskijs Interesse an Mejerchol'ds zeitgenössischen russischen Theaterproduktionen. ${ }^{291}$ Eine Produktion wird dabei (aufgrund der zeitlichen Nähe der Uraufführung und des dort verwendeten Commedia-dell'Arte-Sujets) immer wieder besonders hervorgehoben: Šarf Kolumbiny, eine abgeänderte Version von Arthur Schnitzlers Ballettpantomime Der Schleier der Pierrette ${ }^{292}$, die Mejerchol'd bereits sechs Monate nach der Dresdner Uraufführung des deutschsprachigen Vorbilds im Oktober 1910 in Sankt Petersburg auf die Bühne brachte. Unter anderem bereicherte Mejerchol'd das Stück um die Figur eines Kapellmeisters, der, so der Mejerchol'd-Experte Edward Braun, "[together with] his sinister band [...] [dictated] [t]he rhythm of the entire production“293.

289 Vgl. ebd., S. 661-695; Andrew Wachtel: „The Ballet's Libretto“, in: ,Petrushka', hg. von ders., S. 11-41.

290 Zur charakterlichen Umdeutung des Petruška in den eher melancholischen Pierrot vgl. Catriona Kelly: Petrushka. The Russian Carnival Puppet Theatre, Cambridge 199o, S. 164f.; Taruskin, Stravinsky and the Russian Traditions, Bd. 1, S. 665f. Zur Situation in Westeuropa vgl. Wachtel, „The Ballet's Libretto“, S. 22. Zur Situation in Russland vgl. ebd.; Taruskin, Stravinsky and the Russian Traditions, Bd. 1, S. 674-678; Douglas Clayton: Pierrot in Petrograd. The Commedia dell'Arte/Balagan in Twentieth-Century Russian Theatre and Drama, Montreal 1993, S. 75-124.

291 Vgl. Jordan, Stravinsky Dances, S. 32-35; Walsh, A Creative Spring, S. 17of.; Taruskin, Stravinsky and the Russian Traditions, Bd. 1, S. 676ff.

292 Vgl. hierzu unter anderem Elisabeth Schmieren: „Literarische Pantomime und Ballettpantomime. ,Der Schleier der Pierrette' von Arthur Schnitzler und Ernst von Dohnányi“, in: Arthur Schnitzler und die Musik (Akten des Arthur-Schnitzler-Archivs der Universität Freiburg, Bd.3), hg. von Achim Aurnhammer, Dieter Martin und Günter SCHNitZler, Würzburg 2014, S. 157-175, hier S. 16o.

293 Edward Braun: Meyerhold. A Revolution in Theatre, London 1995, S. 98. 
Sucht man inhaltliche Parallelen zwischen Mejerchol'ds Schnitzler-Adaption und Pétrouchka, wird man - abgesehen vom Commedia-dell'Arte-Sujet - nur an einer Stelle fündig: Der Zauberkünstler, der im ersten und letzten (dem vierten) Bild des Balletts auftritt, ähnelt dem Kapellmeister, den Mejerchol'd in seiner Schnitzler-Adaption im Nachhinein hinzugefügt hat. Die Parallelen lassen sich wie folgt darstellen: ${ }^{294}$ In Pétrouchka erweckt der Zauberkünstler als Inhaber des auf dem Jahrmarkt präsentierten Puppentheaters im ersten Bild seine drei Puppen Petruška, Mohr und Ballerina zum Leben (Fokus, Le tour de passe-passe, Ziffer 30). Nachdem er sie mit seiner magischen Flöte berührt hat (vier Takte vor Ziffer 33), führen die Puppen vor den Augen des Jahrmarktpublikums in mechanischer und puppenhafter Manier einen ,wilden Tanz' auf (Russkaja, Danse russe, Ziffer 33 bis Ziffer 47). Petruška ist die mit den meisten Gefühlen ausgestattete Puppe. Er leidet sowohl unter seinem seltsamen Aussehen als auch unter der Macht des Zauberkünstlers, fühlt sich unfrei und ist traurig. Als er hinter den Kulissen des Puppentheaters Trost und Zuneigung bei der Ballerina sucht, flieht diese vor ihm direkt in die Arme des Mohrs, der im Gegensatz zu Petruška mit rohen und nahezu bösartigen Charakterzügen ausgestattet ist. Nach einer Eifersuchtsszene wird Petruška im vierten Bild vom Mohren getötet. Erst als der Zauberkünstler Petruška wieder in seine ursprünglich leblose Gestalt zurückverwandelt, beruhigt sich die schockierte Menschenmenge, die im vierten Bild Zeuge des Dramas wurde. Die tragische Geschichte erhält eine unverhoffte Wendung, als der Zauberkünstler den tot geglaubten Petruška auf dem Dach des Puppentheaters erblickt: Erstgenannter flieht daraufhin angsterfüllt von der Bühne.

Ähnlich wie der Zauberkünstler zeigt Mejerchol'ds Kapellmeister in Šarf Kolumbiny während der ganzen Produktion Präsenz und kontrolliert durch seine magischen Kräfte sowohl das Orchester als auch das Verhalten der Figuren auf der Bühne. Vergleichbar mit dem Pétrouchka-Ende flieht er am Schluss durch den Zuschauerraum von der Bühne - verschreckt vom tragischen Verlauf der Geschichte, die er durch seine magischen Kräfte hervorgerufen hat.

Es ist überliefert, dass die Figur des Zauberkünstlers und die damit verbundenen mysteriösen und fantastischen Bestandteile für Benua und Stravinskij ein wichtiger, wennnichtsogarzentraler Aspekt des Ballettswaren. ${ }^{295}$

294 Auf die Parallelen wurde bereits hingewiesen von Wachtel, „The Ballet's Libretto“, S. 24; Clayton, Pierrot in Petrograd, S. 138.

295 Die fantastischen und mystischen Elemente sollten überzeugend dargestellt werden. Benua schreibt hierzu an Stravinskij: „Серьезно, необходимо повидаться. Мне кажется чрезвычайно важным связать эту штуку, чтобы она держалась, чтобы все было лихо, тогда только фантастика и таинственность приобретут убедительность““ „Ganz im Ernst, wir müssen uns treffen. Mir scheint es außerordentlich wichtig, die Sache zu 
Sowohl Stravinskijs für den Fokus verwendete düstere Harmonien (7 Takte nach Ziffer 29) können in diesen Kontext eingeordnet werden als auch das von Benua angefertigte Porträt des Magiers, das Letztgenannter in Petruškas Zimmer (zweites Bild) gehängt hatte, „so that it should constantly remind

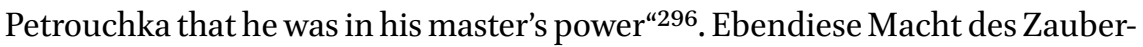
künstlers äußert sich auch musikalisch: Anders als in den zwei mittleren Teilen verarbeitet Stravinskij in den Randbildern populäre russische Volks- und Tanzmelodien. ${ }^{297}$ Als eine Art Melodiecollage lässt er immer wieder einzelne Zitate aus dem Orchester in den Vordergrund treten und lenkt so die Aufmerksamkeit auf eine bestimmte szenische Besonderheit, die gleichsam choreografisch umgesetzt wird (in der Partitur befinden sich jeweils dazugehörige szenische Angaben). Kennt man das Szenario, ist das bunte Jahrmarkttreiben, das dem Zuschauer szenisch auf der Bühne präsentiert wird, auch mit geschlossenen Augen bzw. durch bloßes Hören der Musik wahrnehmbar. Um die Gleichzeitigkeit der vielen Eindrücke auf der Bühne zu verstärken, überlagert Stravinskij immer wieder verschiedene Melodien und Rhythmen - so beispielsweise mit dem Einwurf einer abgespaltenen Version der Anfangsfigur durch die Violine I bei Ziffer 14 (erstmals zu hören in Takt 1 in den Flöten), während das Motiv der ersten Tänzerin ab Ziffer 13 in den Klarinetten erklingt. Diese „naturalistic montage ${ }^{\prime 298}$, wie Taruskin sie nennt, endet ab Ziffer 29, kurz bevor der Zauberkünstler zum ersten Mal auf der Bühne erscheint. Mit dem Einsatz seiner magischen Flöte ab Ziffer 30 wird die Collage vollkommen zurückgenommen und das musikalische Geschehen auf eine einzelne Melodielinie reduziert. In der Russkaja (Ziffer 33) beginnen die Marionetten dann - entfesselt von der magischen Flöte des Zauberkünstlers (4 Takte vor Ziffer 33) - ihren fremdgeleiteten Tanz.

Es überrascht nicht, dass die unmittelbaren Reaktionen auf die Russkaja von Stravinskijs Kollegen in Russland bescheiden ausfielen. Die hämmernden, eher unfeinen Quintparallelen des Klaviers ab Ziffer 43 sind nur ein Grund

verbinden, damit es bestehen bleibt, damit alles auf Zack bleibt, nur dann werden die fantastischen und geheimnisvollen Elemente ihre Überzeugungskraft entfalten." Brief von Benua an Stravinskij vom 12./25. Dezember 1910, ediert in: Perepiska, Bd. 1, hg. von Varunc, S. 256.

296 Benois, Reminiscences, S. 333-334. Für Benua war es zentral, dass der Zauberkünstler auf dem Porträt die ganze Zeit auf Petruška hinunterblicken sollte. Vgl. Wachtel, „The Ballets' Libretto“, S. 33 .

297 Vgl. hierzu Richard Taruskin: „Stravinsky's ,Petrushka“, in: ,Petrushka, hg. von Wachtel, S. 67-114, hier S. 7of.; Taruskin, Stravinsky and the Russian Traditions, Bd.1, S. $696 f$.

298 Taruskin, „Stravinsky's ,Petrushka““, S. 77. 
dafür. ${ }^{299}$ Genau diese in zwei Vierertaktgruppen gegliederte und größtenteils aus Sechzehnteln bestehende musikalische Figur, die Stravinskij ab Ziffer 43 im Klavier exponiert, bestimmt die Russkaja als zentrale und wiederkehrende Gestalt von Anfang an. Sie erklingt gleich zu Beginn des Tanzes (Teil A, Ziffer 33 bis 34, siehe unpag. Tafelteil, Notenbeispiel 1), ist durch den G-Dur-Septakkord auf der ersten Zählzeit harmonisch klar bestimmt und wird an ihrem Ende (als zu den Zwischenteilen überleitendes Moment) zu einem e-Moll-Akkord geführt. Analog zum Tanz der Puppen auf der Bühne wird die Musik aufgrund der metrischen Regelmäßigkeit oft als unnatürlich, ausdruckslos und mechanisch beschrieben, was Stravinskij auch im folgenden Teil B (Ziffer 34 bis 37) durch die konstante Viertaktigkeit der hier erklingenden unterschiedlichen Ostinatomodelle erreicht.

Die mechanisch anmutende Regelmäßigkeit der musikalischen Bewegung am Anfang der Russkaja evoziert im Zuschauerraum Erwartungen an deren Weiterführung. Genau mit diesen Hörerwartungen scheint Stravinskij im weiteren Verlauf der Russkaja zu spielen: Es irritiert den Zuschauer/Zuhörer gleich doppelt, wenn die Anfangsfigur ab Ziffer 37 zum zweiten Mal einsetzt. Anders als am Anfang der Russkaja wird die Figur hier leicht variiert, auftaktartig um einen Schlag nach vorne verschoben und verschleiert ihren Einsatz außerdem durch die lyrisch anmutende Sextakkordkette in Violinen und Flöten, die direkt in den Auftakt zu Ziffer 37 übergeht. Die bekannte musikalische Bewegung kann so erst verzögert wahrgenommen werden. Auch das Vexierspiel mit der zu Anfang klar artikulierten Viertaktigkeit in Teil C (Ziffer 39 bis 42) täuscht die Hörerwartungen des Publikums: Durch das Abspalten und Variieren des dritten Taktes der Solo-Oboen-Figur drei Takte nach Ziffer 40 (zum ersten Mal tritt sie zusammen mit dem Einwurf von Flöte, Oboe, Viola und Cello als eine viertaktige Figur ein Takt nach Ziffer 39 auf) und die direkt daran anschließende Abspaltung und Sequenzierung des variierten Taktes in den Soloviolinen (in den drei Takten vor Ziffer 41) wechselt die Taktgruppenstruktur erstmals von der regelmäßigen Viertaktigkeit zu zwei Dreierphrasen. Wieder ist dieser Wechsel in Ziffer 40 erst verspätet wahrnehmbar - nämlich mit Beginn des zweiten Taktes vor Ziffer 41 (siehe hierzu Ziffer 40 bis 41, unpag. Tafelteil, Notenbeispiel 2).

Die nun folgenden unterschiedlichen, ineinander verschachtelten Taktgruppenmodelle von Klavier, Flöten und Klarinetten (Ziffer 41 bis 42) sowie der unvorbereitete Einsatz der Anfangsmelodie in Form zweier zweitaktiger Einwürfe von Klavier und Piccoloflöte (13 Takte vor Ziffer 43) verschärfen diese

299 Zu den Reaktionen von Andrej Rimskij-Korsakov und Michail Gnesin auf die Russkaja vgl. ebd., S. 83-85. 
Irritation. Was sich in den ersten drei Teilen der Russkaja andeutet, wird im letzten Teil (A“ und D) ab Ziffer 43 forciert: Die Anfangsfigur führt bei ihrem letzten Einsatz ab Ziffer 43 nicht mehr zu dem überleitenden e-Moll-Klang, sondern endet quasi kreisförmig auf ihrem Anfangsklang und könnte in dieser Form ebenso wie die ineinandergreifenden Ostinatomuster in Klavier, Viola und Violinen ab Ziffer 44 endlos wiederholt werden. Das abrupte Aussetzen der Anfangsfigur ab Ziffer 44 und die Akkordeinwürfe des gesamten Orchesters (Ziffer 45, zwei und vier Takte nach Ziffer 45, Ziffer 46) sind weitere Irritationsmomente. Spätestens ab Ziffer 44 ist nicht mehr vorauszusehen, wann ein rhythmischer Akzent folgt und mit ihm eine musikalische Bewegung abgebrochen wird. Und so machen die Störmomente der (vordergründig mechanische Regelmäßigkeit suggerierenden) Russkaja die auf der Bühne stattfindende Beseelung der Puppen im Zuschauerraum körperlich nachvollziehbar: Animiert durch Stravinskijs unvorhersehbare rhythmische Akzente findet sich der Zuschauer/Zuhörer gewissermaßen in jenem fremdgeleiteten Zustand wieder, der gleichzeitig durch die vom Zauberkünstler hervorgerufenen mechanisch ruckhaften Bewegungen der Tänzer auf der Bühne visualisiert wird. Der von Stravinskij und Benua von Anfang an als zentral erachtete Aspekt des Magischen war also nicht nur in Form der Zauberkünstlerfigur in Libretto und Choreografie präsent, sondern auch in der Musik: Die mechanisch anmutende musikalische Bewegung der Russkaja wird von Stravinskij immer wieder bewusst gestört, sodass Hörerwartungen des Publikums unentwegt enttäuscht werden. Stravinskijs kompositorisches Vorgehen könnte derart als Versuch verstanden werden, die (nicht nur architektonisch) vorgegebene Grenze zwischen Bühne und Publikum zu überwinden: Immerhin wird der Zuhörer/Zuschauer ja gewissermaßen durch Stravinskijs Musik ,beseelt' und durch das körperliche Wahrnehmen des fremdgeleiteten Zustands der Marionetten in das Bühnengeschehen integriert. Und ein Ineinandergreifen von Zuschauer- und Bühnenraum wurde von den Theaterreformern Anfang des 20. Jahrhunderts umfangreich diskutiert. ${ }^{300}$

Vor dem Hintergrund von Craigs Vorwürfen gegenüber den Ballets Russes sowie seines bereits dargelegten Konzepts der Über-Marionette und der damit in Zusammenhang stehenden Forderung, den Schauspieler durch eine solche zu ersetzen, drängt sich an dieser Stelle folgende Frage auf: Könnte

300 Die stärkere Zusammenführung von Zuschauer- und Bühnenraum ist eine zentrale Forderung der Theaterreformbewegung Anfang des 20. Jahrhunderts und äußerte sich am prominentesten in den Schriften von Georg Fuchs, der für die Aufhebung der Rampe plädierte. Vgl. Balme, Das Theater von Morgen, S. 16. Zum Einfluss von Georg Fuchs' Schriften auf die Mitglieder der Ballets Russes vgl. Kapitel III.1.2. 
in Pétrouchka und insbesondere im sich in sowohl Libretto, Choreografie als auch Musik äußernden Aspekt des Magischen etwa eine (wenn vielleicht auch nur indirekte) Kritik am Craig'schen Konzept und an der damit verbundenen Kontrolle des Regisseurs stecken? Immerhin handelt es sich bei der Hauptfigur des Balletts um eine durch magische Kräfte des Zauberkünstlers beseelte Marionette, die, anders als die mit weniger Emotionen ausgestatteten Figuren Mohr und Ballerina, unter der allseits gestaltenden Macht und Kontrolle ihres Marionettenspielers leidet.

\subsubsection{Stravinskijs Pétrouchka und Craigs Reformideen}

Mehrfach wurde in der Forschung auf die Nähe des Pétrouchka-Szenarios zum russischen Symbolismus und zum zeitgenössischen sowie populären russischen Theater aufmerksam gemacht. So zeigt Taruskin beispielsweise, dass die gesamte Handlung des ersten Bildes in einer zeitgenössischen Beschreibung zum russischen Jahrmarkttreiben zu finden ist. Was diese Beschreibung allerdings nicht liefert, ist - und das merkt Taruskin auch explizit an - eine Vorlage für den von Stravinskij und Benua als so zentral erachteten Aspekt des Magischen. ${ }^{301}$ Der Slawist Andrew Wachtel sieht den Ursprung des Magischen weder im Symbolismus noch in der Folklore Russlands. Er verortet die Zauberkünstlerfigur und deren satanistische Charakterzüge vielmehr im Kontext des Grotesken und äußert den Verdacht, dass sie möglicherweise auch auf eine Beschäftigung Benuas mit den Werken Nikolaj Gogol's zurückgeführt werden könnte. ${ }^{302}$

Ein Abschnitt aus dem Aufsatz „Teatr odnoj voli“ („Das Theater des einen Willens") des russischen Symbolisten Fëdor Sologub von 1908 liefert einen Hinweis, der bislang noch nicht ausreichend in Verbindung mit Pétrouchka gebracht worden ist; im Zusammenhang mit bereits dargestellten magischen Elementen in Pétrouchka und den "kleptomania“-Bezichtigungen Gordon Craigs erweist sich der Essay aber als aufschlussreich. Sologub beschreibt darin eine Marionette, die an Stravinskijs Pierrot-haften Petruška erinnert, der unter der Macht des Zauberkünstlers leidet, durch dessen Porträt an der Wand ständig an die eigene Unfreiheit erinnert wird, sich für seine ungelenken Bewegungen schämt und dessen Lebendigkeit durch die magischen Kräfte des Zauberkünstlers jederzeit beendet werden kann:

301 Vgl. Taruskin, Stravinsky and the Russian Traditions, Bd. 1, S. 690 und Kapitel III.1.1.1.

302 Vgl. Wachtel, „The Ballet's Libretto“, S. 32-34. 
И нельзя [марионетке] уйти от этого, и даже нельзя [марионетке] забыть это. [...] Бедная марионетка для одной только трагической игры! Оттуда, из-за кулис, кто-то равнодушный дергал тебя за незримую веревочку, кто-то жестокий пытал тебя огненною мукою страдания, кто-то злой пугал тебя бледными ужасами ненавистной жизни [...]. А здесь, в партере, кого-то забавляли твои неловкие движения, - под подергивания страшной веревочки $[. .$.$] . Довольно, [...] все ремарки исполнены довольно точно, -$ сматывается веревочка. ${ }^{303}$

[Die Marionette] kann nicht fliehen, [sie] kann nicht einmal vergessen. [...] Die arme Marionette existiert lediglich aufgrund des tragischen Spiels! Hinter den Kulissen zog jemand Gleichgültiges mit unsichtbarem Faden an dir, jemand Grausames folterte dich mit Höllenqualen, jemand Böses flößte dir Angst ein; mit blassem Schrecken des verhassten Lebens [...]. Doch hier unten, im Parterre, ist jemand von deinen ungeschickten Bewegungen unter dem Zucken dieses fürchterlichen Fadens belustigt [...]. Genug, [...] alle Bühnenanweisungen wurden korrekt ausgeführt - der Faden wird wieder eingewickelt.

Ruft man sich Craigs vorerst absurd erscheinende Behauptung ins Gedächtnis, die Mitglieder der Ballets Russes würden in ihren Produktionen seine Reformideen und -konzepte kopieren, erstaunt folgender Satz Sologubs, der unmittelbar vor seinen Ausführungen zur Marionette steht: „А почему же, однако, и не быть актеру, как марионетка? Для человека это не обидно.“304 („Doch warum im Übrigen sollte der Schauspieler nicht einer Marionette gleichen? Für den Menschen ist das nicht beleidigend.") Dieser Ausruf klingt wie ein Echo auf Craigs Vorschlag, den Schauspieler durch eine Marionette zu ersetzen.

Auch Sologubs Aufsatz erschien 1908 im bereits erwähnten russischen Sammelwerk Teatr. Kniga o novom teatre. Zwar erschien Craigs Aufsatz „The Actor and the Über-Marionette", der international für großes Aufsehen sorgte und auch Kritik nach sich $\operatorname{zog}^{305}$, ebenfalls 1908, sodass ein unmittelbarer Bezug zwischen den beiden Veröffentlichungen unwahrscheinlich erscheint. Es muss allerdings davon ausgegangen werden, dass Craigs Ideen und

303 Sologub, „Teatr odnoj voli“, S. 188f. In einer englischen Übersetzung findet sich der Text unter Fyodor Sologub: „The Theatre of the Single Will“, in: The Russian Symbolist Theatre. An Anthology of Plays and Critical Texts, hg. und übers. von Michael Green, Ann Arbor 1986, S. 147-162, hier S. 154f. Sologubs Aufsatz gilt als polemische Schrift gegen Mejerchol'ds Theaterinnovationen. Vgl. Simon Morrison: Russian Opera and the Symbolist Movement, Berkeley 2002, S. 105; Wachtel, „The Ballet's Libretto“, S. 39. Auch Benua wird in der Literatur als einer der schärfsten Kritiker Mejerchol'ds genannt. Vgl. Braun, Meyerhold, S. 76 .

304 Sologub, „Teatr odnoj voli“, S. 188.

305 Vgl. Grund, Zwischen den Künsten, S. 216. 
Konzepte bereits zuvor in einem ausgewählten russischen Kreis diskutiert worden waren. ${ }^{306}$ Dass sie über Deutschland dorthin gelangt sind, belegen Mejerchol'ds Ausführungen zu Craig von 19o9:

Наши театральные хроникеры своевременно не сообщили о столь знаменательном явлении, как новые сценические опыты Э.Г. Крэга. [...] Соседи-немцы помогли интересующимся судьбами нового театра узнать о новых приемах инсценировки Э.Г. Крэга. Надо было появиться театру Рейнхардта, чтобы после успехов его ,камерных спектаклей напасть на имя Э.Г. Крэга. В сезоне 1904/5 г. мы видим Крэга в Берлине. Здесь он пишет декорации к пьесе Гофмансталя в ,Lessing-Theater (,Лессинг-театр'), а главное, выставляет целый ряд рисунков, эскизов к декорациям [...] и книга его ,The Art of the Theatre' в короткий срок выдерживает два издания в переводе на немецкий язык. ${ }^{307}$

Unsere Theaterberichterstatter haben es seinerzeit außer Acht gelassen, über eine solch bedeutende Erscheinung wie die neuen Bühnenexperimente E.G. Craigs zu berichten. [...] Den am Schicksal des neuen Theaters Interessierten halfen hingegen unsere deutschen Nachbarn, über die neuen Kunstgriffe der Inszenierung von E.G. Craig zu erfahren. Man musste im Theater Reinhardt erscheinen, um nach den Erfolgen seiner Kammerspiele auf den Namen E.G. Craig zu stoßen. In der Saison von 1904/o5 sehen wir Craig in Berlin. Hier entwickelt er die Dekorationen zu Hofmannsthals Stück am Lessing-Theater, und - vor allem stellt er eine ganze Reihe von Zeichnungen und Skizzen zu den Dekorationen aus [...]. Sein Buch ,The Art of the Theatre' erscheint in kürzester Zeit gleich in zwei Auflagen mit Übersetzung ins Deutsche.

Wie Mejerchol'd sich richtig erinnert, erschien Craigs Buch Die Kunst des Theaters 1905 in einer deutschen Übersetzung in Berlin. ${ }^{308}$ Sowohl diese Übersetzung als auch das rasche Bekanntwerden seiner Reformideen gehen auf die leidenschaftlichen Bemühungen des einflussreichen Kunstmäzens Harry Graf Kessler zurück, der Craig seit circa 1903 förderte. ${ }^{309}$

306 Vgl. Taxidou, The Mask, S. 67.

307 Vsevolod Ėmil'evič Mejerchol'd: „Edward Gordon Craig“, ediert in: V.E. Mejerchol'd. Stat'i, pis'ma, reči, besedy, Bd. 1: 1891-1917, hg. von Aleksandr V. FeVRAL'sKIJ, Moskau 1968, S. 167-169. Eine deutsche Übersetzung findet sich auch bei Wsewolod E. MEYERHOLD: „Edward Gordon Craig“, ediert in: Wsewolod E. Meyerhold. Schriften. Aufsätze, Briefe, Reden, Gespräche, Bd. 1: 1891-1917, hg. von Aleksandr V. FevraL'sKiJ, Gesamtredaktion der deutschspr. Ausg. von Gisela SEEgER, Berlin 1979, S. 161-163, hier S. 161f. Zur frühen Rezeption Craigs in Deutschland vgl. Grund, Zwischen den Künsten, S. 64-69.

308 Vgl. Edward Gordon Craig: Die Kunst des Theaters, übers. und eingeleitet von Maurice MAGnUs, mit einem Vorwort von Harry Graf Kessle R, Berlin und Leipzig 1905.

309 Vgl. Lindsay Mary Newman: „Gordon Craig in Germany“, in: German Life and Letters 40 (1986), S. 11-33; DIES.: „Introduction“, in: The Correspondence of Edward Gordon Craig and Count Harry Kessler, hg. von dies., S. 3-16; Grund, Zwischen den Künsten, S. 64-68; 
Es ist naheliegend, dass Mejerchol'd entscheidend daran beteiligt war, dass die in Deutschland zirkulierenden Reformschriften auch bald in Russland wahrgenommen wurden. Der Regisseur stammte aus einer Familie russlanddeutschen Ursprungs und beherrschte daher die deutsche Sprache. Er war schon frühzeitig über die Theaterreformbewegungen in Deutschland informiert und rezipierte beispielsweise bereits 1906 Fuchs' Aufsatz Die Schaubühne der Zukunft ${ }^{310}$. Einige der dort formulierten Ideen fanden sogar Niederschlag in Mejerchol'ds Petersburger Produktionen. ${ }^{311}$ Es verwundert also auch nicht, dass er eine entscheidende Rolle in der frühen Craig-Rezeption in Russland einnimmt, wenn er zum Beispiel 1908 Auszüge aus dessen Schriften Über Bühnen-Ausstattung und Etwas über den Regisseur und die Bühnen-Ausstattung in die russische Sprache übersetzt. ${ }^{312}$ Der Wahrheitsgehalt von Mejerchol'ds Aussage (1909), die russische (Reform-)Theaterbewegung sei ohne den Einfluss Craigs entstanden, ${ }^{313}$ muss jedoch hinterfragt werden. ${ }^{314}$ Die ersten Skizzen zur Über-Marionette fertigte Craig 1905/06 an. Genau in dieser Zeit begleitete er seine neue Lebensgefährtin, die amerikanische Ausdruckstänzerin Isadora Duncan, auf ihre erste Tournee nach Russland. ${ }^{315}$ Olga Taxidou gibt an, dass die russische Presse zum ersten Mal 1906 über Gordon Craig berichtete. ${ }^{316}$ Zunächst zwar nur als Begleiter Isadora Duncans, war er spätestens ab 1908 regelmäßig in Moskau, um seine Hamlet-Produktion am Moskovskij Chudožestvennyj teatr vorzubereiten. ${ }^{317}$

Tamara Barzantny: Harry Graf Kessler und das Theater. Autor. Mäzen. Initiator, Köln 2002, S. 125-139.

310 Vgl. Fuchs, Die Schaubühne der Zukunft.

311 Vgl. Braun, Meyerhold, S. 48-50.

312 Vgl. ebd., S. 85f.

313 Vgl. Mejerchol'd, „Edward Gordon Craig“, S. 161.

314 Manfred Brauneck formuliert diesbezüglich: „Für die Theateravantgarde, die um 1910 an die Öffentlichkeit trat, von den italienischen Futuristen bis zu Mejerchol'ds späteren konstruktivistischen Bühnenexperimenten waren [...] [die] Ideen Gordon Craigs grundlegend." Brauneck, Die Welt als Bühne, Bd. 3, S. 858.

315 Zu Craigs Notizbüchern Uber Marions A, B, 1905-1906 (Bibliothèque Nationale, Département des Arts du Spectacle, Sammlung Craig) vgl. Grund, Zwischen den Künsten, S. $138 \mathrm{f}$. Zu Duncans erster Tournee in Russland vgl. Natalia Stüdemann: Dionysos in Sparta. Isadora Duncan in Russland. Eine Geschichte von Tanz und Körper, Bielefeld 2008, S. 9. $\mathrm{Zu}$ Craigs Russlandaufenthalt 1905 vgl. Newman, The Correspondence of Edward Gordon Craig and Count Harry Kessler, S. 31-37. Zu Isadora Duncan vgl. auch Kapitel III.1.2.1.

316 Vgl. Taxidou, The Mask, S. 67. Taxidou erwähnt den Artikel ohne Autoren-, Orts- und Titelangaben.

317 Zu dieser Produktion vgl. Laurence Senelick: Gordon Craig's Moscow ,Hamlet: A Reconstuction, Westport 1982. Stanislavskij hatte sich bereits 1907 dazu entschlossen, Craig als Regisseur für eine Shakespeare-Inszenierung an das Moskovskij Chudožestvennyj teatr einzuladen, obwohl dieser als schwierig und kompromisslos galt. Vgl. Elisabeth 
Auf die Ähnlichkeiten des Sologub-Artikels zu den Craig'schen Reformideen sowie den nahezu übereinstimmenden Titel der Publikation Kniga o novom teatre mit der von Craig 1905 veröffentlichten Schrift "The Art of the Theatre ist schon hingewiesen worden. ${ }^{318}$ Das Faktum, dass an jenem Sammelband neben Sologub auch Mejerchol'd und Benua beteiligt waren, spricht dafür, dass Benua über Craigs Konzepte informiert war - und wenn nur über Mejerchol'd. ${ }^{319}$

Tatsächlich mehren sich ab dem Sommer 1911 die Hinweise auf Verbindungen zwischen Craig und Personen, die den Ballets Russes nahestanden darunter auch Harry Graf Kessler. ${ }^{320}$ Dieser hatte die Ballets Russes zum ersten Mal zwar schon am 27. Mai 1909 während deren erster Pariser Saison wahrgenommen und direkt im Anschluss daran Hugo von Hofmannsthal begeistert berichtet; ${ }^{321}$ das erste persönliche Treffen zwischen Kessler, Djagilev und Nižinskij fand aber erst im Juni 1911 statt. ${ }^{322}$ Zum Zeitpunkt dieser ersten

NeHRIng: Im Spannungsfeld der Moderne. Theatertheorien zwischen Sprachkrise und ,Versinnlichung'(Forum Modernes Theater, Bd. 32), Tübingen 2004, S. 54.

318 Vgl. Taxidou, The Mask, S. 66 f.

319 Zum Sammelband und zu Benuas Beteiligung daran vgl. Kapitel II.3.

320 Vgl. Barzantny, Harry Graf und das Theater, S. 156.

321 Vgl. ebd., S. 154: „Ich sah gestern hier das russische Ballett; das von der Oper in St. Petersburg hier gastiert. Ganz phänomenal. Für diese Leute würde es sich lohnen ein Ballett zu schreiben. Ein junger Tänzer (mir sind sonst Ballett tanzende Männer ein Brechmittel) ist das Wunderbarste, was ich in dieser Kunst außer der Ruth gesehen habe. Das muß man sehen, um zu begreifen, wie man einen Mann im Ballett verwenden kann. Die höchste Grazie, wirklich wie ein Schmetterling, bei höchster Männlichkeit und jugendlicher Schönheit: die ebenfalls sehr schönen Tänzerinnen waren daneben wie verschwunden, das Publikum wie rasend. Wenn du je ein Ballett schreibst (mit Strauss), müssen wir diesen jungen Nijinski bekommen. Ich werde dir übrigens in der ,Illustration' ein Bild schicken, das dir eine natürlich sehr blasse Idee von dieser Erscheinung gibt! Er erinnert etwas an Kainz in seinen genialen Augenblicken. Dein Harry Kessler." Brief von Harry Graf Kessler an Hugo von Hofmannsthal vom 28. Mai 1909, ediert in: Hugo von Hofmannsthal, Harry Graf Kessler. Briefwechsel 1898-1929, hg. von Hilde BURGER, Frankfurt a.M. 1968, S. 233 f.

322 Vgl. Barzantny, Harry Graf Kessler und das Theater, S. 156. Unter anderem hatte auch Hofmannsthal Kessler gebeten, mit Djagilev in Kontakt zu treten, da er ein Ballett mit den Russen machen wollte: „Wenn du zur Zeit des russischen Ballettgastspiels 6-13 Juni in Paris wärest und mich hiervon durch eine offene Karte zu unterrichten so gut wärest, so hätte ich dann eventuell eine präcise Bitte an dich." Brief von Hofmannsthal an Kessler vom 28. Mai 1911, ediert in: Briefwechsel Hofmannsthal - Kessler, hg. von Burger, S. 328; „Ich hätte 2 Bitten. Sie erklären sich aus meinem Pech in Paris, nichts zu sehen, die Russen zu versäumen [...]. Versuchte durch Astruc irgend eine Verbindung zu finden mit Benois oder Bakst, Astruc konnte mich wegen Zeitmangels nicht empfangen. Nun sitze ich da, isoliert in dieser augenlosen, culturlosen deutschen Theaterwelt. Ich habe einen wunderschönen phantastischen Stoff, geboren für Musik. Erzählte ihn Strauss, er brennt 
Begegnung mit Djagilev kannte Kessler Craig bereits seit mehreren Jahren: Nachdem er ihn und seine radikalen Ideen für ein neues Theater 1903 für Deutschland "entdeckt" hatte, ${ }^{323}$ begann er, Craig intensiv zu fördern, unter anderem indem er ihm wertvolle internationale Kontakte vermittelte - so auch zu Djagilev und seinen Mitarbeitern, zu denen er nach diesem ersten Treffen einen gleichermaßen intensiven Kontakt pflegte wie zu Craig. ${ }^{324}$

Etwa zur gleichen Zeit muss Kessler Craig und dessen Ideen auch Gabriel Astruc und der Comtesse Elisabeth Greffulhe empfohlen haben. Es ist nämlich überliefert, dass beide den britischen Theaterreformer ab 1911 mit künstlerischen Aufträgen unterstützten. ${ }^{325}$ Sowohl Astruc als auch Greffulhe standen Djagilev und den Ballets Russes nahe: Die Comtesse förderte Djagilev seit seinen Anfängen in Paris, und Astruc arbeitete seit 1907 eng mit ihm zusammen. ${ }^{326}$

Von Stravinskij selbst sind bis September 1911 keine direkten Kontakte zur Reformbewegung nachzuweisen: Erst am 24. September/7. Oktober, also drei Monate nach der Pétrouchka-Uraufführung in Paris, forderte er seinen Sankt Petersburger Jugendfreund Andrej Rimskij-Korsakov in einem Brief auf, die ein Jahr zuvor in Russland erschienene russische Übersetzung jenes Reformartikels von Fuchs zu lesen, der erstmals 1906 unter dem Titel Der Tanz in den Flugblättern für künstlerische Kultur veröffentlicht worden war. ${ }^{327}$ Was Craig betrifft, teilt Kessler mit, dass dieser und Stravinskij zumindest einmal in Paris

darauf. [...] Würdest du mir die Liebe tun, eine Verbindung zwischen Bakst und mir herstellen? [...] Ihn überhaupt fragen, ob und wie weit es ihn interressieren würde, für die deutsche Bühne und für mich zu arbeiten [...]. Ich wage die Bitte, weil du ja Diaghilew kennst. Ich sitze hier ohne alle Verbindung [...]. Wenn sich Bakst interressieren könnte, für mich zu arbeiten, würde ich auch sehr gern ein Ballett mit ihm machen." Brief von Hofmannsthal an Kessler vom 10. Juni 1911, ediert in: ebd., S. $329 f$. Im selben Brief nimmt Hofmannsthal auch auf Craig Bezug: „Jetzt wo ich in der Lage bin [...] aus eigener Tasche ein paar lumpige tausend Mark [...] dranzugeben[,] hätte ich auch den Mut Craig wieder in etwas hineinzuziehen. Ich blättere manchmal in der Zeitschrift ,Mask'.“ Ebd.; Kessler schickte am 25. Juni 1911 ein Schreiben, in dem er auf Hofmannsthals Bitten Bezug nimmt: „Diaghilew hat mich inzwischen beauftragt, dich um ein Ballett mit Musik von Strauss für Nijinsky (Hauptrolle) zu bitten. [...] Natürlich würde dich Bakst hier abwarten, wenn du Anfang August herkämest, und die Sache ließe sich dann gleich auch mit Diaghilew und Nijinsky durchsprechen. [Gabriel] Astruc ist auch von dem Plan unterrichtet und erfreut. Er erzählte mir nämlich, er habe bedauert, daß er dich nicht sehen konnte, als du bei ihm warst." Brief von Kessler an Hofmannsthal vom 25. Juni 1911, ediert in: ebd., S. $331 f$.

323 Vgl. Barzantny, Harry Graf Kessler und das Theater, S. 126-131.

324 Ab Herbst 1911 trafen sich Craig, Nižinskij und Djagilev vermehrt. Vgl. Kapitel III.1.2.2.

325 Vgl. Newman, The Correspondence of Edward Gordon Craig and Count Harry Kessler, S. 74.

326 Bezüglich der Zusammenarbeit von Astruc und Djagilev vgl. auch Kapitel III.1.4.

327 Vgl. den Brief von Stravinskij an Andrej Rimskij-Korsakov vom 24. September/7. Oktober 1911, ediert in: Perepiska, Bd. 1, hg. von Varunc, S. 300-302 sowie Kapitel III.1.2. Zum 
zusammentrafen - im Mai 1912. Stravinskij hatte den Briten besucht, da er, so Kessler, „zwischen seinen und Craigs Bestrebungen eine Art von Verwandtschaft [empfand] “328:

Strawinsky meinte, [...] wie Craig Alles auf der Bühne auf die einfachsten, aber suggestivsten Elemente zurückführen wolle, auf ein Spiel von Licht und nackten Massen, so wolle er in der Musik Alles loswerden, was nicht Rhythmus sei (me défaire de tout ce qui n'est pas le rhythme); auf den Rhythmus solle sich suggestiv die Gebärde aufbauen, die weiter sei als das Wort. Hier schiene ihm ein Punkt, wo sich seine Kunst mit der von Craig vereinigen könne. Er brenne drauf, mit Craig Etwas zu machen. ${ }^{329}$

Nach Kesslers Aussage wollte Stravinskij 1912 analog zu Craig auf der Bühne in der Musik alles loswerden, was nicht Rhythmus sei. Selbst einer Zusammenarbeit mit Craig schien er nicht abgeneigt zu sein. Ein Stravinskij-Craig-Ballett sollte es aber dennoch nie geben; das wusste Craig wohl zu verhindern. Dennoch: Es ist mit großer Wahrscheinlichkeit davon auszugehen, dass Stravinskij (spätestens) ${ }^{330}$ durch die enge Zusammenarbeit mit Benua bereits während seiner Arbeit an Pétrouchka vom Reformgedankengut erfahren hat. Denn, wie Taruskin treffend formuliert: „Petrushka changed all that [...]. [By the middle of 1911] [...] Stravinsky changed his attitude toward Russia, toward Fokine, and most of all, toward his own place in the scheme of things. "331 Was war in besagtem Sommer 1911 geschehen? Die Antwort liefert eine ausführliche

Reformartikel vgl. Fuchs, „Der Tanz“. Zu dessen russischer Übersetzung vgl. Georg Fuks: „Tanec“, übers. von L. KrasıL'ščıK“, in: Fial strastej, Sankt Petersburg 1910, S. 59-96.

328 Harry Graf Kessler: Tagebucheintrag vom 23. Mai 1912, ediert in: Harry Graf Kessler. Das Tagebuch 1880-1937, 9 Bde., Stuttgart 2004-2018, hg. von Roland S. KAMZELAK und Ulrich Отт unter Beratung von Hans-Ulrich Simon, Werner Volke und Bernhard Zeller, Bd. 4: 1906-1914, hg. von Jörg SChuster unter Mitarbeit von Janna Brechmacher, Christoph Hilse, Angela Reinthal und Günter Riederer, Stuttgart 2005, S. 825f., hier S. 825. Sehr wahrscheinlich fand noch ein weiteres Treffen von Stravinskij und Craig statt, und zwar in Rom 1917. Zumindest erwähnt Stravinskij ein solches im Gespräch mit Robert Craft, bei dem er beeindruckt von Craigs Marionetten gewesen sein will: „I have also been asked why I failed to take one more step and use puppets, as my late friend Robert Edmond Jones once did for a performance of my, Oedipus' in New York. This notion did occur to me, in fact, and I had been impressed by Gordon Craig's puppets when he showed them to me in Rome in 1917."Vgl. Igor STRAVINSKY und Robert CrafT: Dialogues and a Diary, London 1968, S. 24 sowie Jordan, Stravinsky Dances, S. 542.

329 Tagebucheintrag von Harry Graf Kessler vom 23. Mai 1912, ediert in: Das Tagebuch, Bd. 4, hg. von Kamzelak und Ott, S. 825 .

330 Das erste Skizzenblatt zu Stravinskijs Pétrouchka trägt einen Stempel mit dem Datum 8. September 1910. Vgl. ,Petrushka' (Sketches), Juilliard Manuscript Collection, New York, online einsehbar unter julliardmanuscriptcollection.org (Stand: September 2017).

Taruskin, Stravinsky and the Russian Traditions, Bd. 2, S. 970. 


\section{Replik Stravinskijs an Vladimir Rimskij-Korsakov vom 8./21. Juli 1911, die folgendermaßen anhebt: ${ }^{32}$}

Дорогой Володя, извини меня вперед за нескладность письма. Я очень взволнован твоим письмом, получение которого меня сильно обрадовало, но содержание которого в равной, если не в большей мере огорчило. Тут уж дело идет не о Дягилеве, к нападкам на которого мы все привыкли, и которые для нас уже не так чувствительны, как в былое время. Тут дело идет о гораздо более значительном - о том, чему мы служим вместе с Дягилевым - о Балете. ${ }^{333}$

Lieber Wolodja, bitte verzeih mir im Voraus die Plumpheit des Briefes. Dein Brief bereitet mir große Sorgen, so sehr mich seine Entgegennahme erfreut hat, umso mehr hat mich doch dessen Inhalt betrübt. Es geht hier schon gar nicht mehr um Djagilev - schließlich haben wir uns alle bereits daran gewöhnt, dass er ständig als Zielscheibe herhalten muss, und wir stehen diesen Angriffen weniger empfindsam gegenüber als in vergangenen Zeiten. Nein, hier geht es um etwas

332 Brief von Stravinskij an Vladimir Rimskij-Korsakov vom 8./21. Juli 1911, ediert in: Perepiska, Bd. 1, hg. von Varunc, S. 290-294. Nach Stravinskijs großem Erfolg mit Pétrouchka kam es zu einem größeren Eklat zwischen ihm und der Familie Rimskij-Korsakov. Vgl. Taruskin, Stravinsky and the Russian Traditions, Bd. 2, S. 971. Zeugnis dieses Eklats liefert genanntes Antwortschreiben von Stravinskij an Vladimir Rimskij-Korsakov, das Stravinskij am 8./21. Juli 1911 in Ustilug verfasste und in dem er sich gegen Vladimirs Angriffe verteidigt, die dieser in einem nicht überlieferten Brief geäußert haben muss. Die Rimskij-Korsakovs betrachteten Stravinskijs Zusammenarbeit mit Djagilev und die damit zusammenhängende Hingabe für das Ballett von Anfang an mit Argwohn. Vgl. ebd., Bd. 1, S. 369-384. Wenn auch eher aus persönlichen denn aus ideologischen Gründen hegte das Familienoberhaupt Nikolaj Rimskij-Korsakov eine tiefe Abneigung gegen die mit der Mir Iskusstva und Djagilev in Verbindung stehenden Abende für Zeitgenössische Musik. Taruskin bezeichnete Djagilevs Umfeld in Sankt Petersburg daher treffend als "the other camp“, von dem sich der Kreis um Rimskij-Korsakov stets deutlich abzugrenzen versuchte, und Stravinskij aufgrund seines ,Seitenwechsels' als Überläufer. Vgl. ebd., Bd. 2, S. 969-978 und 1035. Zur Mir Iskusstva und zu den mit ihnen in Zusammenhang stehenden Abenden für Zeitgenössische Musik vgl. Kapitel II.1.1. und Anm. 167. Ab 1909 - also erst nach dem Tod Nikolaj Rimskij-Korsakovs - verschärfte sich die Situation. Anlass gaben Djagilevs jüngst in Paris aufgeführte Ballets-Russes-Produktionen Cléopâtre (19o9) und Shéhérazade (1910), bei denen er Auszüge aus Rimskij-Korsakovs Kompositionen verwenden (Auszüge aus Mlada wurden für das Ballett Cléopâtre verwendet) oder gar ganze Partituren anpassen ließ (der dritte Teil von Shéhérazade wurde für die Djagilev-Adaption weggelassen). Vgl. ebd., S. 971f. Stravinskij - nachmalig wohl bekanntester Schüler Rimskij-Korsakovs und zu diesem Zeitpunkt noch eng befreundet mit dessen Söhnen - stand da bereits mit Djagilev in Kontakt. Zum Zusammentreffen von Djagilev und Stravinskij vgl. Anm. 149. Stravinskijs enge Freundschaft zu den Rimskij-Korsakov-Brüdern, Andrej und Vladimir, sollte seine Zusammenarbeit mit Djagilev nicht überstehen. Vgl. ebd., S. 969-978. Zur engen Freundschaft zwischen Stravinskij und den Rimskij-Korsakov-Brüdern vgl. außerdem Walsh, A Creative Spring, S. 63 f.

Brief von Stravinskij an Vladimir Rimskij-Korsakov vom 8./21. Juli 1911, S. 29of. 
viel Bedeutenderes - nämlich um die Sache, der wir zusammen mit Djagilev dienen: dem Ballett.

\section{Einmal abgesehen von den Streitigkeiten um Djagilev, auf die Stravinskij in ge- nanntem Schreiben eigentlich nicht eingehen möchte und die in Korrelation zur Brieflänge auch nur kurz ausfallen, ${ }^{334}$ ist Stravinskijs Brief an Vladimir}

334 Zu den Streitigkeiten vgl. Walsh, A Creative Spring, S. 169 sowie Anm. 332. Zur Causa Djagilev schreibt Stravinskij dann noch Folgendes: „Но прежде чем говорить об этом - не могу не коснуться опять же того же Дягилева. Я уже не раз говорил, что есть поступки Дягилева, с которыми я согласиться не могу, как, например, музыкальная окрошка ,Клеопатры'. Я это говорю всем и ему говорил не раз. Но при этом я должен оговориться - мне не нравится в этом смесь стилей разных авторов это в музыкальном отношении было неудачно. Я даже предпочел бы ничтожную и глупую музыку Аренского. Принципиально же я ничего не имею, чтобы хорошая музыка (и цельная) хореографически талантливо инсценировалась. Это не оскорбляет мое художественное чувство, которое у меня (думается мне) не в заглохшем состоянии. Что же касается частного случая, как, например, с ,Шехеразадой', где сюжет хореографической пьесы не соответствует сюжету (если так можно выразиться), предпосланному Николаем Андреевичем к своей симфонии, то это не меняет существенно дела. Главное тут не в сюжете, а в дивном зрелище, которое как нельзя лучше переносит тебя в атмосферу гениальной музыки ,Шехеразады'. Единственно о чем я жалею, что не инсценированы все четыре части. Это я своевременно говорил Дягилеву и это меня до сих пор огорчает. [...] Не думай, что моя деятельность протекает во влюбленном поддакивании - наоборот, не проходит дня, чтобы я чего-либо не говорил, спорил, не соглашался - критиковал.“ „Doch bevor wir uns dieses Themas annehmen, sehe ich mich gezwungen, ebendiesen Djagilev betreffend, noch ein paar Worte zu verlieren. Wie ich bereits mehrmals erwähnte, hat Djagilev einige Sachen gemacht, denen ich keinesfalls zustimmen kann, wie zum Beispiel jene musikalisch kalte Brühe namens ,Cléopâtre؛. Ich sage das allen und habe dies ihm gegenüber auch mehrfach erwähnt. Dennoch sollte ich hier klarstellen: Was mir daran missfällt, ist die Vermischung von Stilen verschiedener Autoren. Dies war in Bezug auf die musikalische Umsetzung misslungen. Ich würde dem selbst [Anton] Arenskijs belanglose und dümmliche Musik bevorzugen. Grundsätzlich habe ich nichts dagegen, wenn gute (und ganzheitliche) Musik choreografisch talentvoll inszeniert wird. Dies verletzt nicht mein künstlerisches Empfinden, welches sich bei mir (wie mir scheint) nicht in völlig abgestumpftem Zustand befindet. Was allerdings den nicht seltenen Fall betrifft, wie zum Beispiel mit, Shéhérazade', wo der Plot der Choreografie nicht dem eigentlichen Sujet von Nikolaj Andreevič entspricht (wenn man es so ausdrücken will), das dieser zu seiner Sinfonie hinzufügte, so ändert dies nichts an dem Kern der Sache. Die Hauptsache liegt hierbei nicht im Sujet, sondern in dem prächtigen Spektakel, das dich bei Weitem besser zur Atmosphäre der genialen Musik von ,Shéhérazade führt. Das Einzige, was ich daran tatsächlich bedauernswert finde, ist, dass nicht alle vier Teile inszeniert wurden. Ich habe das auch Djagilev beizeiten gesagt, und es enttäuscht mich immer noch. [...] Glaube nicht, dass sich meine Tätigkeit in verliebtem Zunicken äußert - im Gegenteil: Es vergeht kein Tag, an dem ich nicht irgendetwas sage, mich streite, nicht zustimme, kritisiere." Ebd., S. 291. Am Ende des Abschnitts weist Stravinskij aber noch einmal darauf 
Rimskij-Korsakov vor allem eines: ein profundes Bekenntnis zum Ballett und zu den diesbezüglichen Überzeugungen seines neu gewonnenen Mentors Benua. Und: Im selben Brief äußert Stravinskij auch erstmals seine Unzufriedenheit mit dem Choreografen Fokin, die schließlich 1912 dazu führen wird, dass Fokin als Sacre-Choreograf durch Nižinskij ersetzt wird. ${ }^{335}$

Wie Taruskin schon festgestellt hat, liest sich besagter Briefausschnitt wie eine Zusammenfassung von Benuas Artikel „Beseda o balete“. ${ }^{336}$ Was Taruskin in diesem Zusammenhang aber unberücksichtigt lässt, ist die Tatsache, dass dieser Artikel im russischen Theaterreformband Teatr. Kniga o novom teatre erschien.

Problematisch daran ist, dass die Ansichten, die Benua dort äußert, ohne den Kontext der Reformbewegung nicht ganz zu verstehen sind, was an dieser Stelle noch einmal rekapituliert werden soll: Der Vorschlag des Künstlers in „Beseda o balete“, das Ballett statt Oper oder Drama als die adäquate Kunstform für ein Theater der Zukunft anzuerkennen, wirkte in Anbetracht der Tatsache, dass das Ballett im zaristischen Russland des beginnenden 20. Jahrhunderts als mediokre Kunstform galt, die in den Reformdiskursen keine Rolle spielte, eher ungewöhnlich - und das macht Benua im Dialog zwischen Künstler und Ballettliebhaber auch deutlich. Vor dem Hintergrund der Ideen, die innerhalb der Reformdiskurse kursierten, findet man aber mindestens einen Aspekt, der Benuas Vorschlag legitimiert. Als gemeinsames Moment und zugleich Ausgangspunkt der um 1900 erschienenen Programmschriften und Manifeste zu einer Reform des Theaters ist ja die Orientierung an Richard Wagner und Friedrich Nietzsche bzw. die Rezeption von dessen Geburt der Tragödie zu sehen:Die Musik wurde zum zentralen Theatererlebnis erklärt, und man verlangte nach einer "Erneuerung der mythischen Dimension des Theaters“337, und so wurde das Gesamtkunstwerk neben anderen Wagner'schen Reformideen wie etwa dem Festspiel oder dem Amphitheater umfangreich diskutiert. ${ }^{338}$ Im „vom Wort beherrschte[n] literarische[n] Theater ${ }^{4339}$, das nach einer kritischen Auseinandersetzung mit sozialen $\mathrm{Zu}$ - und Missständen verlangte, sahen die Theaterreformer jedoch keine Möglichkeit, den von Nietzsche adaptierten

hin, dass es ihm im Brief vor allem um das Ballett gehe: „Вот теперь мы вплотную пришли к тому, что подвергается тобою сомнениям. Я говорю о Балете.“ „Jetzt sind wir zu dem angelangt, was du in Zweifel ziehst. Ich spreche vom Ballett." Ebd., S. 291. Die negativen Äußerungen über Fokin überraschen insbesondere deshalb, weil sich Stravinskij bis dahin durchweg positiv über ihn geäußert hatte. Vgl. Kapitel III.1.2.1.

336 Vgl. Taruskin, Stravinsky and the Russian Traditions, Bd. 2, S. 971.

337 Vgl. Brauneck, Theater im 20. Jahrhundert, 2009, S. 153.

338 Vgl. Balme, Das Theater von Morgen, S. 132 sowie Kapitel II.3.

339 Balme, Das Theater von Morgen, S. 132. 
dionysischen Rauschzustand beim Zuschauer zu erzielen. Sie plädierten also für die „Entliterarisierung ${ }^{340}$ des Theaters, was unter anderem dazu führte, dass die Szenografie aufgewertet wurde und man sich vermehrt mit anderen, nicht verbalen Ausdrucksmitteln wie dem Ausdruckstanz oder der Eurhythmie beschäftigte. ${ }^{341}$ Mit dieser dezidierten Abwendung vom literarischen Vorbild gewann der Regisseur zunehmenden Einfluss auf das Theaterkunstwerk, was sich schließlich dahingehend zeigte, dass nicht mehr der Dramatiker, sondern der Regisseur „als der eigentliche Schöpfer" ${ }^{4342}$ des Kunstwerks galt. Da der klassische Charakterdarsteller in diesem Rahmen keinen Raum mehr fand, suchte man nach neuen Vorbildern und entdeckte diese vermehrt im Marionetten- und Maskentheater sowie in der Commedia dell'Arte und kam schließlich zur Überzeugung, dass dem neuen Schauspieler, wie man ihn sich vorstellte, am ehesten der Tänzer (Georg Fuchs) oder die Marionette (Gordon Craig) entsprach. ${ }^{343}$ Da man die Schauspielkunst primär als „die Kunst, den Körper zu bewegen “344, erachtete, wurden die Handlungen des Schauspielers „in Analogie zu Zuständen des Rausches, der Trance oder des Träumens“ ${ }^{345}$ vermehrt als unbewusst geleitet beschrieben. ${ }^{346}$

Vor diesem Hintergrund leuchtet in höchstem Maße ein, warum Benua, der sich in Sankt Petersburg in den Zirkeln der Reformer bewegte, dafür plädierte, das Ballett als Theater der Zukunft zu betrachten: Anders als im Drama oder in der Oper wäre der Tänzer dem Ballett ja bereits inhärent. Und so kämpft Benua in seinem Essay also dafür, dass die Reformer das (neue) Ballett als bessere Alternative zu Oper und Drama anerkennen.

Auch Stravinskij verteidigt das Ballett in der bereits erwähnten Replik gegenüber der Oper (und anderen szenischen Künsten). Er versucht darin, Vladimir Rimskij-Korsakov - der für das Ballett nicht allzu viel übrig hatte davon zu überzeugen, dass es sich beim Ballett keineswegs um eine geringwertigere Kunstform als die der Oper handle - argumentiert also genau so wie Benua 19o8. Für Stravinskij selbst stelle es keinesfalls eine „niedere Form“ der szenischen Künste dar. Er legt Rimskij-Korsakov daher nahe, sich mit dem (künstlerischen) Ballett auseinanderzusetzen, um derart zu begreifen, welch

340 Brauneck, Europas Theater, S. 371. Vgl. auch Grund, Zwischen den Künsten, S. 27. Balme beschreibt dies mit "der Abkehr vom logozentrischen[,] d.h. dem Dramentext verpflichteten Theater". Balme, Das Theater von Morgen, S. 12.

Vgl. ebd., S. 132.

342 Brauneck, Theater im 20. Jahrhundert, 2009, S. 153.

343 Vgl. Brauneck, Theater im 20. Jahrhundert, 1995, S. 64.

344 Ebd.

345 Ebd.

346 Vgl. ebd. 
enormes Potenzial in dieser Kunstform stecke, auch wenn deren Entwicklung noch sehr viel Arbeit darstelle. Durch diese nähere Beschäftigung würde er dann auch erfahren, dass das Ballett ihm eine weit größere künstlerische Freude bereiten würde als die Oper. ${ }^{347}$

347 Vgl. den Brief von Stravinskij an Vladimir Rimskij-Korsakov vom 8./21. Juli 1911, S. 29o294: „[...] Хоть ты и говоришь, что ты вовсе не враг балета, но далее заявляешь, что это „низший род“ сценического искусства. Тут все стало для меня ясным. Из этой фразы для меня ясно, что ты просто не любишь и не интересуешься балетом, не придавая ему большого значения. Скажу тебе только, что я, как раз наоборот, больше всего интересуюсь и люблю балет, и это не пустое увлечение, а серьезное глубокое наслаждение сценическим зрелищем - живою пластикой. И я просто недоумеваю, как это ты, который так любил пластические искусства, так живо интересовался живописью и скульптурой (если ты еще не охладел к этому), так мало уделяешь внимания хореографии - третьей форме пластического искусства [...]. [...] Верно, я, работая в сфере хореографии, почувствовал значительность и нужность того, что делаю (не говорю только о музыке, а обо всем произведении целиком, ибо я автор либретто ,Петрушки' и делал это с такой же любовью, как твой отец работал над своими операми), тогда как ты, с одной стороны, не видя ничего кроме банальных или просто скверных оперных постановок и гадких балетов [...], с другой, в силу своего пристрастия к деятельности Дягилева, не трогаешься с места и, не признавая за хореографией значительности (ибо ты сказал, что балет ниже оперы - а по мне, искусство всегда одинаково - не бывает низших и высших искусств, бывают разные роды искусств - если же ты ставишь ниже одно другого, то это лишь доказывает, что тебе пластика вообще менее дорога, чем другой род искусства - или просто вещь, без которой ты можешь обойтись), мечтаешь лишь о художественной постановке существующих опер, не задумываясь над тем, что опера есть зрелище [...] и , следовательно, так таковое, должно иметь свою собственную самодовлеющую ценность - так же, как ценны пленительные жесты и движения в танце ( ${ }^{*}$ которое ты почему-то ставишь ниже речитатива), созданные фантазией таланта балетмейстера, так же, как музыка, оторванная от зрелища. Это не прикладные искусства - то соединение искусств, одно усиливает и дополняет другое. Я бы еще понял того, который был бы противником всяких соединений, как то: драмы с музыкой - опера, хореографии с музыкой - балет. - Ну, что делать, любит, мол, человек чистое искусство: музыку - так музыку, пластику - так пластику. - Но тебя я не могу понять, дорогой, ибо ты же сам любишь, или любил до сей поры пластические искусства. Понимаю я Николая Андреевича, который сам признавался, что он нечувствителен (ну что ж поделаешь - не чувствует, так не чувствует) к искусствам пластическим, но не понимаю в таком случае, почему его творчество выливалось в формы оперы, а иногда и балета, где же музыка намеренно соединялась с другими искусствами. Думаю, что это происходило не от непонимания или нелюбви к другим искусствам, сколько от недостаточного углубления и знакомства с ним. Вероятно, то же и с тобой, изрекшим ужасную ересь о ,низшей форме (не сердись на меня за грубый тон - он не столь груб, как кажется). Думаю, что если бы ты часто посещал балет (художественный, конечно), то увидал бы, что это ,низшая форма' приносит тебе неизмеримо большие художественные радости, чем любое оперное представление (хотя бы оперы с самой любимой твоей 
музыкой), радость, которую я испытываю уже больше года и которой так страшно хотелось бы Вас заразить и с Вами поделиться. Именно радость открытия целого ,материка', на обработку которого пойдет много сил - многое впереди!“” „[...] Obwohl du behauptest, ganz und gar kein Gegner des Balletts zu sein, verkündest du gleich darauf, dass das Ballett, das niederste Geschlecht' der Bühnenkunst sei. Hier wurde mir alles klar. Aus dieser Phrase wurde mir klar, dass du das Ballett einfach nicht magst und dich nicht dafür interessierst, ihm keine allzu große Bedeutung beimisst. Ich kann dir nur sagen, dass ich mich, ganz im Gegenteil, am meisten für das Ballett interessiere und es liebe. Für mich stellt es keine bloße Unterhaltung dar, sondern wahrlich ernsthaften, tiefen Genuss der Bühnenkunst - der lebendigen Plastik. Und ich kann es einfach nicht fassen, dass ausgerechnet du, der die plastischen Künste so mochte, der sich so lebhaft für Malerei und Bildhauerei interessierte (falls du dich dem überhaupt noch hingeben kannst) -, dass du der Choreografie, der dritten Form der plastischen Künste, solch geringfügige Beachtung schenkst. [...] Wahrlich habe ich, der in der Sphäre der Choreografie arbeitet, die Bedeutsamkeit und Unabdingbarkeit dessen gespürt, was ich mache (ich spreche hierbei nicht nur über Musik, sondern über das gesamte Werk, da ich schließlich der Autor des Librettos von ,Pétrouchka bin und es mit solcher Liebe schuf, wie dein Vater an seinen Opern arbeitete), während du einerseits nichts außer banalen oder einfach schlechten Opernaufführungen und miserablen Balletten siehst [...] und andererseits dich aufgrund der Voreingenommenheit gegenüber der Tätigkeit Djagilevs nicht vom Fleck bewegst, ohne die Bedeutsamkeit der Choreografie zu erkennen (denn du hast schließlich gesagt, dass das Ballett noch niederer sei als die Oper. Wenn es nach mir geht, dann ist die Kunst immer gleich. Es gibt keine niedersten oder höchsten Künste, es gibt verschiedene Kunstgenres. Wenn du allerdings das Eine unterordnest, beweist das nur, dass dir die Plastik insgesamt weniger wert ist als ein anderes Kunstgenre, oder es handelt sich einfach um eine Sache, ohne die du auch gut zurechtkommst), nur von der künstlerischen Inszenierung bereits existierender Opern träumst, und das ohne darüber nachzudenken, dass die Oper ebenso ein Spektakel ist [...]. Ein Spektakel, das folglich einen eigenen, einflussreichen Wert haben sollte - die durch Fantasie und Talent des Ballettmeisters geschaffenen reizvollen Gesten und Bewegungen im Tanz (welche du aus irgendeinem Grund dem Rezitativ unterordnest) genauso wie die Musik, die dem Spektakel entrissen wird. Es sind nicht bloß aneinandergereihte Künste, sondern eine Vereinigung der Künste, bei der das eine das andere verstärkt und ergänzt. Ich hätte ja für einen Gegner aller möglichen Vereinigungen - Drama mit Musik (Oper) oder Choreografie mit Musik (Ballett) noch Verständnis. Was soll man da machen? Anscheinend liebt ein solcher Mensch die reine Kunst - die Musik und nur die Musik oder die Plastik und nur die Plastik. Dich kann ich allerdings nicht verstehen, mein Lieber, denn schließlich magst oder mochtest du doch bis dato noch die plastischen Künste. Ich verstehe Nikolaj Andreevič, der selbst einräumte, er sei unempfindsam gegenüber den plastischen Künsten (was soll man da machen? Wenn er es nicht fühlt, dann fühlt er es eben nicht), doch verstehe ich in diesem Fall nicht, warum sein Schaffen dann in Form der Oper und zuweilen auch des Balletts Gestalt annahm. Formen also, in denen sich die Musik bewusst mit anderen Künsten verbindet. Ich denke, dass es nicht aufgrund von Unverständnis oder Abneigung gegenüber anderen Künsten geschah, sondern vielmehr wegen ungenügender Vertiefung und Vertrautheit mit ihnen. Wahrscheinlich ist es bei dir und deinen Ketzereien über die ,niederste Form' dasselbe (sei nicht wütend auf mich wegen des groben Tons; er ist nicht 
Nach seiner Eloge auf das künstlerische Potenzial des Balletts und einem geradezu überschwänglichen (Liebes-)Bekenntnis - „Скажу тебе только, что я, как раз наоборот, больше всего интересуюсь и люблю балет, и это не пустое увлечение, а серьезное глубокое наслаждение сценическим зрелищем - живою пластикой.“348 („Ich kann dir nur sagen, dass ich mich, ganz im Gegenteil, sehr für das Ballett interessiere und ich es liebe und es [für mich] keine bloße Unterhaltung darstellt, sondern wahrlich ernsthaften, tiefen Genuss der Bühnenkunst - der lebendigen Plastik.") - scheint es ihm wichtig zu sein, Rimskij-Korsakov darauf hinzuweisen, dass seine hier präsentierte ästhetische Überzeugung ganz mit der Benuas übereinstimme:

Вот, что я думаю о балете, будучи совершенно согласен с Бенуа и не находя ничего ужасного в его увлечении балетом. И напрасно ты стараешься меня вырвать из сферы влияния Бенуа - это человек на редкость тонкий, ясновидящий и чуткий не только к пластике, но и к музыке - из всех художников, которых мне теперь довелось видеть и встречать, это самый чуткий к музыке, не говоря уже о том, что он ее знает и понимает не хуже образованного профессионального музыканта. Если же его мнения о музыке тебе не по душе, то это еще не значит, что он в этой области не компетентен. Утверждение же его, что Дягилев певец и композитор, надо понимать просто, как его прикосновенность к пению и сочинительству, ибо и тем, и другим он серьезно занимался, но ни к тому, ни к другому больших способностей не оказалось $[. ..] .^{349}$

Dies ist, was ich vom Ballett halte, in vollkommenem Einverständnis mit Benua, nichts Schreckliches an seiner Begeisterung fürs Ballett findend. Du bemühst dich vergeblich, mich aus Benuas Einflussbereich herauszureißen - er ist ein selten feinfühliger Mensch mit einer klaren Vision und feinfühlig nicht nur zur Plastik, sondern auch zur Musik -, von allen Künstlern, bei denen sich mir die Gelegenheit bot, diese zu sehen und ihnen zu begegnen, ist er am feinfühligsten im Hinblick auf Musik. Es ist nicht so, dass er sie [die Musik] weniger gut kennt und versteht als ein ausgebildeter, professioneller Musiker. Wenn dir seine Meinungen über Musik missbehagen, so bedeutet dies noch lange nicht, dass er in diesem Gebiet nicht kompetent ist. Seine Behauptung, dass Djagilev ein Sänger und Komponist sei, muss man einfach so verstehen wie Djagilevs

so grob, wie es scheint). Ich denke, würdest du öfter ins Ballett gehen (das künstlerische, versteht sich), dann könntest du sehen, dass einem diese ,niederste Form' gewaltig große künstlerische Freuden bringt. Mehr als jede beliebige Opernvorstellung (selbst die Oper mit deiner Lieblingsmusik). Eine Freude, die ich schon seit mehr als einem Jahr verspüre und mit welcher ich dich furchtbar gerne anstecken möchte, um sie mit dir zu teilen. Es ist die Freude, die es mit sich bringt, wenn man einen ganz neuen Kontinent entdeckt. Ein Prozess, der viel Kraft kosten wird. Es liegt also eine Menge vor uns!“

348 Vgl. den Brief von Stravinskij an Vladimir Rimskij-Korsakov vom 8./21. Juli 1911.

349 Brief von Stravinskij an Vladimir Rimskij-Korsakov vom 8./21. Juli 1911. 
Herangehensweise an Gesang und Komposition. Er setzte sich sowohl mit dem einen als auch dem anderen ernsthaft auseinander, allerdings waren bei ihm weder im einen noch im anderen große Fähigkeiten vorhanden [...].

In Anbetracht dessen, dass Stravinskij für Pétrouchka eng mit Benua zusammenarbeitete, scheint es nur konsequent, dass er sich im Juni 1911 - also unmittelbar nach der Pétrouchka-Uraufführung - derart deutlich gegenüber den Vorwürfen Rimskij-Korsakovs positioniert. Schließlich richteten sich diese nicht mehr nur gegen Djagilev, sondern nun auch gegen das Ballett, das von Stravinskij wie Benua für so wichtig erachtet wurde. Stravinskijs Bekenntnis zum Ballett muss nun aber auch als ein Bekenntnis zur Ästhetik seines Mentors Benua verstanden werden, der einzig und allein im Ballett das von den Reformern geforderte Theater der Zukunft für realisierbar hielt. Welche Bedeutung diesem Bekenntnis zugesprochen werden muss, findet sich bereits bei Taruskin: Er bezeichnet den zitierten Brief als Stravinskijs „declaration of independence ${ }^{\text {350 }}$ und sah in ihm „the only major aesthetic pronouncement Stravinsky ever made“351.

Es wird deutlich: Craigs Behauptung, das Gesamtkonzept der BalletsRusses-Produktionen würde auf ihn zurückgehen bzw. die Ballets Russes hätten von ihm und anderen sogar "gestohlen“352, kann auf Grundlage der verfügbaren Quellen in dieser Eindeutigkeit zwar nicht nachgewiesen werden; ein Einfluss Craig'scher Ideen auf die Mitarbeiter der Ballets Russes - zumindest was Stravinskijs Ballett Pétrouchka angeht - ist aber durchaus denkbar.

Der sowohl von Benua als auch von Stravinskij für so wichtig erachtete Aspekt des Magischen geht höchstwahrscheinlich auf die russische Rezeption deutschsprachiger Reformschriften ab 1906 zurück, zu denen auch die deutschen Übersetzungen der Craig-Schriften gezählt werden müssen. Gordon Craigs Ideen im Allgemeinen und sein Konzept der Über-Marionette im Besonderen sind ab 1906 in ausgewählten Kreisen in Russland diskutiert worden - und zwar in theateraffinen Zirkeln, zu denen Benua gehörte. Es ist sehr wahrscheinlich, dass Stravinskij über Benua und Djagilev von Craig oder Craig-nahem Gedankengut erfahren hat. Ob dies schon vor seiner Arbeit an Pétrouchka erfolgte, kann nicht rekonstruiert werden; sein Bekenntnis zum

$35^{\circ}$ Taruskin, Stravinsky and the Russian Traditions, Bd. 2, S. 971.

351 Ebd. Stravinskij war direkt nach Ende der Ballets-Russes-Saison 1911 gemeinsam mit seiner Frau nach Ustilug aufgebrochen, um dort zu arbeiten. Vgl. Walsh, A Creative Spring, S. 168. Das Schreiben von Vladimir Rimskij-Korsakov, das Stravinskijs Brief vom 8./21. Juli vorausgegangen sein muss, ist nicht überliefert. Vgl. Taruskin, Stravinsky and the Russian Traditions, Bd. 2, S. 971.

$35^{2}$ Balance, „Kleptomania, or the Russian Theatre“, S. 98. 
Ballett, zu Benua und dessen ästhetischen Überzeugungen im Juli 1911 deutet aber stark darauf hin. Belegt ist außerdem, dass Stravinskij ab spätestens September 1911 (tanz-)theoretische Schriften der Reformbewegung rezipierte; und eine Partizipation des Publikums am Bühnengeschehen, wie sie in Stravinskijs Russkaja gezeigt werden konnte, wird darin prominent diskutiert. ${ }^{353}$

Direkt im Anschluss an die Balletts-Russes-Saison von 1911 und somit auch direkt im Anschluss an sein Bekenntnis zu Benua und dessen ästhetischen Überzeugungen im Reformdiskurs beeilt sich Stravinskij, die Arbeit am zwischenzeitlich auf Eis gelegten Ballett Das große Opfer wieder aufzunehmen. Es könnte also durchaus sein, dass Stravinskijs Wiederaufnahme des mit Rerich schon 1910 skizzierten Balletts mit der Reformbegegnung und insbesondere der Lektüre des Fuchs-Textes zusammenhängt. Diesen hatte Stravinskij nämlich irgendwann zwischen dessen Erscheinen in Sankt Petersburg 1910 und der ersten schriftlichen Erwähnung im September/Oktober 1911 gelesen. Und bezeichnenderweise entscheidet er sich bezüglich Sacre-Libretto und -Personalien in genau diesem Zeitraum um. Sacre-Forschung?

Am 24. September/7. Oktober 1911 schreibt Stravinskij Andrej Rimskij-Korsakov einen Brief und drängt ihn darin dazu, einen Aufsatz zu lesen. ${ }^{354}$ Es handelte sich um die (1910 in Sankt Petersburg erschienene) russische Übersetzung eines Artikels des deutschen Publizisten und Regisseurs Georg Fuchs (Tane ${ }^{355}$ ), der im Original bereits 1906 unter dem Titel Der Tanz ${ }^{356}$ in den Flugblättern für künstlerische Kultur in Stuttgart veröffentlicht worden war und in dem der Autor unter anderem mit "formaler Zeugungskraft" begabte Individuen dazu auffordert, neue (Tanz-)Formen zu schaffen. ${ }^{357}$

Fuchs gilt heute als einer der einflussreichsten deutschen Theatertheoretiker des 20. Jahrhunderts, obwohl seine Reformvorschläge in Frankreich, Russland und England eine weit größere zeitgenössische Würdigung

\footnotetext{
353 Vgl. hierzu auch Anm. 300.

354 „...] Тут кстати будет заметить, что тебе следует прочесть „Танец“ Георга Фукса в „Фиале страстей“ (СПБ. - изд. „Венок“ - 1910 г.) [...]“ „An dieser Stelle sei im Übrigen anzumerken, dass du den ,Tanz' von Georg Fuchs in der ,Fial strastej‘ lesen solltest." Auszug aus einem Brief von Stravinskij an Andrej Rimskij-Korsakov vom 24. September./7. Oktober 1911, ediert in: Perepiska, Bd. 1, hg. von Varunc, S. 3oof.

355 Vgl. Fuks, „Tanec“.

356 Vgl. Fuchs, „Der Tanz“.

357 Vgl. ebd., S. 1 of.
} 
erfuhren als in Deutschland selbst - dem eigentlichen Ort ihres Entstehens. ${ }^{358}$ Um die Jahrhundertwende hatte er sich vor allem mit seinem Einsatz für die Reform des (Schauspiel-)Theaters hervorgetan. Und in genau diesem Kontext ist auch Der Tanz zu sehen, dem 1905 Die Schaubühne der Zukunft sowie 1909 Die Revolution des Theaters vorausgingen. ${ }^{359}$ Erstgenannte ist Fuchs' nachmalig am meisten zitierte theaterprogrammatische Schrift, die aber nie ins Russische übersetzt wurde; sie gilt mittlerweile als „eine der Gründungsurkunden der antinaturalistischen Bewegungen auf dem Theater in Deutschland ${ }^{4360}$ und Fuchs - neben Gordon Craig, Jacques Copeau, Vsevolod Mejerchol'd und Adolph Appia - als einer der einflussreichsten Vertreter der europäischen Theaterrefombewegung zu Beginn des 20. Jahrhunderts. Letztgenannte Schrift erschien in einer russischen Übersetzung erst 1911 - also ein Jahr nach dem Tanz. ${ }^{361}$

Fuchs' Engagement für die Theaterreform im Allgemeinen und sein Aufruf zum Schaffen neuer (Tanz-)Formen im Besonderen sind primär als (s)ein erster Schritt zu einer allgemeinen Erneuerung der (deutschen) Kultur zu verstehen und müssen deshalb immer in einem (kultur-)politischen Zusammenhang gesehen werden: ${ }^{362}$ Fuchs sah sich und seine Generation - „die Generation von $187{ }^{\prime 363}$ - dazu verpflichtet, eigene Tätigkeiten immer auch „,völkischen` Aufgaben $^{“ 364} \mathrm{zu}$ widmen. Er fühlte sich deshalb dazu berufen, das deutsche

$35^{8}$ Erika Fischer-Lichte merkt an, dass Fuchs' Reformforderungen oftmals völlig losgelöst von seiner weltanschaulich-ideologischen Begründung rezipiert worden seien, und zwar von Vertretern ganz unterschiedlicher ideologischer Überzeugungen. Als Beispiele nennt sie unter anderem Platon Keržencev, Vsevolod Mejerchol'd und Aleksandr Tairov in Russland oder Jacques Copeau in Frankreich. Vgl. Fischer-Lichte, Kurze Geschichte des deutschen Theaters, S. 474.

359 Vgl. Fuchs, Die Schaubühne der Zukunft; DE Rs.: Die Revolution des Theaters. Ergebnisse aus dem Münchner Künstler-Theater, München und Leipzig $19 \circ 9$.

360 Grund, Zwischen den Künsten, S. 26.

361 Vgl. Georg Fuks: Revolucija teatra. Istorija Mjunchenskogo Chudožestvennogo teatra, übers. und redigiert von Akim L'vovič VoLYNSKIJ, Sankt Petersburg 1911.

362 Vgl. Brigitte Ruhwinkel: „Georg Fuchs. Theater als Völkischer Ritus“, in: Handbuch zur ,Völkischen Bewegung: 1871-1918, hg. von Uwe Puschner, Walter Schmitz und Justus H. Ulbricht, München 1999, S. 747-761, hier S. 748.

363 Fuchs, „Der Tanz“, S. 3 .

364 Ruhwinkel, „Georg Fuchs“, S. 747. Zum Begriff ,völkisch` bzw. zur ,Völkischen Ideologie‘ vgl. unter anderem Günter HartunG: „Völkische Ideologie“, in: Handbuch zur ,Völkischen Bewegung', hg. von Puschner, Schmitz und Ulbricht, S. 22-41. Die Herausgeber des genannten Handbuchs geben an, dass die ,völkische‘ Ideologie und Bewegung (insbesondere) der Weimarer Zeit sowohl im nationalen als auch im internationalen Wissenschaftsdiskurs wiederholt im Kontext des Nationalsozialismus als quasi ,unmittelbares Vorspiel des Hitlertums' betrachtet worden sei und dass diese Betrachtung 
Volk aus „dem durch die Industrialisierung entstandenen Chaos“365 und hierin zeigt sich seine Nähe zu Nietzsche - „den Leiden der Individuation“366 zu retten. Die Schaubühne ${ }^{367}$ stellte für ihn ein adäquates Mittel dar, um dieses Vorhaben in die Tat umzusetzen. Als erster Schritt zur Erneuerung der Kultur sollten auf ihr dann diese (neuen Tanz-)Formen gezeigt werden.

Stravinskij wirkt in besagtem Brief an Andrej Rimskij-Korsakov mehr als begeistert von Fuchs' Text, wenn er schreibt:

Я не успокоюсь раньше, чем ты не прочтешь этой статьи и не выскажешь мне своего мнения на бумаге, скрепленной твоей подписью, засвидетельствованной местной полицией. ${ }^{368}$

Ich werde mich nicht eher beruhigen, bis du diesen Artikel liest und mir deine Meinung dazu schriftlich auf Papier zukommen lässt, mit deiner Unterschrift und vom lokalen Polizeipräsidium beglaubigt.

Im zweiten Abschnitt fügt er dann begründend hinzu:

$[Ч]$ то может быть лучше и прекраснее развития раз созданных форм искусства? Разве только одно - создание новых форм. ${ }^{369}$

Was könnte besser und wundervoller sein als das Entwickeln bereits erschaffener Formen der Kunst? Nur eines: das Erschaffen neuer Formen.

schon alleine vor dem Hintergrund der Aneignung des Adjektivs ,völkisch` durch den Nationalsozialismus auch ihre Berechtigung hätte. Zugleich erwähnen sie allerdings auch die ",schwierigen Beziehungen zwischen Völkischen und Nationalsozialisten “ und weisen unter anderem darauf hin, dass Hitler in den "Völkischen“ gewissermaßen auch eine Konkurrenz gesehen habe, deren "Teutschtümelei“ er zwar abgelehnt, für seine Zwecke aber durchaus zu instrumentalisieren gewusst habe. Vgl. Uwe Puschner, Walter Schmitz und Justus H. Ulbricht: „Vorwort“, in: ebd., S. IX-XXIII, hier S. IXf. Fuchs sympathisierte nach 1933 mit der Hitler-Bewegung, unter anderem auch deshalb, weil er in der NSDAP eine „,einheitliche und unwiderstehliche Konzentration aller völkisch gesunden Elemente“ ' zu erkennen glaubte, räumte nach Zusammenbruch des Dritten Reichs allerdings ein, „sich in der Hitler-Bewegung getäuscht zu haben“. Vgl. Ruhwinkel, „Georg Fuchs", S. 757 f.

365 Ebd., S. 748.

366 Lenz Prütting: Die Revolution des Theaters. Studien über Georg Fuchs, München 1971, S. 101. Vgl. auch Fischer-Lichte, Kurze Geschichte des deutschen Theaters, S. 273f.

367 Vgl. Fuchs, Die Schaubühne der Zukunft.

368 Auszug aus dem Brief von Stravinskij an Andrej Rimskij-Korsakov vom 24. September/7. Oktober 1911.

369 Auszug aus ebd. 
Stravinskij beschwört hier die „neue (Kunst-)Form“ als die bessere und schönere Alternative zur Weiterentwicklung bereits bestehender (Kunst-) Formen und versucht im Anschluss daran, Rimskij-Korsakov gewissermaßen davon zu überzeugen, sich - wie er selbst - für ein solches Erschaffen neuer Formen einzusetzen:

Насколько я тебя вижу, ты держишься первого, но так как я тебя не вижу, то не ручаюсь в том, что ты присоединяешься, а, может быть, чего доброго уже и присоединился ко второму не словами и умом, которого ни у кого нет в той мере, в какой ему это нужно, а чувством, которое есть у всякого в той мере, сколько это ему нужно. Так или не так? Верно так! Не мешай себе чувствовать. ${ }^{370}$

So wie ich dich sehe, scheinst du an Ersterem [am Entwickeln bereits erschaffener Formen der Kunst] festzuhalten. Da ich dich nicht sehen kann, kann ich nicht bezeugen, dass du dich dem Zweiten [dem Erschaffen neuer Formen der Kunst] anschließt. Vielleicht hast du dich bereits angeschlossen, nicht mit Wort und Verstand, welche bei niemandem in jenem Maße existieren, in welchem es vonnöten wäre, sondern mit dem Gefühl, welches bei jedem in jenem Maß vorhanden ist, wie es jedem notwendig erscheint. Ist es nicht so? Richtig so! Hindere dich selbst nicht daran, zu fühlen.

Dem Brief ist nicht nur zu entnehmen, dass Stravinskij seinen Freund dazu aufforderte, den kürzlich in Sankt Petersburg erschienenen Artikel von Fuchs (Tanec) zu lesen. Er wollte ihn außerdem davon überzeugen, darin vermittelte Inhalte umzusetzen.

Gedachte Stravinskij etwa, Fuchs' Aufforderung Folge zu leisten und erstmals dessen neue (Tanz-)Formen zu verwirklichen? Und hatte seine Wiederaufnahme des Sacre knapp drei Monate zuvor eventuell etwas damit zu tun?

Angesichts der Bedeutsamkeit, die Fuchs innerhalb der Theaterreformbewegung zugeschrieben wird, sowie der augenscheinlichen thematischen Parallelen zwischen Fuchs-Text und oben zitiertem zweitem Briefabschnitt überrascht, dass sowohl Stravinskijs Lesebefehl an Rimskij-Korsakov als auch sein damit zusammenhängender Hinweis auf die neuen Formen in der einschlägigen Literatur bislang kaum Aufmerksamkeit erfahren haben. Obwohl ein Zusammenhang zwischen erstem und zweitem Briefausschnitt auf der Hand liegt - immerhin entstammen beide Äußerungen zwei aufeinanderfolgenden Abschnitten ein und desselben Briefes -, ist darauf bislang noch nie verwiesen worden - weder von der Musik- noch von der Tanzwissenschaft. Höchstwahrscheinlich geht dies darauf zurück, dass die Musikwissenschaft dem

370 Auszug aus ebd. 
Fuchs-Text noch nie große Bedeutung zugemessen hat. So erwähnt zum Beispiel Steven Walsh die erste Passage in seiner Stravinskij-Biografie und folgert daraus, dass Stravinskijs wachsendes Interesse am Ballett (neben dem Einfluss von Benua) auch in den zeitgenössischen russischen Theaterpropduktionen von Mejerchol'd gründen würde; mit der dazugehörigen Fußnote zeigt er dann allerdings, dass er Fuchs, dessen Tanz-Text sowie den mit Fuchs wie Mejerchol'd in Verbindung stehenden Reformbestrebungen keinerlei Bedeutung beimisst. Diese erwähnt er nicht einmal und notiert stattdessen lapidar:

Letter of 24 September/7 October 1911: [...] The Russian text of Fuchs' essay is Tanets $[. .$.$] . I have failed to trace the German original. { }^{371}$

In der Tat sind Fuchs' Texte heute außerhalb von Deutschland nur schwer zugänglich, da einige von ihnen seit ihrer Erstpublikation nie wieder neu aufgelegt wurden ${ }^{372}$ und lediglich in deutschsprachigen Bibliotheken konsultiert werden können - dies jedoch umstandslos. Die Suche nach dem deutschsprachigen Original auf Grundlage von Stravinskijs Angaben verkompliziert sich möglicherweise dadurch, dass Stravinskij im Brief lediglich den Titel der russischen Übersetzung nennt. ${ }^{373}$ Dass die thematischen Parallelen nie erkannt oder zumindest noch nie dargestellt worden sind, könnte ferner der Tatsache geschuldet sein, dass die im Original zusammenhängenden zwei Abschnitte des Briefes in der Sekundärliteratur stets getrennt voneinander zitiert werden. Walsh beispielsweise erwähnt zwar beide Textpassagen, platziert sie aber jeweils so, dass ein Zusammenhang nur schwer nachvollziehbar ist: Wenn er auf den Fuchs-Text hinweist, ignoriert er Stravinskijs Aufforderung zum Schaffen neuer (Kunst-)Formen; wenn er von jenen neuen Formen spricht, fehlt wiederum der Verweis auf Fuchs' Tanz-Text. ${ }^{374}$ Bei Taruskin verhält es sich ähnlich: Wenn er Stravinskijs Aufforderung zum Schaffen neuer Formen zitiert, gibt er zwar in der dazugehörigen Fußnote an, dass dieser Andrej Rimskij-Korsakov im selben Brief auf den "German dramaturg" Georg Fuchs aufmerksam gemacht habe; auf den Tanz-Text selbst verweist er aber nicht. ${ }^{375}$

371 Walsh, A Creative Spring, S. 59o.

372 Vgl. Balme, Das Theater von Morgen, S. 29. Mittlerweile sind mehrere Textsammlungen zum Reformtheater erschienen. In einer von ihnen wurde unter anderem auch Fuchs' Der Tanz thematisiert. Vgl. Klaus Lazarowicz und Christopher Balme (Hg.): Texte zur Theorie des Theaters, Stuttgart 2008, S. 56-6o.

373 Mir war es möglich, sowohl das deutsche Original als auch dessen russische Übersetzung einzusehen - Letztere in der Rossijskaja Gosudarstvennaja Biblioteka po Iskusstvu während meines Forschungsaufenthalts am Deutschen Historischen Institut in Moskau.

374 Vgl. Walsh, A Creative Spring, S. 17of. und 176.

375 Vgl. Taruskin, Stravinsky and the Russian Traditions, Bd. 2, S. 975. 
Bei Walsh muss wohl tatsächlich davon ausgegangen werden, dass er dem Tanz keine allzu große Bedeutung beigemessen hat. Deshalb verwundert auch nicht, dass er sowohl die Schrift als auch den Fuchs-Kontext nur beiläufig erwähnt. Bei Taruskin liegt der Verdacht nahe, dass er allerhöchstens einen flüchtigen Blick auf besagten Text geworfen hat. Darauf deutet nämlich eine Fußnote hin, in der er vermerkt, dass Fuchs „a strong proponent of choreographic adaptions à la Duncan“376 sei. Und tatsächlich: In der allgemeinen Auffassung von Körper und Körperlichkeit ist eine gewisse Parallele zwischen Fuchs und Duncan auszumachen. ${ }^{377}$ Allein, Fuchs wollte mit seinen spezifischen Aussagen zu Duncan nicht etwa die von ihr propagierten Formen verteidigen, sondern - ganz im Gegenteil - dazu auffordern, sie zu überwinden. ${ }^{378}$ Während die Musikwissenschaft dem Fuchs-Text bis dato also kaum Beachtung schenkt, thematisieren (deutschsprachige) tanzwissenschaftliche Studien zum modernen Ausdruckstanz Fuchs und dessen Schriften sogar überaus häufig - nie jedoch im Kontext der Ballets Russes (und somit auch nicht im Kontext von Djagilev, Nižinskij oder Stravinskij). ${ }^{379}$

Für die Stravinskij- wie die Ballets-Russes-Forschung ist dies folgenschwer. Denn: Im Tanz - das wurde deutlich - ist "das Schaffen neuer Formen“ ein zentrales, wenn nicht sogar das zentrale Thema. Fuchs fordert hierin explizit dazu auf, neue (Tanz-)Formen zu schaffen und bezeichnet noch dazu einen signifikanten Unterschied zwischen tatsächlichen „neuen Formen“ und „wiederbelebten“ alten (Tanz-)Formen. ${ }^{380}$ Es ist genau dieser Unterschied, den Stravinskij im zweiten Briefabschnitt an Rimskij-Korsakov thematisiert. Und die Lektüre des Fuchs-Textes, zu der Stravinskij Rimskij-Korsakov im ersten Abschnitt drängt, ist demnach eine notwendige Voraussetzung dafür, den zweiten

\section{Ebd.}

377 Vgl. unter anderem Grund, Zwischen den Künsten, S. 137.

378 Vgl. Kapitel III.1.2.1.

379 Das ist sowohl für den englisch- als auch den deutschsprachigen Bereich festzustellen. Weder Garafola noch Brandstetter erwähnen Fuchs im Kontext der Ballets Russes. Vgl. unter anderem Gabriele BRANDSTETTER: Tanz-Lektüren. Körperbilder und Raumfiguren der Avantgarde (Scenae), 2. erw. Ausgabe, Freiburg i.Br. 2013, S. 255-259; Garafola weist auf Fuchs in ihrer maßgeblichen Ballets-Russes-Monografie lediglich einmal hin, und zwar wenn sie erwähnt, dass Mejerchol'd sich für seine Theaterarbeiten unter anderem der Fuchs'schen Theorien bedient habe. Eine direkte Verbindung von Fuchs und Ballets Russes bzw. Stravinskij oder Nižinskij stellt sie allerdings nicht her. Vgl. Garafola, Diaghilev's Ballets Russes, S. 55.

38 o Vgl. Fuchs, „Der Tanz“, S. 7-10: „[E]s wäre wohl nur eine romantische Alfanzerei, wollte man da mit der so beliebten Manier der ,Wiederbelebung eingreifen, um so zu einer ,Neubelebung، der Tanzweisen zu gelangen. [...] Unsere Aufgabe ist es also, die Kräfte aufzudecken und in Tätigkeit zu versetzen, durch welche neue Tanzformen geschaffen und in das gesellige Leben eingeführt werden können." 
Teil des Briefes überhaupt erst zu verstehen: Stravinskij macht hier nämlich deutlich, dass er - wie Fuchs - für die wahrhaft "neuen Formen“ einsteht und Rimskij-Korsakov deshalb davon überzeugen will, es ihm gleichzutun.

Stravinskij hatte das Schriftstück also mit Begeisterung gelesen. Insbesondere der darin enthaltene Aufruf zum Schaffen neuer Formen muss ihm zu diesem Zeitpunkt eklatant wichtig erschienen sein; darauf verweist nicht nur die Überschwänglichkeit, mit der er davon berichtet, sondern auch die Dringlichkeit, mit der er sich mit seinem Anliegen an Rimskij-Korsakov wendet. Was zitiertem Brief nicht entnommen werden kann, ist ein genauer Zeitpunkt, wann die Lektüre stattgefunden hat. Die erste (und einzige) schriftliche Erwähnung des Textes (durch Stravinskij selbst) erfolgte in jenem Brief an Andrej Rimskij-Korsakov vom 24. September/7. Oktober 1911. Hatte er den Artikel also gelesen, kurz bevor er Rimskij-Korsakov davon berichtete? Oder könnte er ihn vielleicht auch schon knapp drei Monate füher gelesen haben - etwa zum Zeitpunkt seines Briefes an Nikolaj Rerich vom 2./15. Juli $1911{ }^{381}$ Dort erwähnt Stravinskij Fuchs zwar nicht explizit; zwei Punkte weisen allerdings deutlich darauf hin, dass Stravinskij beim Schreiben den Inhalt des Tanz-Textes bereits gekannt haben muss: Zum einen drängt er darauf, die gemeinsam begonnene Arbeit wieder aufzunehmen - das 1910 skizzierte Ballett Das große Opfer sollte endlich fertiggestellt werden. Hierfür wolle er allerdings szenische Änderungen besprechen, und das sollte so schnell wie möglich ge$\tan$ werden, also am besten schon während Stravinskijs Sommeraufenthalt in Ustilug, im Anschluss an die Ballets-Russes-Saison 1911. ${ }^{382}$ Zum anderen äußert sich Stravinskij zum ersten Mal negativ über den für das Große Opfer vorgesehenen Choreografen Michail Fokin. ${ }^{383}$

Auf den ersten Blick scheinen weder das eine noch das andere mit Stravinskijs Fuchs-Lektüre zusammenzuhängen - immerhin liegen zwischen der sehr dringlich anmutenden Aufforderung an Rerich (Anfang Juli 1911) und seiner Lektüreaufforderung an Rimskij-Korsakov (Ende September 1911) die besagten knappen drei Monate, und Fokin spielt in Fuchs' Text keine Rolle. Liest man den Tanz nun aber mit dem Wissen um Stravinskijs begeisterte Rezeption desselben, so trifft man immer wieder auf Termini und Topoi, die bezüglich des qualitativen Sprungs in der Konzeption des Sacre aufhorchen lassen und die deshalb den dringenden Verdacht nahelegen, dass Stravinskij den Text schon vor Juli 1911 gelesen hatte bzw. deutlich vor dem Brief an

381 Vgl. den Brief von Stravinskij an Rerich vom 2./15. Juli 1911, ediert in: Perepiska, Bd. 1, hg. von Varunc, S. 28gf.

382 Vgl. ebd.

383 Vgl. Taruskin, Stravinsky and the Russian Traditions, Bd. 2, S. 970. 
Rimskij-Korsakov - frühestens aber nach dessen Übersetzung ins Russische 1910. Um einen solch signifikanten Einfluss auf Stravinskijs künstlerische Arbeit und insbesondere auf seinen Sacre nachzuweisen, müssen aber zunächst einmal folgende Fragen geklärt werden: Wer war Georg Fuchs überhaupt? Was genau forderte er im Tanz? Welche Absichten verfolgte er, und in welchem Kontext sind seine Forderungen zu verstehen?

\subsubsection{Fuchs' Reformforderungen und Stravinskijs Sacre}

Wie viele seiner Reformmitstreiter sprach sich Fuchs entschieden gegen einen Naturalismus auf der Bühne aus. Das literarische Theater in seiner althergebrachten (naturalistischen) Form stellte für ihn „eine Kunst ohne Rhythmus, [und] [...] Form, [und somit] [...] eine,Un-Kunst ${ }^{\text {'384 }}$ dar. Er wünschte sich hingegen ein Drama, das „unaufhaltsame, rhythmische Bewegung ${ }^{\text {“385 }}$ des menschlichen Körpers sei ${ }^{386}$, ,in der Absicht, [...] daß man andere Menschen in gleiche oder ähnliche rhythmische Schwingungen und damit in einen gleichen oder ähnlichen Rauschzustand versetzt ${ }^{\text {“387}}{ }^{3}$. Um diese rhythmischen Schwingungen sowohl bei Künstlern als auch bei Zuschauern zu erzielen, setzte er sich unter anderem für die Abschaffung der Rampe ein. Diese galt ihm nämlich „als eine Art architektonische Verfestigung der Trennung von Bühne (Kunst) und Publikum (Leben)“388 - eine Trennung, die er mit der neuen Schaubühne aufzuheben gedachte: Durch sie wollte er ein Gemeinschaftserlebnis schaffen, das den „seltsamen Rausch [vermitteln sollte], der uns überkommt, wenn wir uns als Menge, als einheitlich bewegte Menge fühlen. [Denn es sei] sicher, daß uns ein Schauer durchschüttelt, sobald wir uns mit [...] ungezählten anderen in einer Leidenschaft als ungeheure Einheit, als Masse empfinden. ${ }^{389}$ Ebendieser Rausch sollte sich auf der Bühne entfalten und von dort aus auf das Publikum übergehen.

384 Georg Fuchs: Der Kaiser, die Kultur und die Kunst. Betrachtungen über die Zukunft des Deutschen Volkes. Aus den Papieren eines Unverantwortlichen, München und Leipzig 1904, S. 37 .

385 Fuchs, Die Revolution des Theaters, S. 117 .

386 Vgl. Ruhwinkel, „Georg Fuchs“, S. 749.

387 Fuchs, „Der Tanz“, S. 13.

388 Brauneck, Theater im 20. Jahrhundert, 2009, S. 155. Zur Beschäftigung der Reformer mit neuen Spielräumen vgl. Fischer-Lichte, Kurze Geschichte des deutschen Theaters, S. $263^{-272}$.

389 Fuchs, Die Revolution des Theaters, S. 4 f. Vgl. auch Fischer-Lichte, Kurze Geschichte des deutschen Theaters, S. 274. 
Warum für Fuchs ausgerechnet der Tanz die adäquate Kunstform für sein hehres Vorhaben ist, begründet er mit zwei Argumenten: Erstens würde die von ihm geforderte "gesteigerte Kultur des Körpers“ zum Tanz führen, zweitens aber auch die höchste Form der „Kultur der Geselligkeit“. ${ }^{390}$ Eine gesteigerte Körperkultur forderte Fuchs, weil er das eigentliche Problem der abendländischen Kultur darin sah, dass die Menschen (er spricht im Text von „den Deutschen“) den Körper bzw. das Körperliche zunehmend unterdrücken würden und "Kultur" lediglich als etwas rein Geistiges begriffen. ${ }^{391}$

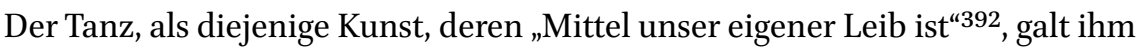
als ideal, da er davon überzeugt war, dass dem menschlichen Körper eine gewisse Rhythmik quasi eingeboren sei - und zwar durch den „Kreislauf [des] [...] Blutes, das eine magische Eurythmie durchpulst"393. In diesem Rhythmus sah er den Motor aller gestalterischen Kräfte, ${ }^{394}$ die den menschlichen Körper „zum Mittel künstlerischer Formschöpfung“395 machen würden. Da das Körperliche aber gegenwärtig unterdrückt werde, sei diese gestalterische Kraft des Rhythmus verloren gegangen, und sie könne lediglich durch eine gesteigerte Körperlichkeit wiederhergestellt werden.

Der zweite Aspekt, der Fuchs zum Tanz führte, die Kultur der Geselligkeit, geht auf seine Forderung nach dem Drama als berauschendem Gemeinschaftserlebnis zurück, vergleichbar mit dem Fest oder kultischen Ritual. Ein solches Drama stelle nämlich die höchste Form der Geselligkeit dar, ${ }^{396}$ und diese habe ihren Ursprung ebenfalls im Tanz, da dieser immer schon Kultform gewesen sei: ${ }^{397}$ Bei den alten Völkern werde der Tanz sogar als die „wichtigste

390 Vgl. Fuchs, „Der Tanz“, S. 7. Zum sich in vielfältiger Weise entwickelnden Interesse an Bewegungs- und Körperkulturen zu Beginn des 20. Jahrhunderts vgl. unter anderem Sabine Huschка: Merce Cunningham und der Moderne Tanz. Körperkonzepte, Choreographie und Tanzästhetik, Würzburg 2000, S. 39-51.

391 Vgl. Fuchs, „Der Tanz“, S. 4: „Für den Deutschen war seither ,Kultur“ etwas rein Geistiges. Daher kam es denn, daß das nun gemach einsetzende Bestreben, das Leben mit Form, mit Kunstgestalt zu durchdringen, sich zunächst nur schüchtern herauswagte in Bezirke, die nicht unmittelbar dem geistigen Reiche eingegliedert sind. Man versuchte sich anfänglich in der Dichtkunst, in der Literatur, dann in der Zierkunst, in der Bau- und Wohnungsgestaltung, endlich in der Kleidung, aber das Nächstliegende faßte man zuletzt, den eigenen Körper!"

392 Ebd., S. 6.

393 Ebd., S. 27.

394 Vgl. Fischer-Lichte, Kurze Geschichte des deutschen Theaters, S. 274.

395 Fuchs, „Der Tanz“, S. 6.

396 Vgl. Fuchs, Die Schaubühne der Zukunft, S. 18.

397 Vgl. Fuchs, „Der Tanz“, S. 7. 
Kultform“398 anerkannt. Ihr heiligstes Mysterium sei nämlich das Opfer, und das Opfer wiederum sei - „als Form betrachtet [- nichts anderes als] Höhe und Mitte der Tanzhandlung “399. Aus diesem Grund wollte Fuchs die antiken Opfermysterien bzw. ,kultischen Tanzorgien' der alten Völker in seinem Reformtheater wieder neu entstehen lassen..$^{400}$

Spätestens mit diesem zweiten Punkt muss Fuchs Stravinskijs Aufmerksamkeit erzielt haben, saß dieser doch seit Sommer 1910 an der Planung eines Balletts mit dem vorläufigen Titel Великал Жертва (Das große Opfer). Immerhin spricht Fuchs hier von alten Völkern und deren antiken Opfermysterien, und ein Opferritual war schließlich auch das Thema seines geplanten Balletts: Am 15. Juli 1910 (julianischer Kalender) hatte die Moskauer Tageszeitung Russkoe Slovo angekündigt, dass Stravinskij zusammen mit Fokin und Rerich an einem Ballett arbeiten würde, das altslawische Riten und Bräuche thematisiere:

Нашь сообщают по телефону изъ Петербурга: Вь ближайшемъ будущем должна появиться интересная балетная новинка. Академик Н. К. Рерихъ, молодой композоторъ ,Жаръ-Птици' И. Ф. Стравинский и балетмейстеръ М. М. Фокинъ работаютъ надъ балетомъ подъ названиемъ „Великая Жертва, посвященнымъ древнеславянскимъ религиознымъ обычаям. Содержание и постановка балета сочинены г. Рерихомъ. ${ }^{401}$

Man teilt uns telefonisch aus SanktPetersburg mit:In sehr naher Zukunft soll eine interessante Ballettneuheit präsentiert werden. Der Akademiker N.K. Rerich, der junge Komponist des ,Feuervogels', I.F. Stravinskij, und der Ballettmeister M.M. Fokin arbeiten an einem Ballett namens ,Das große Opfer', welches der altslawischen Religiosität und ihren Bräuchen gewidmet ist. Der Inhalt und die Inszenierung des Balletts stammen von Rerich.

Ungefähr einen Monat später folgte in der Sankt Petersburger Tageszeitung Peterburgskaja Gazeta eine ganz ähnliche Meldung. Sie enthielt die zusätzliche Information, dass die choreografische Handlung des Balletts in einer Sommernacht stattfinde, aus rituellen Tänzen bestehe und außerdem die erste Arbeit darstelle, die ohne dramatischen Plot ein Abbild der Vergangenheit zeige:

Новый балет даст ряд картин священной ночи и древних славян ... Начинается действие летней ночью и оканчивается перед восходом солнца, когда показываются первые лучи. Собственно хореографическая часть

398 Ebd.

399 Ebd.

400 Vgl. Brandstetter, Tanz-Lektüren, 2013, S. 255.

401 Auszug aus einer Ankündigung des Balletts (ohne Angabe eines Autors) in der Moskauer Tageszeitung Russkoe Slovo, 15. Juli 1910, S. 4. 
заключается в ритуальных плясках. Эта вещь будет первой попыткой, без определенного драматического сюжета, дать воспроизведение старины. ${ }^{402}$

Das neue Ballett zeigt uns eine Reihe von Bildern der heiligen Nacht und der frühen Slawen ... Die Handlung beginnt in einer Sommernacht und endet vor dem Sonnenaufgang, wenn die ersten [Sonnen-]Strahlen erscheinen. Erwartungsgemäß besteht der choreografische Teil aus rituellen Tänzen. Dies wird der erste Versuch sein, ohne ein festgelegtes dramatisches Sujet eine Wiedergabe altslawischer Zeiten herzustellen.

Einem Interview mit Rerich, das einen weiteren Monat später, am 30. September 1910, in der Sankt Petersburger Theaterprogrammzeitschrift Obozrenie Teatrov erschien, ist ferner zu entnehmen, dass das Ballett ein Einakter werden und mit einem Opfer enden solle:

Балет одноактный. Я хочу изобразить, как светлой летней ночью на вершине священного холма [...] происходит ряд ритуальных древнеславянских танцев - оканчивающихся жертвоприношением. ${ }^{403}$

Das Ballett besteht aus einem Akt. Ich möchte darstellen, wie in der hellen Sommernacht auf den Gipfeln des heiligen Hügels [...] eine Reihe altertümlicher, ritueller slawischer Tänze stattfindet, die in einer Opfergabe enden.

Obwohl keiner dieser frühen Berichte eine Jungfrauenfigur oder gar ein Jungfrauenopfer erwähnt, wird gemeinhin angenommen, dass die Jungfrau, die sich im letzten Tanz des 1913 uraufgeführten Sacre zu Tode tanzt, bereits bei den Planungen um 1910 eine Rolle gespielt hatte. ${ }^{404}$

Grund hierfür ist, dass Stravinskij selbst ab den 193oer-Jahren immer wieder behauptete, dass er die Jungfrauenopferidee bereits 1910 beim Beenden seines L'Oiseau de feu gehabt hätte - also vor seinem ersten Treffen mit Rerich. ${ }^{405}$ Den

402 Auszug aus einer Ankündigung des Balletts (ohne Angabe eines Autors) in der Sankt Petersburger Tageszeitung Peterburgskaja Gazeta, 28. August 1910, S. 4.

403 Vgl. Ohne Autor: „Naši Besedy. U N.K. Rericha“, in: Obozrenie Teatrov, Nr. 1187, 30. September 1910, S. 14.

404 Vgl. unter anderem Hill, The Rite of Spring, S. 3 f.

405 Zum ersten Mal begegnet man dieser Idee des Jungfrauenopfers 1931, und zwar in der ersten autorisierten Stravinskij-Biografie von André Schaeffner. Dieser berichtet von der Idee für ein neues Ballett, von der Stravinskij beim Beenden des L'Oiseau de feu geträumt habe. Die Jungfrau ist laut Schaeffner 1910 also bereits fester Bestandteil der Idee: „C'est en achevant d'instrumenter ,l'Oiseau de feu', à Petersbourg, entre fin avril et début de mai 1910, que l'idée du ,Sacre du Printemps' naquit en Strawinsky. Contrairement à ce que l'on a prétendu, cette première idée fut non pas musicale, mais toute plastique, et elle lui vent en rêve. Un ballet se déroula, qui était fait de la danse unique, jusqu’à épouisement de forces, d'une jeune fille devant un group de vieillards fabuleusement âgés, desséchés, presque 
zitierten Pressemitteilungen kann aber nur entnommen werden, dass das von Stravinskij, Rerich und Fokin geplante neue Ballett im September 1910 noch ein Einakter werden, in einer Sommernacht stattfinden, rituelle altslawische Tänze zeigen und mit einem nicht näher spezifizierten Opfer enden sollte. Aufzeichnungen dazu oder gar ein vorläufiges Libretto sind zwar nicht überliefert; ${ }^{406}$ Stravinskijs und Rerichs Intention war es aber, das „neonationalist“

pétrifiés. Dans la réalité la matière de ce rêve devint celle non d'un ballet entier, mais de la scène finale du ,Sacre` où l'Élue, jusqu'alors immobile, se livre à la danse sacrale devant le groupe stupide des Ancêtres." André Sc HAE FF NE R: Strawinsky (Maîtres de la musique ancienne et moderne, Bd. 10), Paris 1931, S. 35. In Stravinskijs Erinnerungen wird die „Idee“ dann zu einer Art „Tagtraum“. Auch hier verlautbart er, dass das Jungfrauenopfer bereits Teil des Plans von 1910 gewesen sei: „En finissant à Saint-Pétersbourg les dernières pages de ,'Oiseau de Feu', j'entrevis un jour, de façon absolument inattendue, car mon esprit était alors occupé par des choses tout à fait différentes, j'entrevis dans mon imagination le spectacle d'un grand rite sacral païen: les vieux sages, assis en cercle et observant la danse à la mort d'une jeune fille, qu'ils sacrifient pour leur rendre propice le dieux du printemps. Ce fut le thème du ,Sacre du Printemps'. Je dois dire que cette vision m'avait fortement impressionné et j'en parlai immédiatemment à mon ami le peintre Nicolas Roerich, spécialiste de l'évocation du paganisme." Stravinsky, Chroniques de ma vie, Bd. 1, S. 69. Stravinskijs Traumversion konnte nie bestätigt werden. Vgl. Taruskin, Stravinsky and the Russian Traditions, Bd. 1, S. 862. Die häufigen Diskrepanzen zwischen Stravinskijs im Nachhinein getätigten Aussagen, zu denen auch die Sacre-Entstehungsgeschichte in seinen Chroniques de ma vie gezählt werden muss, führten dazu, dass die Forschung diese mittlerweile mit einer gewissen Skepsis betrachtet. Vgl. pars pro toto Hill, The Rite of Spring, S. 4: „The discrepancies suggest that Stravinsky's memoirs need to be treated with caution." So wurde Stravinskijs Alleinbeanspruchung des Sacre-Ursprungsgedankens beispielsweise schon häufig angezweifelt. Vgl. Anm. 216. Bezüglich seiner Nennung des Jungfrauenopfers als Teil dieser ersten Idee wurde dies bislang noch nicht getan. Fakt ist aber, dass sich ein erster ausführlicher Handlungsbericht des Balletts, in dem auch das Jungfrauenopfer thematisiert wird, erst 1912 findet, und zwar im Brief von Stravinskij an Findejzen vom 2./15. Dezember 1912. Es ist also zumindest nicht auszuschließen, dass Stravinskijs Angaben dazu, wann die Idee des Jungfrauenopfers erstmals aufkam, nicht der Wahrheit entsprechen.

406 Vgl. unter anderem Taruskin, Stravinsky and the Russian Traditions, Bd. 2, S. 869. Man muss davon ausgehen, dass es bereits 1910 einige schriftliche Notizen zum geplanten Ballett gab. In einem Brief an Nikolaj Rerich vom 14./27. Juli 1910 erwähnt Stravinskij beispielsweise Notizen für das Ballett Великой жертвы (Das große Opfer) und erkundigt sich außerdem bei Rerich, ob sich dieser auch schon diesbezüglich Gedanken gemacht habe: „Начал набрасывать кое-что для Великой Жертвы. Делаете вы что-нибудь для нее [?]“ „Ich habe begonnen, etwas für ,Das große Opfer‘ zu skizzieren. Machen Sie schon etwas dazu?" Der Brief ist ediert in: Perepiska, Bd. 1, hg. von Varunc, S. 231f., hier S. 232. Auch im Brief an Rerich vom 19. Juni/2. Juli 1910 erwähnt Stravinskij ein Szenario. Er hatte es sich wohl auf einen Zettel notiert, den er dann verloren hatte, und bittet Rerich deshalb, ihm das Szenario zu schicken, das er bei ihm gelassen hatte. Vgl. den Brief von Stravinskij an Rerich vom 19. Juni/2. Juli 1910, ediert in: Perepiska, Bd. 1, hg. von Varunc, S. 224-226, 
Ideal der Ballets Russes umzusetzen (Kapitel II.). Dafür musste das Sujet in der russischen Kultur verankert und archaische Vorbilder gefunden werden. ${ }^{407}$ Für das Sommerritual als Vorbild entschieden sie sich höchstwahrscheinlich allein deshalb, weil für die Sommersonnenwende (Ivan Kupala-Tag) die meisten Opferrituale überliefert waren und Rerich sich mit ihnen bereits eingängig beschäftigt hatte. ${ }^{408}$

Es ist augenfällig: In den ersten Abschnitten des Fuchs-Textes muss Stravinskij seine Ballettpläne zumindest teilweise wiedergefunden haben. Was dann folgt, wirkt allerdings eher wie eine fundamentale Kritik an Stravinskijs (und Rerichs) Projektidee. Zwar beschreibt Fuchs, dass einige der Kulthandlungen der alten Völker noch in seiner Zeit in Kult- und Opferhandlungen verschiedener Naturvölker existieren würden; für die von ihm ersehnte Erneuerung der Kultur aber seien diese überlieferten Handlungen nicht zu gebrauchen: Weder seien sie fähig, neue Kunstformen hervorzubringen, noch wäre es ihnen möglich, die alten in irgendeiner Weise fortzubilden:

Das Opfer hat diese Stellung [nämlich Höhe und Mitte der Tanzhandlung zu sein] heute noch in den kultlichen Tanzorgien der Naturvölker [...]. Es ist auch jedem bekannt und jedem offensichtlich, daß die Opferhandlung des christlichen Kultus im Abendmahl durchaus Tanzhandlung ist. In eben dem Maße jedoch, in dem diese Religionen in Dogmen erstarrten, sind sie auch künstlerisch-formal unschöpferisch geworden. Sie sind ,fossil' geworden und mit ihnen ihre Kultformen, neue werden nicht mehr hervorgebracht, die alten nicht fortgebildet und bereichert. Das gilt auch von den religiösen Elementen des alten Heidentums, die ja noch jahrhunderte- und jahrtausendelang neben der [sic] christlichen fortbestanden, zwar immer mehr verblassend, aber doch mit seltsamen Resten bis an die Schwelle unseres Zeitalters während. ${ }^{409}$

hier S. 226: „Теперь вот что. Я потерял тот листок, где написал либретто „Великой Жертвы. Ради Бога, пришлите мне его тотчас заказным вместе с листком-памяткой, который я у Вас оставил и не взял при отъезде.“ „Folgendes. Ich habe jenes Blatt verloren, wo ich das Libretto des ,Großen Opfers‘ niedergeschrieben hatte. Ich bitte Sie, senden Sie mir es sofort zusammen mit dem Merkblatt, das ich bei Ihnen gelassen und bei der Abreise nicht mitgenommen habe."

407 Vgl. Ohne Autor, „Naši Besedy. U N.K. Rericha“, S. 14: „Эта вещь [gemeint ist damit das geplante Ballett Das große Opfer] будет первой попыткой, без определенного драматического сюжета, дать воспроизведение старины.“ „Dies wird der erste Versuch sein, ohne ein festgelegtes dramatisches Sujet eine Wiedergabe der antiken Zeiten herzustellen."

408 Vgl. Taruskin, Stravinsky and the Russian Traditions, Bd. 1, S. 866.

409 Fuchs, „Der Tanz“, S. 7. 
Fuchs war also davon überzeugt, dass die alten, noch überlieferten Formen „fossil" und somit "künstlerisch-formal unschöpferisch“ geworden seien. Er versucht dies dann ausgerechnet am Beispiel der "Gesellschaftstänze ${ }^{410} \mathrm{zu}$ verdeutlichen - und somit an den für Stravinskij und Rerich für Das große Opfer so wichtigen Volkstanzvorbildern. Diese seien nämlich eine der wenigen „altheidnischen Kultformen“, die zu Beginn des 20. Jahrhunderts überhaupt noch zu erleben seien:

[W]o die urtümliche Bauernkultur noch einigermaßen aufrecht steht [- also in abgeschiedenen Regionen -], ist die Beziehung der [...] Tänze und Reigen zu den alten Götterfesten, zu dem Wechsel der Jahreszeiten, zu Saat und Ernte usw. noch durchsichtig. ${ }^{411}$

Wolle man nun also diese spezifischen Tänze und Reigen erleben, müsse man bei den Feierlichkeiten zum Wechsel der Jahreszeiten mit der Suche beginnnen. Das hatten Stravinskij und Rerich getan. Doch Fuchs macht im Anschluss daran deutlich, dass diese noch existierenden alten Formen ganz sicher nicht als Vorbild für neue Tanzformen zu gebrauchen seien. Ganz im Gegenteil:

Nur ein Wahnsinniger könnte auf den Gedanken kommen, durch eine ,ästhetische Beeinflussung' der ,Gesellschaftstänze` eine neue Tanzkultur erzeugen zu wollen. Sie sind, wie auch das ,Ballett', lediglich ein Stoffgebiet für den Satiriker. Auch unser, sich von Tag zu Tag mehrendes Wissen um die Tanzkunst unserer Altvorderen und der großen Kulturen bis zur Antike hinauf nützt uns zu gar nichts, denn nur aus der lebendigen Rhythmik des Lebens selbst, des geselligen Lebens unserer Zeit kann auch lebendige Tanzform aufspringen, und archaisierendes lehrhaftes Inbewegungsetzen alter Reliefs, Bildtafeln und

410 Ebd. Fuchs verwendet im Text den Begriff ,Gesellschaftstanz' gewissermaßen gleichbedeutend mit dem des ,Volkstanzes' bzw. versteht den ,Volkstanz' als eine Art Unterkategorie des ,Gesellschaftstanzes'. Heute wird der Begriff ,Gesellschaftstanz' meistens in Abgrenzung zum Begriff des, Volkstanzes' verwendet. So werden unter dem Terminus ,Gesellschaftstanz' in der MGG beispielsweise Tanzformen subsumiert, die sich „zunächst im Bereiche des Hofes [...] und der aristokratischen, später der bürgerlichen Gesellschaft" entwickelten. Sie alle werden (im Unterschied zum theatralischen Tanz) von Laien ausgeführt, spielen „im geselligen zwischenmenschlichen Beziehungsgeflecht eine wichtige sozialisierende Rolle“ und sind „im Unterschied zum Volkstanz [...] in Quellen dokumentiert“. Mit dem Terminus ,Volkstanz' werden am gleichen Ort hingegen „alle Tanzphänomene ritueller und geselliger Art [bezeichnet], die nicht zum Bühnentanz (Ballett) oder zum Gesellschaftstanz bis hin zum modernen (Disco-)Tanz gehören“. Vgl. Dahms, Woitas, Oberzaucher-Schüller, Bröcker u.a., Art. ,Tanz', Sp. 265 und $364 f$.

411 Fuchs, „Der Tanz“, S. 7. 
Tonfigürchen ist weit eher geeignet, die tanzschöpferische Kraft der modernen Rassen zu betäuben und in die Irre zu führen, als sie anzufeuern. [...] [U]ns [fehlt] jede Kontrolle darüber, ob wir die Bilder nach alten Tanzfiguren überhaupt richtig deuten. Diese Bilder sind doch alle von Künstlern geschaffen [...] und Künstler sind doch keine naturalistischen Episodenerzähler und keine exakten Kulturhistoriker. [...] Wir können also von alten Tanzformen gar nichts mehr wissen; wir vermögen nur, aus den etwa erhaltenen Tanzweisen, aus den Versen der Reigenlieder, aus den Schilderungen der Dichter, aus bunten Wandmalereien, Erz- und Steinbildern und Münzgeprägen, aus den erhaltenen Gewändern, Schuhen und Geschmeiden, aus den Abmessungen der Tanzsäle und aus der überkommenen Kunst von der gesamten Rhythmik des öffentlichen und häuslichen Lebens uns einen romantischen Traum vorzugaukeln, in dem die Jahrhunderte und Jahrtausende am Reigen die Hände ineinander flechten; aber welche Gruppe wir aus dieser mannigfach bewegten Folge auch herausgreifen mögen, um sie in Fleisch und Blut zu verwirklichen, sie wird in unseren Sälen und auf unseren Festen immer gespenstig wirken - im besten Falle - oder aber als Maskerade. Der Versuch wird ja oft genug gemacht; und jedesmal hat man ein leises Grauen dabei wie bei einer Totenbeschwörung und nicht die Empfindung eines Erlebnisses, sondern eines schattenhaften Traumvorganges - im besten Falle $[\ldots] .412$

Eine Erneuerung der Kultur durch ein Wiederbeleben alter Tanzformen hielt Fuchs also für völlig abwegig. Zur Stärkung seiner Argumentation rekurriert er dann sogar auf das Ballett, da er darin ja genauso wie viele andere Reformer eine antiquierte Kunstform sah, die für eine Reform nicht nutzbar gemacht werden könnte: Wie das Ballett seien alte (Volks-)Tanzformen nur noch ein „Stoffgebiet für den Satiriker“. Denn ein „archaisierendes [...] Inbewegungsetzen alter Reliefs" und Bilder könne ganz sicher nicht die schöpferische Kraft des modernen Menschen entfachen. Das sei schon oft versucht worden, und zwar ohne Erfolg.

Fuchs betrachtete es daher als seine Aufgabe bzw. als die Aufgabe seiner Generation, „die[jenigen] Kräfte aufzudecken und in Tätigkeit zu versetzen, durch welche neue Tanzformen geschaffen und in das gesellige Leben eingeführt werden könn[t]en“413. Im Gegensatz zu „allen anderen Sport[formen]“414 seien Tanzformen aber genuine Kunstformen und „bedürf[t]en [so] [...] zu ihrem Entstehen [immer] der künstlerischen Intuition, [und somit] des mit formaler Zeugungskraft begabten Individuums“415: Er forderte also, dass „berufsmäßige Künstler [...] Tanzformen schaffen und zeigen [sollten], welche

\footnotetext{
412 Ebd., S. 8f.

413 Ebd., S. 10.

414 Ebd., S. 11.

415 Ebd.
} 
unserer Zeit und unserem modernen Empfinden gemäß “416 seien. Diese sollten dann von der Bühne „in die Schulen, in die Turnhallen, in die sportlichen Veranstaltungen“417 übernommen werden.

Noch einmal zur Erinnerung: Es war Benua, der die Kunstform Ballett bereits 1908 in seinem Artikel „Beseda o balete“ gegen jene Vorurteile der Reformer verteidigt hatte, auf die auch Fuchs im Text verweist: ${ }^{118}$ Man hielt das Ballett für eine veraltete Kunstform - ein „Stoffgebiet für den Satiriker“419 -, die sich für zeitgenössische Experimente nicht mehr eignen würde. Benua aber war davon überzeugt, dass das Ballett lediglich erneuert werden müsste, um das von den Reformern geforderte Theater der Zukunft, das laut Fuchs „unaufhaltsame, rhythmische Bewegung ${ }^{420}$ sein müsse, zu verwirklichen. Stravinskij teilte die ästhetischen Ansichten seines Mentors Benua voll und ganz: ${ }^{421}$ Auch er war davon überzeugt, mit einem neuartigen Ballett jenes reformatorische Theater realisieren zu können. Den ersten Schritt auf dem Weg dorthin zeigt Fuchs im Tanz auf: Zunächst seien mit formaler Zeugungskraft begabte Individuen gefordert, neue (Tanz-)Formen zu schaffen. Und vom Schaffen neuer Formen hatte Stravinskij Andrej Rimskij-Korsakov in seinem Brief vom 24. September/7. Oktober 1911 schließlich vorgeschwärmt. ${ }^{422}$ Hatte der „berufsmäßige Künstler “423 Stravinskij Fuchs' Imperativ also zum Anlass genommen, seine Arbeit am Großen Opfer wiederaufzunehmen? Immerhin hatte er mit Rerich dafür ja bereits ein Jahr zuvor ein Sujet ausgearbeitet, das dem von Fuchs gewünschten Opfermysterium in weiten Teilen ähnelte.

Fakt ist, dass zentrale Topoi und Termini des Sacre in den Ankündigungen für Das große Opfer 1910 noch nicht genannt werden ${ }^{424}$ - so unter anderem die in der Einleitung erklingenden Dudki, die für die Danse de la terre beschriebene Tanzekstase sowie die am Ende tanzende (Jung-)Frau. All diese Details hatten Rerich und Stravinskij dem Libretto mutmaßlich erst im Zuge

\footnotetext{
416 Ebd., S. 15 .

417 Ebd.

418 Vgl. Kapitel II.3.1.

419 Fuchs, „Der Tanz“, S. 8.

420 Fuchs, Die Revolution des Theaters, S. 117.

421 Vgl. Kapitel III.1.1.2.

422 Vgl. den Brief von Stravinskij an Andrej Rimskij-Korsakov vom 24. September/7. Oktober 1911.

423 Fuchs, „Der Tanz“, S. 15.

424 Walsh äußert sich dazu beispielsweise folgendermaßen: „In any case it seems likely that these early scenarios [die Szenarios von 1910, die nicht überliefert sind] differed in important details from the plan Stravinsky took away from Talashkino after a few days there." Walsh, A Creative Spring, S. 173 f.
} 
ihres zweiten Treffens im Sommer 1911 hinzugefügt: Am 2./15. Juli 1911 wandte sich Stravinskij an Rerich, um ein Treffen zu vereinbaren. Er wollte unbedingt zu einer endgültigen Übereinkunft bezüglich ihres Balletts kommen. Beide hatten die Vorbereitungen für Das große Opfer aufgrund anderer Projekte zunächst hintangestellt, ${ }^{425}$ und so hatte es Rerich dann offenbar auch nicht so eilig, die Arbeit am gemeinsamen Projekt mit Stravinskij wiederaufzunehmen. ${ }^{426}$ Letztgenanntem schien die Angelegenheit aber derart wichtig, dass er auf einem schnellstmöglichen Treffen insistierte:

[...] Трудно Вам ответить, для чего нам надо увидеться. Чувствую, что надо, чтобы окончательно столковаться о нашем детище, за которое я примусь осенью и надеюсь кончить, если буду здоров, к весне. ${ }^{427}$

[...] Es fällt mir schwer, Ihnen zu antworten, weshalb wir uns treffen müssen. Ich fühle, dass es notwendig ist, damit wir uns endgültig über unser Werk einig werden, dessen ich mich im Herbst annehmen werde und hoffe, dieses dann zu vollenden, wenn ich gesund sein werde, zum Frühling.

Er wollte unbedingt noch einige szenische Fragen vor dem Sommer geklärt haben. Auf den Winter konnten sie unter anderem auch deshalb nicht verschoben werden, weil er plante, diesen gemeinsam mit seiner Familie in der Schweiz zu verbringen: ${ }^{428}$

Есть сценические вопросы. Кроме того, надо повидаться нам уже потому, что зиму в Петербурге я непроведу, - все мы уедем в Швейцарию (вероятно), а оттуда, должно быть, в Париж. ${ }^{429}$

Es gibt szenische Fragen. Außerdem müssen wir uns treffen, da ich den Winter nicht in Sankt Petersburg verbringen werde - wir werden alle (vermutlich) in die Schweiz fahren und von dort aus voraussichtlich nach Paris.

425 Stravinskij hatte hauptsächlich an Pétrouchka gearbeitet. Zu Rerichs Projekten vgl. unter anderem Hill, The Rite of Spring, S. 7 .

426 Vgl. ebd.

427 Brief von Stravinskij an Rerich vom 2./15. Juli 1911, S. 289.

428 Zu Stravinskijs Plänen für einen Aufenthalt in der Schweiz vgl. unter anderem den Brief von Stravinskij an Aleksandr Benua vom 30. Juni/13. Juli 1911, ediert in: Perepiska, Bd. 1, hg. von Varunc, S. $285^{-287}$.

429 Brief von Stravinskij an Rerich vom 2./15. Juli 1911, S. 289. 
Schließlich konnte sich Stravinskij durchsetzen, und er und Rerich trafen sich in der Künstlerkolonie Talaškino, südlich von Smolensk - höchstwahrscheinlich in der letzten Juliwoche. ${ }^{430}$ Die Peterburgskaja Gazeta berichtete darüber am 7. September 1911:

Художник Н.К. Рерих и композитор И.Ф. Стравинский переделали свой одноактный балет в двухактный, дав ему новое название: „Праздник весны'. Балет пойдет летом за границей [...].431

Der Künstler N.K. Rerich und der Komponist I.F. Stravinskij haben ihren Einakter in ein aus zwei Akten bestehendes Ballett geändert und diesem folgenden neuen Namen gegeben: ,Die Frühlingsfeier'. Das Ballett wird im Sommer im Ausland zu sehen sein $[\ldots]$.

Stravinskij und Rerich hatten sich also während ihres zweiten Treffens entschieden, dem Ballett einen zweiten Akt hinzuzufügen. Außerdem kamen sie überein, nicht mehr - wie ursprünglich geplant - ein Ritual zur Sommersonnenwende zu zeigen, sondern ein Frühlingsritual. Dementsprechend änderten sie auch den Namen des Werks: von Великая Жертва (Das große Opfer) zu Праздник весны (Frühlingsfest).

In Stravinskijs Chroniques de ma vie ist zu lesen, dass Rerich und er sich bereits in Talaškino sowohl über den definitiven Handlungsplan als auch über die Titel der einzelnen Tänze einig geworden waren. ${ }^{432}$ Auch von diesem zweiten Treffen ist der Handlungsplan allerdings nicht überliefert; aus den Angaben in Stravinskijs Notizbuch, das dieser Ende August direkt nach seiner Rückkehr nach Ustilug begann, ergänzt durch seine Angaben in einem Brief an Rerich vom September 1911, kann aber immerhin auf die geplanten Titel und ursprüngliche Abfolge der Tänze und somit auf das Libretto geschlossen werden: ${ }^{433}$

430 Vgl. Taruskin, Stravinsky and the Russian Traditions, Bd. 1, S. 871; Walsh, A creative Spring, S. ${ }_{173}$ f. Die russische Künstlerin und Mäzenin Marija Teniševa hatte die Künstlerkolonie Talaškino 1893 zur Förderung der russischen Volkskultur gegründet. Vgl. unter anderem Mary E. Davis: Ballets Russes Style. Diaghilev's Dancers and Paris Fashion, London 2010, S. 66f. sowie Anm. 198.

431 Auszug aus einer Ankündigung (ohne Namen eines Autors) in der Peterburgskaja Gazeta, 7. September 1911, zit. in: Elena Ivanovna Poljakova: Nikolaj Rerich (Žizn’v Iskusstve), Moskau 1973, S. 170.

432 Vgl. Taruskin, Stravinsky and the Russian Traditions, Bd. 1, S. 873; Stravinsky und Craft, Expositions and Developments, S. 141 und 161.

433 Vgl. Taruskin, Stravinsky and the Russian Traditions, Bd. 1, S. 873f. 


\begin{tabular}{|c|c|c|}
\hline $\begin{array}{l}\text { Bezeichnung in den } \\
\text { Skizzen }^{434}\end{array}$ & Wörtliche Übersetzung & Spätere Bezeichnung \\
\hline & & Première Partie \\
\hline [Дудки] & Schalmeien & Introduction \\
\hline [Гадания на прутиках] & $\begin{array}{l}\text { Weissagungen mit kleinen } \\
\text { Ruten }\end{array}$ & Les augures printaniers \\
\hline Хоровод & Reigentanz & Rondes printanières \\
\hline Игра в города & Spiel der Städte & Jeux des cités rivales \\
\hline Идут-ведут & Sie gehen und bringen [ihn] & Cortège du sage \\
\hline Игра умыкания & Spiel der Entführung & Jeu du rapt \\
\hline Выплясывание земли & Das Austanzen der Erde & $\begin{array}{l}\text { Danse de la terre } \\
\text { Seconde Partie }\end{array}$ \\
\hline Хороводы, тайные игры & $\begin{array}{l}\text { Reigentänze, geheime } \\
\text { Spiele }\end{array}$ & $\begin{array}{l}\text { Cercles mystérieux des } \\
\text { adolescentes }\end{array}$ \\
\hline $\begin{array}{l}\text { Величание - дикая } \\
\text { пляска (Амазоны) }\end{array}$ & $\begin{array}{l}\text { Preisung - wilder Tanz } \\
\text { (Amazonen) }\end{array}$ & Glorification de l'élue \\
\hline Действо старцев & Handlung der Ältesten & $\begin{array}{l}\text { Action rituelle des } \\
\text { ancêtres }\end{array}$ \\
\hline Пляска священная & Heiliger Tanz & Danse sacrale \\
\hline
\end{tabular}

Dass die Pläne für Das große Opfer von denjenigen für das Frühlingsfest von 1911 in wichtigen Details abweichen, wurde in der Forschung bereits hinreichend diskutiert. ${ }^{435}$ Die Frage nach dem Warum wurde hierbei allerdings noch nie gestellt.. ${ }^{436}$

434 Die Tabelle mit den russischen Titeln findet sich ebd., S. 873. Die deutschen Übersetzungen sind entnommen aus Christoph Flam : Igor Strawinsky.,Der Feuervogel', Petruschka', Le Sacre du printemps', Kassel u.a. 2013, S.134. Stravinskijs Notizen sind faksimiliert in:Stravinsky, ,The Rite of Spring: Sketches 1911-1913. Die in Klammern angegebenen ersten zwei russischen Titel finden sich nicht im Notizbuch, werden aber von Stravinskij in einem Brief an Rerich vom 13./26. September 1911 erwähnt. Vgl. Taruskin, Stravinsky and the Russian Traditions, Bd. 1, S. 873; Flamm, S. 178, Anm. 28. Der Brief ist ediert in: Perepiska, Bd. 1, hg. von Varunc, S. 3oo. Van den Toorn gibt die Titel der Tänze (inklusive Datierungen und Seitenangaben im Notizbuch) an. Vgl. van den Toorn, Stravinsky and,The Rite of Spring', S. 24.

435 So unter anderem Walsh, A Creative Spring, S. 173f.; Taruskin, Stravinsky and the Russian Traditions, Bd. 1, S. 871 .

436 Vgl. hierzu unter anderem Walsh, A Creative Spring, S. 173f.; Taruskin, Stravinsky and the Russian Traditions, Bd. 1, S. 871-881. Sowohl Walsh als auch Taruskin liefern hier keine stichfeste Begründung für die Wiederaufnahme des Balletts. 
Sollte der Fuchs-Text dazu geführt haben, dass Stravinskij die Arbeit am Großen Opfer wiederaufnahm, müsste er die Schrift vor dem Sommer 1911 gelesen haben. Den entscheidenden Hinweis darauf, dass sich dies tatsächlich so verhalten hat, liefert lediglich ein Detail: seine plötzliche Ablehnung von Fokin, die er erstmals im zitierten Brief an Vladimir Rimskij-Korsakov vom 8./21. Juli 1911 äußert - also noch vor der Wiederaufnahme des Balletts. Sie führte am Ende dazu, dass Fokin 1912 durch Vaclav Nižinskij ersetzt wurde. Einen plausiblen Grund hierfür liefert nur Fuchs' Text: Fokin war maßgeblich beeinflusst von der amerikanischen Ausdruckstänzerin Isadora Duncan. ${ }^{437}$ Doch Duncan - das wird bei der Tanz-Lektüre offensichtlich und soll deshalb kurz rekapituliert werden - war für Fuchs ein rotes Tuch, zumindest betreffend das Schaffen „neuer Formen“.

Der Reformer macht ja deutlich, dass das künstlerische Individuum, das er zum Schaffen neuer und dem "modernen Empfinden“ gemäßer (Tanz-) Formen benötige, auf keinen Fall auf alte (Tanz-)Formen zurückgreifen dürfe. Und genau dort setzt seine Kritik an Duncan an. Über diese sagt er: Nur „wer $[\ldots]$ voreilig $[\ldots]$ urteilt, könnte $[\ldots]$ hier ein[]werfen, daß Isadora Duncan jene Tat [das heißt das künstlerische Schaffen neuer Formen, die dem modernen Empfinden gemäß sind] schon gewagt hätte“438:

[I]hr lag nichts ferner als ein schöpferisches Ausbilden von Formen. Sie bemühte sich, die von antiken Bildwerken abgelesenen Posen aneinander zu reihen und ließ dazu gute Musik aufspielen, mehr [allerdings] um die Lücken zwischen den aneinander gereihten Posen auszufüllen, als um die von der Musik ausschwingenden Rhythmen im Körperlichen widerzuspiegeln. ${ }^{439}$

Genau Letzteres forderte Fuchs aber ja für die neuen Formen.

Heute gilt Duncan als Pionierin des modernen Ausdruckstanzes. Sie war 1899 nach einem wenig erfolgreichen Debüt in den USA nach London und von dort aus 1900 nach Paris gegangen und hatte mit ihren tänzerischen Darbietungen und Vorträgen das Interesse zahlreicher Künstler und Intellektueller auf sich gezogen. ${ }^{440}$ 1906, als Der Tanz erschien, hatte sie also - und darauf scheint Fuchs anzuspielen - namhafte Bewunderer in allen europäischen Metropolen

\footnotetext{
437 Vgl. Garafola, Diaghilev's Ballets Russes, S. 40-44.

438 Fuchs, „Der Tanz“, S. 17.

439 Ebd.

440 Vgl. unter anderem Hafemann, Schamlose Tänze, S. 18; Daniel Schümann: Die Suche nach dem ,neuen Menschen' in der deutschen und russischen Literatur der Jahrhundertwende. Frank Wedekinds ,Mine-Haha' und Michail Petrovič Arcybaševs ,Sanin' (Vorträge und Abhandlungen zur Slavistik, Bd. 40), München, Berlin und Washington D.C. 20o1, S. 66 .
} 
inklusive Moskau und Sankt Petersburg ${ }^{41}$, unter ihnen auch Fokin. Ihre ersten Auftritte in Sankt Petersburg 1904 hatten bei ihm einen bleibenden Eindruck hinterlassen und sollten seine zukünftigen Choreografien entscheidend prägen. ${ }^{442}$

Was genau aber hatte ihn so nachhaltig beeindruckt? Duncan erfand ein völlig eigenes, auf Empfinden und Improvisation beruhendes Bewegungskorpus und das gänzlich ohne professionelle (klassische) Tanzausbildung. Maßgeblich beeinflusst hatten sie dabei Theorien des französischen Sprecherziehers und Bewegungspädagogen François Delsarte, der die Entsprechung zwischen innerer und äußerer Bewegung sowie die Einheit von Körper, Geist und Seele proklamierte. ${ }^{443}$ Ein codiertes Bewegungsvokabular wie dasjenige des

441 Vgl. unter anderem G.B.L. Wilson: Art. ,Duncan', in: The New Grove, Bd. 5, S. 715f. 1903 veröffentlichte Duncan in Deutschland ihre tanzprogrammatische Schrift Der Tanz der Zukunft, in der sie ihre Reformideen erstmals auch verschriftlichte. Vgl. Isadora DunCAN: Der Tanz der Zukunft (The Dance of the Future). Eine Vorlesung, übers. und eingeleitet von Karl Federn, Leipzig 1903. Zum Eindruck, den Duncan auf den deutschen Kultur- und Kunstbetrieb gemacht hat, vgl. unter anderem den Aufsatz von Claudia JeschKe und Gabi Vettermann: „Isadora Duncan, Berlin and Munich in 19o6. Just an Ordinary Year in a Dancer's Carreer", in: Dance Chronicle 18/2 (1995), S. 217-229. Zu Isadora Duncans Einfluss auf die russische Tanzszene vgl. unter anderem Elizabeth Souritz: „Isadora Duncan's Influence on Dance in Russia“, in: ebd., S. 281-291; Elizabeth Souritz: „Isadora Duncan and Prewar Russian Dancemakers", in: The Ballets Russes and its World, hg. von Lynn GARAFola und Nancy VAN Norman BAe R, London 1999, S. 97-115, hier S. 104-114; Natalia Roslavleva: Era of the Russian Ballet, London 1966, S. 176f.

442 Vgl. Garafola, Diaghilev's Ballets Russes, S. 41; Scholl, From Petipa to Balanchine, S. 59; Souritz, „Isadora Duncan and Prewar Russian Dancemakers“; Souritz, „Isadora Duncan's Influence on Dance in Russia“; Stüdemann, Dionysos in Sparta, S. 68-88. Fokin versuchte zeitlebens, den Einfluss von Duncan herunterzuspielen; Tim Scholl zeigt allerdings einige direkte Einflüsse auf. Vgl. Scholl, From Petipa to Balanchine, S. 58-61. Dass Fokin Duncan bewunderte, wird zudem im folgenden Abschnitt seiner postum veröffentlichten Memoiren sehr deutlich: „Babylon, Judea, Egypt, Greece, Italy, France, Scandinavia, Russia, is the path of the development which the art of the dance has followed, pasing over three continents of the Old World, and litterally forming a circle. America has remained outside this circle. This does not mean that America until now has not contributed to the art of dance. On the contrary, I consider the greatest manifestations of recent times to be seperate and so dissimilar achievements of Isadora Duncan, Lois Fuller and Ruth St. Denis. [...] I wish to talk about Isadora Duncan in some detail. She was the greatest American gift to the art of dance. Duncan proved that all the primitive, plain, natural movements - a simple step, run, turn on both feet, small jump on one foot - are far better then all the richness of the ballet technique, if to this technique must be sacrificed grace, expressiveness, and beauty." Fokine, Memoirs of a Ballet Master, S. 256. Für die russische Ausgabe vgl. Michail Forin: Protiv tečenija. Vospominanija baletmejstera. Stat'i, interv'ju i pis'ma, Leningrad 1981, S. 256.

443 Vgl. Claudia Jeschke: Art. ,Duncan', in: $M G G$ 2, Personenteil: Bd. 5, Kassel u.a. 20o1, Sp. 1592-1594, hier Sp.1593; Claudia Jeschke und Gabi VettermanN: „François 
klassischen Tanzes lehnte sie hingegen radikal ab und machte es sich zum Ziel, all ihre Bewegungen aus der energetisch-dynamischen Kraft des eigenen Körpers heraus zu entwickeln. ${ }^{44}$ Ihre choreografische Arbeit bestand dann darin, die sich aus dem Körper entfaltende Energie in bestimmte kinetische Formen zu transformieren und so für den Betrachter sichtbar zu machen. Als Vorbilder dafür dienten ihr größtenteils Bewegungsdarstellungen aus dem antiken Griechenland und der Renaissance. ${ }^{445}$

Fuchs' Kritik an Duncan bezog sich vor allem darauf, dass sie auf alte (Tanz-) Formen und -Vorbilder zurückgegriffen habe. ${ }^{446} \mathrm{Ihr}$ Auftreten habe lediglich dahingehend einen „sehr großen Wert gehabt, daß die ihr zu Anfang gewidmete leidenschaftliche Teilnahme klar bewies, wie lebendig das Verlangen

Delsarte“, in: Ausdruckstanz. Eine mitteleuropäische Bewegung der ersten Hälfte des 2o. Jahrhunderts (Beiträge zur Tanzkultur, Bd. 4), hg. von Gunhild OвerzaucherSCHÜLLER unter Mitarbeit von Alfred OBERZAUCher und Thomas SteIERT, Wilhelmshaven 1992, S. 15-24.

444 Zu Duncans Kritik am klassischen Ballett vgl. Duncan, Der Tanz der Zukunft, S. 30-32.

445 Duncan notiert diesbezüglich in ihren Memoiren: „Den größten Teil unserer freien Zeit verbrachten wir im British Museum, wo Raymond von allen griechischen Vasen und Basreliefs Skizzen anfertigte; zu Hause kopierte ich dann die Bewegung dieser Figuren [gemeint sind hier Tanzszenen der Bacchantinnen und Mänaden auf griechischen Vasenbildern und Trinkschalen], nach Musikstücken, die mit dem Rhythmus der Beine, der dionysischen Kopfhaltung und dem Werfen des Thyrsusstabes harmonisch übereinstimmtem." Isadora Duncan: Memoiren, nach dem englischen Manuskript bearbeitet von Clemens ZELL, Zürich, Leipzig und Wien 1928, S. $56 f$. Zu Duncans Bewegungssprache allgemein sowie zu Bildungsgütern und Kunstschätzen alter und moderner europäischer Kultur, die sie seit ihrer Ankunft in London 1899 rezipierte, vgl. unter anderem Huschka, Merce Cunningham und der Moderne Tanz, S. 74-78; Brandstetter, Tanz-Lektüren, 2013, S. $78-84$.

446 Diese Kritik äußerten auch andere Zeitgenossen, obwohl Duncan selbst immer wieder betonte, dass es ihr nicht darum gehe, „zu den Tänzen der alten Griechen zurückzukehren“. Vgl. Brandstetter, Tanz-Lektüren, 2013, S. 81-84. So schreibt beispielsweise der deutsche Schriftsteller Hans Brandenburg, der sich in seinem literarischen Werk intensiv mit dem modernen Ausdruckstanz auseinandersetzte, in seiner 1913 erschienenen Schrift Der moderne Tanz über Duncan: „Mit philologischer und archäologischer Rekonstruktion reihte sie Posen aneinander und gab statt der Bewegung kopierte Bewegungsmomente, die zudem nicht dem Tanz, sondern der Bildenden Kunst angehören." Hans BrandenBURG: Der moderne Tanz (München 1913), 3. erw. Aufl. München 1921, S. 3o. In Duncans bereits 1903 erschienenem Manifest Der Tanz der Zukunft kam sie dieser Art Kritik wie folgt zuvor: „[Ich] möchte [...] ein naheliegendes Missverständnis vermeiden. Aus dem, was ich gesagt, könnte man leicht schließen, es wäre meine Absicht, zu den Tänzen der alten Griechen zurückzukehren, und ich dächte, daß der Tanz der Zukunft ein Wiederaufleben der antiken Tänze oder sogar der Tänze wilder Stämme sein würde. Nein, der Tanz der Zukunft wird eine neue Bewegung sein, eine Frucht der ganzen Entwicklung, die die Menschheit hinter sich hat. Zu den Tänzen der Griechen zurückzukehren, würde ebenso unmöglich sein, wie es unnötig ist." Duncan, Der Tanz der Zukunft, S. 43 f. 
wieder [...] nach einer strengeren, reineren Kultur der mimischen Kunst und des Tanzes“447 sei. In dem Moment, in dem „die Duncan diese Kundgebung auslöste, war ihre Sendung [aber] auch schon erfüllt" ${ }^{448}$. Sie habe durch ihre „wissenschaftlich ausgewählten antiken Posen“449 nur einen „abstrakten [und] [...] ,körperlosen' Tanz ${ }^{4450}$ geschaffen, für den man den „rassig-schönen Leib [...] mit eigener, vollblütiger Rhythmik ${ }^{4451}$ nicht benötige. Genau diesen „rassig-schönen Leib“ vermisste Fuchs aber an den bestehenden Tanzformen in Deutschland. Und so legt er die Tatsache, dass gerade die Deutschen einen solch abstrakten und körperlosen Tanz wie den der Duncan derart bewunderten, als einen weiteren Beleg dafür aus, dass sie ihren Körper noch nicht als kulturelles und künstlerisches Ausdrucksmittel entdeckt hätten. ${ }^{452}$ Das Vernachlässigen des Körpers würde sich bei den Deutschen ja schließlich auch im Kult um Richard Wagner äußern:

\begin{abstract}
Der Wagnerkult ist der andere Pol, um den sich jenes Deutschland konzentriert. Nirgends zeigte sich deutlicher, daß der Deutsche seinen Körper noch nicht entdeckt hatte, als hier, wo man die lächerlichsten Verunstaltungen der Leiblichkeit duldet: die Siegfriede mit den eingeschnürten Bierbäuchen, die Siegmunde mit wurstartig ausgestopften Trikotbeinen, die Walküren, die ihre freie Zeit zwischen Schüsseln voll dampfender Leberknödel und schäumenden Maßkrügen im Münchner Hofbräuhaus zu verbringen scheinen, die Isolden, die als ,Riesendamen ' vor den Jahrmarktsbuden unwiderstehliche Anziehungskraft auf die Sinne der Schlächterburschen ausüben müßten. Das alles vertrug sich in der ,geistigen Kultur' der deutschen ,Gebildeten' aufs beste mit einer Musik und einer dramatischen Symbolik, die ihr als das ,Tiefste und ,Erhabenste aller künstlerischen Offenbarungen galt. Auch das erklärt sich einzig durch die Unsinnlichkeit, durch die des eignen Leibes und Blutes unbewußte, im theoretischen ,Kunstverständnis‘ sich erschöpfende Abstraktion. [...] Das Mißverhältnis würde sie in dem Augenblicke entsetzen, in dem sie es wahrnehmen. Aber sie nehmen es nicht wahr, weil ihre Sinne gar nicht beteiligt sind beim endgültigen Erleben der Kunstform. ${ }^{453}$
\end{abstract}

Es ist gut möglich, dass Djagilev und die Mitglieder der Ballets Russes Fuchs' Meinung diesbezüglich teilten - das lässt zumindest folgende Bemerkung Djagilevs vermuten, die dieser (allerdings erst) 1928 zu Papier brachte:

\footnotetext{
447 Fuchs, „Der Tanz“, S. 17.

448 Ebd.

449 Ebd., S. 19.

450 Ebd.

451 Ebd.

$45^{2}$ Vgl. ebd.

453 Ebd., S. 2o.
} 
И Дункан, и Далькроз, и Лабан, и Вигман - великолепные деятели в искании новой школы. Их труд над разработкой человеческого тела, этого совершеннейшего хореографического инструмента, достоин всяческого одобрения. Но их борьба с ,устаревшей“ классикой привела Германию в тот тупик, из которого она не может выбраться. Германия может превосходно двигаться, но она не умеет танцевать. ${ }^{454}$

Duncan, Dalcroze, Laban und Wigman sind herausragende Figuren in der Suche nach einer neuen Schule. Ihre Bemühungen um eine Bearbeitung des menschlichen Körpers, dieses vollkommensten choreografischen Instruments, verdienen meine völlige Zustimmung. Aber ihr Kampf mit der veralteten Klassik hat Deutschland an einen Punkt gebracht, aus dem es sich nicht mehr befreien kann. Deutschland kann sich vorzüglich bewegen, aber es kann nicht tanzen.

Dieses deutsche „Ignorieren der sinnlichen Form“455, das sich sowohl in der Duncan-Bewunderung als auch im Wagner-Kult äußerte, wollte Fuchs also mithilfe der neuen (Tanz-)Formen überwinden. Nur so glaubte er, die (deutsche) Kultur erneuern zu können:

Wir wollen eine Kultur auf Grund der Rechte, die mit uns geboren sind, und wir wollen all unsere Lebensformen steigern zur höchsten, erschöpfendsten, befreiendsten Ausdrucksfülle. Der Tanz kann für uns nichts mehr sein, als ein bis zum ekstatischen Orgiasmus aufschäumendes Erleben der in unserer Körperlichkeit gebunden[en] rhythmischen Mächte. ${ }^{456}$

Was hat all das nun aber mit Stravinskijs plötzlich einsetzender Abneigung gegenüber Fokin zu tun? Zum ersten Mal äußerte sich Stravinskij am 8./21. Juli 1911 negativ über Fokin - also nur sechs Tage, nachdem er sich an Rerich gewandt hatte, weil er die Arbeit am Opfer-Ballett wiederaufnehmen wollte. ${ }^{457}$ Ein gutes halbes Jahr zuvor, im November 1910, hatte er sich noch leidenschaftlich für den Verbleib Fokins bei den Ballets Russes eingesetzt; ${ }^{458}$ während ihrer Zusammenarbeit an Pétrouchka (mit Benua und Fokin) muss also etwas vorgefallen sein, was Stravinskij veranlasste, seine Meinung über den Choreo-

454 Sergej DJAGILEv: „O Klassike“ (1928), in: Sergej Djagilev i russkoe iskusstvo. Stat'i, otkrytye pis'ma, interv'ju, perepiska, sovremenniki o Djagileve, 2 Bde., hg. von Il'ja ZILbERŠTEJN und Vladimir Sam Kov, Moskau 1982, Bd. 1, S. 250-252, hier S. 251. Die hier angegebene deutsche Übersetzung findet sich bei Stüdemann, Dionysos in Sparta, S. $76 \mathrm{f}$.

455 Fuchs, „Der Tanz", S. 20.

456 Ebd., S. 21.

457 Vgl. hierzu den Brief von Stravinskij an Vladimir Rimskij-Korsakov vom 8./21. Juli 1911.

$45^{8}$ Fokin und Djagilev hatten am Ende der Saison von 1910 über Geld gestritten. Stravinskij sah deshalb das mit Fokin geplante Große Opfer in Gefahr. Vgl. Taruskin, Stravinsky and the Russian Traditions, Bd. 2, S. $969 f$. 
grafen zu ändern. Denn im selben Brief, in dem er sich gegenüber Vladimir Rimskij-Korsakov zu Benua und dem Ballett bekennt, ${ }^{459}$ urteilt er Fokin folgendermaßen ab:

Еще я хотел тебе написать, об одной вещи: Напрасно ты придаешь такое большое значение Фокину как балетмейстеру [...]. Вообще, Фокину придается слишком большое значение, и в то же время забывают о том, в какой среде воспитывался его талант. Те же Бенуа, Дягилев, Бакст - его ближайшие вдохновители, на которых он теперь обращает очень мало внимания и делает из-за этого вещи более самостоятельные и гораздо менее удачные, нежели прежде. Если бы ты знал, каких невероятных усилий и неприятностей стоила нам с Бенуа постановка „Петрушки“ из-за своенравного и деспотичного и, в то же время, не достаточно чуткого Фокина. Но об этом в другой раз ... ${ }^{460}$

Ich möchte dir noch bezüglich einer Sache schreiben: Zu Unrecht misst du Fokin solch große Bedeutung als Ballettmeister bei [...]. Überhaupt wird Fokin viel zu große Bedeutung beigemessen, und gleichzeitig vergisst man gerne, in welchem Umfeld sein Talent ,zur Schule gegangen‘ ist. Nämlich bei Benua, Djagilev, Bakst - die unmittelbaren Quellen seiner Inspiration, denen er nun nur wenig Aufmerksamkeit widmet und deshalb Sachen macht, die selbständiger und weniger erfolgreich sind als früher. Wenn du nur wüsstest, welch unglaubliche Bemühungen und Unannehmlichkeiten uns die Inszenierung von ,Pétrouchka mit Benua gekostet hat - nur wegen des eigensinnigen und despotischen und gleichzeitig nicht genügend feinfühligen Fokin. Doch darüber ein anderes Mal ...

Stravinskij beschreibt hier Fokin plötzlich als launisch, despotisch und eigensinnig und behauptet, die Zusammenarbeit mit ihm an Pétrouchka sei unangenehm und anstrengend gewesen. Außerdem werde er als Choreograf völlig überschätzt.

Während andere Autoren der Frage nach Stravinskijs plötzlicher Ablehnung gegenüber Fokin gar nicht erst nachgehen, führt sie Taruskin - genauso wie andere Veränderungen aus dem Sommer 1911 - auf Stravinskijs herausragende Erfolge in Paris zurück. ${ }^{461}$ Dies könnte durchaus ein möglicher Grund gewesen sein. Nimmt man aber an, Stravinskij habe den Fuchs-Artikel bereits vor Juli 1911 gelesen, so ist es viel wahrscheinlicher, dass die plötzlichen Vorbehalte gegenüber Fokin mit Stravinskijs Beschäftigung mit den Reformern und insbesondere mit seiner Rezeption des Fuchs-Textes in Verbindung stehen. Dieser

459 Vgl. Kapitel III.1.1.2.

46o Brief von Stravinskij an Vladimir Rimskij-Korsakov vom 8./21. Juli 1911.

461 ",Petrushka' changed all that. The incredible lionizing Stravinsky experienced in Paris changed his attitude toward Russia, toward Fokine, and most of all, toward his own place in the scheme of things." Taruskin, Stravinsky and the Russian Traditions, Bd. 2, S. 97 o. 
Verdacht wird durch einen Brief vom 4./17. März 1912 bestätigt, den Stravinskij an seine Mutter schrieb und in dem er seine Kritik an Fokin zum ersten Mal konkretisierte:

Я считаю Фокина конченным художником [...] надо (вернее, хочется) создавать новые формы, о которых и не снилось злому, алчному и одаренному Фокину. Все это ,habilité', от которой спасенья нет! Гениальности надо, не ,habilité' 462

Ich halte Fokin für einen veralteten Künstler [...]. Man sollte (besser gesagt, es ist wünschenswert) neue Formen [(zu)] schaffen, von denen der bösartige, gierige und talentierte Fokin noch nicht einmal träumte. Das alles ist ,habilitée, vor der es kein Entrinnen gibt! Wir brauchen Genialität, nicht, habilitée.

Stravinskijs Kritik an Fokin fällt im Brief an seine Mutter nicht nur ungleich härter aus als in seinem Schreiben an Vladimir Rimskij-Korsakov vom Juli 1911, sie verweist auch mehr als deutlich auf Fuchs und damit auf den Zeitpunkt seiner Fuchs-Lektüre: Es waren die „neuen Formen“, die Stravinskij im Brief an Andrej Rimskij-Korsakov vom September/Oktober 1911 besonders herausstellte, als er diesen über den Tanz-Text informierte. Für ebendiese „neuen Formen" hatte sich Stravinskij gegenüber Andrej Rimskij-Korsakov auch stark gemacht, da er ihn davon überzeugen wollte, sich - wie er selbst - für sie einzusetzen. Fokin - so teilt Stravinskij dann seiner Mutter mit - sei für jene „neuen Formen" aber nicht zu gebrauchen.

Fakt ist, dass sich Stravinskij in beiden Briefen von Fokin distanzierte. Es ist auch mit großer Wahrscheinlichkeit anzunehmen, dass er dies in beiden Briefen aus demselben Grund tat, und so muss davon ausgegangen werden, dass er Fuchs' Tanz schon vor dem 8./21. Juli 1911 gelesen hatte. Für diese Annahme spricht auch der zweite Punkt, mit dem Stravinskij seine Fokin-Ablehnung begründet: Nachdem er beteuert, dass auch Djagilev und Benua mittlerweile klar geworden sei, dass das, was Fokin mache, nicht neu sei, ${ }^{463}$ informiert er seine Mutter, dass sie (Stravinskij schreibt an dieser Stelle „wir“ und bezieht sich

462 Brief von Stravinskij an seine Mutter vom 4./17. März 1912, ediert in: Perepiska, Bd. 1, hg. von Varunc, S. 319-321, hier S. 319.

463 „Так и Фокин. В самом начале своей деятельности он казался необыкновенно передовым. При ближайшем же с ним (с его творчеством) знакомстве я (да не только я, а Дягилев и Бенуа и другие) увидел, что он в сущности совсем не нов и даже не стремится к этому. Это безусловно так - и при этом ,habilité опять-таки не хуже Петипа-старика.“ „So auch Fokin. Zu Beginn seines Schaffens schien er ungewöhnlich befähigt zu sein. Bei näherer Bekanntschaft mit ihm (oder seinem Schaffen) musste ich (nicht nur ich, sondern auch Djagilev, Benua und andere) feststellen, dass er im Kern der Sache ganz und gar nicht neu ist und auch nicht einmal danach strebt. Das 
höchstwahrscheinlich auf diejenigen Kollegen, die seine Meinung über Fokin teilten $)^{464}$ danach strebten, die Bewegung als Kunst wieder neu zu beleben. Um dieses Ziel zu erreichen, hätten sie sich zunächst mit Balletten zufriedengeben müssen, bei denen sie Altes erneuert oder umgeändert hätten. Jetzt aber sei es an der Zeit, neue Formen zu schaffen:

Это тем более досадно, что ведь переделки сочинений, написанных не для сцены, не составляли нашей цели - (but), это было лишь вызвано необходимостью (слишком ничтожна была хореографическая литература-и нам,помышляющим овозрождении пластического искусства „движения“, пришлось удовольствоваться на первых порах переделками: „Сильфиды“- Шопен, „Карнавал“- Шуман, „Клеопатре“ - [...] „Шехеразада“Н. Римский-Корсаков, етс. етс.) Я рассматриваю эту эпоху переделок как необходимое зло, на котором долго немыслимо останавливаться - надо (вернее, хочется) создавать новые формы [...].465

Umso bedauerlicher ist dies, da doch die Umarbeitung der Stücke, die nicht für die Bühne geschrieben worden sind, nicht unser Ziel war - (aber) wir mussten uns in der ersten Zeit lediglich aufgrund der Notwendigkeit (die choreografische Literatur war zu belanglos - und uns, die an die Wiederbelebung der plastischen Kunst, ,der Bewegungen', glaubten, viel zu winzig) auf Umarbeitungen beschränken: ,Les Sylphides‘ - Šopen (Chopin), ,Carnaval' - Šuman (Schuman), ,Cleopâtre $-[\ldots]$, Shéhérazade ${ }^{\prime}-$ N. Rimskij-Korsakov etc. etc.). Ich betrachte diese Epoche der Umarbeitungen als ein notwendiges Übel, in der es undenkbar ist, lange stehen zu bleiben - wir müssen (oder besser gesagt, es wäre wünschenswert) neue Formen (zu) schaffen.

Die Choreografien der Ballettbeispiele, die Stravinskij hier angibt, stammen allesamt von Fokin. Und somit wird deutlich, dass er Fokins Arbeit als repräsentativ für eine Art Übergangsepoche hielt. ${ }^{466}$ Diese Epoche beschreibt

ist zweifellos so. Auch wenn [seine], habilité‘ wiederum nicht schlechter ist als der alte Petipa." Brief von Stravinskij an seine Mutter vom 4./7. März 1912, S. $319 f$.

464 Dass Benua und Djagilev Stravinskijs Meinung über Fokin teilten, kommuniziert Stravinskij seiner Mutter im selben Brief. Höchstwahrscheinlich bezog er auch Nižinskij in jenes „wir“ ein. Vgl. ebd., S. 319.

465 Ebd.

466 Tim Scholl verweist in Bezug auf Les Sylphides, das Stravinskij im Brief an seine Mutter als erstes „Übergangs“-Beispiel nennt, auf die Parallelen von Fokins Arbeit zu derjenigen von Duncan: „,Les] Sylphides' re-created the era of romantic ballet, the age of Giselle and the original ,Sylphide' [Uraufführung am 12. März 1832], the period when point technique was still developing. [...] Fokin's ballerinas, possessed of the full range of techniques their Russian training afforded them, were asked not to use it. [...] His [Fokins] method of reconstructing the dances of the 183 os was not unlike Isadora's ,recreation' of Greek dance [...]." Scholl, From Petipa to Balanchine, S. 64. 
er als "notwendiges Übel“, das lediglich dazu gedient habe, langfristig das übergeordnete Ziel der Wiederbelebung der „Bewegung“ als Kunst zu erreichen.

Auffallend ist, dass Stravinskij Fokin nicht nur für ungeeignet hielt, die von Fuchs geforderten neuen Formen zu schaffen. Im Brief an seine Mutter bringt er den Choreografen außerdem noch mit dem von Fuchs (und anderen Reformern) so kritisierten (alten) Ballett in Verbindung. Dies wird besonders deutlich, wenn er noch nachschiebt: „Это безусловно так - и при этом ,habilité опять-таки не хуже Петипа-старика.“467 („Das ist zweifellos so. Auch wenn [seine] , habilité wiederum nicht schlechter ist als der alte Petipa.") Mit dem Verweis darauf, Fokins ,habilité sei nicht schlechter als der „alte Petipa $^{4668}$, stellt Stravinskij nämlich einen direkten Bezug her zwischen Fokins Ballett und dem „alten“ zaristischen Ballett der Petipa-Ära. Ebenjenes „alte“ Ballett war es aber doch, dass er und Benua im Sinne der Reformer erneuern wollten. ${ }^{469}$ Vor dem Hintergrund des Fuchs-Textes wird also in zweifacher Weise deutlich, warum sich Stravinskij (genauso wie Benua und Djagilev) von Fokin distanzieren musste.

Wie aber muss man sich nun diese „neuen Formen“ vorstellen? Als Paradebeispiel gilt Fuchs der Schlaftanz der hypnotisierten Magdeleine (Guipet):470 Im Februar 1904 hatte er die Traumtänzerin bei einem ihrer Auftritte in der

467 Brief von Stravinskij an seine Mutter vom 4./7. März 1912, S. $319 f$.

468 Stravinskij rekurriert hier auf den französischstämmigen Tänzer, Ballettmeister, Pädagogen und Choreografen Marius Petipa, der von 1848 bis 1903 in Sankt Petersburg wirkte. Mit seinen Arbeiten etablierte er „einen [eigenen] Stil, eine Ästhetik, eine Gattung und eine Schule“, was ihn bis heute zur „Identifikationsfigur für die ,danse d'ecole“ macht. Vgl. Gunhild Oberzaucher-Schüller: Art. ,Petipa', in: MGG 2, Personenteil: Bd.13, Kassel u.a. 2005, Sp. 393-395, hier Sp. 394f.

469 Es ist sehr ungewöhnlich, dass Stravinskij (gemeinsam mit Benua) einen Bezug zwischen Fokin und dem alten zaristischen Ballett der Petipa-Ära herstellt. Während er Fokins Arbeit damit dem , alten Ballett' zuordnet, sehen andere Zeitgenossen in Fokins Choreografien (genauso wie in denen des Moskauer Choreografen Aleksandr Gorskij) jenes (von Stravinskij und Benua gewünschte), neue Ballett' nämlich bereits verwirklicht. Vgl. die Ausführungen über „The New Ballet“ von Scholl, From Petipa to Balanchine, S. 55-67. Scholl beschreibt hier, wie Tanzautoren die Terminologie der Theaterreformer (,neues Theater') sehr schnell für ihren Bereich (,neues Ballett') adaptierten. Im Folgenden soll die Bezeichnung ,neues Ballett' aber nicht - wie bei Scholl - die Ballette von Fokin und Gorskij bezeichnen, sondern im Sinne des Stravinskij'schen Verständnisses gebraucht werden: Das von Stravinskij geforderte, neue Ballett' sollte noch einen Schritt weiter gehen und auch die Bewegungssprache des Reformchoreografen Fokin überwinden.

470 Vgl. Fuchs, „Der Tanz“, S. 21. Zur Traumtänzerin Magdeleine vgl. unter anderem Gabriele Brandstetter: „Psychologie des Ausdrucks und Ausdruckstanz. Aspekte der Wechselwirkung am Beispiel der ,Traumtänzerin' Magdeleine G.., in: Ausdruckstanz, hg. von Oberzaucher-Schüller u.a., S. 199-211. Die Begegnung mit der Traumtänzerin Magdeleine wird in der Literatur häufig als Initialmoment der Fuchs'schen Reformtexte beschrieben. 
Psychologischen Gesellschaft in München erstmals gesehen und war sofort hellauf von ihrer Darbietung begeistert. ${ }^{471}$ Albert von Schrenck-Notzing, ein deutscher Mediziner und Mitglied jener Gesellschaft, hatte Magdeleine und ihren Magnetopathen Emile Magnin Anfang 1904 nach München eingeladen; Schrenck-Notzing forschte bereits seit Anfang des 20. Jahrhunderts über die Künstlerische Bedeutung der Ausdrucksbewegung in Hysterie und Hypnose. ${ }^{472} \mathrm{Ihm}$ waren die unter Hypnose hervorgebrachten künstlerischen Qualitäten der Magdeleine auf Reisen in Paris aufgefallen, und er wollte sie deshalb gemeinsam mit seinen Kollegen beobachten. ${ }^{473}$ In Die Traumtänzerin Magdeleine G. Eine psychologische Studie über Hypnose und dramatische Kunst beschreibt er sie dann unter anderem als einen „somnambule[n] Reflexautomaten ${ }^{474}$. Er hatte den Eindruck, dass man durch die Hypnose den Ausdruck der Tänzerin und ihre an die Oberfläche tretenden Empfindungen und Bewegungen vollkommen kontrollieren konnte. So unter anderem auch mithilfe der Musik:

Da frappiert zunächst die ausserordentliche Sicherheit und Feinheit ihres musikalischen Gefühls. Sie fasst die feinsten Nuancen der Musik auf und gibt sie mimisch wieder, sie markiert durch die Bewegungen kleinere Fehler im Spiel (Detonieren im Gesang) in Form von Unlustreaktion, oder durch Ausdruck von Schmerz, ähnlich verhält sie sich bei schlechter Musik, bis zu vollständigen Abwehrbewegungen gegen den Spieler. Ihre Person ist also keineswegs ein einfaches automatisches willenloses Werkzeug für die Toneinwirkung, trotz des oben erwähnten mechanischen Charakters zahlreicher Interpretationen. [...] Ihrem slavischen Naturell liegen ganz besonders gut ungarische und polnische Tanzweisen; mit zu den besten Darbietungen gehören ihre Uebersetzungen von Chopin. Bei den musikalischen Darstellungen solcher Art steigert sich ihre

471 Die Begeisterung geht aus einem Artikel hervor, den Fuchs im Anschluss an die Aufführungen der Magdeleine in München veröffentlichte. Vgl. Prütting, Die Revolution des Theaters, S. 134f. Der Artikel erschien in den Münchner Neuesten Nachrichten, Nr. 89, 1904 und wurde vollständig in seinen Tanz-Aufsatz übernommen. Vgl. Prütting, Die Revolution des Theaters, S. 421, Anm. 123.

472 Im Winter 1902 hatte Schrenck-Notzing einen ersten Vortrag zu diesem Thema gehalten. Vgl. Priska PytLıк: Okkultismus und Moderne. Ein kulturhistorisches Phänomen und seine Bedeutung für die Literatur um 19oo, Paderborn u.a. 2005, S. 64.

473 Vgl. ebd., S. 64f. Zu den Untersuchungen der Münchner Psychologischen Gesellschaft vgl. unter anderem Ulrich Linse: „Mit Trancemedien und Fotoapparat der Seele auf der Spur. Die Hypnose-Experimente der Münchner ,Psychologischen Gesellschaft'“, in: Trancemedien und neue Medien um 19oo. Ein anderer Blick auf die Moderne (Medienumbrüche, Bd. 39), hg. von Marcus Hahn und Erhard Sc ü̈тt PELZ, Bielefeld 2009, S. 97-144.

474 Albert von Schrenck-Notzing: Die Traumtänzerin Magdeleine G. Eine psychologische Studie über Hypnose und dramatische Kunst, Stuttgart 1904, S. 107. In der zeitgenössischen Sacre-Rezeption werden die Bewegungen der Tänzer teilweise auch als reflexartig beschrieben und die Tänzer selbst als Automaten bezeichnet. Vgl. Kapitel III.2. 
künstlerische Anpassung mitunter bis zu dem Inbegriff von Grazie, Anmut und Zierlichkeit. Ihr Körper folgt allen wechselnden Rhythmen mit einer Leichtigkeit und organischen Einheitlichkeit, die selbst der virtuosesten Tanztechnik unerreichbar bliebe. [...] Zweifellos spielen hierbei im Gegensatze zu dem rein automatischen Teil ihrer Leistungen ihre künstlerisch gestaltende Phantasie und der schauspielerische Gedanke eine entscheidende Rolle. Denn sie erheben ihre Darbietungen erst auf ein künstlerisches Niveau. Unser Ballett könnte aus ihrem vergeistigten Bewegungsspiel viel Neues erlernen. [...] Einer der interessantesten Punkte ist das Verhalten der Traumtänzerin gegenüber dem Improvisieren auf dem Klavier oder auf der Orgel. Wie bereits erwähnt wurde, erfolgt auch meist hier ein blitzschnelles Erfassen jeder Tonfarbe, jeder harmonischen und melodischen Wendung; und die Art und Weise, wie sie auch hier unvorbereitet die feinsten rhythmischen Figuren zu charakterisieren versteht, kann wohl als einzigartig bezeichnet werden. Ihre Anpassung ist eine so feine, dass es nicht gelingt, sie z.B. auf Glatteis zu führen; sie erfasst die Stimmung oft schneller, als sie von dem Pianisten in Tönen ausgedrückt ist, und frappiert auch hier mitunter durch das Voraneilen ihrer Bewegungen. Andererseits aber verhält sie sich auch abwartend [...]. Man kann sie aber so vollständig mit dem Klavier beherrschen, dass man nur dem auf sie eingeübten Pianisten den Ausdruck anzugeben braucht, damit er sie durch die Töne dazu nötigt. ${ }^{475}$

Die von Schrenck-Notzing hier am Ende angesprochene Kontrolle über die hypnotisierte Tänzerin erinnert in Teilen an die in Kapitel III.1.1. vorgestellte Idee Gordon Craigs, die Stravinskij höchstwahrscheinlich in Pétrouchka verarbeitet hat: Craig wollte ja den Schauspieler durch eine Marionette ersetzen, damit er (als Regisseur) dessen Agieren auf der Bühne vollständig kontrollieren könnte. Schrenck-Notzing fügt nun - wenn auch sicher nicht intendiert - eine zusätzliche Ebene zu Craigs Theorie hinzu: die der Musik. Ist es bei Craig der Regisseur (oder Choreograf), der die Bewegungen des Schauspielers (oder Tänzers) kontrolliert, übernimmt diese Rolle in Schrenck-Notzings Beschreibung nun die Musik. ${ }^{476}$

Während der Beobachtungsvorführungen waren neben den Medizinern um Schrenck-Notzing auch wichtige Vertreter der Münchner Kunst- und

475 Schrenck-Notzing, Die Traumtänzerin Magdeleine G., S. 107-113.

476 Vgl. hierzu auch die diesbezügliche Anmerkung von Hans-Christian von Herrmann: Das Archiv der Bühne. Eine Archäologie des Theaters und seiner Wissenschaft, München 2005, S. 203: „[U]m 1900 [rückt] zum künstlerischen Zustand schlechthin auf, [was Hegel auch im Hinblick auf Kleist aus dem Bereich der Kunst ausgeschlossen hatte - ein dem ,Inneren' des Individuums ,fremdartiges Jenseits', ,von welchem es bestimmt und regiert wird'] [...]. An die Stelle des Maschinisten und der Fäden sind [...] ein Hypnotiseur und ein Klavierspieler getreten, die ihre somnambule Puppe durch musikalisch-akustische Reize oder Signale steuern." Im Sacre und insbesondere in der Danse sacrale scheint der Musik eine der Beschreibung Schrenck-Notzings vergleichbare Kontrollfunktion zuzukommen. Vgl. hierzu insbesondere die Analyse in Kapitel III.1.3. 
Kulturszene anwesend ${ }^{477}$ - unter ihnen auch Georg Fuchs. Im Gegensatz zu Schrenck-Notzing, den ja am Tanz der hypnotisierten Tänzerin vor allem der Kontrollaspekt faszinierte, glaubte Fuchs darin eine Kunst zu erkennen, die aus dem unbewussten Inneren entstand: ${ }^{478}$ Die Hypnose verhelfe der Magdeleine dazu, ihre „Hemmungsvorstellungen zu beseitigen“479, sodass sie ihr „Innerstes enthüllen und [ihren] [...] eigenen Leib preisgeben“480 könne. Durch die Hypnose würden Geheimnisse offenbart, „die sonst alle Instinkte, Empfindungen und Gewohnheiten [...] verschleiern“481:

Sie [die Magdeleine] ist die tragische Muse. Niemals ist das Mysterium der Vergöttlichung alles Menschlichen, der Vollendung in Qual und Lust so rein uns Kindern einer entgötterten Zeit vor Augen getreten, wie hier. Sie ,schläft', sie hat keine Absicht und keinen Willen und keine Berechnung: rein, wie in den Gesichten der hl. Katharina, steigen die gestaltenden Mächte aus dem Brunnen ihrer Seele, in den klingende Rhythmen von oben eintauchen, die dunklen Fluten seiner Tiefe erregend. - Wie die Fittige des Engels über die Wasser des Teiches Bethesda, so streichen die Melodien die Fläche ihrer Seele: sie zittert, sie schwankt, sie träufelt sich in zarten Wellen, sie rollt auf in wiegenden Kreisen, sie wogt gischtend empor, sie schäumt in jagenden, heulenden Sturmfluten dahin um endlich wieder zu verebben in der schweigenden, regungslosen Stille heiliger Mittagsruhe. Und was dort geschieht im dunklen Land, im ,Unbetretenen, nicht zu Betretenden', wird im vollkommensten Spiegelbild hervorgekehrt vor unser entzücktes Auge. ,Was im Labyrinth der Brust wandelt durch die Nacht', tritt durch sie ans Licht des irdischen Lebens: wir dürfen es sehen, wir dürfen es erleben, rein und vollkommen, wie es geschieht. Nimmermehr wäre das möglich, wenn nicht in dieser Frau die Gnade schöpferischen Gestaltens wohnte. Wir wissen zu wohl, daß nicht jede Frau im Banne des zauberischen Wachschlafs das vollbringen könnte, was die Madeleine [Fuchs schreibt Madeleine statt Magdeleine, LZ] tut, um nur einen Augenblick an ihrer schöpferischen Begnadung zweifeln zu können. ${ }^{482}$

Dass gerade die Hypnose im Falle der Magdeleine dazu verhalf, ihr Innerstes an die Oberfläche zu tragen, stellte für Fuchs auch keine Überraschung dar; schließlich erachtete er den Zustand des Rausches als unerlässliche Voraussetzung für den Tanz. ${ }^{483}$ Um diesen Standpunkt zu bekräftigen, verweist

\footnotetext{
477 Vgl. unter anderem Pytlik, Okkultismus und Moderne, S. 65 f.

478 Nicht alle Beobachter waren Fuchs' Meinung. Es gab unter Schriftstellern und Künstlern sogar eine große Diskussion darüber, ob man den unter Hypnose vollführten Tanz denn tatsächlich als Kunst bezeichnen könne. Vgl. Pytlik, Okkultismus und Moderne, S. 66.

479 Fuchs, „Der Tanz“, S. 21.

480 Ebd., S. 21f.

481 Ebd.

482 Ebd., S. 24f.

483 Vgl. ebd., S. 23.
} 
Fuchs dann erneut auf die Tanzgewohnheiten der „Naturvölker“ und zitiert im Anschluss einen Bericht des deutschen Astronomen Karl Schwarzschild, den dieser über algerische Festlichkeiten zur Sonnenfinsternis vom 30. August 1905 verfasst hatte. ${ }^{484}$ An jenem Bericht, so Fuchs, könne man sehr gut zeigen, dass die Hypnose bereits bei den Naturvölkern dahingehend gewirkt habe, „konventionelle [...] Hemmungsvorstellungen [...] [aufzulösen, und so die] orgiastische Tanzekstase [vorzubereiten] ${ }^{485}$. In der deutschsprachigen Fassung des Textes findet sich dann folgendes Schwarzschild-Zitat, das in der russischen Ausgabe jedoch fehlt:

Das Fremde und Wilde kam erst bei den Feierlichkeiten zum Vorschein [...]. Am Abend zog der winselnde Ton der arabischen Tuba über die Stadt. Im Hof der Moschee war Tanz der Aissanahs. Umringt von allen Schwarzen, Braunen und Weißen [...] stand im Fackelschein eine Kette von etwa fünfzig meist jüngeren Leuten. Die Arme hatten sie untergefaßt. Vor ihnen auf Matten saßen die noch unfertigen Zöglinge und die alten Meister der Sekte [...]. Die Kette war in unaufhörlicher wiegender Bewegung. Nach dem durchdringenden eintönigen klagenden Gebetsrhythmus der Musik neigten sich die Oberleiber, und bei jedem Takt flogen die Köpfe mit einem heftigen Ruck der Halsmuskeln nach vorne. So ging es stundenlang, und es war kein Wunder, daß schließlich jeder in der Kette um einen Teil seiner Besinnung kam. Wer von den Burschen die Hypnose nahe fühlte, zog aufgeregt in der Reihe Weste und Hemd aus und trat in Hose und Gürtel vor. [...] Ich sehe noch einen der ersten vor mir [...]. Einer der Alten hielt ihm Eisennägel und Glasscherben vor, er faßte sie mit den Zähnen und schluckte sie mit verzweifeltem Ekel hinunter. Andere fraßen lebende Skorpione oder stachen sich mit Messern und Schwertern, die ihnen die Alten gaben, in Leib, Schulter, Wange, Augenlieder. Blut wurde nicht sichtbar, und die Wunden schienen sich gleich zu schließen. Schien einer Schmerzen zu fühlen, so wurde er von einem Alten untergepackt und durch die rhythmische Halsmassage wieder empfindlos gemacht. Es muß nach dem, was mir einer der Burschen sagte, ein Zustand sein wie Angetrunkenheit. Man kennt noch Bekannte und Umgebung, ist aber unempfindlich und im Nebel. Gegen Mitternacht hatte der Taumel alle ergriffen. ${ }^{486}$

Gegen Mitternacht seien alle Beteiligten derart vom Taumel ergriffen gewesen, dass Schwarzschild das Gefühl hatte, dass sich der hypnotisierte Zustand der

484 Vgl. Karl Schwarzschild: Ueber die totale Sonnenfinsternis vom 30. August 1905, Göttingen 19o6. Zu Schwarzschild allgemein vgl. unter anderem Manfred ScHROEDER, Hans-Jürgen Borcher und Hans-Heinrich VoIGT: „Physik um die Jahrhundertwende“, in: Europäische Jahrhundertwende. Wissenschaften, Literatur und Kunst um 19oo, hg. von Ulrich MöLK, Göttingen 1999, S. 145-148.

485 Fuchs, „Der Tanz“, S. 22.

486 Ebd., S. $22 f$. 
sich bewegenden Masse auf ihn selbst übertragen hatte. Und so stellt er sich am Ende des von Fuchs zitierten Abschnitts die selbstreflektierende Frage:

[W]ar man [etwa] selbst hypnotisiert von dem ewig gleichen Schrei der Musik und den roten Flammen, in denen sich die dunklen Leiber bewegten, und meinte [vielleicht sogar] Tiefen zu sehen, die nicht vorhanden waren?487

Hier istes sinnvoll,noch einmal zuStravinskijzurückzugehen und zurAnnahme, er habe mit dem Sacre versucht, die von Fuchs propagierten neuen Formen umzusetzen. Fuchs selbst hatte im Anschluss an seinen Schwarzschild-Exkurs diesbezüglich nämlich betont (und das findet sich auch in der russischen Ausgabe), dass der „korybantisch-manädische Rauschzustand [...] die unerlässliche Voraussetzung des Tanzes" ${ }^{488}$ sei und Schwarzschild „ähnliche Schilderungen [...] auch über [...] Tanzorgien anderer Naturvölker bekannt ${ }^{\text {“489 }}$ seien. Neue (Tanz-)Formen - so Fuchs' Resümee - seien also „[w]eit entfernt von allem Bewußten [...] in der Seele der Schaffenden “490 zu suchen.

An zwei Stellen sind nun tatsächlich Parallelen zwischen Schwarzschilds Beschreibungen und dem Sacre auszumachen: Mit einem „winselnden Ton“ oder, besser noch, mit winselnden Tönen kann nämlich auch die Introduction der Adoration de la Terre, also die Einleitung zum ersten Bild des Sacre, beschrieben werden. Sie wird von jenem berühmten und ungewöhnlich hohen Fagottsolo umrahmt, das am Anfang einsam aus dem Orchestergraben emporsteigt und dann die Einleitung auch schließt - und zwar durch sein Wiederaufgreifen bei Ziffer 12 in verkürzter und um einen Halbton nach unten

\footnotetext{
487 Ebd., S. 23.

488 Ebd.; Fuks, „Tanec“, S. 82.

489 Fuchs, „Der Tanz“, S. 23; Fuks, „Tanec“, S. 82.

490 Fuchs, „Der Tanz“, S. 25. Vgl. in diesem Kontext Brandstetters Ausführungen zu verschiedenen Konzepten des Tanzes zu Beginn des 20. Jahrhunderts, insbesondere zu „Bewegungsrausch. Trance-Tanz und Bacchanal“ in: Brandstetter, Tanz-Lektüren, 2013, S. 251-326, hier: S. 251: „In der Thematisierung von Trance in den unterschiedlichen Mustern von Dreh-Tänzen und Ritualen [...] artikulieren die Ausdruckstänzer die Vorstellung, daß ,Natur' - als verlorene ,Ursprünglichkeit' und Ganzheit des Subjekts - über Erfahrungen der Ich-Auflösung in transpersonaler Einheit, vermittelt über körperliche Bewegung wieder erreichbar sei. Es gilt, das im Prozeß der Zivilisation ,Verschüttete', das individuelle oder das kollektive Unbewußte als Hort einer archaischen Form menschlicher Kreativität, in der Trance-Bewegung des Tanzes wieder freizulegen. So wird der ekstatische Tanz, beziehungsweise die ,Darstellung von Ekstatse im Medium des freien Tanzes, ,zum Ort und zur Praxis der Herstellung des Präkulturellen in der Kultur““ Zum ,Orgiasmus‘ und Hypnosetanz speziell bei Fuchs vgl. ebd., S. 255-259.
} 
versetzter Form. ${ }^{491}$ Innerhalb dieser Klammer entwickelt sich ein Bläserteppich, der durch abwechselnde und teils sich überlagernde Motivfragmente der einzelnen Holz- und Blechblasinstrumente generiert wird. Dieser flirrende Charakter wird durch die verschiedenen Einwürfe der Streicher unterstützt, die dergestalt eingesetzt werden, dass sie ebenfalls an Bläser erinnern - so zum Beispiel der lang gehaltene Triller der Violine 1, der fünf Takte vor Ziffer 7 einsetzt, der Pizzicato-Einwurf des Solocellos ab Ziffer 7 oder die lang gezogenen Flageolett-Töne der Kontrabass-Soli ab Ziffer 10, zu denen sich ab Ziffer 11 Flageolettglissandi der Viola gesellen. ${ }^{492}$ Während einer kurzen Überleitung [vier Takte nach Ziffer 12 bis Ziffer 13] hebt sich dann der Vorhang [drei Takte von Ziffer 13], und das Publikum erhascht einen ersten Blick auf die Szenerie, wenn die Augures printaniers mit 32 Wiederholungen ein und desselben Achtelakkords in den Streichern [Ziffer 13 bis Ziffer 14] beginnen - jeder einzelne von ihnen gespielt im Abstrich und staccato.

Leider kann nicht eindeutig festgestellt werden, welche Bewegungen die Tänzer in diesem Moment auf der Bühne vollführten. Im Gegensatz zur ausführlichen Dokumentation von Stravinskijs kompositorischer Arbeit berichten nämlich nur vergleichsweise wenige Quellen von Nižinskijs Choreografie. ${ }^{493}$ Die Situation wird noch dadurch erschwert, dass von Nižinskij selbst keinerlei Angaben überliefert sind und alle Quellen aus zweiter Hand stammen: Neben Zeitzeugenberichten in Form von Interviews, Erinnerungen und Kritiken sowie einigen wenigen - allerdings hinter der Bühne geschossenen - Fotografien ${ }^{494}$ handelt es sich dabei einerseits um Bleistiftskizzen der französischen Malerin und damaligen Kunststudentin Valentine Gross, die diese während der Pariser

491 Mit Ende der verkürzten Fagottmelodie vier Takte nach Ziffer 12 und dem an dieser Stelle ebenfalls einsetzenden Triller in der Klarinette beginnt der Übergang zu den Augures printaniers. Vgl. Volker Scherliess: Igor Strawinsky. Le Sacre du Printemps, München 1982, S. 41.

492 Für eine umfangreiche Beschreibung der übereinandergelegten Motive und Einwürfe der Holz- und Blechblasinstrumente vgl. ebd., S. 36-42.

493 Neben dem Notentext liegen sowohl Stravinskijs Skizzen als auch das Autograf der Partitur und diesbezügliche Kommentare des Komponisten selbst vor. Einen Überblick über die Sacre-Skizzen Stravinskijs, die in der Sammlung Strawinsky der Paul Sacher Stiftung in Basel liegen, gibt Tatiana Baranova Monighetri: „Working on ,The Rite of Spring. Stravinsky's Sketches for the Ballet at the Paul Sacher Stiftung“, in: Igor Stravinsky. Sounds and Gestures of Modernism, hg. von Massimiliano Locanto, Turnhout 2014, S. $101-136$.

494 Als Beispiel für eine solche Fotografie vgl. eine der hinter der Bühne aufgenommenen Aufnahmen des französischen Fotografen Charles Gerschel, siehe unpag. Tafelteil, Abbildung 17 . 
Aufführungen von 1913 verfertigt hatte, ${ }^{495}$ und andererseits um zwei vierhändige Sacre-Klavierauszüge, die Angaben zur Choreografie von 1913 enthalten sollen. Der eine befindet sich im Rambert Dance Archive in London ${ }^{496}$ : Marie Rambert - Djagilev hatte die Jaques-Dalcroze-Schülerin 1912 engagiert, damit diese Nižinskij bei der Arbeit am Sacre assistiert - will ein halbes Jahr nach der Uraufführung Nižinskijs choreografische Anweisungen aus der Erinnerung heraus nachgetragen haben. Der andere Auszug liegt in der Paul Sacher Stiftung in Basel und enthält jene handschriftlichen Eintragungen, die Stravinskij als Grundlage für seine Transkription erhaltener choreografischer Notizen dienten, die dieser 1969 im Anhang der Sacre-Skizzen unter dem Titel The Stravinsky-Nijinsky Choreography veröffentlicht hatte. ${ }^{497}$ Die Basler Partitur wurde unmittelbar nach der Premiere an die Pariser Mäzenin Misia Sert verschenkt, 1920 aber wieder an Djagilev zurückgegeben. ${ }^{498}$ Bislang konnte nicht nachgewiesen werden, ob sich die darin enthaltenen handschriftlichen Choreografieangaben tatsächlich auf Nižinskijs Ursprungschoreografie beziehen - eine genaue zeitliche und personelle Zuordnung der Eintragungen ist nämlich nicht möglich, ${ }^{499}$ und die wissenschaftlichen Interpretationen variieren. So kam Stephanie Jordan in ihrer Monografie Stravinsky Dances zum Ergebnis, dass es sich dabei um Notizen zur zweiten choreografischen Version des Sacre handeln müsse, die Léonide Massine 1920 realisiert hatte. ${ }^{500}$ Jörg Rothkamm hingegen nimmt an, dass der Klavierauszug Angaben beider

495 Einige dieser Skizzen sind ediert bei Buckle, Nijinsky on Stage, S. 131-141; Hodson, Nijinskys Crime Against Grace. Vgl. auch Valentine Gross' Pastelle, die diese auf Grundlage der Skizzen anfertigte. Einige von ihnen sind abgebildet bei Jann PASLER: „Music and Spectacle in ,Petrushka' and the ,Rite of Spring'“, in: Confronting Stravinsky, hg. von dies., S. 53-81, hier Abb. 4.1.-4.4., unpag. S. 76a-d. Die Pastelle sind Teil der Ekstrom Collection des Victoria \& Albert Museum, London, THM/7/8/3/1.

496 Vgl. Igor Stravinsky: ,Le Sacre du Printemps. Tableaux de la russie païenne en deux parties. Réduction pour piano à quatre mains par l'auteur, Berlin, Moskau und Sankt Petersburg 1913, Klavierauszug mit russischen Eintragungen zur Choreografie (1913) von Marie Rambert, Rambert Dance Archive, London, MR/o7/o12. Teile dieses Klavierauszugs wurden publiziert in Marie RAmвеRT: Quicksilver, London 1972, S. 65 und in Hodson, Nijinsky's Crime against Grace.

497 Vgl. Strawinsky, Le Sacre du Printemps. Réduction pour piano à quatre mains par l'auteur sowie Anm. 77f. Zu Stravinskijs Transkription erhaltener choreografischer Notizen vgl. ders., Appendix III. Stravinskijs veröffentlichte Transkriptionen sind allerdings unvollständig und fehlerhaft. Vgl. u.a. Rothkamm, Ballettmusik im 19. und 20. Jahrhundert, S. 212.

498 Vgl. Jordan, Stravinsky Dances, S. 421.

499 Vgl. Anm. 78.

500 Jordan begründet dies anhand inhaltlicher Parallelen von Choreografie und Eintragungen. Vgl. Jordan, Stravinsky Dances, S. 431-444. 
Choreografien enthält. ${ }^{501}$ Er führt dies unter anderem darauf zurück, dass die Partitur 1920 wieder an Djagilev zurückgegeben wurde, der zu jener Zeit eine Neueinstudierung des Sacre (mit Léonide Massine als Choreografen) plante. Die Rückgabe sei ein Indiz dafür, dass das Exemplar wichtige Informationen zur Uraufführungschoreografie enthalten habe. ${ }^{502}$ Für Rothkamms These spricht die Tatsache, dass einige Angaben der Basler Quelle mit den Angaben Ramberts im Londoner Auszug übereinstimmen. ${ }^{503}$ Da ausgeschlossen werden kann, dass Rambert Massines Choreografie von 1920 kannte, müssten also zumindest die übereinstimmenden Eintragungen auf Nižinskijs Choreografie von 1913 zurückgehen. ${ }^{504}$

Es wird deutlich: Aufgrund der desolaten Quellenlage können so gut wie keine eindeutigen Angaben über Nižinskijs für den Sacre entworfene Bewegungsabläufe gemacht werden; noch ist es möglich, ausgeführte Bewegungen einer eindeutigen Stelle in der Partitur zuzuordnen. ${ }^{505}$ Legt man die unterschiedlichen Quellenfragmente übereinander, lassen sich aber an bestimmten Stellen Übereinstimmungen lokalisieren, die zumindest auf grobe Bewegungsmuster schließen lassen. So zum Beispiel zu Beginn der Augures printaniers: Ramberts notiert hier nämlich „Юноши на месте“ („Junge Männer am Platz"), was darauf verweist, dass sich die Tänzer an dieser Stelle am Platz bzw. auf der Stelle bewegten. Auch andere Zeitzeugen berichten von einer gleichförmigen bzw. sich ständig wiederholenden Bewegung der Tänzer

501 Vgl. hierzu seine Anmerkungen zur Urheberschaft der Eintragungen im Basler Klavierauszug in: Rothkamm, Ballettmusik im 19. und 20. Jahrhundert, S. 231-233.

502 Vgl. ebd., S. 233.

503 Vgl. Leila ZICKg RAF: Igor Strawinskys, Le Sacre du Printemps' unter besonderer Berücksichtigung von Vaslav Nijinskys Choreografie und deren Stellung im Ursprungswerk, Mschr. Magisterarbeit, Universität Freiburg 2010.

504 Marie Rambert hatte die Sacre-Choreografie Léonide Massines nie gesehen, da sie lediglich 1912 und 1913 bei den Ballets Russes unter Vertrag stand und schon 1914 nach England zog, um bei Enrico Cecchetti Tanz zu studieren. Erst 1928 kehrte sie für einen Besuch nach Paris zurück. Vgl. Rambert, Quicksilver, S. $79 f$.

505 In Fachkreisen sieht man den Authentizitätsanspruch des 1989 von Hodson erfolgten Rekonstruktionsversuchs von Nižinskijs Sacre-Choreografie mittlerweile kritisch, und Hodson selbst gab an, dass die Choreografie lediglich 85 Prozent des Originals enthalte. Vgl. Jordan, Stravinsky Dances, S. 443. Die Hodson-Choreografie sollte deshalb unbedingt als eine Interpretation der damals zur Verfügung stehenden Quellen gesehen werden und nicht als eine veritable Rekonstruktion, wie dies häufig (sicher auch aus Vermarktungsgründen) bei Veranstaltungsankündigungen geschieht. So unter anderem bei der Ankündigung von Hodsons Sacre in der Pressemitteilung der Hamburger Ballett-Tage 20o9, vgl. www.tanznetz.de/forum/thread/14908/35-hamburger-ballett-tage (Stand: September 2017), oder bei diversen Ankündigungen besagter Choreografie zum 100. Jubiläum der Uraufführung im Théâtre des Champs-Élysées in Paris 2013. 
zu Beginn des Sacre. So zum Beispiel der französische Musikkritiker Adolphe Boschot, der in seiner Rezension vom 30. Mai 1913 den ersten Teil des Balletts folgendermaßen beschreibt:

\begin{abstract}
Imaginez des gens affublés des couleurs les plus hurlantes [...], de peaux de bêtes ou de tuniques pourpres, gesticulant comme des possédés, qui répètent cent fois de suite le même geste: ils piétinent sur place, ils piétinent, ils piétinent, ils piétinent et ils piétinent ... Couic: ils se cassent en deux et se saluent. Et ils piétinent, ils piétinent, ils piétinent ... Couic: une petite vieille tombe la tête par terre et nous montre son troisième dessous ... Et ils piétinent, ils piétinent ... Et puis ce sont des groupes qui évoluent en ordre ultra-serré. ${ }^{506}$
\end{abstract}

Die Tänzer haben also im ersten Teil des Sacre (Adoration de la terre) - das geht aus dem Kontext des Artikels hervor - immer wieder dieselbe stampfende Bewegung ausgeführt und dabei wild gestikuliert. ${ }^{507}$ Mit einem kurzen Blick in Partitur und Libretto sowie in Verbindung mit den Notizen Ramberts ist zu vermuten, dass Boschot im zitierten Abschnitt den Beginn der Augures printaniers [Ziffer 13 bis 22] beschreibt: Ihm zufolge wiederholte sich die stampfende und gleichförmige Bewegung der Tänzer an dieser Stelle nämlich insgesamt dreimal, wobei zwischen zweiter und dritter Wiederholung die Alte Frau aufgetreten sei. Die zuvor beschriebene Akkordsequenz tritt während der ersten 76 Takte [Ziffer 13 bis 22] der Augures printaniers ebenfalls dreimal (in jeweils leicht veränderter Form) auf [Ziffer 13 bis 14; vier Takte vor Ziffer 15 bis 16; Ziffer 18 bis zwei Takte vor Ziffer 22]. Bei Ziffer 15, also zwischen der zweiten und dritten Wiederholung der Akkordsequenz, betritt laut Basler Auszug die Alte Frau erstmals die Bühne - markiert durch die synkopierten Einwürfe von Piccoloflöte, erster Violine und hohen Blechbläsern. Jeweils zu Beginn der Akkordsequenzwiederholung [sowohl fünf Takte nach Ziffer 14 als auch bei Ziffer 18] notiert Rambert außerdem: „снова на месте“ („Von Neuem auf der Stelle“). Die Tänzer wiederholten die gleichförmige Bewegung also immer dann, wenn die Akkordsequenz in der Musik zu hören war - also genau so, wie von Boschot beschrieben. ${ }^{508}$

Mit Öffnen des Vorhangs - das kann mit Blick auf die genannten Quellen folglich konstatiert werden - konfrontierten die Tänzer das Publikum mit einer

\footnotetext{
5o6 Adolphe Bозснот: „Le Sacre du printemps'. Ballet de MM. Roerich, Stravinsky et Nijinsky“, in: L’Écho de Paris, 3o. Mai 1913, S. 6, Sp. 1f., hier Sp. 1. Der Artikel ist abgedruckt in: Dossier de presse, hg. von Lésure, S. 15f., hier S. 16.

507 Den direkt daran anschließenden Abschnitt beginnt Boschot mit „Au second act [...]“. Boschot, „Le Sacre du printemps““, Sp. 1.

5 o8 Hodson gebrauchte den Rambert-Auszug auch für ihren Rekonstruktionsversuch. Vgl. Hodson, Nijinsky's Crime against Grace.
} 
monotonen (höchstwahrscheinlich stampfenden) Bewegung, und zwar zum durchdringenden und gleichbleibenden Rhythmus der Musik - im Grunde also vergleichbar mit der Szenerie, die Schwarzschild im zuvor zitierten Abschnitt beschreibt. Von Beginn an wird im Sacre diese Monotonie allerdings akustisch gestört, und zwar in Form von unregelmäßig gesetzten dynamischen Akzenten der Streicher, die noch dadurch intensiviert werden, dass im sforzato einsetzende Hörner den akzentuierten Akkord an den betroffenen Stellen verdoppeln. ${ }^{509}$ Die daraus entstehende ungleichmäßige Gliederung von neun, zwei, sechs, drei, vier, fünf und drei Achteln löst beim Zuhörer eine Irritation aus, da sie nicht antizipiert werden kann. Unmittelbar nach der Introduction des Sacre wird das Publikum also mit jenem musikalischen Mittel konfrontiert, das bereits am Beispiel der Pétrouchka-Russkaja beschrieben wurde. ${ }^{510}$

Aber noch einmal zurück zu Schwarzschild: Auch der Taumel, in den sowohl Ausführende als auch Zuschauende am Ende der von ihm beschriebenen algerischen Feierlichkeiten fallen, weist Parallelen zum Sacre auf - immerhin war das Ende des ersten Teils als ein vom Frühling getränkter Rausch geplant, das der deutsche Stravinskij-Experte Volker Scherliess durchaus treffend mit „Taumel und Ekstase“ beschreibt. ${ }^{511}$ In einem Brief vom 2./15. Dezember 1912 an Nikolaj Findejzen, den russischen Musikwissenschaftler und Herausgeber der Russkaja Muzykal'naja Gazeta, formulierte Stravinskij den Inhalt des ersten Sacre-Bildes folgendermaßen:

Часть первая, носящая название,Поцелуй земли', заключает в себе древние славянские игры - радость весны. Оркестровое вступление - пой дудок весенних, далее после поднятия занавеса - гадания, игры хороводные, игра умыкания, хоровод-игра с городом, и все это прерывается шествием ,Старейшего-мудрейшего, старца, который дает земле поцелуй. Бешеное выплясывание земли опьяненных весною людей заключает первуючасть. ${ }^{512}$

$5 \circ 9$ Von den insgesamt 32 Akkorden ist so das zehnte, zwölfte, achzehnte, einundzwanzigste, fünfundzwanzigste und dreißigste Achtel klanglich hervorgehoben, sodass sich eine sehr unregelmäßige Gliederung von neun, zwei, sechs, drei, vier, fünf und drei Achteln ergibt. Mit Ausnahme von Takt 6 und 7 befindet sich der musikalische Akzent jeweils auf den unbetonten Zählzeiten. Vgl. unter anderem die choreomusikalischen Beobachtungen dieser Stelle von Rothkamm, Ballettmusik im 19. und 20. Jahrhundert, S. 212-215.

$510 \quad$ Vgl. Kapitel III.1.1.1.

511 Vgl. Scherliess, Igor Strawinsky. Le Sacre du printemps, S. 67.

512 Brief von Stravinskij an Findejzen vom 2./15. Dezember 1912. Sowohl Dudki (bzw. die spätere Introduction) als auch Das Austanzen der Erde wurden erst während des zweiten Treffens mit Rerich 1911 zum Libretto hinzugefügt. Vgl. Taruskin, Stravinsky and the Russian Tradition, Bd. 1, S. 873 und 89of. 
Der erste Teil, der den Namen ,Kuss der Erde' trägt, beinhaltet altslawische Spiele - die Freuden des Frühlings. Die orchestrale Einleitung besteht aus dem Gesang frühlingshafter Flöten und Pfeifen; danach, nachdem sich der Vorhang hebt, sieht man Wahrsagerei, Reigenspiele, ein Entführungsspiel, ein Reigenspiel der Städte - und all das wird unterbrochen von der Prozession des, Ältesten und Weisesten', des Greises, der der Erde einen Kuss gibt. Tollwütige Tänze der frühlingstrunkenen Menschen zur Huldigung der Erde schließen den ersten Teil ab.

Es ist also durchaus möglich, dass Stravinskij auch den Inhalt des deutschsprachigen Originals des Fuchs-Textes kannte. Dafür spricht ein weiterer Abschnitt des Textes, der nicht vollständig ins Russische übersetzt wurde: Am Ende seiner Schrift Der Tanz widmet sich Fuchs nämlich noch einmal der Bedeutung der Schaubühne für den geforderten Erneuerungsprozess der Kultur. Er versucht dann, jenes „moderne Empfinden“ zu beschreiben, dem die neue Tanzform zu entsprechen hätte. Um die Gesellschaft zur gewünschten gesteigerten Kultur des Körpers zu erziehen, müsse der Tanz „zur Grundlage aller erzieherischen und gesellig-festlichen Einrichtungen“ ${ }^{413}$ gemacht werden. Und um die geforderte „Erziehungspraxis ${ }^{5514}$ in Deutschland zu etablieren, sollte die Schaubühne mithilfe der neuen (Tanz-)Formen die Vorbilder dafür schaffen:

Auf ihr [der Schaubühne] erscheinen uns die schönsten Männer und die schönsten Frauen, schön durch die vollkommene Harmonie alles dessen, was unsere Rasse auszeichnet [...]. - Sie sind ganz das, was wir alle sein wollen, ach, vergebens schmachtend und ringend im niederen Kreise des Irdischen; und alle ihre Gebärden und alle ihre Blicke [...] und alle ihre Tänze sind jubelentfachende Offenbarungen des vollendeten Lebens und der göttlichen Würde, der triumphierenden Schönheit der Seele. ${ }^{515}$

Die Schaubühne sollte also quasi „die hohe Schule der [...] Tanzkunst sein“516. In ihren Übungsräumen sollten ,junge [...] Männer und [...] Mädchen alles finden, was nötig ist, um den Körper zu einer äußerst erreichbaren Schönheit und Ausdrucksfähigkeit $\mathrm{zu}$ entwickeln“517. Im deutschsprachigen Original benennt Fuchs dann sogar sein ideales Vorbild: Frank Wedekinds

513 Fuchs, „Der Tanz“, S. 42.

514 Ebd.

515 Ebd.

516 Ebd., S. 35 .

517 Ebd. 


\author{
unveröffentlichte Erzählung Mine-Haha oder Über die körperliche Erziehung \\ der jungen Mädchen: ${ }^{18}$
}

518 Ebd., S. 36. In Frank Wedekinds Romanfragment Mine-Haha schildert die Ich-Erzählerin Hidalla, wie sie ihre Kindheit und Jugend (bis zum 14. Lebensjahr) in einem Park verbrachte, der mit einer großen Mauer von der Außenwelt abgetrennt war. Die ersten sieben Jahre verbringt sie zusammen mit anderen Mädchen und Jungen. Mit vier Jahren beginnt ihre gymnastische Erziehung: Die junge Erwachsene Gertrud unterrichtet sie. Gertrud zeigt den Kindern Übungen, die diese korrekt nachmachen müssen. Wenn den Mädchen und Jungen die korrekte Ausführung der Übungen misslingt, werden sie von ihr mit einer Weidenrute geschlagen, die Gertrud immer bei sich trägt: „Bei den weiteren Übungen sah Gertrud vor allen Dingen darauf, daß wir beim Gehen die Hüften straff gespannt hielten. Wenn eins sich in den Hüften gehen ließ oder gar einknickte, bekam es eins hinten auf.“ Frank WE DE KIN D: „Mine-Haha oder Über die körperliche Erziehung der jungen Mädchen“, in: DERs.:, Mine-Haha' und andere Erzählungen, München 1955, S. 5-52, hier S. 10. Ab dem fünften Lebensjahr müssen die Kinder selbst erzieherische Aufgaben übernehmen: Jedem Mädchen und jedem Jungen wird ein jüngeres Kind zugeteilt, für das sie Verantwortung übernehmen müssen. Das siebte Lebensjahr bildet für Hidalla eine Art Zensur: Sie wird von den Jungen getrennt und in ein anderes Haus gebracht, in dem nur Mädchen wohnen. Hier sind alle Mädchen unterschiedlichen Alters, und es herrscht eine sehr strenge Hierarchie. Hidalla wohnt in diesem Haus weitere sieben Jahre - also bis zu ihrer Pubertät. Neben der gymnastischen Erziehung erhalten sie und die anderen Mädchen Tanz- und Musikunterricht. Hidalla lernt in dieser Zeit auch die Verbote des Parks kennen: Mädchen beispielsweise, die versuchen, über die Mauer zu steigen oder sich einem anderen Mädchen in irgendeiner Weise körperlich zu nähern, müssen zur Strafe lebenslang im Park bleiben und arbeiten. Und deshalb gelten den Mädchen zwei alte und hässliche Frauen im Park als abschreckendes Beispiel. Im Text werden diese zwei alten Frauen auch als hässliche Ungeheuer und Scheusale beschrieben. Vgl. ebd., S. $24 f$. Einmal im Jahr treffen fremde Damen ein, um unter den 12-jährigen Mädchen eines auszuwählen. Wird ein Mädchen ausgewählt, bedeutet das für sie eine Ehre: „Vor mir ging Iris, das schöne stattliche Geschöpf, das vor zwei Jahren mit Lora um die Ehre gestritten hatte, auserlesen zu werden." Ebd., S. 51. Die Erzählerin vermittelt dem Leser, dass die Mädchen des betroffenen Jahrgangs bereits im Voraus ahnen, auf wen die Auswahl in diesem Jahr treffen würde: „Pamela erzählte dann vom vorigen Jahr, wo die Auswahl bei ihnen stattgefunden. Sie hätten alle schon im voraus gewußt, daß es Isabella treffen werde. Blanka, die uns eben das Fleisch vorlegte, sagte, sie wisse auch schon, wen es im nächsten Jahr treffen werde. Pamela, Irene, Melusine und Filissa sahen auf Wera. Wera wurde dunkelrot bis unter die Haare. Sie warf Blanka einen Blick aus ihren schönen Augen zu, sah aber gleich wieder auf ihren Teller nieder. Ein feines Lächeln lag auf ihren geschlossenen Lippen." Ebd., S. 28. Sobald die Mädchen alt genug sind, müssen sie in einem Theater vor Publikum tanzen. Das Theater befindet sich zwar auch im Park, ist aber durch eine unterirdische Bahn mit der Außenwelt verbunden, sodass die Zuschauer für die Aufführungen von der Stadt ins Theater gelangen können, ohne den Park zu betreten. Die Mädchen müssen dort in Pantomimen mitwirken, deren Inhalte sie allerdings nicht verstehen. Mit einer gewissen Naivität stellen sie Themen wie Beischlaf oder Schwangerschaft dar, worüber sich die Zuschauer im Zuschauerraum amüsieren. Die Auftritte im Theater - so stellt sich heraus - sichern die finanzielle Unterhaltung des Parks, den Hidalla dann mit 
Wie Tänzer und Darsteller zu erziehen seien, das ist vollendet fachlich und vollendet schön geschildert worden von Frank Wedekind. [...] [Mine-Haha] ist eine der ganz wenigen deutschen Schriften der neueren Zeit, die jeder gelesen haben muß, der mitreden will, wenn von körperlicher Erziehung, von moderner gymnischer Schönheit, von Tanz und Drama ernsthaft gehandelt wird. ${ }^{519}$

Es war also das pädagogische Bewegungskonzept, das Fuchs in Wedekinds Beschreibungen der tanzenden Mädchen so faszinierte. ${ }^{520}$ Wedekind beschreibe hierin nämlich, wie „vollkommen gewachsene junge Frauen unterrichten [und damit] Vorbild in allem [seien] “521. Mädchen wiederum, „welche [bereits] eine gewisse Stufe erreicht [...] [hätten, würden] im ,Theater' vor einem Publikum [tanzen], das [...] aus der unbekannten großen Welt“522 herzugeströmt sei:

Die kleinen Mädchen wandern, indem sie heranreifen in dem Parke, in dem sie in anmutigster Klösterlichkeit leben, von Station zu Station. Zum Tanz tritt die Musik. Vollkommen gewachsene junge Frauen unterrichten und sind Vorbild

Beginn ihrer Menstruation verlassen muss. In einer Zeremonie werden die Mädchen am Ende des Textes mit einer Gruppe von Jungen zusammengeführt. Vgl. ebd., S. 5-52.

519 Fuchs, „Der Tanz“, S. 36. Der Tanz der Mädchen in Wedekinds Mine-Haha stellt für Fuchs (exakt wie der Tanz der Magdeleine) einen Vorboten jenes Zukunftstheaters dar, nach dem er strebt. Vgl. Gregor Gum PERT: Die Rede vom Tanz. Körperästhetik in der Literatur der Jahrhundertwende, München 1994, S. 25.

520 Zum pädagogischen Bewegungskonzept vgl. unter anderem Hafemann, Schamlose Tänze, S. 70; Ortrud Gutjahr: „Mit den Hüften denken lernen? Körperrituale und Körperordnung in Frank Wedekinds ,Mine-Haha oder Über die körperliche Erziehung der jungen Mädchen“, in: Kontinuität - Diskontinuität. Diskurse zu Frank Wedekinds literarischer Produktion (1903-1918) (Tagungsband mit den Beiträgen zum internationalen Symposium der Editions- und Forschungsstelle Frank Wedekind an der FU Darmstadt im Oktober 1999), hg. von Sigrid DreisEL und Hartmud VinçON, Würzburg 2001, S. 33-56, hier S. 38-40; Ortrud GutJahr: „Erziehung zur Schamlosigkeit. Frank Wedekinds ,Mine-Haha oder Über die körperliche Erziehung der jungen Mädchen` und der intertextuelle Bezug zu ,Frühlings Erwachen“', in: Frank Wedekind (Freiburger literaturpsychologische Gespräche. Jahrbuch für Literatur und Psychoanalyse, Bd. 20), hg. von DIEs., Würzburg 2001, S. 93124, insbesondere S. 104f. Gregor Gumpert stellte heraus, dass Fuchs' Einordung des Fragments in den Kontext einer Tanz- und Theaterreform keineswegs isoliert gewesen sei. Wedekinds Mine-Haha ließ sich in mancherlei Weise als pädagogische ,Propagandaschrift' lesen und je nach Einschätzung der Kritiker verstehen oder auch missverstehen. Vgl. Gumpert, Die Rede vom Tanz, S. 15. Gumpert macht außerdem deutlich, dass der Fragmentcharakter des Wedekind-Textes, genauso wie die Editionslage seines Kontextes zu einer Bandbreite von Interpretationen des Werkes geführt habe und dass Fuchs' Betonung des Erziehungssystems bei Wedekind und des durch den Tanz vermittelten Körperbewusstseins lediglich eine von vielen möglichen Lesarten darstelle. Vgl. ebd., S. $11-45$.

521 Fuchs, „Der Tanz", S. 38.

522 Ebd. 
in allem. Die Mädchen, welche eine gewisse Stufe erreicht haben, tanzen im ,Theater' vor einem Publikum, das von da draußen, aus der unbekannten großen Welt herzuströmt. 523

Zur Verdeutlichung dieser Lehrfunktion der vollkommen gewachsenen Frauen zitiert Fuchs dann einige (gekürzte) Textpassagen aus Mine-Haha, in denen Wedekind die Lehrerin Gertrud beim Unterrichten der Mädchen beschreibt:

Gertrud (die Lehrerin) zog die Weidenrute, die sie in der Rechten hielt, durch die linke Hand und sah uns eines nach dem anderen lächelnd an. Dann nahm sie ihr Kleid mit beiden Händen so weit hinauf, daß man ihre Beine bis über die Knie sehen konnte, und zeigte uns, wie man gehen müsse. - Sie hob die Knie ein wenig und setzte den Fuß mit der Fußspitze auf; dann ließ sie langsam die Ferse nieder, aber nicht, bevor nicht der Fußrücken bis zur großen Zehe mit dem Schienbein eine gerade Linie gebildet hatte. Ihr volles, rundes, aber zart geformtes Knie streckte sich in demselben Moment, wo die Ferse die Erde berührte. Wir alle mußten unsere Kleidchen hinaufraffen und mit den eingestützten Händen über den Hüften festhalten. Dann ging das Marschieren los. - Bei den weiteren Übungen sah Gertrud von allen Dingen darauf, daß wir beim Gehen die Hüften straff gespannt hielten. - Die Hüften, das sei der Mittelpunkt; der müsse unbeweglich - bleiben. Aber alle anderen Bewegungen, im Oberkörper sowohl wie in den Beinen bis in die Zehenspitzen, müßten von den Hüften ausgehen. [...] Den Kopf mußten wir so weit wie möglich zurücklegen und die Hände hinter den Kopf gefaltet halten. Solange die Übung dauerte, durften wir mit den Fersen die Erde nicht berühren. - Die Knie durften wir nur ganz wenig biegen und während des Laufens den Fuß nur mit der Spitze aufsetzen. ${ }^{524}$

Auch im ersten Bild des Sacre spielt das Heranziehen von Jugendlichen eine Rolle. Und eine unterrichtende Frau mit einer Rute lieferte Stravinskij und Rerich hierfür das Vorbild. Das geht aus einem Brief vom 13./26. September 1911 hervor, den Stravinskij an Rerich geschrieben hatte, um ihm eine Art Zwischenbericht über sein Fortkommen am gemeinsamem Projekt zukommen zu lassen. Stravinskij beschreibt darin, dass er beim Skizzieren der Гадание на прутиках (Weissagungen mit kleinen Ruten) ständig die Alte Frau vor Augen habe, die immerzu umherrenne und dabei ihre Bewegungen immer wieder abrupt unterbreche:

523 Ebd. Zu Wedekinds Tanzbeschreibungen in Mine-Haha vgl. unter anderem Hafemann, Schamlose Tänze; Schümann, Die Suche nach dem, neuen Menschen:

524 Wedekind zit. in: Fuchs, „Der Tanz“, S. 37. Fuchs fasst hier einige Textausschnitte des Originals zusammen. Mit ,-‘ kennzeichnet er die Auslassungen. Die hier von Fuchs zitierten Originalausschnitte finden sich in Wedekind, „Mine-Haha oder Über die körperliche Erziehung der jungen Mädchen“, S. gf. 
Я уже начал сочинять: ,набросал“ (как выражаются) вступление („Дудки‘) и пошел дальше, ,набросав‘ и ,Гадание на прутиках‘; страшно увлечен!

Музыка выходит свежей. Образ старушки в беличьих шкурках не выходит у меня из головы и все время, как сочиняю ,Гадание, стоит предо мной и бежит впереди всех, изредка лишь останавливаясь, прерывая плавное течение общей ,рыси .525

Ich habe bereits begonnen, zu komponieren: [Ich] habe die Einleitung (,Schalmeien') entworfen (wie man sagt) und bin weiter gegangen, habe die ,Weissagungen mit den kleinen Ruten' skizziert; [und] bin völlig hingerissen!

Die Musik erscheint frischer. Die Erscheinung der Greisin in Eichhörnchenfellen geht mir nicht aus dem Kopf, und die ganze Zeit, wie ich ,die Weissagungen verfasse, steht sie vor mir und läuft allen voraus, nur hin und wieder stehen bleibend, die fließende Strömung des ,Trabes' unterbrechend.

Der Teil des Balletts, von dem Stravinskij hier spricht, findet sich später in der Sacre-Partitur als Les augures printaniers - jenem Teil also, der auch vom Journalisten Adolphe Boschot beschrieben wurde. Die nachträglich erfolgte Titeländerung hatte aber keinen Einfluss auf die ursprüngliche Idee der Weissagungen mit den Ruten. Denn noch in seinem Artikel „Ce que je voulu exprimer dans ,Le Sacre du printemps““, der am Uraufführungstag des Balletts in der Comœdia erschien, beschreibt Stravinskij die Alte Frau und ihre Funktion sehr genau:

Dans le premier Tableau, des Adolescents se montrent avec une vieille, très vieille femme, dont on ne connaît ni l'âge, ni le siècle, qui connaît les secrets de la nature et apprend à ses fils la Prédiction. Elle court, courbée sur la terre, mi-femme, mi-bête. Les Adolescents à coté d'elles sont les Augures printaniers, qui marquent de leur pas, sur place, le rhythme du Printemps, le battement du pouls du Printemps. ${ }^{526}$

Die Alte sei also in die Geheimnisse der Natur eingeweiht und unterrichte die heranwachsenden Mädchen und Jungen in der Weissagung. Die Jugendlichen wiederum seien die Vorboten des Frühlings, die mit ihren Schritten am Platz den Rhythmus des Frühlings markierten. Als Vorbild für diese Alte identifizierte Taruskin die russischen Volchvy, die schamanistisch in die Geheimnisse der Weissagung eingeweiht waren und in direkter Verbindung zu den

525 Brief von Stravinskij an Rerich vom 13./26. September 1911, ediert in: Perepiska, Bd. 1, hg. von Varunc, S. 300.

$5^{26}$ Igor' Stravinskij: „Ce que j’ai voulu exprimer dans ,Le Sacre du Printemps“', in:Montjoie!, 29. Juni 1913, abgedruckt in: Dossier de presse, hg. von Lésure, S. 13-15, hier S. 14. 
Weissagungsritualen des Frühlingsfestes (Semik) standen. ${ }^{527}$ Auch erinnert die bei Fuchs beschriebene und aus der Mine-Haha zitierte Gehbewegung, bei der die Fersen nicht den Boden berühren durften, der Kopf so weit wie möglich zurückgelegt und die Hände hinter ihm gefaltet werden mussten, an eine Bewegung, die Valentin Gross während der Sacre-Proben in ihren Skizzen festgehalten hatte (siehe unpag. Tafelteil, Abb.1). Aufgrund der Angaben von Marie Rambert im von ihr annotierten vierhändigen Klavierauszug identifizierte Hodson diese Bewegung zum ersten Mal zu Beginn der Rondes printanières [Ziffer 49]. ${ }^{528}$ Könnten also diese im Frühling stattfindenden Weissagungsrituale ein Grund dafür gewesen sein, dass Stravinskij und Rerich das Ballett von einem Sommer- in ein Frühlingsritual umwandelten?

Noch ein weiterer Aspekt im Tanz verweist auf eine Verbindung zwischen Stravinskijs Fuchs-Lektüre und seiner Wiederaufnahme des Sacre: Fuchs sieht in Wedekinds Beschreibungen der tanzenden Frau(en) nämlich jene „[moderne] Anschauung des Leibes“529 verwirklicht, die er sich für die neuen (Tanz-)Formen wünscht: Wedekind würde ohne Rückgriffe auf Vorbilder aus Antike oder Renaissance den reinen Zustand „der modernen Seele“ bzw. den „Lebensdrang [...] [der] modernen Rasse“530 formulieren. ${ }^{531}$ In der Stellung der Frau, wie sie sich in der Erzählung Mine-Haha manifestiere, zeige sich die „absolute Modernität“. Denn:

Die Frau ist [bei Wedekind] nicht schön für den Mann. Sie tanzt nicht für den Mann. Sie ist selbstständig-schöpferisch, aus ihr selbst und um ihrer selbst

527 Taruskin bezieht sich bei der Beschreibung dieser Volchvy auf einen Artikel eines gewissen Moskauer Professors S. Smirnov von 1909: „Smirnov links ,old women, dead to love and labor, [...] wholly immersed in the secrets of sorcery' directly with the divination rites of Semik. He cites an eighteenth-century manuscript that contains the following report: ,Volkhvï and heretical women and old women soothsayers reviled of God and a host of others make magic and tie the ends of birch branches and weave them [...] and toss willows dipped in pitch on walls to see who will live and who will die that year." Taruskin, Stravinsky and the Russian Traditions, Bd. 1, S. 887.

$5_{28}$ Vgl. Hodson, Nijinsky's Crime against Grace, S. 65 f.

529 Fuchs, „Der Tanz", S. 40.

530 Ebd.

531 Das pädagogische Bewegungskonzept, das Wedekind in seiner Mine-Haha beschreibt, wird häufig als Gegenteil des natürlichen und freien Bewegungskonzepts der Isadora Duncan beschrieben. Wedekind nehme mit seinen Beschreibungen des Körpers, die bei ihm bereits ab 1895 zu finden sind, fundamentale Diskurse der Jahrhundertwende vorweg und durchkreuze damit entstehende Konzepte der natürlichen Bewegung. Vgl. Hafemann, Schamlose Tänze, S. 70; außerdem Gutjahr, „Mit den Hüften denken lernen?“, S. 38; dies., „Erziehung zur Schamlosigkeit“. 
willen. Ja sie geht voran und scheint, fragend zurückgebeugt den Mann aufzufordern, ihr zu folgen..$^{532}$

Die selbstständig-schöpferische und tanzende Frau ist es, die Fuchs am Textende als Vorbild für die zukünftige Kultur identifizert. Er unterstreicht seine gewonnene Erkenntnis mit den Worten: „Daß er [der Mann] ihr folge, darauf kommt es jetzt an. [Denn:] Die tanzende Frau ist die Herrin und Mutter unserer werdenden Kultur.“533 Und so drängt sich an dieser Stelle die Frage auf: Könnte die tanzende Frau, die Fuchs als Vorbild für die zukünftige Kultur identifiziert, ein Grund dafür gewesen sein, dass im letzten Tanz des Sacre, in der Danse sacrale, eine (Jung-)Frau in einer ganz neuen (Tanz-)Form vor den Augen des Publikums tanzt?

Wie bereits dargelegt, enthielten die Pressemitteilungen zu den ersten Sacre-Entwürfen von 1910 keinen Hinweis auf eine Jungfrau, sodass davon ausgegangen werden muss, dass auch dieses Detail erst nach dem zweiten Treffen mit Rerich im Sommer 1911 hinzugekommen ist - auch wenn Stravinskij später anderes behauptete. ${ }^{534}$ Taruskin geht auf die Frage des Zeitpunkts nicht weiter ein, hält es aber für wahrscheinlich, dass Stravinskij Rerich bereits 1910 mit der Jungfrauenopferidee konfrontierte. Dies wird unter anderem deutlich in seinen Ausführungen zur Autorfrage des Librettos. Hier insistiert Taruskin darauf, dass die Idee des Jungfrauenopfers nicht von Rerich, sondern nur von Stravinskij selbst gestammt haben könne. ${ }^{535}$ Ein wirkliches Vorbild für ein Menschenopfer sei nämlich in keiner der archäologisch gedachten Quellen zu finden, und Rerich sei bezüglich des Authentizitätsanspruchs zu gewissenhaft gewesen, als dass er in einem derartigen Fall ein Menschenopfer für das Ballett vorgeschlagen hätte. Nur einem Stravinskij, der der romantischen Musiktheatertradition und ihren Klischees zutiefst verhaftet gewesen sei, sei die Idee eines gipfelnden Opfertanzes der Ballerina zuzutrauen. ${ }^{536}$

Hieran anschließend macht Taruskin dann einen Vorschlag, wie es möglicherweise zum Konzept des Sacre und zu der Idee des Jungfrauenopfers gekommen sein mag:

532 Fuchs, „Der Tanz“, S. 40.

533 Ebd. Alexandra Kolb diskutiert Wedekinds Mine-Haha unter anderem auch im Hinblick auf die Frauenemanzipationsbewegung. Vgl. Alexandra Kolb: Performing Femininity. Dance and Literature in German Modernism, Bern 2009, S. 224-241. In diesem Kontext vgl. auch das Kapitel zu „Weiblichkeitsmuster und Körperbilder im Tanz" von Brandstetter, Tanz-Lektüren, 2013, S. 123-25o.

534 Vgl. Anm. 405.

535 Taruskin, Stravinsky and the Russian Traditions, Bd. 1, S. 864. Zur Autorfrage vgl. auch Kapitel II.2.2.

536 Vgl. Taruskin, Stravinsky and the Russian Traditions, Bd. 1, S. 864. 
What probably happened was this: Stravinsky, having had an idea for a ,Stone Age' ballet - very possibly after having read Roerich's articles or hearing him speak of his beloved pagan antiquities as a good subject for scenic treatment, but also recalling the Gorodetsky's Yar' and the Sacrifice in Rogneda (if not Norma) got in touch with Roerich, who in all likelyhood already had a libretto - probably fashioned after the tender Neolithic fantasy in ,Joy in Art' - ready and waiting. Each could later brag to his own satisfactation that he had been the originator of the project. 537

Die Dichte der relativierenden Einschübe, die Taruskin in diesem Absatz macht - „probably“, „very possible“, „all likelyhood“, „probably“-, macht hier vor allem eines deutlich: Möglicherweise könnte es so gewesen sein. Möglicherweise könnte es aber auch ganz anders gewesen sein, und Stravinskij war (unter anderem) durch Fuchs' Reformschrift Der Tanz dazu inspiriert worden, die darin geforderten neuen Formen auf der Bühne umzusetzen.

Gerade mit dem Wissen um sein reges Interesse an theaterreformatorischem Gedankengut sticht ins Auge, dass Stravinskij den Sacre spätestens ab 1912 als „Choreodrama“538 bezeichnete. Durch diese neue Kunstform - so Stravinskij in

537 Ebd., S. 865.

538 Vgl.hierzu den Brief von Stravinskij an Findejzen vom 2./15. Dezember 1912: Первая мысль о моей новой хореодраме ,Весна священная' появилась у меня еще при окончании ,Жар-птицы“ весною 1910 года.“ „Der erste Gedanke für mein neues Choreodrama ,Le Sacre du printemps' kam mir im Frühling 1910, als ich gerade ,L'Oiseau de feu' beendete.“ Der Begriff oder die Gattungsbezeichnung Choreodrama wird im deutschen Sprachraum gemeinhin im Hinblick auf den italienischen Tänzer, Choreografen und Ballettmeister Viganò Salvatore verwendet, der 1801 mit Ludwig van Beethoven für das Ballett Die Geschöpfe des Prometheus zusammenarbeitete. Als Ballettmeister an der Mailänder Scala (1813-1821) entwickelte er die Form des Choreodramas. Und als charakteristisch für diese neue Form gilt, dass Bühnenbild, Bewegung und Musik zu groß angelegten Tableaus verschmolzen - ein musikdramatisches Konzept also, das sich wenig später auch in der Grand Opéra findet. Nach Salvatores Tod gerieten aber sowohl seine Ballette als auch das Konzept des Choreodramas in Vergessenheit. Vgl. Monika Wortas: Art. ,Viganò, Salvatore', in: Das große Tanz-Lexikon. Tanzkulturen. Epochen. Personen. Werke, hg. von Annette Hartmann und Monika Woitas, Laaber 2016, S. 665-667. Anscheinend wurde der Begriff Choreodrama zur Zeit der Stalin-Herrschaft auch für die damals in der Sowjetunion vorherrschende Ballettgattung drambalet (dramatičeskij balet) verwendet. Dies behauptet zumindest Kristen Hamm in ihrer 2009 an der University of Illinois entstandenen Masterarbeit. Vgl. Kristen Elizabeth Намм: „The Friendship of Peoples“. Soviet Ballet, Nationalities Policy, and the Artistic Media. 1953-1968, M.A. Thesis, University of Illinois 2009, S. 13. Zum drambalet vgl. auch Tim SCHOLL: „The Ballet Avant-Garde II. The ,New' Russian and Soviet Dance in the Twentieth Century", in: The Cambridge Companion to Ballet, hg. von Kant, S. 212-223. 
einem Interview vom September 1912 - sollte das Ballett in seiner herkömmlichen Form ersetzt werden. ${ }^{539}$ 20. Jahrhunderts virulenten Reformtexte aufmerksam geworden. Was Craigs theoretische Schriften angeht, so geben Harry Graf Kesslers Tagebucheintragungen Zeugnis davon, dass Nižinskij damit zum ersten Mal spätestens am 11. November 1911 konfrontiert worden war, und zwar als er in London einer Diskussion von Craig und Djagilev beiwohnte, bei der es um genau diese Theorien ging. Die beiden diskutierten dort unter anderem die Rolle des Schauspielers:

Vormittags bei Craig. [...] Abends zu den Russen. ,Armide‘, ,Sylphide‘, ,Cléopâtre‘. Nachher soupierten Diaghilew, Nijinsky und Craig mit mir im ,Savoy'; wir blieben bis zwei Uhr in der Bar zusammen. Craig und Diaghilew diskutierten durch Vermittlung meines Dolmetschers über Craigs Bühnenschirme und Theatertheorien, während Nijinsky, ohne ein Wort zu verstehen, die ganzen drei Stunden schweigend und lächelnd dasass; dieses fortwährende Lächeln hat Etwas Japanisches oder Mongolisches; es ist wie eine Art von atavistischer mongolischer Höflichkeit. Diaghilew wandte gegen Craigs Bühnenschirme (die er übrigens noch nicht gesehen hat, sondern nur aus meiner Beschreibung kennt) ein, dass sie eine Verarmung der Materialien des Regisseurs, aus denen er seine Welt aufbaut, bedeuten würden (une sorte d'ascétisme) und dass es widersinnig sei, einen lebendigen Schauspieler in eine gänzlich abstrakte Dekoration hineinzustellen. Craig weigerte sich, direkt auf diese Einwände zu antworten. Er sagte, man solle ihm doch Zeit lassen, selber zu probieren. Er wolle nichts, als ,the material art of the Theatre' suchen. Bis jetzt sei dieses Material aus allen andren Künsten zusammengeraubt, aus der Poesie, aus der Musik, der Malerei, der Architektur. Was er wolle, sei dem Theater ein Material schenken, das ihm eigen sei, wie der Stein der Bildhauerei oder das Wort der Poesie; dieses unendlich komposite und brüchige Material, mit dem bis jetzt das Theater arbeitet, zu einem edlen, homogenen machen. Dazu müsse man aber jenes bisherige Material erst geduldig durchprobieren (sift it through), ohne irgendetwas beiseitezulassen, bis man ,the right thing' finde. Dazu solle ihm seine Theaterschule dienen, die weniger eine Schule als eine Versuchsanstalt werden solle.

539 Vgl. Krasovskaja, Russkij baletnyj teatr načala dvadcatogo veka, S. 432: „В общем, я сторонник так называемой хореодрамы, которая должна заменить тип современных балетов.“ „Im Allgemeinen bin ich ein Befürworter des sogenannten Choreodramas, das das Ballett in seiner heutigen Form ersetzen wird.“ Krasovskaja zitiert Stravinskij hier aus einem Interview von M. DvinsKIJ: „U Igora Stravinskogo“, in: Birževye vedemosti, 25. September 1912, S. 5. Am 27. September 1912 äußerte sich Stravinskij in der Peterburgskaja Gazeta dann noch einmal folgendermaßen: „[O]pera does not attract me at all. What interests me is choreographic drama." Peterburgskaja Gazeta, 27. September 1912 (julianischer Kalender), übers. und zit. in: Taruskin, Stravinsky and the Russian Traditions, Bd. 2, S. 982. 
Diaghilews wiederholt nachdrücklich gestellte Frage, ob er den lebendigen Schauspieler beibehalten oder abschaffen wolle, weigerte er sich absolut zu beantworten. Sehr erschöpft gingen wir um zwei auseinander. ${ }^{540}$

Auch wenn Craig sich im Gespräch mit Djagilev 1911 noch nicht ganz festgelegt hatte, ob er als Schauspieler nun das tote dem lebendigen Material vorziehe, wird klar, dass im Kreis der Ballets-Russes-Mitglieder die Frage nach der Bedeutung des Schauspielers in Craigs Theorien schon damals diskutiert wurde. Wie wichtig Djagilev die Klärung dieser Frage gewesen sein muss, wird in Kesslers Beschreibung eines zweiten Treffens deutlich, das ebenfalls in London stattgefunden hatte, nur zwei Tage nach dem beschriebenen ersten Zusammenkommen der beiden:

Vormittags mit Nijinsky und Diaghilew zu Craig, der uns seine Bühnenschirme vorführte. Diaghilew kam wieder auf die Frage des lebendigen Schauspielers zurück und insistierte so, dass Craig empfindlich wurde und die Vorführung einschlafen liess. Er war durch Nichts dazu zu bringen, sie wieder aufzunehmen. Es sei ihm unmöglich, weil diese Schirme wie ein Instrument seien, die jede Stimmung ausdrücken könnten, wenn er sie mit Lust und Liebe handhabe, die aber tot seien, wenn er durch Einreden und Kritisieren im Erfinden der Motive gehemmt würde. Die etwas peinliche Lage wurde überbrückt durch eine Einladung Diaghilews an Craig für heute Abend zum Ballett. ${ }^{541}$

Am 23. Februar 1913, also nur gute drei Monate vor der Uraufführung des Sacre, berichtet Kessler von einem gemeinsamen Frühstück mit Nižinskij, Craig, Djagilev und dem englischen Komponisten und Dirigenten Vaughn Williams in London. Wieder fand eine Diskussion statt, bei der das Verhältnis zwischen Regisseur und Schauspieler eruiert wurde. Dieses Mal allerdings zwischen Craig und Nižinskij:

Craig meinte zwei extreme Standpunkte seien haltbar: man könne lebendige Schauspieler verwenden dann sie respektieren, die ganze Regie auf ihrer gegebenen Individualität aufbauen, oder im Gegenteil wie totes Material, Marionetten benutzen und dann alles vorschreiben. Er bevorzuge heute das Erstere; Nijinsky erwiderte, er wolle lebendige Schauspieler, aber sie so lange bearbeiten, bis sie wie totes Material gehorchten. Eine Einigung war

540 Harry Graf Kessler: Tagebucheintrag vom 1. November 1911, ediert in: Das Tagebuch, Bd. 4, hg. von Kamzelak und Ott, S. $736 f$.

541 Harry Graf Kessler: Tagebucheintrag vom 3. November 1911, ediert in: Das Tagebuch, Bd. 4, hg. von Kamzelak und Ott, S. 737 f. 
nicht zu erzielen, offenbar streiten sich hier das englische und das slawische Temperament. Craig mag deshalb auch nicht den Faun; weil die Figuren tot seien. ${ }^{542}$

Craig positioniert sich hier ganz klar in Richtung der von ihm erdachten ÜberMarionette als gleichsames Gestaltungsobjekt des Regisseurs (Kapitel III.1.1.). Nižinskij hingegen schien mit keiner der von Craig vorgeschlagenen Lösungen zufrieden, sondern bevorzugte ein anderes, eigenes Modell.

Djagilev stellte Craig 1911 bezüglich des lebendigen Schauspielers zunächst vor allem Verständnisfragen, die dieser zu jenem Zeitpunkt anscheinend noch nicht beantworten konnte. Zwei Jahre später - in direkter Konfrontation mit Nižinskij - erhielt dieser Konflikt dann aber eine zusätzliche Ebene: Nižinskij ging es nämlich nicht mehr nur darum, Craigs (komplexe) Theorien und Vorstellungen besser zu verstehen oder die Frage beantwortet zu wissen, ob Craig das tote gegenüber dem lebendigen Material bevorzuge. ${ }^{543}$ Das Streitgespräch

542 Harry Graf Kessler: Tagebucheintrag vom 23. Februar 1913, ediert in: Das Tagebuch, Bd. 4, hg. von Kamzelak und Ott, S. 869 .

543 Craig diskuitierte seine Theorien zu diesem Zeitpunkt mit vielen Kulturschaffenden, zu denen Kessler auch oftmals den ersten Kontakt hergestellt hatte. So berichtet Kessler beispielsweise am 28. Juni 1911: „Der Dichter Marc Lafargue hat bei mir gefrühstückt. [...] Später in St. Germain Denis besucht. [...] Er erzählte mir, auf Craig durch mich aufmerksam geworden, Rouché [gemeint ist der französische Herausgeber und Operndirektor Jacques Rouché, der ab 1907 die Kulturzeitschrift La Grand Revue herausgab und 1910 bis 1913 das Théâtre des Arts sowie ab 1913 die Pariser Oper leitete] veranlasst, mit diesem in Unterhaltung zu treten. Craig habe darauf Rouché folgende Vorschläge gemacht: Er solle zunächst sein Theater auf 10 Jahre schließen [...]." Harry Graf Kessler: Tagebucheintrag vom 28. Juni 1911, ediert in: Das Tagebuch, Bd. 4, hg. von Kamzelak und Ott, S. 696. Dass Craig in solchen Gesprächen auch über seine Theorie der Über-Marionette sprach, geht aus Kesslers Tagebucheintrag vom 13. April 1912 hervor: „Ich führte Maillol [gemeint ist der französische Bildhauer und Maler Artistide Maillol] vom Louvre aus zu Craig. [...] Er zeigte Maillol zuerst sein Theater, die Stellungen und Beleuchtungen seiner Wandschirme mit einer Figurine im Vordergrund. Maillol war sofort sehr entzückt. [...] Craig taute zum ersten Mal, seit ich ihn kenne, ganz auf. [...] Maillols Bewunderung schien zu steigen. [...] Craig war so erfreut, dass er sogar seine Haupterfindung, die ,Übermarionette, zum ersten Mal in meiner Gegenwart, erklärte, nachdem Maillol erzählt hatte, wie er und seine Freunde auf dem Bouchorschen [gemeint ist der französische Autor und Dramatiker Maurice Bouchor] Marionettentheater Shakespeares ,Sturm' gegeben und durch die Marionetten einen viel grösseren Eindruck als durch lebendige Schauspieler erzielt hätten. Craig sagte, seine Idee sei, Marionetten zu machen, die etwa überlebensgross seien (statt wie bisher puppenhaft klein); das Problem sei nur, wie sie in Bewegung setzen: er scheint daran zu denken, einen wirklichen Menschen oder einen Schauspieler in die Marionette hineinzustecken, in ihr sozusagen [zu] verkapseln. Maillol erbot sich, einen Abend bei Craig zu arrangieren, um Craigs Theater Bonnard [gemeint ist der französische Maler Pierre Bonnard], Maurice Denis, Vuillard [gemeint ist der 
resultierte vielmehr aus der Tatsache, dass Nižinskij Craigs Konzept ein eigenes (erweitertes) Konzept entgegenstellte: Laut Kessler wollte Ersterer den lebendigen Schauspieler nämlich so lange bearbeiten, bis er ihm voll und ganz gehorche. Nižinskij beabsichtigte also, den Schauspieler durch seine choreografischen Anweisungen in einen Zustand der Besinnungs- oder Willenlosigkeit zu versetzen. Durch diesen Zustand konnte er sich dann den lebendigen Schauspieler bzw. Tänzer gefügig machen - ähnlich also wie Craig die (leblosen) Marionetten.

Fragt sich an dieser Stelle nur, welchem Zweck das Ganze dienen sollte. Die Antwort führt erneut zu Fuchs: Ein besinnungs- oder bewusstseinsloser $\mathrm{Zu}-$ stand, der von einer übergeordneten Instanz kontrolliert oder geleitet wird, galt Fuchs als unerlässliche Voraussetzung für den Tanz. ${ }^{544}$ Über die „künstlerische Tat", wie er sie sich wünschte, hatte er ja geschrieben:

Schlafwandelnd wird jede künstlerische Tat getan. Weit entfernt von allem Bewußten gebiert sich jede Form in der Seele der Schaffenden. Doch sie hervorzubringen, sie als Werk herauszustellen, bedarf sonst überall bewußten Handelns. [...] Ein zauberischer Befehl erlöst den Leib der Madeleine von den Gesetzen des Irdischen und von ihrer Schwerkraft. 545

Es ist nicht überliefert, ob Nižinskij den Tanz gelesen hat. Wenn Stravinskij es sich aber tatsächlich zum Ziel gemacht hatte, Fuchs' neue (Tanz-)Formen zu realisieren, um mit dem Sacre jenes Theater der Zukunft entstehen zu lassen, das die Erneuerung der Kultur erzielen sollte, ist dies sehr wahrscheinlich. Denn den unbewussten Zustand bzw. die Ekstase hielt Fuchs ja für die unabdingbare Voraussetzung für jene neuen (Tanz-)Formen. Außerdem hatten Nižinskij und Djagilev 1912 Hellerau besucht - die 1910 eröffnete Bildungsanstalt von Émile Jaques-Dalcroze. ${ }^{546}$

französische Maler Édouard Vuillard], Mme Edwards [gemeint ist Misia Sert, die als in Russland geborene Marija Godebskaja 1905 den französischen Journalisten und Millionär Alfred Edwards heiratete und seinen Namen annahm, dann aber, mit Beginn ihrer dritten Ehe mit Josep Maria Sert, ab 1920 den Namen Misia Sert trug] zu zeigen: er wolle selber an sie schreiben, um sie aufzufordern." Ebd., S. 808.

544 Vgl. Fuchs, „Der Tanz“, S. 23.

545 Ebd., S. 25.

546 Zur Gartenstadt Hellerau allgemein vgl. Corona Hepp: Avantgarde. Moderne Kunst, Kulturkritik und Reformbewegungen nach der Jahrhundertwende (Deutsche Geschichte der neuesten Zeit vom 19. Jahrhundert bis zur Gegenwart), München 1987, S. 167-171. Zum Besuch von Djagilev und Nižinskij in Hellerau vgl. Bronislava NiJins Ka: Early Memoirs, hg. und übers. von Irina Nijinska und Jean Rawlinson, Durham und London 1992, S. 468; Garafola, Diaghilevs Ballets Russes, S. 6o. 
Über diesen Besuch wird in der Literatur immer wieder der Verdacht geäußert, dass Nižinskij sich dort Inspiration und Hilfe für seine Sacre-Choreografie geholt habe. Bestätigt werden konnte dies nie. ${ }^{547}$ Die finnische Tanzwissenschaftlerin und Nižinskij-Expertin Hanna Järvinen bestreitet sogar einen Einfluss Dalcrozes auf Nižinskijs Sacre: Djagilev habe Rambert nicht als Nižinskijs Assistentin engagiert, um Nižinskij Dalcroze beizubringen - wie das häufig interpretiert würde -, sondern ganz im Gegenteil: um den Ballets-Russes-Tänzern Nižinskij beizubringen. ${ }^{548}$

Auch Wedekind hat Hellerau (im Juni) 1912 besucht. Gerade im Hinblick auf Fuchs und dessen Wedekind-Rezeption im Tanz erweist sich die Tatsache als aufschlussreich, dass über Dalcroze in der Literatur oftmals behauptet wird, er habe sich für die von ihm entwickelte rhythmische Ausdrucksgymnastik von Wedekinds Mine-Haha beeinflussen lassen: Sowohl der Wedekind-Biograf Artur Kutscher als auch Fritz Strich, der Herausgeber der Briefe des Schriftstellers, weisen darauf hin. ${ }^{549}$ Von Wedekind und Dalcroze selbst sind derartige Angaben allerdings nicht überliefert, und so konnte diese Behauptung nie belegt werden. ${ }^{550}$

Ein Auszug aus dem 1913 erschienenen Wedekind-Porträt von Paul Friedrich lässt nun aber vermuten, dass Kutscher wie Strich mit dieser Behauptung ein Gerücht aufgriffen, das bereits um 1912/13 existierte. Der Autor schreibt zu Mine-Haha:

Ich erkenne, daß Wedekind Schönheit der Frauen anstrebt und die natürliche Grazie der Männerleiber durch sinnvolle Entwicklung gehoben sehen möchte! Aber diese Idee ist abstrus, lächerlich und entbehrt für mich - ich bekenne es

547 Vgl. hierzu unter anderem Selma Landen Oром: „The Dalcroze Method, Marie Rambert, and ,Le Sacre du printemps“", in: Modernist Cultures 9/1 (2014), S. 7-26; Garafola, „Diaghilev's Ballets Russes“, S. 6of.; Gunhild Oberzaucher-Schüller: „Aus den Anfängen der modernen Choreographie (IV). ,Ihre Musik tönt nicht nur in meinen Ohren, mein ganzer Organismus vibriert'. Über den Stellenwert von Émile Jaques-Dalcrozes ,Rhythmischer Gymnastik' in Vaslav Nijinskys ,Sacre'-Choreographie“, in: Bühnenkunst 1 (1989), S. 68-74; DIES. und Elisabeth SuRITZ: „Aus den Anfängen der modernen Choreographie (III). ,Die Musik durchdringt den menschlichen Körper und wandelt sich zur Freude für das Auge‘. Vaslav Nijinsky und die Methode Jaques-Dalcroze“, in: Bühnenkunst 4 (1988), S. 81-85.

548 Vgl. Järvinen, The Myth of Genius in Movement, S. $329 f$.

549 Vgl. Artur Kutscher: Frank Wedekind. Sein Leben und seine Werke, 3 Bde., München 1922-1931, Bd. 2, München 1927, S. 130; Fritz Strich (Hg.): Frank Wedekind. Gesammelte Briefe, 2 Bde., München 1924, Bd. 2, S. 370. Diese Behauptung zieht sich durch die Wedekind-Literatur bis 1985. Vgl. Gumpert, Die Rede vom Tanz, S. 15; Schümann, Die Suche nach dem, neuen Menschen', S. $26 f$.

550 Vgl. Schümann, Die Suche nach dem,neuen Menschen', S. 23-26. 
freimütig - unreinen Menschen - eines leise-lüsternen Beigeschmacks. Dabei ist die ganze Einkleidung mit ihrer romanhaft-unmöglichen Phantastik trotz aller Versuche, den langatmigen Schwulst über Bein- und Fußstreckungen, rhythmisches Gehen und schönes Tanzen interessant zu machen, unendlich monoton und langweilig. Immerhin könnte es sein, daß diese sonderbare ,Erziehungsschrift' Herrn Jaques Dalcroze zu seiner Eurythmik in Hellerau begeistert hat. Als kurze Anregung zu rhythmischen Tanz- und Turnspielen für Mädchen ließe ich mir das Ganze gefallen, obschon ich der Meinung bin, daß, wie jedes echte Mädel von Natur tanzen kann, es auch, was ja sicher am schönsten wirkt, unbewußt seine Geschlechtsnatur in seinen Bewegungen zum Ausdruck bringt. ${ }^{551}$

Es wäre also durchaus denkbar, dass der Hellerau-Besuch von Djagilev und Nižinskij etwas mit Stravinskijs Fuchs-Rezeption bzw. seinen damit in $\mathrm{Zu}-$ sammenhang stehenden Plänen für den Sacre zu tun hatte. Möglicherweise hatten die beiden gar das Ziel, mit diesem Besuch Wedekinds in Mine-Haha entworfene Utopie besser zu begreifen. Diese Annahme würde zumindest Järvinens These stützen, Djagilev habe die Dalcroze-Schülerin Rambert als Nižinskijs Assistentin engagiert, um den Ballets-Russes-Tänzern Nižinskij (und Stravinskij) beizubringen:Schließlich sollte sich Fuchs' Erziehungskonzept - so das Gerücht - in der rhythmischen Erziehungsanstalt Dalcrozes widerspiegeln. Und Fuchs' Erziehungskonzept war ein wichtiger Bestandteil für den Erfolg der Erneuerung der Schaubühne und somit auch derjenigen der Kultur.

Auch wenn in der russischen Ausgabe lediglich auf Wedekinds Schrift verwiesen wird und dort die im deutschen Text zitierten Wedekind-Abschnitte fehlen: Man muss davon ausgehen, dass der Schriftsteller im Allgemeinen und seine Mine-Haha im Besonderen russischen Kulturschaffenden um 1911 ein Begriff waren. Wesentliche Teile des Mine-Haha-Fragments entstanden bereits 1895, und Fuchs bezieht sich im Tanz auf die Kapitel 1 bis 3, die 1901 in der Münchner Jugendstilzeitschrift Die Insel veröffentlicht worden waren. Erst die 1903 erschienene zweite, erweiterte Ausgabe, der Wedekind noch ein viertes Kapitel sowie Vor- und Nachwort hinzufügte, erzielte dann eine weitreichendere Wirkung. ${ }^{552}$ Darauf, dass diese bis nach Russland reichte, verweist

551 Paul Friedrich: Frank Wedekind (Der moderne Dichter, Bd. 1), Berlin 1913, S. 22. Der deutsche Musik- und Kunsthistoriker Oscar Bie bringt Wedekinds Mine-Haha bereits 1907 in die Nähe der Dalcroze-Erziehungsanstalt. Vgl. Oscar BIE: „Tanzschule“, in: Die neue Rundschau 18/1 (1907), S. 638-639, hier S. 639 .

$55^{2}$ Vgl. Schümann, Die Suche nach dem ,neuen Menschen', S. 2O-29. Zur Entstehungs- und Publikationsgeschichte der Mine-Haha vgl. auch Kutscher, Frank Wedekind, S. 126; Walter Schmitz und Uwe Schneider: „Editorische Nachbemerkung, in: Frank Wedekind: ,Mine-Haha oder Über die körperliche Erziehung der jungen Mädchen', Frankfurt a.M. und Leipzig 1994, S. 92-96; Hafemann, Schamlose Tänze, S. 61-63. 
der russische Revolutionär und Theoretiker Lev Trockij in einem 1908 veröffentlichten Artikel, der in der deutschen Zeitschrift Die neue Zeit erschien und in dem er sich eingehend mit der Erzählung beschäftigt:553

[...] wir leben in einer Zeit des sich immer mehr vertiefenden Internationalismus. Die russische Intelligenz hat in kaum einem Jahre Wedekind eine Popularität verschafft, deren er sich in seinem Vaterlande nicht erfreut. 554

Eine umfassende Untersuchung der Wedekind- bzw. Mine-Haha-Rezeption in Russland zu Beginn des 20. Jahrhunderts steht noch aus. Der deutsche Slawist Daniel Schümann vermutet aber, dass in den russischen Metropolen Moskau und Sankt Petersburg jene breite Wedekind-Rezeption, auf die auch Trockij rekurriert, spätestens nach der ersten russischen Aufführung von Wedekinds Frühlings Erwachen (im Herbst 1907 in Sankt Petersburg) einsetzt. ${ }^{555}$ Sollten nun also Stravinskij, Nižinskijund Djagilev um 1911 Wedekind und insbesondere sein Mine-Haha-Fragment gekannt haben, ist es sehr wahrscheinlich, dass sie auch von einem eventuellen Zusammenhang zwischen Mine-Haha und dem Dalcroze-System gehört hatten. Im Falle Stravinskijs ist dies umso wahrscheinlicher, als er in jenem Brief, in dem er auf Fuchs verweist, im Postskriptum vermerkt: „Не читай статью кн. Волконскаго в № 6 ,Аполлона' - не стоит.“556 („Lies nicht den Artikel von Volkonskij in der 6ten Nummer des ,Apollon'. Es lohnt sich nicht.") Er rät Rimskij-Korsakov also davon ab, einen Text des russischen Musik- und Theaterpädagogen Sergej Volkonskij zu lesen, der kurz zuvor in der Sankt Petersburger Kunstzeitschrift Apollon erschienen war und

553 Vgl. Daniel SchümanN: „Zum Begriff und zur Denkfigur ,neuer Mensch‘ um 1900. Beobachtungen zu Texten von M.P. Arcybašev, Z.N. Gippius, S. Przybyszewski und F. Wedekind“, in: Russische Begriffsgeschichte der Neuzeit. Beiträge zu einem Forschungsdesiderat, hg. von Peter Thie RG en unter Mitarb. von Martina Munk, Köln, Weimar und Wien 2006, S. 369-394, hier S. 377. Zum genannten Trockij-Artikel vgl. Lev TrocKIJ: „Frank Wedekind“, in: Die neue Zeit. Wochenzeitschrift der deutschen Sozialdemokratie 28 (1908), S. 63-70. Trockij hatte 1904 einige Monate in München gelebt, „das damals als die demokratischste und künstlerischste Stadt Deutschlands galt. [Dort habe er] die bayrische Sozialdemokratie, die Münchner Galerien und die Zeichner des ,Simplicissimus' recht gut kennengelernt." Vgl. Leo Trozкі: Mein Leben. Versuch einer Autobiographie, autorisierte Übersetzung nach dem Manuskript von Alexandra RAмm, Berlin 1929, S. 103 .

554 Trockij, „Frank Wedekind“, S. 63.

555 Vgl. Schümann, Die Suche nach dem, neuen Menschen', S. 24-31.

556 Brief von Stravinskij an Andrej Rimskij-Korsakov vom 24. September/7. Oktober 1911, S. 301. 
in dem es um die von Dalcroze damals erst jüngst eröffnete Bildungsanstalt für Musik und Rhythmus in Hellerau ging. ${ }^{557}$

Unbestritten bleibt, dass sich Stravinskij, Djagilev und Nižinskij ab 1911 vermehrt mit theaterreformatorischem Gedankengut auseinandersetzten. Es ist davon auszugehen, dass es ihnen weniger darum ging, einzelne Theorien oder Reformmodelle eins zu eins zu verwirklichen; vielmehr nutzten sie das Theorienkonvolut als Inspirationsquelle für ihre eigenen Ideen und mischten Teile daraus mit ästhetischen Idealen, die die Ballets Russes bereits zuvor vertreten hatten. Auf diese eigenen Ideen verweist Kessler, wenn er in seinem Tagebuch davon berichtet, dass Stravinskij und Craig sich persönlich getroffen hätten. Denn: Dass Stravinskij zwischen seinen Plänen und den Reformansätzen Craigs eine gewisse Verwandtschaft verspürte, impliziert schließlich auch, dass er seine eigenen Pläne klar von denen von Craig abgrenzte. Im Hinblick auf die steinbruchartige Verwendung der Reformideen erweist sich eine weitere Angabe Kesslers als aufschlussreich. Dieser berichtet auch, dass Stravinskij sich vorgenommen hätte, in seiner Musik alles auf den Rhythmus zu reduzieren, auf den sich suggestiv die Gebärde aufbauen solle. ${ }^{558}$ Exakt in diesem Punkt fühlte er sich mit Craig verwandt, der auf der Bühne alles auf die einfachsten und suggestivsten Elemente zu reduzieren gedachte. Bei genauerer Betrachtung ist es wieder eine Fuchs'sche Forderung, die Stravinskij hier verwirklichen wollte: Indem Fuchs Duncan kritisierte und zu ihrer Überwindung aufrief, forderte er schließlich unter anderem auch implizit dazu auf, dass sich die Rhythmen der Musik in den Bewegungen auf der Bühne wiederfinden sollten. ${ }^{559}$

Als Stravinskij die Arbeit am Sacre wiederaufnahm, hatte er sich mit großer Wahrscheinlichkeit also vorgenommen, die von Fuchs im Tanz geforderten neuen (Tanz-)Formen zu verwirklichen und als erstes „künstlerisches Individuum" das von den Reformern geforderte Theater der Zukunft umzusetzen: Fuchs zielte auf eine gesteigerte Kultur des Körpers ${ }^{560}$ und hatte als ideale Vermittlungsinstanz dafür die Schaubühne auserkoren. Auf ihr sollte die selbstständig schöpferische Frau in einer neuen Form tanzen, um damit

557 Vgl. Sergej Volkonskij: „Čelovek i ritm. Sistema Žaka Dal'kroza“, in: Apollon 6 (1911), S. 33-5o. Varunc nennt Volkonskij als ersten Autor, der in Russland über Dalcroze berichtete. Vgl. Varunc, Perepiska, Bd. 1, S. 302.

$55^{8}$ Vgl. Kapitel III.1.1.2. Der genannte Tagebucheintrag von Harry Graf Kessler vom 23. Mai 1912 ist dort zitiert.

559 Vgl. Fuchs, „Der Tanz“, S. 17

56o Vgl. ebd., S. 41: „Die Entdeckung des eigenen Körpers bedeutet für eine Rasse den Empfang eines Kunstgesetzes, die Geburt eines Kulturprinzips.“ 
zum Vorbild für die künftige Kultur zu werden. ${ }^{561}$ Ihr neuer Tanz sollte völlig frei von Vorbildern und aus dem unbewussten Inneren heraus entstehen und in den Bewegungen die von der Musik ausschwingenden Rhythmen widerspiegeln. ${ }^{562}$ Auch andere Reformkonzepte wurden im Ballets-RussesKreis rezipiert und diskutiert - darunter Craigs umstrittenes Konzept der Über-Marionette und der damit verbundene Aspekt der Kontrolle des Regisseurs über das Bühnengeschehen. Dieser Kontrollaspekt spielte höchstwahrscheinlich auch für Nižinskijs Herangehensweise an die Choreografie eine Rolle. Glaubt man den Ausführungen seiner Schwester Bronislava Nižinskaja, die den Sacre-Probenprozess von Anfang an begleitet hatte, forderte Nižinskij von den Tänzern eine ganz präzise Ausführung der von ihm vorgegebenen Bewegungen, mit denen er Stravinskijs Musik exakt nachgezeichnet hatte:

Nijinskij's creation of a novel structure in the choreography and his innovative movements and poses demanded an exactness of execution to the minutest detail. All this was strange and unfamiliar to the artists brought up in the traditions of the old classical ballet [...]. Sometimes when they were so tired and exhausted by the long rehearsals they refused altogether to work with Nijinsky. [...] Often Diaghilev had to intervene, mostly to calm Nijinsky, who did not understand that certain of his created ,pas-movements', which he demonstrated with such ease in a huge jump, were not possible for the average dancer. Nijinsky was indignantly angry, believing that this inability of an artist to repeat the ,pasmovement' after him was a deliberate act of obstruction, and he accused the artists of wanting to sabotage his ballet. I remember one particular incident during the early rehearsals in Monte Carlo. Nijinsky demonstrated a ,pas-movement' in the choreography to the musical count of 5/4. During his huge leap he counted $5(3+2)$. On count 1 , high in the air, he bent one leg at the knee and stretched his right arm above his head, on count 2 he bent his body towards the left, on count 3 he bent his body towards the right, then on count 1, still high in the air, he stretched his body upwards again and then finally came down lowering his arm on count 2, graphically rendering each note of the uneven measure. Nijinsky worked in this manner on each measure, accenting the beats for the artists, and

561 Vgl. ebd., S. 4 O.

562 Vgl. ebd., S. 17. Brandstetter beschreibt den Tanz der Auserwählten als einen Tanz, der für das zeitgenössische Publikum nicht mehr als ,Tanz' identifizierbar gewesen sei und führt dann (mit Rekurs auf den Rekonstruktionsversuch) aus: „Sie steht lange und unbeweglich in der Kreismitte, sie steht mit einwärts gedrehten Füßen, mit tief gebeugten Knien, mit seitwärts geknicktem, auf die Hand gestütztem Kopf [...]. Während die Gruppe den Ring um sie zieht, beginnen die Beine zu zittern. Das Zittern geht in ihren ganzen Körper über, ein Schütteln wie in einem Krampf. Zuletzt springt sie in der Mitte des Kreises immer wieder in die Vertikale, und zwar mit seitlich geknicktem Kopf; d.h. in einer Haltung, die durch diesen Achsenbruch völlig in die Desorientierung treibt. Sie springt, bis sie zusammenbricht - im körperlichen Vollzug des Opfers als Selbstopfer. [...] - im Verein mit Strawinskys rhythmischen Exaltationen." Brandstetter, „Grenzgänge II“, S. 14. 
would not proceed in his composition until he obtained from each artist the exact execution. ${ }^{563}$

Mit Nižinskij als Relais hatte Stravinskij die Bewegungen auf der Bühne über seine Musik in der Hand. Und vor dem Hintergrund der dargelegten Reformüberlegungen leuchtet dies auch in höchstem Maße ein. Denn: Sind es nicht die unvorhersehbaren Rhythmen der Musik, die im letzten Tanz des Sacre, der Danse sacrale, die Bewegungen der Jungfrau bestimmen? Und sind es nicht genau diese Rhythmen, die das gesamte „Choreodrama“ mit Vorhangöffnung [einen Takt vor Ziffer 13] von Anfang an definieren? Eine finale Antwort liefert womöglich nur die Musik selbst.

\section{Realisierung „Neuer (Tanz-)Formen“: Die Danse sacrale als} Fallbeispiel

Where the ,Firebird' had been a ballet ruled by the choreographer, ,Petrushka represented the first time that Stravinsky, in Lincoln Kirstein's memorable phrase, ,made music, not to serve dance, but to control it'. This radical, indeed subversive departure transformed ballet forever. [...] The music of ,Petrushka' accomplished another feat as well. Through it, Stravinsky at last became Stravinsky. To study the creative history of this great ballet, then, will be in large measure to witness Stravinsky's process of self-discovery. ${ }^{564}$

Mit diesem Passus endet Taruskin in Stravinsky and the Russian Traditions den einleitenden Abschnitt zum Pétrouchka-Kapitel „Punch into Pierrot“. Seine These: Mit Pétrouchka wurde Stravinskij zu Stravinskij; vor allem auch durch die

563 Nijinska, Early Memoirs, S. 46o. Claudia Jeschke, die sich eingehend mit Nižinskij und dessen Bewegungssprache und -notation beschäftigt hat, konstatiert bezüglich der Notation insbesondere Folgendes: „Read as choreographic philosophy, Nijinsky's notation concentrates on the body's capability for rhythmic and motoric coordination. His physiological manner of dealing with time and energy approaches the understanding of rhythm found in Stravinsky's ballets scores [...]. Nijinsky's interest in dance notation can be generally subsumed among the conditions of control and vitality, as it combines an analytical, systemic, and thus controlled view of corporeality and action with newly invented movements generated through the perception of physical and cultural energy. [...] He manipulated the body in time (music) and space with his dance notation, treating it as a movement machine and thereby opening up the dancing body to distinctively different and individual kinetic utterances that resist aesthetic codification." Claudia JEsCHKE: ,.... retrouver la source de variété ...': Nijinsky's Choreographic Textures“, in: Avatar of Modernity, hg. von Danuser und Zimmermann, S. 130-152, hier S. 142-151.

564 Taruskin, Stravinsky and the Russian Traditions, Bd. 1, S. 662. 
Begegnung mit Benua ${ }^{565}$ entwickelte er hier die für seine Werke so typischen „essential characteristics“566 nepodvižnost', drobnost' und uproščenie, die sich in ihrer Kombination dann erstmals vollständig im Sacre manifestierten. ${ }^{567}$ Glaubt man Lincoln Kirstein, dem Mitbegründer des New York City Ballet, brachte diese von Taruskin beschriebene Individuation Stravinskijs mitunter auch mit sich, dass seine Musik dem Tanz nicht mehr bloß diente, sondern ihn vielmehr kontrollierte. ${ }^{568}$ Dies lässt aufmerken. Denn wurde eine Kontrolle des Bühnengeschehens nicht von jenem Reformkreis diskutiert, mit dem sich Benua seit spätestens 1908 auseinandergesetzt hatte? Und spielte der Aspekt der Kontrolle bei Benuas und Stravinskijs gemeinsamer Arbeit Pétrouchka nicht auch eine essenzielle Rolle?569

Nepodvižnost' übersetzt Taruskin mit „immobility“570 und verweist damit auf die für Stravinskij so typischen Ostinatostrukturen, Wiederholungen und Reihungen. ${ }^{571}$ Drobnost' ("this quality of beeing a sum of parts“572) hingegen findet sein kompositorisches Äquivalent in der vielfach beschriebenen Baukasten-, Schablonen- oder Montagetechnik - ebenjenem Spiel mit Motiven und Bausteinen, die immer wieder in verschiedener Weise miteinander kombiniert, parallel oder versetzt hintereinander oder übereinander gebracht werden und meist völlig unvermittelt enden. ${ }^{573}$ Mit dem Sacre - so schließt Taruskin einige Abschnitte später - würde Stravinskijs Musik „no longer meet the normative criteria traditionally deemed essential to coherent musical discourse ${ }^{\text {“574. }}$. Und fügt dann ferner noch hinzu:

565 Taruskin beendet den Abschnitt wie folgt: „The proper evaluation of Alexander Benois's role in facilitating that process, so scandalously slighted in Stravinsky's memoirs and in the immense parasitic literature his memoirs have spawned, will be one of the missions of the chapter." Ebd.

566 Ebd., Bd. 2, S. 1675 .

567 Vgl. ebd., Bd. 1, S. 951-966.

568 Vgl. Lincoln Kinstein: Four Centuries of Ballet. Fifty Masterworks, New York 1984, S. 194: „Stravinsky's stunning score [gemeint ist ,Pétrouchka'], following ,Firebird' (1910) marked him as the era's composer, the seminal influence on progressive choreography. Throughout his carreer, he has made music, not to serve dance, but to control it."

569 Vgl. Kapitel III.1.1.

570 Taruskin, Stravinsky and the Russian Traditions, Bd. 2, S. 1449.

571 Vgl. ebd., S. 1449 f.

572 Ebd., S. 1451.

573 Vgl. ebd., Bd. 1, S. 955-957. Für eine Beschreibung der Baukasten- bzw. Schablonentechnik vgl. unter anderem Scherliess, Art. ,Igor' Fëdorovič Stravinskij', Sp. 147; Volker SCHE RLIESS: Igor Strawinsky und seine Zeit, Laaber 1983, S. 102-154.

574 Taruskin, Stravinsky and the Russian Traditions, Bd. 1, S. 9566. 
There would be no harmonic progression, no thematic or motivic development, no smoothly executed transitions. His would be a music not of progress but of state, deriving its coherence and its momentum from the calculated interplay of ,immobile‘ uniformities and abrupt discontinuities. ${ }^{575}$

Schon allein in Anbetracht der hier deutlich werdenden Sonderstellung des Sacre innerhalb der Musikgeschichte des 20. Jahrhunderts überrascht nicht, dass er zum Gegenstand zahlreicher musiktheoretischer Betrachtungen wurde. Zum 10o. Jubiläum der Uraufführung fasste Jonathan Bernard alle bis dato erschienenen (und für ihn) nennenswerten musikwissenschaftlichen Sacre-Analysen zusammen und resümierte: „Nearly everyone, it seems, who has ever written analytically about Stravinsky has written about Le Sacre at one time or another.“576 Den bereits existierenden analytischen Arbeiten soll hier keine weitere erschöpfende Sacre-Analyse hinzugefügt werden. Vielmehr sollen Stichproben am Werk eruieren, ob und inwiefern sich die dargelegten Bezüge zwischen Ballets Russes und Theaterreform sowie die daraus gewonnenen historiografischen Erkenntnisse im Notentext wiederfinden. Aufgrund des interdisziplinären Ansatzes bietet es sich an, insbesondere auf jene analytischen Ansätze zurückzugreifen, die sich Musik und Tanz in gleichem Maße widmen. Allein, das Gros jener Musiktheoretiker, das sich mit dem Sacre beschäftigt, konzentriert sich ausschließlich auf die Musik; Extramusikalisches wie Choreografie und/oder Arbeitsweise des Choreografen klammern die allermeisten von ihnen nahezu aus. So widmete beispielsweise Pierre Boulez dem Sacre seinen einflussreichen Aufsatz Stravinsky demeure, in dem er sich intensiv mit dessen rhythmischer Struktur auseinandersetzt; ${ }^{577}$ und der amerikanische Musiktheoretiker Allen Forte konzentrierte sich auf die harmonische Disposition des Werks. ${ }^{578}$ Selbst Stravinskij-Experten wie Taruskin oder van den Toorn, die in ihren Studien auf die Wichtigkeit des außermusikalischen Kontexts für die Enstehung des Sacre verweisen, verzichten bei der Analyse auf ein Miteinbeziehen derChoreografie bzw. der dazu überlieferten Quellen. 579 Die kanadische Musikwissenschaftlerin Tamara Levitz hat dieses Verbannen des Außermusikalischen innerhalb des musiktheoretischen Sacre-Diskurses

575 Ebd.

576 Bernard, „Le Sacre' Analyzed“, S. 284.

577 Vgl. Boulez, „Stravinsky demeure“.

578 Vgl. Allen Forte: The Harmonic Organisation of,The Rite of Spring', New Haven 1978.

579 Vgl. Taruskin, Stravinsky and the Russian Traditions; van den Toorn, Stravinsky and ,The Rite of Spring' sowie Kapitel I.2.1. 
kritisiert und darauf aufmerksam gemacht, dass dieses Vorgehen (auch) zu Missinterpretationen geführt habe. ${ }^{580}$

Eine Musik und Tanz einende Analyse legte erstmals Stephanie Jordan vor. Mit choreomusikalischen Analysemethoden allgemein setzte sie sich schon in ihrer 2000 erschienenen Monografie Moving Music auseinander, bevor sie ihre darin gewonnenen Erkenntnisse 2007 in Stravinsky Dances insbesondere auf ,Nižinskijs' Sacre anwandte ${ }^{581}$ - also auf den Rekonstruktionsversuch von Millicent Hodson und nicht etwa auf das Original von Nižinskij, von dem ja nachweislich kaum etwas tradiert ist. ${ }^{582}$ Jordan liefert also keine tatsächliche musikchoreografische Analyse des Stravinskij-Nižinskij-Sacre. Dennoch erweisen sich einige ihrer theoretischen Überlegungen als aufschlussreich. Sie beschreibt nämlich zwei Faktoren, die für eine choreomusikalische Analyse des Sacre essenziell seien: zum einen die rhythmische Strukur des Werks und zum anderen die damit zusammenhängende Hörerfahrung des Tänzers bzw. Choreografen. Um diese Hörerfahrung zu verdeutlichen, rekurriert sie unter anderem auf Auszüge aus van den Toorns Monografie Stravinsky and,The Rite of Spring und begründet dies wie folgt:

[...] Van den Toorn's book on Sacre includes writing on rhythm that is directly useful to my work. [...] He addresses how we actually experience rhythm through time, which I would read as processes of cognitive psychology, as well as learning and education in listening to music. Alongside his typology of rhythmic structure, his analysis of how we perceive metre is especially important to choreomusical discussion of ,Sacre؛. Van den Toorn understands that we hold patterns, regularities within us, so that we sense disruptions as significant contributing factors to the energy and vitality within Stravinsky's music. Concomitantly, we also seek stability when the music is unstable. I content that we experience these metrical regularities and irregularities in choreography as much as in music, and that in some ,Sacres' $[\ldots]$ they are key point of contact between the two media $[\ldots] .^{583}$

58 o Vgl. Levitz, „The Chosen One's Choice“.

581 Vgl. Stephanie Jordan: Moving Music. Dialogues with Music in Twentieth-Century Ballet, London 2000; dies., Stravinsky Dances, S. 411-505.

582 Ebd., S. 423. Auch Levitz bezieht sich in ihrem Aufsatz „The Chosen One's Choice“ auf den von Hodson und Archer vorgelegten Rekonstruktionsversuch. Wie Jordan, die darauf hinweist, dass Hodsons Choreografie weniger eine veritable Rekonstruktion als vielmehr eine auf Quellenmaterial fußende choreografische Version darstelle, ist sich Levitz aber der Problematik der Rekonstruktion bewusst und gibt an, dass sie sich deshalb lediglich auf Gesten beziehe, die historisch dokumentiert seien. Vgl. Levitz, „The Chosen One's Choice“, S. 105, Anm. 74. Zum Rekonstruktionsversuch vgl. auch Kapitel I.2.2. und insbesondere die Anm. 94 und 97.

583 Jordan, Stravinsky Dances, S. 419. 
Van den Toorns Rhythmusanalyse könne sie gerade deshalb für ihre choreomusikalische Analyse nutzbar machen, weil dieser sich auch damit beschäftige, inwiefern der Hörer Rhythmus im Zeitverlauf vernehme. In der von ihm beschriebenen Wahrnehmung von Regularitäten und Irregularitäten erkennt Jordan einen auf musikalischer Bildung und Erziehung beruhenden kognitionspsychologischen Prozess, der auch in (einigen) Sacre-Choreografien erfahrbar würde.

Van den Toorn geht davon aus, dass man nur durch ein "conservative“584 Hören zu Erkenntnissen in Bezug auf die Unterbrechungen und Störungen in Stravinskijs Musik kommen könne. ${ }^{585}$ Ein von van den Toorn so bezeichneter "conservative listener" würde stets instinktiv nach Mustern oder Regularitäten in der Musik suchen, um dann so lange wie möglich an ihnen festzuhalten. Unterbrechungen oder Störungen der erwarteten Regularität seien für ihn also umso intensiver wahrnehmbar. ${ }^{586}$ In der von Jordan zitierten Studie definiert van den Toorn für den Sacre dann auch zwei sich quasi gegenüberstehende

584 Van den Toorn, Stravinsky and ,The Rite of Spring', S. 67. Van den Toorn unterscheidet zwischen einem „conservative“ und einem „radical listener“ bzw. Interpreten von Stravinskijs Musik und bezieht sich in der Begriffswahl auf Andrew Imbrie: „Extra Measures and Metrical Ambiguity in Beethoven", in: Beethoven Studies, Bd. 1, hg. von Alan Tyson, New York 1973, S. 45-66. ",[R]adical' interpreters“ erkennt van den Toorn beispielsweise in Pierre Boulez, Theodor W. Adorno, Cecil Gray und Constant Lambert. Sie würden in ihren Analysen dazu neigen, die von ihm thematisierte Wahrnehmung von Irregularitäten zu ignorieren: „[...] like earlier critics Boulez takes the irregular or shifting meters as face value. Indeed, his extensive analysis of rhythm in ,The Rite' includes no mention at all of the role of steady metric periodicity, even though steady meters govern much of the music in Part I with, by and large, their traditional hierarchical implications intact. [...] Boulez tends therefore to ignore the grain against which the disruptive effect of the invention is felt." Van den Toorn, Stravinsky and ,The Rite of Spring', S. 67.

585 Vgl. hierzu Jordan, Stravinsky Dances, S. 576; van den Toorn, Stravinsky and,The Rite of Spring', S. 67 .

586 Vgl. ebd. van den Toorn macht darauf aufmerksam, dass Kritiker auch schon vorher auf ein körperliches Empfinden der Unterbrechungen und Störungen aufmerksam gemacht haben, diese aber negativ bewerteten. Als beispielhaft für diese frühe (negative) Sacre-Rezeption nennt er die „,radical' interpreters“ Cecil GraY: A Survey of Contemporary Music, London 1924 und Constant Lambert: Music Ho! A Study of Music in Decline, London 1934. Vgl. van den Toorn, Stravinsky and ,The Rite of Spring', S. 57f. Auch wenn jene Autoren heute kaum mehr beachtet werden, sieht er in ihren kritischen Äußerungen einen Ausgangspunkt für alle später folgenden kritischen Bewertungen von Stravinskijs Kompositionsweise - miteingeschlossen Adornos Bemerkungen in dessen Philosophie der Neuen Musik, in der er die unvorbereitet einsetzenden Akzentverschiebungen im Sacre als „konvulsive [...] Stöße und Schocks“ beschreibt. Vgl. van den Toorn, Stravinsky and ,The Rite of Spring', S. 58-63; Theodor W. Adonno: Philosophie der neuen Musik (Theodor W. Adorno. Gesammelte Schriften, Bd. 12), hg. von Rolf Tiedemann unter Mitwirkung von Gretel Adorno u.a., Frankfurt a.M. 2003. In diesem Kontext vgl. auch 
rhythmisch-metrische Strukturprinzipien, die er als Type I und Type II bezeichnet. Ausgerechnet in deren Verhältnis von Regularität und Irregularität sieht er ein wichtiges Differenzierungsmerkmal:587 Type I zeichne sich insbesondere durch eine im Vordergrund stehende metrische Irregularität aus, die sich meist durch ein unregelmäßiges oder ständig wechselndes Metrum offenbare. Im Sacre erkenne er Type I deshalb in Jeu du rapt [Ziffer 37 bis 48], Jeux des cités rivales [Ziffer 57 bis 67], Glorification de l'élue [Ziffer 104 bis 121] oder der Danse sacrale [ab Ziffer 142]; hier würden sich dann meist "two or more blocks of contrasting material [...] in constant and often rapid juxtaposition “588 abwechseln. Type II zeichne sich hingegen in erster Linie durch eine vordergründige Regularität aus, die aus einem eher statischen Metrum resultiere. ${ }^{589}$ Dieser Typus manifestiere sich insbesondere in Les augures printaniers [Ziffer 13 bis 37], Cortège du sage [Ziffer 67 bis 71] oder der Danse de la terre [Ziffer 72 bis 79]; hier würden weitgehend zwei oder mehr wiederkehrende „periods, cycles, or spans“ überlagert werden, „that [...] vary independently of $[\ldots]$ one another" ${ }^{490}$. Die Störung bzw. Verschiebung ereigne sich bei Type I und $I I$ also an einer jeweils anderen Stelle: Würden bei Type I die einzelnen Motive, Linien oder Teile alle denselben irregulären Perioden unterliegen und derart synchron nur vertikal bzw. harmonisch voranschreiten, unterlägen die jeweiligen Motivwiederholungen in Type II einer unterschiedlichen Periodizi-

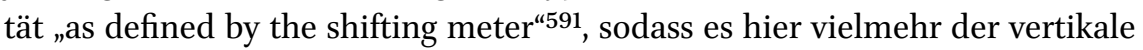
bzw. harmonische Zusammenfall wäre, der einer konstanten Änderung bzw. Verschiebung unterliegt. ${ }^{592}$ Dennoch seien aber sowohl Type I als auch Type II immer sowohl Regularität als auch Irregularität inhärent, sodass beide am ehesten mit einem "play“ zwischen "fixed metric identity“ und "displacement" charakterisiert werden könnten. ${ }^{593}$

Jordans Ausführungen zu Adornos Stravinskij-Rezeption in Jordan, Stravinsky Dances, S. 97-107.

587 Vgl. van den Toorn, Stravinsky and,The Rite of Spring', S. 99-101.

588 Ebd., S. 99.

589 Die Beschreibungen von Type I und Type II findet sich ebd., S. 97-114.

590 Ebd., S. 100.

591 Ebd., S. 102.

592 Vgl. ebd., S. 101.

593 Vgl. ebd. Die amerikanische Musiktheoretikerin Gretchen Horlacher macht darauf aufmerksam, dass Begriffe wie "block“ oder "superimposition“, die für Stravinskijs Kompositionstechnik sehr oft verwendet werden, dazu beitragen würden, dass Stravinskijs Musik häufig als „broadly discontinious, static, or deadlocked“ beschrieben werde. In Building Blocks zeigt sie aber auf, dass die Einzigartigkeit der Stravinskij'schen „repetitions“ gerade in der Verschmelzung von Elementen liege, die sowohl „stasis 
Interessant ist nun, dass Jordan die von van den Toorn beschriebenen Störmomente in der Musik als Schlüssel ihrer interdependenten Sacre-Analyse benennt:594 Diese Störungen seien nicht nur zentrale Berührungspunkte der beiden Medien Musik und Choreografie, sondern auch verantwortlich dafür, dass Energie und Vitalität der Musik an den Hörer weitergeleitet würden. 595 Bezeichnenderweise erinnert sie damit an die Fuchs'sche Forderung, dass sich die von der Musik ausgehenden Rhythmen im Tanz widerspiegeln sollten. Und mit ihrer Aussage, „we sense disruptions as significant contributing factors to the energy and vitality of Stravinsky's music", benennt sie im Grunde, was in der vorliegenden Arbeit unter den Begriff Gemeinschaftsrausch subsumiert wurde. Gerade Rausch und Körperlichkeit, wie sie sich auf der Bühne manifestierten, sollten ja auf den Zuschauerraum bzw. das Publikum übertragen werden. Und so weisen Jordans musikchoreografische Überlegungen zum Sacre zumindest im Ansatz Parallelen zu jenen Reformpunkten auf, die Stravinskij und Nižinskij zwischen 1911 und 1913 immer wieder thematisiert und - wie in Kapitel III.1.1. und III.1.2. gezeigt - zu ihrem ästhetischen Programm erkoren hatten:

1. Die Macht des Regisseurs über das Bühnengeschehen, wie Gordon Craig sie diskutierte - Stravinskij und Nižinskij strebten deshalb nach der Kontrolle der Bewegungen durch die Rhythmen der Musik.

2. Das Schaffen neuer (Tanz-)Formen ohne Vorbilder, wie Georg Fuchs sie forderte - sie sollten sich im Zustand der Hypnose entwickeln und die Rhythmen der Musik widerspiegeln.

3. Das Integrieren des (Theater-)Publikums ins Bühnengeschehen - in einem Gemeinschaftsrausch sollte der Zuschauer zu einer gesteigerten Körperlichkeit erzogen werden und damit die Gesellschaft zu einer neuen Kultur.

Musikalisch disruptive und den Zuhörer bzw. Zuschauer (ver-)störende Momente, wie sie unter anderem van den Toorn und Jordan für den Sacre beschreiben, finden sich auch in Stravinskijs Pétrouchka-Russkaja und sind - wie in Kapitel III.1.1. diskutiert - insbesondere auf seine und Benuas Beschäftigung mit der Theaterreform zurückzuführen: Durch das musikalische Vexierspiel konnten nicht nur die Tänzer auf der Bühne mittels der Musik kontrolliert, sondern außerdem auch das Theaterpublikum in das Bühnengeschehen integriert werden. Anders als in der Russkaja, in der sich die disruptiven

or discontinuity“ als auch „activity and continuity“ erfahrbar machten. Vgl. Gretchen G. HORLACHE R: Building Blocks. Repetition and Continuity in the Music of Stravinsky, New York 2011, S. vii-ix.

594 Vgl. Jordan, Stravinsky Dances, S. 419.

595 Vgl. ebd. 
Elemente zu Beginn nur vorsichtig andeuten und im Verlaufe des Stücks aus der vordergründig Regelmäßigkeit suggerierenden Anlage hervortreten, sind nun im Sacre regelmäßige und unregelmäßige Strukturen von Anfang bis Ende immer gleichzeitig präsent. Abschnitten mit besonders intensiven Unregelmäßigkeiten wie beispielsweise den Augures printaniers [insbesondere Ziffer 13 bis 22] stehen stets solche entgegen, bei denen die Unregelmäßigkeiten stark zurückgenommen sind - so etwa in den Rondes printanières [insbesondere Ziffer 48 bis 54] - und im Gesamtverlauf deshalb regelmäßiger wirken. Taruskin erkennt in diesem Spiel zwischen Regularität und Irregularität den Motor der gesamtformalen Steigerung des Sacre, wenn er das Prinzip der „accumulation“596 als richtungsweisende Verfahrensweise bezeichnet, auf dem das gesamte Ballett aufgebaut sei: Beide Teile (Bild I und II) würden nicht nur als Ganzes, sondern auch für sich allein genommen eine Steigerung erfahren, indem sie jeweils leise und zurückgenommen beginnen und ekstatisch enden. Hervorgerufen würde diese Ekstase zum einen durch eine stetig ansteigende Spannung, die aus Erwartung einer drohenden Änderung nach einer längeren Zeit gleichbleibender musikalischer Bewegung eintritt, und zum anderen durch eine sukzessiv ansteigende Lautstärke, die aus der Übereinanderschichtung immer wieder neuer Elemente und Motive resultiert.597

Nimmt man an, dass Tänzer und Publikum im Sacre (wie in Pétrouchka) durch die Erfahrung der Irregularitäten tatsächlich kontrolliert bzw. in das Bühnengeschehen integriert werden sollten, könnte die Erfahrung der Regularitäten dazu dienen, bei Tänzern und Publikum jenen hypnotischen $\mathrm{Zu}$ stand herzustellen, den sich Fuchs für die Ausführung der neuen Tanzformen gewünscht hatte. Gerade dann wären das Spiel zwischen Unregelmäßigkeit (Kontrolle) und Regelmäßigkeit (Hypnose) sowie die durch deren Steigerung hervorgerufene Ekstase nachvollziehbar: Auf das Publikum sollte schließlich nicht nur der Rhythmus der Musik übertragen werden, sondern auch jener unbewusste Zustand, in dem die Tänzer auf der Bühne die Bewegungen ausführten. Nur in einer Symbiose von Kontrolle (Unregelmäßigkeit) und Hypnose (Regelmäßigkeit) konnte schließlich der geforderte Gemeinschaftsrausch entstehen.

In besonderem Maße wird das Zusammenspiel von Kontrolle, Hypnose und Gemeinschaftsrausch im abschließenden Tanz des Sacre nachvollziehbar - jenem Tanz, in dem das namensgebende Opfer vollzogen wird: in der Danse sacrale. Der inhaltliche Kulminations- und zugleich Endpunkt des Choreodramas, der Erschöpfungstod der Jungfrau, äußert sich auch

596 Taruskin, Stravinsky and the Russian Traditions, Bd. 1, S. 597.

597 Vgl. ebd., S. 857 . 
musikalisch. ${ }^{598}$ Insgesamt besteht die Danse sacrale aus 275 Takten und ist durch eine rondoartige Anlage in fünf unterschiedlich lange Teile gegliedert: A - B - A' - C - A'. Sie alle tragen zur gesamtformalen Steigerung bei, die am Ende des abschließenden Teils A" ihren Endpunkt findet: A [Ziffer 142 bis 148] beginnt (nach einem Eröffnungsakkord über $e s$ ) mit einem Klang auf $d$, besteht aus 33 Takten und kehrt als Formteil insgesamt zweimal wieder - zunächst als vollständige Wiederholung A' [167 bis 173]) (33 Takte) um einen Halbton nach unten transponiert; am Ende dann stark modifiziert und in ausgedehnter Form A" [Ziffer 186 bis 201] (73 Takte), beginnend mit einem Klang auf $a$ und endend auf $d$. Zwar trennt A derart, rondotypisch, die kontrastierenden und in der Steigerung jeweils zurückgenommeneren Formteile B [149 bis 166] (88 Takte) und C [174 bis 185] (54 Takte) voneinander, kehrt in seiner Ursprungsform allerdings an keiner Stelle wieder. Eine (reguläre) Reprise im eigentlichen Sinne - beginnend also mit einem Klang auf $d$ - ereignet sich lediglich andeutungsweise, und zwar durch einen siebentaktigen Einschub $\mathrm{A}^{1}$ [Ziffer 18o bis 181], durch den wiederum das kontrastierende Couplet $C$ unterbrochen wird.

An dieser großformalen Anlage als Quasirondo wird ein ästhetisches Prinzip deutlich, das sich in der Danse sacrale von Anfang bis Ende auf unterschiedlichen Ebenen manifestiert und sich aufgrund der Steigerungsform im Verlauf des Tanzes auch intensiviert: das Verzahnen und Gegeneinanderausspielen von regulären und irregulären Strukturen, wobei Regularität immer mit Irregularitäten konfrontiert und/oder Irregularitäten in Regularität überführt werden.

So beginnt der A-Teil der Danse sacrale bei Ziffer 142 mit einem synkopenartig und im staccatissimo und forte einsetzenden dissonanten Akkord über es (zuvor genannter Eröffnungsakkord), der aufgrund der direkt daran anschließenden Pause mit Fermate vom Hörer auch als abschließender Akkord des vorangehenden Teils wahrgenommen werden kann. In seiner Funktion also nicht eindeutig bestimmbar und somit irregulär, wird er bzw. sein Material nach der Fermate [einen Takt nach Ziffer 142] dann allerdings in eine regelmäßige viertaktige Bewegungsstruktur überführt (Motiv a; siehe unpag. Tafelteil, Notenbeispiel 3), die bei Ziffer 143 noch einmal vollständig - also ebenfalls ganz regulär - wiederholt wird.

598 Scherliess hat die Danse sacrale deshalb auch mit der „Summe des bisher Gehörten“ beschrieben: Alles, was den Sacre von Anfang an bestimmt, würde am Ende des Balletts noch einmal in potenzierter und konzentrierter Form erlebbar. Vgl. Scherliess, Igor Strawinsky. Le Sacre du printemps, S. 78. 
Diese auf formaler Ebene sicht- und hörbare regelmäßige Struktur des Motivs wird bei näherer Betrachtung auf gleich zwei Ebenen manipuliert und in eine Irregularität überführt: einerseits motivintern - und zwar in sowohl rhythmischer als auch klanglicher Hinsicht -, andererseits durch die Fortführung des Motivs auf der eben beschriebenen formalen Ebene selbst. Rhythmisch kann a als ein zusammengesetztes Motiv aus den Elementen $\mathrm{a}_{1}$ und $a_{2}$ beschrieben werden, die zumindest gemeinsam betrachtet einigermaßen irreguläre Strukturen aufweisen. So besteht $\mathrm{a}_{1}$ aus einem im staccatissimo gespielten 16tel-Impuls der Kontrabässe auf der ersten Zählzeit des 2/16-Taktes [einen Takt nach Ziffer 142], auf den dann Holzbläser, Hörner und Streicher mit drei synkopischen Schlägen [Takt 1 und 2 nach Ziffer 142] (im staccatissimo gespielt) reagieren. Diese drei aufeinanderfolgenden synkopischen Schläge brechen ein regelmäßiges Betonungsschema gewissermaßen per se auf. Doch die auf rhythmischer Ebene für den "conservative listener" wahrnehmbare Irregularität äußert sich nicht (nur) durch diese Synkopierung, sondern (vor allem) durch die crescendierte Überbindung des dritten Schlags [drei Takte nach Ziffer 142] auf die erste Zählzeit des vierten Takts nach Ziffer 142: Der zunächst angenommene rhythmische Höhepunkt des Motivs (auf dem dritten Synkopenschlag) wird derart auf die erste Zählzeit des folgenden 2/8-Taktes [einen Takt vor Ziffer 143] verschoben. Und so folgt dem bereits akzentuierten Schlag eine weitere Amplificatio auf der ersten Zählzeit des Folgetaktes. An diesen quasi nachgeschobenen rhythmischen Höhepunkt schließt dann das zweite Motivelement $\mathrm{a}_{2}$ an, das seinerseits aus drei absteigenden staccatissimo 16teln besteht. Auf klanglicher Ebene äußert sich die Manipulation der vordergründigen Regularität noch etwas deutlicher: Zwar wird der Eröffnungsakkord zu Beginn von a insgesamt dreimal (also regulär) wiederholt; im Detail betrachtet bilden diese drei Motivakkorde aber drei unterschiedliche Klänge: Während der erste Motivakkord (ein Takt nach Ziffer 142) noch eine exakte Wiederholung des Eröffnungsakkords darstellt, besteht der zweite Motivakkord (zwei Takte nach Ziffer 142) nur noch aus dem gleichen Tonvorrat, ihm wird aber das klangliche Fundament entzogen, da der zuvor tiefste Ton des Akkords - das es des Violincellos - nun in den Bratschen erklingt. Bei der dritten Wiederholung des Akkords bleibt dieses Mal zwar das es in den Bratschen beibehalten, es folgt nun aber der Einsatz von Hörnern und Posaune, die den Klang noch einmal intensivieren und die zuvor auf rhythmischer Ebene beschriebene crescendierte Überbindung in den Folgetakt verstärken.

Auf formaler Ebene evoziert die (regelmäßige) Wiederholung von a [Ziffer 143 bis vier Takte nach Ziffer 143] trotz beschriebener motivinterner Irregularitäten nun eine Erwartung betreffend den dritten Motiveinsatz a' [ein Takt vor Ziffer 144]. Mit ihr wird aber unmittelbar nach dem (dritten) Einsatz von 
a' gebrochen: Wie schon bei den zwei vorherigen Einsätzen beginnt a' zwar noch mit einem impulsgebenden Schlag der Kontrabässe, dem ein erster Synkopenschlag folgt, wird dann aber abgebrochen - und zwar durch eine fanfarenartige fünftönige Figur aus zwei 8teln und drei 16teln [Ziffer 144f.] (Motiv a', siehe unpag. Tafelteil Notenbeispiel 3 und 4).

Diese irregulär einsetzende Fanfarenfigur wird nach einem erneuten Einsatz von a [drei Takte vor Ziffer 145 bis Ziffer 145] bei Ziffer 145 noch einmal wiederholt. Dieses Mal allerdings mit kleinen Veränderungen und somit nicht regulär: Ihr zweiter Einsatz erfolgt losgelöst vom Impulsschlag, und die beginnenden zwei 8tel werden durch zwei 16tel ersetzt. Am Ende des A-Teils, nach einem erneuten Einsatz von a, wird schließlich auch das ,reguläre Anfangsmotiv in die Irregularität überführt: Spätestens ab Ziffer 146 verselbstständigen sich $\mathrm{a}_{1}$ und $\mathrm{a}_{2}$ (Impuls und synkopierte Schläge sowie drei absteigende 16tel) und werden in meist verkürzter und immer wieder veränderter Form unterschiedlich miteinander kombiniert, sodass sich der "conservative listener" bis zum Ende des A-Teils [Ziffer 149] ganz in der Unvorhersehbarkeit des musikalisch-rhythmischen Geschehens verliert. Ausgerechnet am (zumindest vorläufigen) Höhepunkt der akustischen Desorientierung tritt dann ein weiteres irreguläres Element auf: das Kleinterzmotiv $\mathrm{b}(d-f)$ in Kontrabass und Posaunen (Kleinterzmotiv b, siehe unpag. Tafelteil, Notenbeispiel 5), das bis zum Ende von A in unregelmäßiger Abfolge immer wiederkehrt.

In seiner Unregelmäßigkeit wird b in A' ab Ziffer 171 ganz regulär wiederholt wenn auch hier um einen Halbton nach unten transponiert als b' (cis-e). Mit dem Einsatz von A" erfährt dann aber auch dieses (irregulär auftretende) Motiv eine unerwartete Transformation: Nicht nur erklingt b" $(a-c)$ in A" bereits ab dem ersten Takt [Ziffer 186] und bleibt auch bis zum Ende des Teils präsent. Im Verlaufe von A" wird die unregelmäßige Abfolge seines Einsatzes vielmehr in eine regelmäßige Struktur übergeführt: Ab Ziffer 193 erklingt die Figur (mit nur einigen wenigen Ausnahmen) bereits in jedem Takt und spätestens ab Ziffer 199 dann in einer ganz regelmäßigen Abfolge von 2/16teln, die jeweils von einer 2/16tel-Pause unterbrochen werden.

In B wird ein Kontrast zu A erzielt, der schon im Notenbild sichtbar ist: Im Gegensatz zum forte-Akkordeinwurf des A-Teils beginnt das Couplet zurückgenommen, im piano bzw. pianissimo. Das zuvor nahezu taktweise wechselnde Metrum wird durch ein fast regelmäßiges Changieren von 3/8telund 2/8tel-Takten abgelöst, und mit Ausnahme von Ziffer 161 bis 162 wird der gesamte Teil von monoton wirkenden Akkordrepetitionen bestimmt: Während des gesamten Teils folgt jeweils einem 1/16tel- bzw. 2/32tel-Einwurf eine 1/16teloder 3/16tel-Pause (Akkordrepetitionen, siehe unpag. Tafelteil, Notenbeispiel 6). 
Indem die Akkordrepetitionen durch jeweils unregelmäßig auftretende und sich akkumulierende Motivfragmente überlagert werden, wird B in Intensität und Dynamik in insgesamt drei Schüben [Ziffer 149 bis Ziffer 153; Ziffer 153 bis Ziffer 162; Ziffer 162 bis Ziffer 167] gesteigert, wobei die Schübe jeweils am Ende abrupt ab- oder in sich zusammenbrechen. Während des ersten Schubs [Ziffer 149 bis 153] erklingen die Akkordrepetitionen lediglich in den tiefen Streichern (Violine II, Bratsche, Cello und Kontrabass), Hörnern und im Fagott und im pianissimo mit einem gleichbleibenden Klang über $g$. Bei Ziffer 151 wird die Gleichförmigkeit dann erstmals durch einen fanfarenartigen forte-Einwurf der Posaune gestört, der zwei Takte später - intensiviert durch einen Lauf der Violine I - noch einmal wiederholt wird, um direkt im Anschluss [ein Takt vor Ziffer 152] von den Trompeten aufgegriffen zu werden. Bei Ziffer $15^{2}$ werden die Akkordrepetitionen dann durch Violine I, Oboe und Klarinette gestört, die mit Triller und Liegetönen zunächst im piano einsetzen. Mit einem crescendierten Glissando und Lauf der Violinen und Flöten zwei Takte vor Ziffer 153 kommt der erste Schub zu einem vorläufigen Höhe- und zugleich Endpunkt. Im zweiten Schub sind Intensität wie Dynamik der aufkommenden Irregularitäten gesteigert. Nicht nur erfolgen die fanfarenartigen Einwürfe hier häufiger und anders instrumentiert, auch die (regulären) Akkordrepetitionen selbst werden in eine gewisse Irregularität übergeführt: Zunächst beginnen sie wieder in den tiefen Streichern, Hörnern und im Fagott mit einem Klang auf $g$. Dieses Mal allerdings im forte. Bei Ziffer 154 verschiebt sich der Klang dann aber zum ersten Mal um eine Quint nach oben auf $d$ und wird durch ein hohes $a$ " der Violine I intensiviert. Ein Takt nach Ziffer 155 folgt der erste fanfarenartige Einwurf - nun jedoch in Piccoloflöte, kleiner Klarinette und kleiner Trompete. Auch diesem Einwurf folgt eine kurzzeitige Verschiebung des Akkordklangs (zwei 32tel) drei Takte nach Ziffer 155. Ab Ziffer 157 häufen sich dann sowohl Akkordverschiebungen als auch Einwürfe und münden bei Ziffer 159 in ein repetitives rhythmisches wie klangliches Unisono im fortissimo. Dieses Unisono bricht bei Ziffer 161 in einer chromatischen Abwärtsbewegung im forte fortissimo in sich zusammen und führt erneut zu einem unvorbereiteten Schubende. B endet schließlich mit dem dritten Schub ab Ziffer 162. Erneut beginnen die Akkordwiederholungen in den tiefen Streichern sowie Hörnern und im Fagott, im piano bzw. pianissimo - jetzt allerdings mit einem Klang über $f$. Nun führen die unregelmäßig aufretenden Einwürfe, Läufe und Triller in Flöten, Oboe und Violine I bei Ziffer 165 in eine kreisende Quintolenbewegung der Flöten und Violine I, die von lang gehaltenen Trillern in den Klarinetten begleitet wird. Vergleichbar mit dem Ende der Pétrouchka-Russkaja könnte diese kreisförmige Figur nun endlos 
weitergeführt werden. ${ }^{599}$ Doch auch sie bricht wieder unvorbereitet ab - mit einem Glissando der genannten Instrumente einen Takt vor Ziffer 167.

Auch C bildet einen Kontrast zu A: Der Teil besteht mit Ausnahme der ersten elf Takte fast durchgängig aus 2/4tel-Takten; in Bass und Schlagwerk finden sich sogar durchgehende triolische Rhythmen. Akustisch sind die genannten Regelmäßigkeiten mit Beginn des Teils aber kaum wahrnehmbar. Erst ab Ziffer 177 treten regelmäßigere Strukturen wieder in den Vordergrund. Noch sehr viel deutlicher geschieht dies dann nach dem kurzen Einschub von $\mathrm{A}^{1} \mathrm{ab}$ Ziffer 181: Die peitschenartigen Vorschlagsklänge der Flöten, die chromatisch absteigenden Dreiklänge der Holzbläser oder der fanfarenartige Einwurf der Blechbläser [zwei Takte vor Ziffer 182] treten hier zunächst ganz regelmäßig auf. Sie werden allerdings sofort wieder irregulär versetzt oder echoartig ineinander verschoben und leiten derart direkt über in den abschließenden Teil A".

Während die Couplets B und C für sich genommen als (für die rondoartige Anlage reguläre) Irregularitäten gelten können, da sie die wiederkehrenden (und somit regulären) A-Teile unterbrechen und ihnen kontrastierend gegenüberstehen, wird die auf formaler Ebene klare Hierarchie spätestens bei Ziffer 18o mit dem Einsatz von $A_{1}$ gestört. An dieser Stelle unterbricht der (eigentlich regulär wiederkehrende) Teil $A$ das (ursprünglich irreguläre) Couplet $C$ und führt damit zur Umkehr der zuvor artikulierten Rangordnung oder stellt diese zumindest infrage: Mit dem Einsatz von $\mathrm{A}_{1}$ erwartet der "conservative listener“ eine Reprise bzw. eine dritte (reguläre) Wiederholung des ersten Formteils. Stattdessen wird $\mathrm{A}_{1}$ aber bereits nach sieben Takten abgebrochen, $\mathrm{C}$ direkt im Anschluss daran wieder aufgenommen und A" derart modifiziert, dass der Teil nicht als (reguläre) Reprise identifizierbar ist. Ein "conservative listener" kann damit nicht mehr eindeutig unterscheiden, welcher Teil nun irregulär ist und unterbricht und welcher regulär ist und unterbrochen wird.

Eine solche ,Verwirrung des Publikums' ist geradezu deckungsgleich mit dem zugrunde gelegten ästhetischen Programm: Wenn ein Zuhörer bzw. Zuschauer nicht mehr in der Lage ist, zu unterscheiden, was Fixpunkt ist und was sich um diesen Fixpunkt bewegt, wurde ihm gewissermaßen die Kontrolle über seinen (normalen) Bewusstseinszustand genommen. Spätestens im letzten Teil der Danse sacrale befindet er sich folglich im Rausch - gemeinsam mit der sich auf der Bühne verausgabenden Tänzerin. ${ }^{600}$

599 Vgl. Kapitel III.1.1.1.

6 oo $\mathrm{Zu}$ einer vermuteten engen Verknüpfung von Musik und alterierten Bewusstseinszuständen allgemein vgl. den Aufsatz des deutschen Musikwissenschaftlers und -ethnologen Christian KAdEN: „Klang als Brücke zwischen den Welten. Musik und 


\subsection{Das Théâtre des Champs-Élysées als Schaubühne der Zukunft?}

Sucht man nach weiteren Verbindungslinien zwischen Ballets Russes und Theaterreform, stößt man unweigerlich auf das Théâtre des Champs-Élysées. Nach der Pariser Weltausstellung von 1900 galt jener , nouveau temple de l'art" ${ }^{4} 01$ als Frankreichs prestigeträchtigstes Bauprojekt. Er wurde am 31. März 1913 mit einem Festival eröffnet, das fast drei Monate andauerte; ${ }^{602}$ ein Höhepunkt dieser Inaugurationsreihe war die Uraufführung des Sacre du printemps. ${ }^{603}$

Als Architekt des Gebäudes wird häufig der Franzose Auguste Perret genannt. Dabei wird ignoriert, dass vor ihm bereits drei andere Architekten mit der Theaterplanung beschäftigt waren: Auf den Schweizer Henri Fivaz, der

Trance. Musik und Ekstase“, in: Rausch. Trance. Ekstase. Zur Kultur psychischer Ausnahmezustände (Edition Kulturwissenschaft, Bd. 78), hg. von Michael Schetsche und Renate-Berenike SснміDт, Bielefeld 2016, S. 239-26o.

601 Als „nouveau temple de l'art“ wurde das Theater 1912 angekündigt. Vgl. Ankündigung der Ballets-Russes-Saison 1913 im Programme des Ballets russes, 1912, zit. in: Roland HuescA: „Le Théâtre des Champs-Élysées à l'heure des Ballets Russes“, in: Vingtième Siècle. Revue d'histoire 63 (1999), S. 3-15, hier S. 13.

6o2 Vgl. Christian Freigang: Auguste Perret, die Architekturdebatte und die ,Konservative Revolution in Frankreich 1900-1930, München 2003, S. 41. Es existiert nur sehr wenig Literatur über das Théâtre des Champs-Élysées und seine Entstehungsgeschichte. Die nachfolgenden Angaben orientieren sich deshalb großteils an den Ausführungen von Christian Freigang, der sich in seiner Habilitationsschrift intensiv mit der Baugeschichte des Theaters auseinandergesetzt hat. Freigang gibt darin den 2. April 1913 als Eröffnungsdatum an. Vgl. ebd., S. 33. Henry van de Velde berichtet aber korrekt, dass schon am 31. März unter Felix Weingartner Hector Berlioz' Benvenuto Cellini aufgeführt wurde und am 1. April 1913 Carl Maria von Webers Freischütz. Am 2. April folgte dann das von Freigang beschriebene Konzert. Vgl. hierzu die Angaben von Henry van De Velde: Récit de ma vie, 2 Bde., Brüssel 1992-1995, Bd. 2: 1900-1913: Berlin, Paris, Weimar, hg. und kommentiert von Anne vaN Loo in Zusammenarbeit mit Frabrice VAN DE KerCKHOVE, Brüssel 1995, S. 339. Zum 10o. Jubiläum der Eröffnung erschien Nathalie SERG ENT (Hg.): Théâtre. Comédie et studio des Champs-Élysées. Trois scènes et une formidable aventure, Paris 2013. Quellen und Daten zum Theater sind insbesondere auch in folgenden Arbeiten zu finden, die vor Freigangs Studie erschienen sind: Gabriel Astruc: Le Pavillon des Fantômes. Souvenirs, Paris 1929; van de Velde, Récit de ma vie; Bernard MARreY: „Qui est l'architecte du Théâtre des Champs-Élysées?“, in: L'Architecture aujourd'hui 174 (1974), S. 114-125; Jean-Michel Nectoux (Hg.): 1913. Le Théâtre des Champs-Élysées, Paris 1987; Léon Ploegaerts und Pierre Puttemans: L'OEuvre architecturale de Henry van den Velde, Brüssel und Québec 1987, S. 104-115; Claude LoupIAC: L'architecture théâtrale en France à la Belle Époque et le cas du Théâtre des Champs-Élysées, Thèse de doctorat, Université Paris 1 Panthéon-Sorbonne 1993; Huesca, „Le Théâtre des Champs-Élysées à l'heure des Ballets Russes“; DERS.: Triomphes et Scandales. La belle époque des Ballets Russes, Paris 2001, S. 75-92.

603 Zur Eröffnungssaison und insbesondere zur Saison der Ballets Russes 1913 vgl. unter anderem Jean-Michel Nectoux: „La Saison Astruc“, in: 1913. Le Théâtre des ChampsÉlysées, hg. von ders., S. 104-127. 
das Projekt freiwillig verließ, folgten (1906) der Franzose Roger Bouvard sowie (1910) der erfahrene belgische Theaterarchitekt Henry van de Velde. ${ }^{604}$ Letztgenannter hatte sich schon frühzeitig mit den in Kapitel III. vorgestellten Reformkonzepten beschäftigt und 1904 mit Gordon Craig über aktuelle Tendenzen der Theaterreform diskutiert. ${ }^{605}$ Zudem war er an bekannten Reformprojekten wie dem Weimarer Hoftheater beteiligt gewesen. ${ }^{606} \mathrm{Im}$ Januar 1911 bat van de Velde Perret und dessen Bauunternehmen um einen Kostenvoranschlag für die technische Umsetzung seiner Entwürfe, die die Baugesellschaft kurz zuvor bewilligt hatte. Und über genau diese Entwürfe schreibt der deutsche Kunst- und Architekturhistoriker Christian Freigang:

604 Vgl. Freigang, Auguste Perret, S. 40-42. Freigang gibt an, dass das Theater in Frankreich bis in die 198oer-Jahre Perret zugeordnet wurde. Vgl. ebd., S. 40. Fachfremde Literatur übernahm die alte Darstellung allerdings häufig auch noch nach dieser Zäsur. So beispielsweise Modris Eksteins: Rites of Spring. The Great War and the Birth of the Modern Age (1989), Toronto 2012: „The theater is one of the finer examples of Auguste Perret, whom some consider ,the father of modern French architecture'. Constructed between 1911 and 1913, it belongs to the first generation of buildings to be erected with reinforced concrete. But in addition to the use of new materials, steel and concrete in place of brick or stone, a major concern of Perret was to incorporate and project in his work that he regarded as a new honesty and simplicity of style." Ebd., S. 27. Oder Scheijen, Diaghilev: „The Theatre, now known as the Théâtre des Champs-Élysées, was the work of Auguste Perret, the future teacher of Le Corbusier, who envisioned it as an example of ultramodern design." Ebd., S. 256.

605 Die beiden sollen sich zum ersten Mal 1904 in Weimar getroffen haben. Vgl. Grund, Zwischen den Künsten, S. 68f. Van de Velde berichtet in seiner Autobiografie von dieser Begegnung. Vgl. Henry van DE VELDE: Geschichte meines Lebens, hg. und übertr. von Hans Curjel, München 1962, S. 270-272. Auch im Brief von Kessler an Hofmannsthal vom 22. November 1904, ediert in: Briefwechsel Hofmannsthal - Kessler, hg. von Burger, S. 67f., finden sich Hinweise auf dieses Treffen. Ferner existiert ein Foto (datiert 1903/o4), auf dem Kessler, van de Velde und Craig vor dem Modell des Dumont Theaters stehen. Vgl. unpag. Tafelteil, Abb. 10. Kessler hatte die beiden in Weimar zusammengebracht. Vgl. Grund, Zwischen den Künsten, S. $68 \mathrm{f}$.

606 Vgl. Freigang, Auguste Perret, S. 51. Vgl. hierzu auch Ulrich Schulze: „Formen für Reformen. Henry van de Veldes Theaterarchitektur", in: Henry van de Velde. Ein europäischer Künstler seiner Zeit, hg. von Klaus-Jürgen Sемвасн und Birgit Schulte, Köln 1992, S. 341-357; Christian Hес нт: Streit um die richtige Moderne. Henryvan de Velde, Max Littmann und der Neubau des Weimarer Hoftheaters (Weimarer Schriften, Bd. 59), Weimar 2005. Zur Planungs- und Baugeschichte des Weimarer Hoftheaters allgemein vgl. Katja Zeune R: „Theaterbau um 19oo. Das Hoftheater Weimar“, in: Thesis 48/2 (2002), S. 68-93. Eine knappe Zusammenfassung bietet Bernd-Peter Sc HAul:Das Prinzregententheater in München und die Reform des Theaterbaus um 19oo. Max Littmann als Theaterarchitekt, München 1987, S. 135-137. Van de Velde wird in Fachkreisen immer wieder im Kontext der Reformbewegung genannt. So unter anderem bei Brauneck, Theater im 20. Jahrhundert, 2009, S. 155 . 
Tatsächlich [...] handelt es sich bei dem [...] Entwurf um eine Bühnengestaltung mit variablem Proszenium, wie sie von Georg Fuchs theoretisch formuliert worden war, um über die Vorderbühne eine Brücke zwischen Schauspieler und Publikum zu schaffen. ${ }^{607}$

War das Théâtre des Champs-Élysées also als Reformtheater im Fuchs'schen Sinne geplant? ${ }^{608}$

Vor dem Hintergrund der dargelegten Beziehungen zwischen BalletsRusses-Mitarbeitern und Vertretern der europäischen Theaterreform wäre es nicht ganz unwesentlich, wenn der Sacre seine Uraufführung in einem Theater erfahren hätte, dessen Bauplanung zwischenzeitlich von ähnlichen Ideen beeinflusst war. Dazu kommt noch, dass sowohl der Theaterbau als auch die programmatische Ausrichtung und Organisation der Eröffnungssaison auf ein und dieselbe Person zurückgehen, nämlich Gabriel Astruc. Der umtriebige Pariser Musikkritiker, Kulturschaffende und -förderer organisierte zwischen 1905 und 1912 die Grande Saison de Paris, die gänzlich unterschiedliche Festivals und Konzertreihen versammelte - unter ihnen ab 1907 auch Djagilevs Saison Russe sowie ab 1910 die Saisons der Ballets Russes. ${ }^{609}$

607 Freigang, Auguste Perret, S. 51.

608 Das ebenfalls 1913 eröffnete Théâtre du Vieux Colombier, das vom französischen Theaterreformer Jacques Copeau geleitet wurde, stand in Zusammenhang mit den Bühnenreformen von Appia und Craig. Vgl. ebd., S. 84.

609 Zur Grande Saison de Paris und zu den angegliederten Festivals wie beispielsweise der Saison Russe oder der Saison Italienne vgl. César Andrés LeAL: Re-Thinking Paris at the Fin-de-Siècle. A New Vision of Parisian Musical Culture from the Perspective of Gabriel Astruc (1854-1938), PhD Dissertation, University of Kentucky 2014, S. 132-163; Pierre Lebaillif schreibt in seinem Vorwort zur 1987 erschienenen Neuauflage der Memoiren von Gabriel Astruc über die Grande Saison de Paris: „Entre 1905 et 1912, il [Astruc] organise près de mille représentations sous le nom de ,Grande Saison de Paris'. Chaque printemps est désormais l'événement Astruc: 1905, saison italienne avec Caruso et la Melba; 1907, création de ,Salomé sous la direction de Richard Strauss; à partir de 1909 et pour huit saisons, les Ballets Russes; 1910 le Metropolitan de New York dirigé par Toscanini; 1911, création du ,Martyre de Saint Sébastien'." Vgl. Pierre Lebaillif: „Le rêve d'un directeur“, in: Gabriel Astruc: Le Pavillon des Fantômes. Souvenirs (1929), neue und erw. Ausgabe, hg. von Olivier CoR Pet, Paris 2003, S. 25-33, hier S. 31f. Oliver Corpet merkt in seinem Vorwort zur 2003 erschienenen Neuauflage von Astrucs Memoiren an, dass die zentrale Rolle Astrucs im Pariser Kulturleben in der ersten Hälfte des 2o. Jahrhunderts viel zu selten anerkannt wird. Vgl. Olivier CоRPет: „Astruc-Le-Magnifique ou les folies d'un grand parisien“, in: Astruc, Le Pavillon des Fantômes. Souvenirs (1929), 2003, S. 7-24., hier S. 7 f. Tatsächlich finden sich zu ihm nur sehr wenige wissenschaftliche Untersuchungen. In jüngster Zeit erschienen sind Roland HuescA: „Gabriel Astruc. Un entrepreneur de spectacle à la Belle-Époque“, in: Directeurs de théâtre $\left(X I X^{e}-X X^{e}\right.$ siècles). Histoire d'une profession, hg. von Pascale Goetschel und Jean-Claude Yon, Paris 20o8, S. 143-165 sowie die bereits genannte Dissertation von Leal, Re-thinking Paris at the Fin-de-Siècle. 
Astruc hatte sich vorgenommen, ein modernes Musiktheater für Paris zu bauen, da dort Anfang des 2o. Jahrhunderts - gemessen an Vielfalt und Fülle des Musik(theater)programms - ein veritabler Mangel an modern ausgestatteten Aufführungsstätten herrschte. Die Opéra Nationale de Paris genügte seinen Ansprüchen zwar, war für einen externen Veranstalter wie ihn aber viel zu selten anzumieten. ${ }^{610}$

1901 wandte er sich also an den befreundeten Henri Fivaz. Und zu diesem Zeitpunkt stand fest: Sein neuer Bau sollte sich an den neuesten Entwicklungen der Theaterarchitektur orientieren. Das Bayreuther Festspielhaus galt ihm folglich genauso als Vorbild wie das nach diesem entworfene Prinzregententheater in München, das erst kurz zuvor (1900/o1) vom deutschen Architekten Max Littmann fertiggestellt worden war. ${ }^{611}$ Benannt werden sollte das Theater nach den Avenues des Champs-Élysées, wo Astruc sich 1906 die

Eine Zusammenfassung von Astrucs kulturellen Aktivitäten in Paris findet sich bei Garafola, Diaghilev's Ballets Russes, S. 177-179. 2013 wurde Mes Scandales, ein „(fast) unveröffentlichte[s]" Manuskript von Astruc, publiziert und 2015 ins Deutsche übersetzt. Vgl. hierzu Olivier Corpet: „Vorwort“, in: Gabriel Astruc: Meine Skandale. Strauss, Debussy, Strawinsky, aus dem Französischen von Joachim KALKA, Berlin 2015, S. 7-15, hier S. 7. Für die französische Ausgabe vgl. Gabriel Astruc: Mes Scandales, mit einem Vorwort von Emile Vuillermoz (1936) und Texten von Olivier Corpet und Myriam Chimènes, Paris 2013.

610 Vgl. Freigang, Auguste Perret, S. 40-42. Zur prekären Aufführungssituation vgl. unter anderem auch Nectoux, „La Saison Astruc“: „Les concerts de musique de chambre et les récitals se tenaient, $[\ldots]$ dans les salons des facteurs de piano [...], situation améliorée quelque peu en 1907 par l'ouverture de la Salle Gaveau [...]. Les concerts symphoniques étaient plus mal lotis encore puisque l'unique salle digne de ce nom: la salle du Conservatoire, $[\ldots]$ célèbre par son acoustique exeptionelle, $[\ldots]$ strictement résérvée aux quelques vingt-quatre concerts annuels de la Société des concerts du Conservatoire. Les sociétés de concerts symphoniques concurrentes jouaient dans les salles de théâtres: les Concerts Colonne mobilisaient le Châtelet, le dimanche après-midi, tandis que les Concerts Lamoureux s'étaient transportés du Cirque d'été [...], au Théâtre Sarah Bernhardt, puis à la Salle Gaveau. À l'occasion de l'Exposition Universelle de 1878, on avait $[. .$.$] essayé de remédier à cette situation en construisant une Salle des Fêtes dans$ le Palais du Trocadéro. On avait vu grand [...], si grand que l'acoustique était entachée de phénomènes d'échos, d'un effet fâcheux." Ebd., S. 104.

611 Vgl. Freigang, Auguste Perret, S. 81. Zu jener Reformarchitektur um 1900, auf die sich Astruc bezieht, vgl. unter anderem Schaul, Das Prinzregententheater in München und die Reform des Theaterbaus um 19oo. Die beteiligten Architekten unternahmen auch Studienreisen nach Deutschland und besorgten sich Fachliteratur zum Reformtheaterbau. Vgl. Freigang, Auguste Perret, S. 41. Welch weitreichende Kreise Astrucs Reformtheaterpläne zogen, zeigt der Artikel "Opera at Versailles“ in der New York Times vom 8. März 19o8, in dem Astrucs neues Theater als „The French Bayreuth“ bezeichntet wird. Vgl. Leal, Re-Thinking Paris at the Fin-de-Siècle, S. 268. 
städtische Pachtkonzession für ein unbebautes Grundstück gesichert hatte. ${ }^{612}$ Doch obwohl er damals schon die ersten unterstützungswilligen Mäzene von seinem Vorhaben überzeugt hatte, ${ }^{613} \mathrm{kam}$ dann doch alles anders als geplant: Den größten Einschnitt erfuhr das Bauvorhaben, als die Société du Théâtre des Champs-Élysées zum Jahreswechsel 1909/10 beschloss, den Standort in die Avenue Montaigne zu verlegen. Astruc hatte dieser Gesellschaft aufgrund finanzieller und privater Schwierigkeiten zwischenzeitlich die Bauträgerschaft übertragen. ${ }^{614}$ Zwar war er als ihr Hauptaktionär immer noch Mitglied des Verwaltungsrates, hatte aber zunehmend an Einfluss auf ihre Entscheidungen verloren. ${ }^{615}$ In einem Punkt konnte Astruc sich 1910 allerdings noch durchsetzen:

612 Auf besagtem Grundstück hatte zuvor der Cirque d'été gestanden, der 1902 abgerissen worden war. Vgl. Freigang, Auguste Perret, S. 41; Leal, Re-thinking Paris at the Fin-de-Siècle, S. 242-247.

613 Vgl. Freigang, Auguste Perret, S. 4lf.

614 Ebd., S. 45. Die Société du Théâtre des Champs-Élysées wurde 1907 zur finanziellen Sicherung des Projeks gegründet. Vgl. ebd., S. 40-42.

615 Eine äußerst negative Pressekampagne, die gegen Astruc und sein angeblich zu elitäres Musiktheater gerichtet war, trug hierzu ebenso bei wie antisemitische Ressentiments, die sich seit 1907 mehrten. Vgl. ebd., S. 43. Astruc genoss den Ruf eines Xenophilen, dessen Vorliebe für Fremdes und Unbekanntes sich insbesondere in seiner Begeisterung für fremde Kultur(en) äußerte. Aufgrund seiner jüdischen Abstammung wurden seine erfolgreichen Kulturaktivitäten allerdings auch zur Zielscheibe von Antisemiten. Diese glaubten in ihm ein Beispiel jenes mächtigen und gefährlichen Juden zu erkennen, der die Gesellschaft gefährden würde. Caddy macht darauf aufmerksam, dass auch andere Persönlichkeiten im Umkreis der Ballets Russes antisemitischer Hetze ausgesetzt waren. Vgl. Caddy, The Ballets Russes and Beyond, S. 136f. Nährboden könnte dem gegeben haben, dass die Ballets Russes aufgrund von Astrucs Kontakten auch von einigen wohlhabenden Juden finanziert wurden - unter ihnen Henri de Rothschild, Isaac de Camondo, Henri Deutsch de la Meurthe, Otto Kahn, Arthur Raffalovich und Charles Ephrussi. Vgl. Järvinen, Dancing Genius, S. 54f. Ein weiterer Grund für Astrucs schwindenden Einfluss muss dem Finanzunternehmer Gabriel Thomas zugeschrieben werden, der 1908 den Vorstand des Verwaltungrates übernommen und seitdem immer wieder versucht hatte, Astrucs Einfluss zu minimieren. Der Streit zwischen Astruc und Thomas ging zeitweise sogar so weit, dass Thomas Astruc den Zugang zur Baustelle verbot. Nach Fertigstellung des Theaters verlangte Thomas von Astruc schließlich so hohe Mieten, dass dieser nach Beendigung der ersten Saison 1913 bankrottging. Vgl. Freigang, Auguste Perret, S. 42-45. Weitere Aspekte zur Konkurrenz zwischen Astruc und Thomas finden sich in der Korrespondenz zwischen Thomas und Maurice Denis sowie in den Sitzungsprotokollen des Verwaltungsrats. Vgl. ebd., S. 42. Nähere Informationen zu Gabriel Thomas finden sich unter anderem bei Bernard MARREY: Revers d'un chef-d'œuvre. La Naissance du Théâtre des Champs-Élysées. 1910-1922, Paris 2007, S. 22-24. Freigang bezeichnet den alten Standort in den Champs-Élysées als Astrucs letzten Trumpf, was den Theaterbau angeht. Für diesen hatte schließlich er die Konzessionsvereinbarungen mit der Stadt getroffen. Vgl. Freigang, Auguste Perret, S. 45 . 
Er überzeugte die Baugesellschaft, den belgischen Theaterarchitekten Henry van de Velde einzustellen, was am 18. Juni 1910 dann auch passierte. ${ }^{616}$

Es kann zwar nur gemutmaßt werden, dass Astrucs leidenschaftliches Bemühen um van de Velde als Berater für Bouvard mit dessen Verbindungen zum Reformtheater zu tun hatte - anzunehmen ist es aber. Astruc hatte sich vorgenommen, den Bau an den aktuellsten Strömungen der Theaterarchitektur zu orientieren. Seit Projektauftakt hatte sich in jenem Bereich allerdings einiges getan: Bei der geforderten Einheit von Schauspieler und Publikum, die sich auch architektonisch manifestieren sollte, handelte es sich mittlerweile nicht mehr nur um ein rein theoretisches Konstrukt. ${ }^{617}$ Georg Fuchs, der in seinen (theoretischen) Texten unter anderem für die Abschaffung der Rampe plädiert hatte, um mit einer ausgeweiteten Vorderbühne eine Art Brücke zwischen Schauspieler und Publikum zu schaffen, ${ }^{618}$ hatte hierfür zwischenzeitlich quasi ein Modelltheater errichtet - gemeinsam mit dem Reformarchitekten Max Littmann. ${ }^{619}$ Die Bühne des Münchner Künstlertheaters, das von den beiden konzipiert und von Littmann 1908 fertiggestellt worden war, ragte weit in den Zuschauerraum hinein und war mit einem variablen Proszenium ausgestattet. ${ }^{620}$ Ein solches Proszenium hatte Littman im selben Jahr auch am Weimarer Hoftheater verwirklicht - an jenem Theater also, an dessen Planungen van de Velde ursprünglich beteiligt gewesen war. ${ }^{621}$

Genau solch ein Proszenium erkennt nun aber Christian Freigang in van de Veldes Plänen für das Théâtre des Champs-Élysées. Und zwar in jenen Plänen, die dieser im Dezember 1910 zum ersten Mal vorlegte und die im März 1911 die Grundlage von Perrets Ausführungsauftrag bildeten: Für den vorderen Bühnenbereich ist darin ein Orchestergraben geplant, der - in abgedeckter Form - zugleich eine bespielbare Vorderbühne bildet. ${ }^{622}$

616 Astruc überzeugte die Baugesellschaft gemeinsam mit Maurice Denis, der für einen Großteil der malerischen Ausstattung des Theaters verantwortlich zeichnete. Vgl. ebd., S. 48. Für die Umstände, die den Verwaltungsrat und Thomas dazu brachten, Astrucs (und Denis') Vorschlag anzunehmen, vgl. ebd., S. 48f. und 98.

617 Vgl. Fischer-Lichte, Kurze Geschichte des deutschen Theaters, S. 265.

618 Diese Idee legte Fuchs 1905 ausführlich in Die Schaubühne der Zukunft dar. Vgl. Fuchs, Die Schaubühne der Zukunft. Sie findet sich aber auch schon in früheren Texten - so etwa in ders., Die Revolution des Theaters und DERs.: „Die Schaubühne. Ein Fest des Lebens“, in: Wiener Rundschau 3/20 (1899). Vgl. auch Anm. 3oo sowie Kapitel III.1.2.

619 Vgl. Freigang, Auguste Perret, S. 51.

620 Vgl. Fischer-Lichte, Kurze Geschichte des deutschen Theaters, S. 265.

621 Vgl. Freigang, Auguste Perret, S. 48-53. Zum Neubau des Weimarer Hoftheaters vgl. Hecht, Streit um die richtige Moderne.

622 Vgl. Freigang, Auguste Perret, S. 51. 
Van de Velde hatte Bouvard nicht nur beraten, wie anfangs von der Baugesellschaft vorgesehen, sondern die Baupläne in Absprache mit seinem Kollegen umfangreich verändert, sodass er schließlich die gesamtgestalterische Leitung des Projekts übertragen bekam und im Januar 1911 Perrets Baufirma damit beauftragen konnte, sich um die technische Ausführung zu kümmern. ${ }^{623}$ Dem Bauausführungsvertrag, den Perret im März 1911 unterzeichntete, lag also ursprünglich eine Planserie zugrunde, die ganz auf van de Veldes Plänen vom Dezember 1910 beruhte. Die Bezüge zu Fuchs' Theorien und insbesondere zu dem von ihm und Littmann entworfenen Bühnenmodell sind darin deutlich zu erkennen. ${ }^{624}$

Allein van de Veldes Pläne für das Théatre des Champs-Élysées und insbesondere das von Fuchs inspirierte Proszenium wurden in dieser 1911 vorgelegten Form nie realisiert. Direkt nach Vertragsunterzeichnung begann Perrets Büro nämlich damit, van de Veldes Pläne abzuändern und den Verwaltungsrat schlussendlich davon zu überzeugen, ihre statt van de Veldes Entwürfe umzusetzen. Und so ist das Théâtre des Champs-Élysées heute weniger als eine Manifestation der Reformforderungen zu betrachten, als vielmehr als ein Rückzug von ihnen. ${ }^{625}$ Hinzu kommt, dass der kurz darauf einsetzende Weltkrieg sowie eine bis in die 1920er-Jahre hineinreichende und überaus wirksame Öffentlichkeitsarbeit des Perret-Büros schließlich dazu beitrugen, dass van de Veldes Beteiligung am Bau in Vergessenheit geriet. ${ }^{626}$

Mit großer Sicherheit wusste Djagilev von Astrucs Plänen für das neue Theater. Dafür musste die öffentliche Berichterstattung genauso gesorgt haben wie die Tatsache, dass sich die beiden seit Djagilevs Anfängen in Paris kannten

623 Van de Velde hatte Perret am 26. Januar 1911 bei einem Abendessen bei Théo von Rysselberghe kennengelernt und ihm drei Tage später seine Pläne zukommen lassen mit der Bitte um einen Kostenvoranschlag für eine Ausführung in Eisenbeton. Vgl. ebd., S. 53 .

624 Vgl. ebd., S. 53f. Am 4. März 1911 hatte Perret van de Velde lediglich ein paar kleine technische Anweisungen zukommen lassen, die van de Velde dann in die endgültige Planserie eingearbeitet hatte. Zwei Abbildungen dieser Planserie finden sich ebd., S. 54. Zum großen Einfluss von Max Littmanns Theater auf van de Velde vgl. ebd., S. 89.

625 Eine ausführliche Beschreibung von Perrets Änderungen findet sich ebd., S. 54-59. Perret war mit seiner Übernahmestrategie wohl vor allem deshalb erfolgreich, weil er in seiner Doppelfunktion als Architekt und Bauingenieur bzw. -unternehmer mit seinem Konzept niedrigere Kosten anbieten konnte. Van de Velde blieb daraufhin zunächst noch beratend am Bau tätig, zog sich aber immer weiter aus dem Projekt zurück. Vgl. ebd., S. 55 .

$626 \mathrm{Zu}$ den frühen wissenschaftlichen Untersuchungen, die van de Veldes Anteil am Theaterbau thematisieren, vgl. Marrey, "Qui est l'architecte du Théâtre des Champs-Élysées?“; Ploegarts und Puttemanns, L'ouvre architecturale de Henry van de Velde, S. 106-115; Claude Loupiac: „Le ballet des architectes“, in: 1913. Le Théâtre des Champs-Élysées, hg. von Nectoux, S. 22-53. 
und seitdem eine intensive und erfolgreiche Geschäftsbeziehung pflegten: Begegnet waren sie sich zum ersten Mal 1906 im Salon der Comtesse Greffulhe, woraufhin sie sogleich (1907) in der Opéra Nationale de Paris die Concerts historiques russes zusammen organisierten. ${ }^{627}$ Astruc versorgte Djagilev daraufhin immer wieder mit vielversprechenden Kontakten zu oft zukünftigen Investoren und Partnern und unterstützte ihn außerdem in geschäftlichen Belangen; Verträge, Verhandlungen und Korrespondenzen von Djagilevs Pariser Aktivitäten sowie deren Öffentlichkeits- und Pressearbeit lagen von 1907 bis 1913 in Astrucs Hand. ${ }^{628}$

Ob Djagilev auch von den Turbulenzen rund um den Theaterbau wusste, ist nicht nachzuweisen. Was aber mit sehr großer Wahrscheinlichkeit gesagt werden kann, ist, dass die geschilderten Querelen keinerlei Auswirkungen auf Astrucs Programmplanungen für die Eröffnungssaison von 1913 hatten.${ }^{629}$ Eine Durchsicht der Gabriel Astruc Papers, die als Mikrofilm in der Dance Collection der New York Public Library for the Performing Arts zugänglich sind und in denen sich insbesondere Astrucs Korrespondenz bezüglich der Vorbereitungen für die Ballets-Russes-Saison von 1913 befindet, bestätigte diesen Verdacht insofern, als die Streitigkeiten rund um den Theaterbau hierin nirgends auftauchen.

Auf Grundlage von Korrespondenz und Ankündigungsmaterial könnte man allerdings vermuten, dass Astruc in der Kommunikation mit Partnern und Publikum die Bau- und Architektenstreitigkeiten bewusst aussparte, um so mit seinem ursprünglich geplanten ,neuen Theater weiterhin im Gespräch zu bleiben. Darauf verweist zumindest ein Telegramm, das er vor dem 12. Juli 1911 geschrieben haben muss und in dem er Djagilev darüber informiert, dass Otto Hermann Kahn, Vorstandsmitglied der Metropolitan Opera in New York, dem Generalintendanten jener Oper, Giulio Gatti-Casazza, von Djagilevs Plänen für die neue Ballets-Russes-Saison 1913 im „neuen Theater“ berichtet habe. ${ }^{630}$ Offenbar waren Kenntnisse über Astrucs Pläne für das „neue Theater“

627 Vgl. Garafola, Diaghilev's Ballets Russes, S. 275.

628 Vgl. ebd., S. 278; Järvinen, Dancing Genius, S. 38.

629 Freigang bermerkte mir gegenüber in einem persönlichen Gespräch, dass in der Bauplanung keinerlei Hinweise auf künstlerische Konzepte aufzufinden und deshalb Bau und Inszenierungen höchstwahrscheinlich deutlich getrennt voneinander zu sehen seien.

63 Vgl. die Kopie des Briefes von Djagilev an Astruc vom 12. Juli 1911, Papers of Gabriel Astruc. 1906-1914, Dance Collection, The New York Public Library for the Performing Arts, New York, Collection Number ZBD-161, Reel 1, Folder 51. Djagilev zitiert hier folgenden Telegrammtext von Astruc, auf den er sich dann im daran anschließenden Brief bezieht: „I have received the following telegram from you - MP PC Diaghilew Hotel Waldorf London Monsieur Gatticasazza me prie vous notifier de nouveau sa proposition executer programme existant vingtune personne avec condition essentielle tournée strictement 
im Juli 1911 also bereits bis nach Übersee gelangt ${ }^{631}$ - zusammen mit der Information, dass Djagilevs 1913er-Saison in jenem "neuen Theater“ stattfinden sollte. ${ }^{632}$

\section{Der Sacre als ästhetische Zäsur in der Ballets-Russes-Rezeption}

Es wurde bereits darauf hingewiesen, dass Stravinskij „Zwischen seinen und Craigs Bestrebungen eine Art von Verwandtschaft" ${ }^{433}$ verspürte und dass sich zwischen Craigs Reformkonzepten und Stravinskijs Sacre-Plänen Parallelen ausmachen lassen: Vergleichbar mit Craig, der den Schauspieler im Drama durch eine Marionette ersetzen wollte, um so die absolute Macht über das Bühnengeschehen zu erhalten, hatte sich Stravinskij für den Sacre vorgenommen, die Bewegungen der Tänzer zu kontrollieren. Durch Nižinskijs Anweisungen wurden die Tänzer also gewissermaßen zu unbewusst agierenden Subjekten und konnten so - wie Automaten - in ihren Bewegungen von Stravinskijs Musik gelenkt werden.

obligatoire dans vingtcinque villes inviron Gatticasezza oblige quitter Paris demain soir pour Italie ... G. declare qu'il viendra Londres semaine prochaine avec les plus favorables dispositions pour arranger avec vous et Monseur Kahn qui a informé Gatte votre entrevue saison ballet russe new theatre 1913 Câblez nettement quel parti adoptez Astruc.“ Giulio Gatti-Casazza bekleidete das Amt des Generalintendanten der Metropolitan Opera von 1908 bis 1935. Vgl. Howard Taubman: „Preface to the 1973 Edition“, in: Giulio Gatti-CASAZza: Memories of the Opera, New York 1973, S. V-XVII, hier S. V.

631 Freigang gibt an, dass der Bau des Theaters spätestens mit der Presseaffäre um Astruc und dem Standort auf den Champs-Élysées zu einem beliebten Gesprächsthema auch außerhalb Frankreichs geworden war und dass man die Eröffnung überall mit Spannung erwartete. Vgl. Freigang, Auguste Perret, S. 101.

632 Dass dies in der Öffentlichkeit höchstwahrscheinlich so wahrgenommen wurde, darauf verweist auch Jacques-Émile Blanche in seinem bereits erwähnten (allerdings erst im Dezember 1913 erschienenen) „Bilan artistique de 1913“. Darin ist mitunter Folgendes zu lesen: „Nous étant proposé d'étudier les rapports du public et des artistes d'aujourd'hui, nous avons pensé que l'entreprise du théâtre des Champs-Élysées (puisque la forme dramatique est la plus populaire, la plus accessible à la masse) devrait nous y aider. [...] On a tenu à ce que cet édifice nous mît en disposition, par sa sobriété élégante mais un peu froide, pour mieux suivre des représentations d'Art, sorte de ,Bühnenfestspiele comme Wagner les voulut à Bayreuth. Peut-être, pensions-nous, pourrait-on réussir ici ce qu'on dit impossible à l'Opéra [...]. Le danger couru par les initiateurs du théâtre des Champs-Èlysées tint à ce qu'ils pensèrent pouvoir communier dans l'art ceux qui vont au spectacle pour s'exhiber ou prendre un plaisir anodin, et ceux qui y vont pour s'exalter. Ils voulurent imposer aux premiers les habitudes d'esprit des seconds.“ Blanche, „Un bilan artistique de $1913^{\prime \prime}$, S. 517 f.

633 Harry Graf Kessler: Tagebucheintrag vom 23. Mai 1912, S. 825. 
Eine solche Gedankenfolge passt zu der Tatsache, dass sich Stravinskij 15 Jahre lang (1915 bis 1930) mit einem Musikautomaten beschäftigte: dem mechanischen Klavier. Er gilt außerdem als erster Komponist, der mit seiner Étude pour Pianola (1917) ein Werk für jenes Instrument schuf, das erstmals 1897 zum Verkauf angeboten worden war. ${ }^{634}$ Gemeinhin wird Stravinskijs Beschäftigung mit dem Pianola deshalb auch als Vorbote einer allgemeinen Faszination am Mechanischen gesehen, die spätestens in der Musik der Neuen Sachlichkeit konkret greifbar wird - so etwa in Oskar Schlemmers Triadischem Ballett (1922/23), George Antheils Ballet Mécanique (1924/25) oder Stravinskijs eigenen neoklassischen (Ballett-)Werken. ${ }^{635}$ Beispielhaft für die diesbezügliche Opinio communis steht folgende Beobachtung des britischen Musikwissenschaftlers und Stravinskij-Experten Jonathan Cross:

Fascination with the machine as symbol of the ,progress' of the modern age was a feature of many modern movements - most prominently Russian and Italian Futurism, Vorticism, Constructivism, De Stijl and at the Bauhaus - and also had its impact on composers as diverse as Honegger and Milhaud, Antheil and Varèse. Stravinsky's own fascination with the mechanical pianola from the late teens and into the 1920 s was a catalyst to many contemporaries, and indeed to important successors such as Nancarrow. ${ }^{636}$

Am Ende fügt er noch hinzu:

But it is to the ,mechanistic' aspect of his repetitions that most composers working with Stravinsky's modernist legacy have been drawn. Indeed the ,proto-Futurism' of the Rite's ostinatos is something which did not escape even contemporary attention. ${ }^{637}$

Obwohl die radikale Modernität des Sacre insbesondere auf dessen mechanistische Anklänge und motorische Ästhetik zurückgeführt wird, werden Stravinskijs frühe russische Ballette - L'Oiseau de feu, Pétrouchka

634 Vgl. Mark McFarland: „Stravinsky and the Pianola. A Relationship Reconsidered“, in: Revue de Musicologie 97/1 (2011), S. 85-109, hier S. 85; Rex LAwson: „Stravinsky and the Pianola“, in: Confronting Stravinsky, hg. von Pasler, S. 284-301, hier S. 284; Albrecht DüMLING: „Meine kleine Nähmaschine؛. Kurt Tucholskys Grammophon-Vorlieben“, in: Tucholsky und die Medien. Dokumentation der Tagung 2005 "Wir leben in einer merkwürdigen Zeit" (Schriftenreihe der Kurt Tucholsky-Gesellschaft, Bd. 3), hg. von Friedhelm GREIS und Ian KING, Sankt Ingbert 2006, S. 83-102, hier S. 89.

635 Zum Terminus Neue Sachlichkeit in der Musik sowie zur Bezeichnung Mechanische Musik in diesem Kontext vgl. Nils Grosch: Die Musik der Neuen Sachlichkeit, Stuttgart u.a. 1999, S. $1-20$ und $56-89$.

636 Jonathan Cross: The Stravinsky Legacy, Cambridge 1998, S. 12.

637 Ebd. 
und Sacre - im Allgemeinen getrennt von denjenigen der neoklassischen Periode (ab den 192oer-Jahren) gesehen und somit normalerweise auch nicht in Zusammenhang mit seinem Interesse für das Pianola gebracht. ${ }^{638}$ Auf das Pianola aufmerksam wurde Stravinskij allerdings schon vor der Uraufführung des Sacre, nämlich spätestens am 8. Dezember 1912 in Berlin, als ihn Arnold Schönberg zu einer Aufführung seines Pierrot Lunaire in den Choralion-Saal eingeladen hatte. ${ }^{639}$ Offenbar spielte Stravinskij danach mit dem Gedanken, das mechanische Instrument für den Sacre einzusetzen. Jedenfalls muss er Djagilev etwas Entsprechendes mitgeteilt haben, denn zehn Tage nach dem Konzert in Berlin telegrafierte ihm der Impresario, dass er ein Pianola-Arrangement für jenes Ballett als unnötig erachte. ${ }^{640}$ Zwar schrieb er für jenes Instrument explizit nur ein einziges Werk: die anfangs genannte Étude pour Pianola; ${ }^{641}$ zwischen 1914 und 1929 verbrachte er aber auffallend viel Zeit damit, bereits bestehende Kompositionen auf Pianolarollen

638 Eine Ausnahme bildet sicherlich Daniel Albright, der 1989 die These aufstellte, dass Stravinskijs Bühnenwerken (er schließt Pétrouchka und Sacre mit ein) das Maschinenhafte quasi eingeschrieben sei. Vgl. Daniel Albrig ht: Stravinsky. The Music Box and the Nightingale, New York 1989. Vgl. auch Jordan, Stravinsky Dances, S. 97-107.

639 Vgl. McFarland, „Stravinsky and the Pianola“, S. 87f. Schönberg hatte Stravinskij persönlich zu diesem Konzert eingeladen. Letzterer war mit den Ballets Russes auf Tour. Vier Tage zuvor hatte Schönberg in Berlin einer Pétrouchka-Aufführung beigewohnt. Vgl. Taruskin, Stravinsky and the Russian Traditions, Bd. 1, S. 824. Der Pianola-Experte Rex Lawson war in seinem Aufsatz zu "Stravinsky and the Pianola“ von 1986 noch davon ausgegangen, dass Stravinskij erst 1914 mit dem Pianola in Berührung gekommen sei, hatte dies aber später revidiert. Vgl. McFarland, „Stravinsky and the Pianola“, S. 87f. Alfred Dolge gibt 1911 an, dass die Choralion Company genauso wie die Aeolian Company eine Tochtergesellschaft der Aeolian, Weber, Piano \& Pianola Company war. Vgl. hierzu unter anderem Alfred DoLge: Pianos and Their Makers. A Comprehensive History of the Development of the Piano from the Monochord to the Concert Grand Player Piano, Covina 1911, S. 332: „In 1903 [...] [Harry B. Tremaine] organized the ,Aeolian, Weber, Piano \& Pianola Company', [...] controlling the following subsidiary companies: The ,Aeolian Company', the ,Orchestrelle Company' (London), the ,Choralion Company' (Berlin), the ,Aeolian Company, Ltd. Paris‘ [...]." McFarland gibt dagegen an, dass die „,Choralion Company ${ }^{\prime}[\ldots]$ the German subsidiary of the ,Aeolian Company“" war. Vgl. McFarland, „Stravinsky and the Pianola", S. 88.

640 Vgl. hierzu das Telegramm von Sergej Djagilev an Stravinskij vom 5./18. Dezember 1912, Sammlung Igor Strawinsky, Paul Sacher Stiftung, Basel: „Répetitions pas commencées avons pas dessins pas besoin arrangements pour pianola. Diaghilew.“

641 Vgl. McFarland, „Stravinsky and the Pianola“, S. 85f. Bei den Étude pour Pianola von 1917 handelte es sich um eine Auftragskomposition für die Orchestrelle Company in London. Vgl. Lawson, „Stravinsky and the Pianola“, S. 290 und 295. 
einzuspielen ${ }^{642}$, und plante zeitweilig sogar, das Instrument für sein Ballett Les Noces (Svadebka) einzusetzen. ${ }^{643}$

Taruskin charakterisiert Stravinskijs ausgeprägtes Pianolainteresse als „infatuation“644, und Robert Craft, Stravinskijs langjähriger Assistent, beschreibt es als „one of the inexplicable eccentricities of his carreer ${ }^{4645}$. Er selbst gibt aber an, im Pianola eine Möglichkeit erkannt zu haben, die ihm unliebsame Rolle des Interpreten zu umgehen, ${ }^{646}$ "[pour créer] un document durable pouvant servir à ceux des exécutants qui tiennent à connaître mes intentions et à les suivre plutôt qu'à s'égarer dans des interprétations arbitraires de mon texte musical ${ }^{4647}$. Stravinskijs Vision, den Interpreten mithilfe eines Klang-

642 Eine Auflistung sämtlicher Werke, die Stravinskij auf Notenrollen eingespielt hat, findet sich ebd., S. 297-301.

643 Vgl. Taruskin, Stravinsky and the Russian Traditions, Bd. 2, S. 1453; Lawson, „Stravinsky and the Pianola“; McFarland, „Stravinsky and the Pianola“, S. 85; Margarita MAzo: „Igor Stravinsky's ,Les Noces'. The Rite of Passage“, in: Igor Stravinsky. Les Noces. Study Score, hg. von DIES., London 2005, S. v-xxiii.

644 Taruskin, Stravinsky and the Russian Traditions, Bd. 2, S. 1453.

645 Stravinsky und Craft, Stravinsky in Pictures and Documents, S. 164.

646 Vgl. McFarland, „Stravinsky and the Pianola“, S. 87.

647 Igor Stravins ky: Chroniques de ma vie, Neuausgabe, Paris 200o, S. 125: „Linterêt [gemeint ist Stravinskijs Interesse an der Arbeit mit dem Pianola] que je portais à ce travail était double. Pour éviter dans l'avenir une déformation de mes œuvres par leurs interprètes, j'avais toujours cherché un moyen de poser des limites à une liberté redoutable, surtout répandue de nos jours et qui empêche le public de se faire une juste idée des intentions de l'auteur. Cette possibilité m'était offerte par les rouleaux du piano mécanique. Un peu plus tard les disques de gramophone devaient me la renouveler. De cette façon je pouvais fixer pour l'avenir les rapports des mouvements (,tempi') et établir les nuances telles que je les voulais. Certes, cela ne me garantissait en rien, et pendant les six ans qui se sont écoulés depuis, j'ai pu, hélas! constater maintes fois toute l'inefficacité de cette mesure au point de vue pratique. Pourtant, avec ces transcriptions, j'ai créé un document durable pouvant servir à ceux des exécutants qui tiennent à connaître mes intentions et à les suivre plutôt qu'à s'égarer dans des interprétations arbitraires de mon texte musical. En second lieu, ce travail me donnait une satisfaction d'un autre ordre. Il ne consistait pas seulement en la simple réduction d'une œuvre orchestrale pour un piano à sept octaves. C'était tout un travail d'adaptation à un instrument qui, d'une part, possède des possibilités illimitées en fait de précision, de vélocité et de polyphonie, et, d'autre part, présente constamment de sérieux obstacles à l'établissement des rapports dynamiques. Ces occupations développaient et exerçaient mon imagination en me posant toujours de nouveaux problèmes d'ordres instrumental intimement liés avec ceux de l'acoustique, voire de l'harmonie et de la conduite des voix." Ebd. Taruskin weist darauf hin, dass der Pianola-Experte Rex Lawson im September 1982 während eines Vortrags im Rahmen eines internationalen Stravinskij-Symposiums in San Diego überzeugend demonstriert hatte, dass Dynamik, Tempo und Anschlag vom Pianolisten gestaltet werden und dass die Rollen daher nur eingeschränkt Stravinskijs Darbietung wiedergeben könnten. Offenbar hatte der Schweizer Dirigent Ernest Ansermet Stravinskij auch schon 1919 darauf 
automaten auszuschalten, weist also ebenfalls eine Parallele zu Craigs Reformforderung auf: Immerhin wollte der Komponist dergestalt das Klangresultat steuern bzw. kontrollieren. Und so würde Stravinskijs Faszination für das Mechanische nicht - wie allgemein angenommen - von seinem Pianolaerlebnis von 1912 herrühren, sondern wäre bereits um 1910 durch seine Begegnung mit dem Ballett und den Reformansichten einzelner Ballets-Russes-Mitglieder ausgelöst worden. Wäre es dann aber nicht durchaus möglich, dass Komponist und Choreograf für den Sacre eine mechanistische Ästhetik intendierten?

Belegt ist nur, dass sich Stravinskij und Nižinskij während ihrer Arbeit am Sacre mit Reformgedankengutund damit zusammenhängenden mechanischen Bewegungsabläufen auseinandergesetzt hatten. Was die zur Verfügung stehenden Quellen aufseiten der Produktion nicht liefern, ist ein Hinweis darauf, ob Komponist und Choreograf deshalb für das Werk eine Ästhetik des Mechanischen intendierten. ${ }^{648}$ Die einzige Möglichkeit, dem beizukommen, besteht in einer (Re-)Lektüre der Besprechungen, die im Anschluss an die Uraufführung des Balletts entstanden sind - in Paris, Sankt Petersburg und Moskau. Sie sollen deshalb im Folgenden nicht nur danach befragt werden, ob denn Publikum und Presse die spezifischen Reformpunkte wahrgenommen hatten, sondern auch danach, in welcher Weise die Rezensenten über sie berichteten bzw. welche Bilder sie verwendeten, um das Bühnengeschehen in Worte zu fassen. Eventuell geben die Kritiker abseits ihrer künstlerischen Bewertung Informationen über die Ästhetik preis, die an jenem Abend hörbar und sichtbar wurde, und verraten damit indirekt etwas über die künstlerische Motivation von Komponist und Choreograf.

2.1 Die Rezeption der Ballets Russes in Russland und Frankreich

Anfang des 2o. Jahrhunderts informierten Individuen wie Nikolaj Minskij die russische Bevölkerung über das Pariser Kulturleben. Der russische (Theater-) Autor und Essayist lebte seit 1905 als Exilant in der französischen Hauptstadt

hingewiesen. Vgl. Taruskin, Stravinsky and the Russian Traditions, Bd. 2, S. 1453. Taruskin bezieht sich mit seiner Anmerkung über Ansermet auf dessen Brief an Stravinskij vom 12. Juli 1919, ediert in: Stravinsky in Pictures and Documents, hg. von Stravinsky und Craft, S. 164f. Ansermet lässt Stravinskij darin detaillierte Informationen über das Pianola sowie dessen Vor- und Nachteile zukommen. Er gibt darin auch an, diese Informationen aus Gesprächen mit einem Pianola-Spieler erhalten zu haben.

648 Matthew McDonald versucht in seinem 2010 erschienenen Aufsatz "Jeux de Nombres. Automated Rhythm in the Rite of Spring" nachzuweisen, dass Stravinskij zur Generierung der irregulären Rhythmen und Metren im Sacre während des kompositorischen Prozesses auf ein mechanisches Verfahren zurückgegriff. Vgl. Matthew McDonALD: "Jeux de Nombres: Automated Rhythm in ,The Rite of Spring“', in:Journal of the American Musicological Society 63/3 (2010), S. 499-551. 
und arbeitete von dort aus vorwiegend als Korrespondent für verschiendene Zeitungen und Magazine in Russland. ${ }^{649}$ Über die Sacre-Premiere und Publikumsreaktionen berichtet er seinen Landsleuten einen Tag nach der Uraufführung in der Moskauer Tageszeitung Utro Rossii Folgendes:

Любопытно то, что европейская критика провозгласила Дягилева смелымъ новаторомъ и преобразователемъ хореографіи какъ разъ тогда, когда онъ ставилъ старые, романтическіе по содержанію и классическіе по технике балеты [...]. Но какъ только Нижинскій, а вследъ за нимъ и Стравинскій задались целью кореннымъ образомъ преобразовать технику и содерженіе балета, публика озверела и критики заговорили о северныхъ варварахъ. ${ }^{650}$

Es ist erstaunlich, dass die europäische Kritik Djagilev ausgerechnet dann als mutigen Neudenker und Reformator der Choreografie proklamiert hat, als er veraltete, inhaltlich romantische und handwerklich klassische Ballette zeigte [...]. Doch sobald Nižinskij und in der Folge Stravinskij sich fest vornahmen, Technik und Inhalt des Balletts grundlegend zu verändern, geriet das Publikum außer sich, und Kritiker sprachen über die nördlichen Barbaren.

Sowohl die „europäischen“ Kritiker als auch er als russischer Korrespondent scheinen den Sacre also als eine ästhetische Zäsur im Werk der Ballets Russes wahrzunehmen. Doch zwei Dinge fallen hierbei besonders auf: Zum einen scheint es beinahe so, als hätten ,die Russen' anders über die Ballets Russes berichtet als ,die Franzosen' bzw. ,Europäer' ${ }^{651}$ Die französischen Kritiker hatten Djagilevs und insbesondere Fokins Ballettproduktionen aufgrund

649 Vgl. Maxim D. Shrayer: Abschnitt ,Nikolay Minsky (1855-1937)', in: An Anthology of Jewish-Russian Literature. Two Centuries of Dual Identity in Prose and Poetry, 2 Bde., hg. von DERS., Armonk 2007, Bd. 1: 1801-1953, S. 83-85: Minskij war Sympathisant der Bol'ševiki und gab zusammen mit Vladimir Lenin und Maksim Gor'kij von Oktober bis Dezember 1905 die Tageszeitung Novaja Žizn' heraus - die erste offizielle Zeitung der bolschewikischen Fraktion der Sozialdemokratischen Arbeiterpartei Russlands. Im Dezember 1905 wurde er verhaftet. Nachdem er gegen Kaution freigelassen worden war, floh er ins Ausland und lebte dort bis zu seiner Begnadigung 1913.

$65^{\circ}$ Nikolaj Minskij: „Prazdnik” Vesny“, in: Utro Rossii, Nr. 123, 30. Mai/12. Juni 1913, S. 2.

651 Minskij verweist durch seine Formulierung auf einen signifikanten Unterschied zwischen der „europäischen“ Kritik und seiner eigenen - der ,russischen'. Eine solche Dichotomie zwischen ,Europäern' bzw. ,Franzosen` und ,Russen` muss natürlich als Generalisierung begriffen werden und ist allein deshalb schon problematisch, weil Journalisten und (Kunst-)Kritiker zu Beginn des 2o. Jahrhunderts größtenteils über einen bildungsbürgerlichen Hintergrund und eine akademische Ausbildung verfügten und auch die Leserschaft einen vergleichbaren Hintergrund vorwies. Dennoch sollen sich die folgenden Ausführungen an der von Minskij vorgebrachten Vereinfachung orientieren. Zur Situation der Journalisten zu Beginn des 2o. Jahrhunderts vgl. Jörg REQUATE: Journalismus als Beruf. Entstehung und Entwicklung des Journalistenberufs im 19. Jahrhundert. Deutschland im internationalen Vergleich, Göttingen 1995. 
ihrer Andersartigkeit nahezu ausnahmslos gelobt und als innovativ oder gar revolutionär charakterisiert; ${ }^{652}$ Minskij hingegen beschreibt sie als antiquiert und uninspiriert. Und zum anderen beurteilt er auch den Sacre offenbar vollkommen anders als seine europäischen Kollegen: Zwar sieht auch er die erwähnte ästhetische Zäsur, bewertet diese aber gänzlich unterschiedlich. Die Europäer, so Minskij, seien plötzlich verärgert gewesen und hätten sich ob der augenscheinlichen Barbarei mokiert. Tatsächlich sei mit Stravinskijs und Nižinskijs neuem Werk nun aber zum ersten Mal etwas wirklich Neues auf der Ballettbühne zu sehen.

Einige Abschnitte später führt Minskij dies noch weiter aus. Dabei beschreibt er zwar nur die Choreografie, am Ende verweist er aber explizit darauf, dass alles von ihm Geschriebene auch für die Musik gelte: 653

Нижинский въ своей новой манерь постарался избегнутъ той и другой опасности. Критикуя ,Праздник Весны', Лало въ Тетps восклицаетъ: „Во всемъ балете нетъ не одного движения, ни одной линии, которыя носили бы печатъ грации, изящества, легкости, благородства, красноречия и выразительности'. Перефразируя эти слова, хочется воскликнутъ: „Какъ хорошо, что в балете Нижинскаго нетъ не одной линии, ни одного движения, которые бы носили печатъ грации, изящества, легкости, благородства, красноречия и выразительности', ибо все эти термины не что иное, какъ румяна и белила, подъ которыми скрываются усталостъ и рутина.

[...] Я назвалъ [новую] манеруНижинскаго не реализомъ, но нео-реализомъ. Если исходная точка его балета чисто реалъная, то цель его - насквозь эстетическая. Посредствомъ ритма онъ отрываетъ реальное движение отъ действительности и делаетъ его не только объектомъ искусства, но искусственнымъ, почти автомато-образнымъ. ${ }^{654}$

Nižinskij hat sich auf seine eigene neue Art bemüht, die ein oder andere Gefahr zu vermeiden. ,Das Frühlingsfest' kritisierend, verkündet Lalo in Temps: Im ganzen Ballett gibt es nicht eine Bewegung, nicht eine Linie, die die Signatur der Anmut, der Feinheit, der Leichtigkeit, des Edelmutes, der Redekunst und der Ausdruckskraft tragen. Diese Wörter paraphrasierend, möchte man ausrufen: Ach, wie gut, dass es im Ballett von Nižinskij nicht eine einzige klare Linie gibt, keinerlei Bewegung, die die Signatur der Anmut, der Feinheiten, der Leichtigkeit, des Edelmutes, der Redekunst und der Ausdruckskraft tragen würde, weil

652 Vgl. Juliet Be Llow: Modernism on Stage. The Ballets Russes and the Parisian Avant-Garde, Farnham 2013, S. 47.

653 Vgl. Minskij, „Prazdnik” Vesny“, S. 2: „Все, что говорилъ о танцахъ Нижинскаго, вполне относится къ партитуре Стравинскаго [...].“ „Alles, was ich über die Tänze von Nižinskij gesagt habe, lässt sich durchaus auf die Partitur von Stravinskij [...] beziehen.“

654 Vgl. Minskij, „Prazdnik” Vesny“, S. 2. 
all diese Termini nichts anderes sind als rote und weiße Schminke, unter denen sich Trägheit und Schematismus verstecken.

[...] Ich würde den [neuen] Stil von Nižinskij [deshalb auch] nicht Realismus nennen, sondern Neo-Realismus. Wenn der Ausgangspunkt seines Balletts rein real ist, so ist sein Ziel ein durch und durch ästhetisches. Durch den Rhythmus entreißt er die reale Bewegung der Wirklichkeit und macht sie nicht nur zum Gegenstand der Künste, sondern sogar künstlich, fast schon automatenhaft.

Nicht nur macht Minskij hier noch einmal deutlich, dass er gerade jene Punkte an der Sacre-Choreografie als positiv empfand, die der französische Journalist Pierre Lalo kritisiert hatte; er weist auch darauf hin, dass das von den französischen Kritikern so negativ belegte Authentische nur als Ausgangspunkt der Choreografie zu bewerten sei. Durch den Rhythmus löse Nižinskij dann aber jene archaischen Bewegungen aus der Wirklichkeit heraus und verwandle sie in artifizielle, fast schon automatenhafte Kunstobjekte.

Um also den im fernen Russland weilenden Lesern seinen subjektiven Eindruck der tänzerischen Bewegungen auf der Bühne vor das geistige Auge zu führen, gebraucht Minskij ausgerechnet das Bild des Automaten. Die Tänze erinnerten ihn also offenbar an Maschinen, die eine ihnen einprogrammierte Tätigkeit ausführten - unbewusst, willenlos und fremdgeleitet.

Die meisten russischen Rezensionen, die unmittelbar nach der Pariser Uraufführung erschienen, stammen von Tanz- oder Theaterkritikern. Wie Minskij beschäftigen sie sich vor allem mit der Choreografie und erwähnen die Musik oft nur am Rande. ${ }^{655}$ Auch die französische Proklamation des Werkes als Skandalon rekurriert grosso modo auf die Choreografie. ${ }^{656}$ Im Folgenden sollen deshalb vor allem die Beschreibungen der Choreografie einer Revision unterzogen werden, und zwar auf zwei Ebenen. (1.) Da Kunstwerke und deren zeitgenössische Rezeption immer auch Seismografen des Zeitgeistes sind, ${ }^{657}$ kann anhand von Minskijs Sacre-Kritik gemutmaßt werden, dass die

655 Vgl. Svetlana SAVEn Ko: „,Vesna svyashchennaya in Its Homeland: Reception of ,The Rite in Russia and the Soviet Union“, in: Avatar of Modernity, hg. von Danuser und Zimmermann, S. 240-262, hier S. 245.

656 Vgl. Caddy, The Ballets Russes and Beyond, S. 121. Das Gros der französischen Rezensionen ist versammelt bei Bullard, The First Performance. Auch bei François Lésure findet sich eine Auswahl an französischen Presseberichten. Vgl. Lésure, Dossier de presse. Die meisten von ihnen sind im Original über den Online-Katalog der Bibliothèque nationale de France zugänglich.

657 Dies zeigt beispielsweise Ursula Brandstätter auf. Vgl. Ursula BRANDStätter: Bildende Kunst und Musik im Dialog. Ästhetische, zeichentheoretische und wahrnehmungspsychologische Überlegungen zu einem kunstspartenübergreifenden Konzept ästhetischer Bildung, Augsburg 2004, S. 206. 
kulturelle Disposition der russischen Rezipienten im Jahr 1913 eine andere war als die der französischen. Daraus ergeben sich folgende Fragen: Ist Minskijs Beobachtung repräsentativ für die russische Berichterstattung, und hatten die Russen die Ballets Russes im Allgemeinen und den Sacre im Besonderen tatsächlich anders rezipiert als die Franzosen? Unabhängig davon, wie Russen und Franzosen den Sacre bewerteten, soll infolgedessen (2.) danach gefragt werden, wie die Rezensenten über die Choreografie berichteten bzw. welche Bilder sie verwendeten, um die Bewegungen zu beschreiben. Oder konkret: Erkannten auch andere Kritiker im Sacre dieselbe mechanistische Ästhetik wie Minskij?

Aktuelle Sacre-Diskurse werden vielfach von Begriffen dominiert, die dem Phänomen des Primitivismus zuzuordnen sind: Archaismus, Ursprünglichkeit und Barbarei werden mindestens genauso häufig genannt wie Ritualität, Opfer und Gewalt. ${ }^{658}$ Vergleicht man damit die europäische Rezeption von 1913, ergeben sich auf den ersten Blick kaum wesentliche Unterschiede: Schon damals beschrieben französische Journalisten das Ballett überaus häufig als Stilisierung des Barbarischen oder gar rohe Darstellung desselbigen. 659

Russland und sein Volk mit dem Unzivilisierten, Anderen und Exotischen zu konnotieren, war im Frankreich jener Zeit keine Novität. Noch bis weit ins

658 Vgl. Kapitel I.2.

659 Vgl. Nancy Berman: Primitivism and the Parisian Avant-Garde. 1910-1925, PhD Dissertation, McGill University 2001, S. 98f. Berman beschäftigt sich in ihrer Dissertation mit dem Phänomen des Primitivismus im Paris des beginnenden 20. Jahrhunderts, untersucht, inwiefern sich dieser in musikalischen Werken äußert (Le Sacre du printemps [1913], Les Noces [1923] und La Création du monde [1923]) und bezieht sich hier unter anderem auf Pierre LALO: „Remarks on the Ballet, Le Sacre du printemps“', übers. von Daniel Gregory Mason, in: The New Music Review 12/143 (1913): „Believe me, I can fully appreciate all the value to our so-called amateurs and real snobs of an esthetics which represents things further back by principle or system of esthetics than the farthest archeology, and aspires to discover the principles of the primordial humanity to ,stylize', as they say in their jargon, the original barbarism. But it is impossible for me to agree with them. There is no ,stylisation' in the ,Sacre du printemps', - one may note in passing that people never spoke so much of ,style' as now, in a time which is almost destitute of it. The dances of Esquimaux in the natural state are exactly like those of the ,Sacre', which could be mistaken for them, and neither of them has any style, for the simple reason that neither the crude nor the barbarious can have style." Ebd., ediert in: Bullard, The First Performance, Bd. 2, S. 238-249, hier S. 243. Der überwiegende Teil der französischen Kritiker hatte über den Sacre negativ berichtet - und zwar sowohl über die Musik als auch über die Choreografie. Vgl. Järvinen, The Myth of Genius in Movement, S. 299. 
19. Jahrhundert hinein hatten Europäer das Zarenreich als Hybrid zwischen Europa und Asien gesehen und seinen zivilisatorischen Status quo irgendwo zwischen Gesittung und Barbarei verortet. Zu Beginn des 20. Jahrhunderts hatte sich an dieser Vorstellung zwar noch nicht allzu viel geändert, Franzosen fingen nun aber an, die russischen Stereotype zu bewundern. ${ }^{660}$ Gerade weil man Russland also den westlichen Gesellschaften im zivilisatorischen Prozess als weit unterlegen erachtete, glaubte man, in deren Kunst, Bewegung und Verhalten eine naive Frische und Kraft zu erkennen, die dem Westen abhandengekommen war. ${ }^{661} \mathrm{Im}$ Tanz schien sich diese postulierte Körper-Geist-Dichotomie zwischen Russen und Franzosen besonders deutlich

66o Der Russlandbericht des französischen Reiseschriftstellers Astolphe de Custine hatte das Russlandbild der Franzosen entscheidend geprägt. La Russie en 1839 war 1843 erschienen und aufgrund des großen Erfolgs noch im selben Jahr ins Englische und Deutsche übersetzt worden. Vgl. Berman, Primitivism and the Parisian Avant-Garde, S. 64-77. Custine entwirft in seinem Bericht aus unterschiedlichen Motivationen heraus ein äußerst negatives Russlandbild. Er wollte (1.) eine erste realistische Darstellung der russischen Verhältnisse geben, (2.) das autokratische System und die damit einhergehenden Missstände in der Gesellschaft anklagen und (3.) Europa vor der russischen Gefahr warnen. Vgl. hierzu unter anderem Christian Sigrist: Das Russlandbild des Marquis de Custine. Von der CivilisationskritikzurRusslandfeindlichkeit,Frankfurta.M.199o,S. 23f. Raymond T. McNally beschreibt, wie auch schon die französische Russlandberichterstattung der 1910er- und 1920er-Jahre zur Russophobie in Frankreich beitrugen. Vgl. Raymond T. MCnALLY: „The Origins of Russophobia in France. 1812-1830“, in: The American Slavic and East European Review 17/2 (1958), S. 173-189. Zum negativen Russlandbild, das in Europa seit über 500 Jahren existierte, vgl. Marshall T. PoE: ,A People Born to Slavery.' Russia in Early Modern European Ethnography. 1448-1748, Ithaca und London 2000; Martin MAliA: Russia under Western Eyes. From the Bronze Horseman to the Lenin Mausoleum, Cambridge 1999; Effi BÖHLKE: „Russlandbilder aus dem 18. und 19. Jahrhundert. Entworfen in der deutschen und französischen politisch-philosophischen Literatur", in: Osteuropa 5 (2002), S. 576597; Michel Mervau und Jean-Claude Ro Be rTi: Une infinie brutalité. L'image de la Russie dans la France de XVI e et XVII e siècle, Paris 1991. Die Beliebtheit der russischen Literatur soll genauso zum Gesinnungswandel beigetragen haben wie die Französisch-Russische Allianz. Vgl. hierzu Gianni CARIANI: „La découverte de l'art russe en France. 1871-1914“, in: Revue des études slaves 71/2 (1999), S. 391-405; Murielle Avice-Hanoun: „Lalliance franco-russe (1892-1914)“, in: Deutschland - Frankreich - Russland. Begegnungen und Konfrontationen, hg. von Ilja Mieck und Pierre Guillen, München 200o, S. 109-124; George F. Kennan: The Fateful Alliance. France, Russia, and the Coming of the First World War, New York 1984.

661 Vgl. Hanna Järvinen: „The Russian Barnum'. Russian Opinions on Diaghilev's Ballets Russes. 1909-1914“, in: Dance Research 26/1 (2008), S. 18-41, hier S. 25; DIES.: „,Great Horizons Flooded with the Alien Light of the Sun'. ,Le Sacre du Printemps' in the Russian Context“, in: Dance Research 31/1 (2013), S. 1-28, hier S. 5. Zur Vorstellung, vorzivilisatorische Kunst könne die eigene Kultur wiederbeleben, vgl. unter anderem Colin Rhodes: Primitivism and Modern Art, London 1994, S. 8; Elazar BARKAN und Ronald Bush: „Introduction“, in: Prehistories of the Future. The Primitivist Project and the Culture 
zu offenbaren. Der französische Schriftsteller Abel Bonnard konstatierte dementsprechend während der ersten Ballets-Russes-Saison 1910:

Nous [das heißt die Franzosen, LZ] ne savons plus qu'est la danse. Nous nous sommes plus assez sauvages. Nous sommes des gens trop civilisés, trop policés, trop effacés: nous avons perdu l'habitude d'exprimer notre sentiment par tout notre corps; à peine de nous le laissons se produire sur notre visage et transparaître dans nos paroles; et il ne lui reste bientôt plus ques nos yeux où se réfugier. Nos gestes mêmes sont appauvris, limités, réduits et tombent de nous comme les branches d'un arbre qu'on émonde. Nous sommes tout en tête. Notre corps est pour ainsi dire abandoné $\left[\ldots . .{ }^{662}\right.$

Jene „Russophilie“663, mit der Djagilevs erste Ballets-Russes-Saison zusammenfiel, trug nicht nur entscheidend zum phänomenalen Erfolg der Kompanie bei, sondern sorgte auch für das Stigma des Primitiven und Exotischen, das seine Produktionen von Anfang an trugen - ein Stigma, das das Pariser Publikum und die französische Presse allerdings nicht negativ bewerteten, sondern beinahe ausschließlich positiv. ${ }^{664}$ Pars pro toto steht dafür das Resümee von Jean-Louis Vaudoyers, das der Publizist im Anschluss an die Saison 1910 in der Revue de Paris zieht:

Restés barbares dans une Europe qui est, si l'on peut dire, civilisée jusqu'à la corde, les Russes sont au moment le plus fécond. Le plus beau, de leur développement intérieur. Très neuf, avides et sincères comme des enfants, ils se donnent tout entiers et se cherchent avec fièvre. Ils ne sont pas entravés comme nous par les formules, et l'incrédulité ne les a pas énervés; ils ignorent la satiété occidentale. ${ }^{665}$

Mit der Saison 1913 - insbesondere mit der Uraufführung des Sacre - erfuhr die Begeisterung der Franzosen für die russische Rohheit und Exotik allerdings eine

of Modernism, hg. von Dies., Stanford 1995, S. 1-19; Shearer West: Fin de Siècle. Art and Society in an Age of Uncertainty, London 1993, S. 131-138.

662 Abel Bonnard: „Le Ballet Russe“, in: Le Figaro, 18. Juni 1910, S. 1.

663 Gianni CARIANi: Une France russophile? Découverte, réception, impact. La diffusion de la culture russe en France de 1881 à 1914, PhD Dissertation, Université de Strasbourg 1998, S. 166. Vgl. auch ebd., S. 156-187; Anne Hogenhuis-Seliverstoff: „Russophilie et germanophobie en France et en Russie entre 1878 et 1918“, in: Deutschland - Frankreich Russland, hg. von Mieck und Guillen, München 2000, S. 71-86.

664 Einen Überblick über die Ballets-Russes-Berichterstattung in Frankreich gibt Caddy, The Ballets Russes and Beyond, S. 115-159. Vgl. auch Joan Acocella: The Reception of Diaghilev's Ballets Russes by Artists and Intellectuals in Paris and London. 1909-1914, PhD Dissertation, Rutgers University 1984.

665 Jean-Louis VAudoye R: „Variations sur les Ballets Russes“, in: La Revue de Paris 17/4 (15. Juli 1910), S. 333-352, hier S. 333 . 
Wende. Zwar gab es durchaus auch positive Stimmen, doch wie von Minskij beobachtet, störte viele Rezensenten die veränderte Ästhetik, die die Ballets Russes mit einem Mal präsentierten, und so beklagten französische Kritiker am Sacre zum Beispiel, dass sein fremdes Sujet - anders als bei L'Oiseau de feu oderPétrouchka -nicht in eine ihnen vertrauteSprache übersetzt worden sei. ${ }^{666}$ Der französische Musikwissenschaftler Louis Laloy machte diesen Wahrnehmungswandel in seiner Besprechung der Sacre-Premiere in der Grande revue sehr deutlich:

Le musicien qui imite un orchestre exotique ne renonce pas pour cela aux instruments nationaux; la danse comme la musique de nos pays a son langage, approprié à nos moeurs, à nos tempéraments, à nos traditions, à nos façons de penser et de sentir. C'est dans ce langage que l'artiste doit traduire les impressions qui lui viennent de la nature ou d'un art étranger; il sera conduit parfois à l'enrichir de locutions nouvelles; mais il est vain de prétendre le remplacer par autre langage, que personne n'entend, pas même celui qui le parle à la façon des perroquets, articulant des signes dont le sens lui échappe. ${ }^{667}$

Die Ballets Russes waren in Frankreich von ihrer ersten Saison an gerade wegen ihrer Andersartigkeit gelobt worden. Doch genau dieses Andere und Exotische konnotiert Laloy nun mit einem Mal negativ.668 Andere Kritiker machten sich darüber sogar lustig - zum Beispiel Adolphe Boschot, der in seiner viel zitierten Sacre-Rezension in der Tageszeitung L'Écho de Paris folgenden Abschnitt schrieb:

On veut nous montrer les danses de la Russie préhistorique: on nous présente donc, pour faire primitif, des danses de sauvages, de caraïbes et de canaques ... Soit, mais il est impossible de ne pas rire. Imaginez des gens affublés des couleurs

666 Vgl. Berman, Primitivism and the Parisian Avant-Garde, S. 93; Sarah Kenne L: „Le Sacre du printemps. Primitivism, Popular Dance, and the Parisian Avant-Garde“, in: Nottingham French Studies 44/3 (2005), S. 4-23, hier S. 15.

667 Louis Laloy: „La Musique“, in: La Grande Revue, 25. Juni 1913, ediert in: Bullard, The First Performance, Bd. 3, S. 16o-163.

668 Vgl. Caddy, The Ballets Russes and Beyond, S. 144. Die Kritik an den Ballets Russes wurde durch den aufkeimenden Nationalismus und Antisemitismus noch zusätzlich geschärft. Auch gegen Gabriel Astruc, der sich in vielfältiger Weise für nicht französische Kunst einsetzte, wurde öffentlich protestiert. Vgl. Berman, Primitivism and the Parisian Avant-Garde, S. 93-99; Caddy, The Ballets Russes and Beyond, S. 136f. sowie Kapitel III.1.4. Zum Erstarken des Nationalismus in Frankreich vgl. Eugen Weber: The Nationalist Revival in France. 1905-1915, Berkeley und Los Angeles 1959; Robert Томвs (Hg.): Nationhood and Nationalism in France. From Boulangism to the Great War. 1889-1918, London 1991; James F. Mcmillan: Twentieth-Century France. Politics and Society. 1898-1991, London u.a. 1992, S. 31-38. 
les plus hurlantes, de bonnets pointus et de peignoirs de bains, de peaux de bêtes ou de tuniques pourpres, gesticulant comme des possédés, [...] on trouverait toujours de quoi rire. ${ }^{669}$

Auch in Russland führte der Sacre dazu, dass die Ballets Russes 1913 anders wahrgenommen wurden - allerdings mit umgekehrtem Vorzeichen, hatten viele russische Rezensenten Djagilev und seine Pariser Kompanie bislang doch vor allem kritisiert. ${ }^{670}$ Für die Russen war die Ästhetik der in Paris so gefeierten Fokin-Ballette alles andere als neu: Nicht nur orientierte sich ihre Ausstattung an derjenigen der Mamontov-Opern, und einige der Ballette waren bereits in Sankt Petersburg zu sehen gewesen; ${ }^{671}$ viel entscheidender war die Tatsache, dass die choreografischen Neuerungen von Fokin - genau jene also, welche die Franzosen so euphorisch bejubelten - auf russischen Bühnen schon seit 1900 präsent waren, und zwar vor allem in den Arbeiten des russischen Choreografen Aleksandr Gorskij, der seit 1900 als Ballettregisseur des kaiserlichen Bol'šoi-Theaters in Moskau wirkte. ${ }^{672}$ Sowohl Gorskij als auch Fokin hatten

669 Adolphe Возснот: „Le Sacre du printemps. Ballet de MM. Roerich, Stravinsky et Nijinsky“, in: L'Écho de Paris, Nr. 10518, 30. Mai 1913, S. 6.

670 Es gibt nur sehr wenige Untersuchungen zur Rezeption der Ballets Russes in Russland. Am ausführlichsten beschäftigte sich damit bislang die finnische Tanzhistorikerin Hanna Järvinen. Vgl. Järvinen, „,The Russian Barnum“. Järvinen schreibt, dass die Russen nicht verstehen konnten, dass man die zarististische Kunstform Ballett mit Wörtern wie „wild“, „exotisch“ oder „barbarisch“ beschrieb. Vgl. ebd., S. 26. Deshalb äußerte sich die Kritik an Djagilev in Russland unter anderem auch darin, dass man ihm vorwarf, den Franzosen ein verzerrtes Russlandbild zu vermitteln oder gar zweitklassige Tänzer als anerkannte Stars zu vermarkten. Vgl. ebd., S. 28-30; dies., Dancing Genius, S. 191f. Zur spezifischen Rezeption des Sacre in Russland (und der Sowjetunion) vgl. Järvinen, „,Great Horizons Flooded with the Alien Light of the Sun " sowie den Text der russischen Musikwissenschaftlerin Savenko, „Vesna svyashchennaya' in Its Homeland“. Einige russische Sacre-Rezensionen finden sich auch bei Taruskin, Stravinsky and the Russian Traditions, Bd. 2, S. 1006-1022 und bei Irina VeršıninA: Rannie balety Stravinskogo. ,Žar-ptica' ,Petruška' ,Vesna svjaščennaja', Moskau 1967, S. 136-143. Dank eines Stipendiums des Deutschen Historischen Instituts Moskau war es mir möglich, diverse russische Ballets-Russes-Berichte aus den Beständen der Rossijskaja Gosudarstvennaja Biblioteka in Moskau einzusehen.

671 Vgl. Järvinen, The Myth of Genius in Movement, S. 147: Unter anderem war Les Sylphides (Paris, 1909) bereits 1907 unter dem Titel Chopiniana in Sankt Petersburg aufgeführt worden; Le Pavillon d'Armide (Paris, 1909) 1907 im Mariinskij-Theater in Sankt Petersburg zu sehen und Carnaval (Paris, 1910) zuvor (ebenfalls 1910) in Pavlovsk aufgeführt worden.

672 Das westliche Publikum wurde erst durch Fokin auf jene Reformästhetik aufmerksam, die Gorskij bereits ab 1900 in Moskau etabliert hatte. Vgl. Scholl, From Petipa to Balanchine. Dass Gorskij im Westen sehr lange kaum Aufmerksamkeit erzielte, ist sicherlich mitunter der Tatsache zuzuschreiben, dass sich Fokin im Westen auch als alleiniger Ballettreformer inszenierte. So hatte er beispielsweise 1914 einen Artikel in der New York Times veröffentlicht, in dem er fünf Prinzipen des Neuen Balletts aufstellte. Vgl. Michel FoKIn: „Five 
es sich zum Ziel gemacht, mit Konventionen des klassischen Petipa-Balletts zu brechen, und sich dabei vom aktuellen russischen Sprechtheater beeinflussen lassen. ${ }^{673}$ Mit Erscheinen der Aufsatzsammlung Teatr. Kniga o novom teatre, die nicht nur in Theaterkreisen für Aufmerksamkeit sorgte, ${ }^{674}$ begannen russische Tanzkritiker, die sich darin manifestierende Reformterminologie auf die neuen Ballettformen anzuwenden: In Anlehnung an den Begriff des novyj teatr (Neues Theater) bezeichneten sie ab 1909 sowohl Gorskijs (ab 1900 in Moskau) als auch Fokins (ab 1905 in Sankt Petersburg, dann aber vor allem ab 1909 in Paris entstandene) Arbeiten vermehrt als novyj balet (Neues Ballett), um sie vom staryj balet (Alten Ballett) der Petipa-Ära abzugrenzen. ${ }^{675}$ Wie einflussreich der Reformband zu jener Zeit gewesen sein muss, zeigt sich unter anderem auch in der russischen Architekturszene: Auch hier bediente man sich der Reformausdrücke, um neuere Stile von älteren abzugrenzen. ${ }^{676}$ Nichtsdestoweniger - und das ist bezüglich der russischen Djagilev-Kritik entscheidend - galt den Theaterreformern Ballett per se als veraltet und zaristisch und daher als eine Kunstform, die ihnen für ihre zeitgenössischen Experimente - wie etwa das von ihnen geforderte Theater der Zukunft (Teatr buduščego - nicht geeignet schien. ${ }^{677}$

Principles for the New Ballet", in: The New York Times, 6. Juli 1914, o.S. Vier dieser fünf Prinzipien können aber schon in Gorskijs CEuvre nachgewiesen werden. Vgl. Järvinen, The Myth of Genius in Movement, S. 142f.; Scholl, From Petipa to Balanchine, S. 6of. Zu Gorskijs und Fokins Ballettreformen allgemein vgl. Elizaveta SuRIC: Choreografičeskoe iskusstvo $v$ dvadcatych godov, Moskau 1979 bzw. die englische Übersetzung: Elizabeth Souritz: Soviet Choreographers in the 1920s, übers. von Lynn VISson, hg. von Sally BANES, Durham 1990.

673 Gorskijs wichtigste Produktionen entstanden in Moskau und waren stark von den zeitgleich erfolgreichen Produktionen des Moskovskij Chudožestvennyj teatr beeinflusst. Fokins erste Arbeiten in Sankt Petersburg und dann später in Paris waren hingegen eher von den frühen Arbeiten des zu der Zeit in Sankt Petersburg wirkenden Mejerchol'd beeinflusst sowie von der Bewegungssprache Duncans. Vgl. Scholl, From Petipa to Balanchine, S. 58 f. Zur Ballettästhetik Marius Petipas vgl. unter anderem Lynn Garafola: „Russian Ballet in the Age of Petipa“, in: The Cambridge Companion to Ballett, hg. von Kant, S. 151-163.

674 Vgl. Kapitel II.3.1. und III.1.2.

675 Vgl. Scholl, From Petipa to Balanchine, S. 55. Scholl gibt an, dass zwischen 1909 und 1911 direkt nach der Veröffentlichung von Teatr. Kniga o novom teatre - russische Tanzkritiker vermehrt von jenem neuen Ballettstil berichteten. So unter anderem Valerian SvETLOv: Sovremennyj balet, Sankt Petersburg 1911; Andrej Levinson”: „O novom” balete“, in: Apollon 8 (1911), S. 30-49; Andrej LeVinson": „O starom” i novom" balete“, in: Ežegodnik” imperatorskich teatrov"1 (1913), S. 1-2O.

676 Vgl. Scholl, From Petipa to Balanchine, S. 146; William Craft Brumfie ld: The Origins of Modernism in Russian Architecture, Berkeley 1991, S. 47-48.

677 Vgl. Kapitel II.3.1. 
Vor diesem Hintergrund überrascht umso mehr, dass die russische SacreBerichterstattung größtenteils positiv ausfiel, ${ }^{678}$ denn schließlich waren es vor allem russische Ballett- und Theaterkritiker, die aus Paris berichteten. ${ }^{679}$ E. Pann" beispielsweise beschrieb das Werk in der Moskauer Theaterzeitschrift Maski als das Gelungenste, was die Djagilev-Kompanie bislang hervorgebracht habe, und ernannte Stravinskij und Nižinskij zu den Erneuerern von Tanz und Musik:

Можно рассматривать какъ самое крупное событие въ молодой пока истории Дягилевскаго предприятия: она ознаменовала собою решительное вступление на путь Ритма. Оба молодых новатора; одинъ въ области музыки, другой въ области хореографии, дали крупное и убедительное художественное усилие. ${ }^{680}$

Man kann es [das Ballett Sacre] als das größte Ereignis in der jungen Geschichte des Djagilev-Unternehmens betrachten: Es kennzeichnet den entschlossenen Eintritt auf den Weg des Rhythmus. Beide jungen Erneuerer haben sich in beachtenswerter Weise künstlerisch bemüht; der eine auf dem Gebiet der Musik, der andere auf dem Gebiet der Choreografie.

Auch der russische Theaterkritiker und Balletthistoriker Valerian Svetlov weist in der Peterburgskaja Gazeta darauf hin, dass der Sacre auf dem Gebiet der

678 Vgl. Järvinen, „The Russian Barnum“', S. 27; Järvinen zeigt, dass die positive Berichterstattung in Russland bereits mit Nižinskijs Jeux-Choreografie begann. Vgl. ebd., S. 34. Die Erstaufführung von Jeux fand ebenfalls während der Ballets-Russes-Saison 1913 statt, allerdings zwei Wochen vor dem Sacre. Die Jeux-Tänzer wurden von Rezensenten unter anderem mit Puppen oder Automaten verglichen. Vgl. Sarah Kennel: Bodies, Statues, and Machines: Dance and the Visual Arts in France, 1900-1925, PhD Dissertation, University of California (Berkeley) 2003, S. 231.

679 Vgl. Savenko, „Vesna svyashchennaya in Its Homeland“, S. 245. Es erschienen in Russland im unmittelbaren Anschluss an die Erstaufführung nur insgesamt drei Rezensionen, die sich vor allem mit der Musik des Sacre beschäftigten. Eine von ihnen soll hier vernachlässigt werden, da nur zwei der Kritiker an jenem Abend tatsächlich vor Ort gewesen waren. Von ihren Berichten fiel einer positiv und einer negativ aus. Und der negative Bericht stammte ausgerechnet von Andrej Rimskij-Korsakov. Taruskin begründet dessen negative Grundhaltung gegenüber dem Sacre deshalb mit den persönlichen Spannungen zwischen der Familie Rimskij-Korsakov und Djagilev, in die schließlich auch Stravinskij hineingezogen wurde. Zu einer näheren Besprechung der russischen Musikrezensionen vgl. Taruskin, Stravinsky and the Russian Traditions, Bd. 2, S. 1006-1022. Zu Taruskins Begründung der negativen Kritik von Andrej Rimskij-Korsakov vgl. ebd., S. 1013f. Zu den Streitigkeiten zwischen der Familie Rimskij-Korsakov und Djagilev bzw. Stravinskij vgl. außerdem Anm. $33^{2}$.

68 o E. Pann, zit. in: Järvinen, „,Great Horizons Flooded with the Alien Light of the Sun“, S. 14. Järvinen gibt als Quelle E. PANn, in: Maski 7-8 (1913-1914) an. Die zitierte Passage konnte an angegebener Stelle allerdings nicht gefunden werden. 
Choreografie absolut neu und ohne Vorbilder sei, und lobt ferner die außergewöhnliche Leistung von Maria Piltz, die die Auserwählte getanzt hatte:

Девушка начинаетъ танецъ, который длится четыре минуты. Вещь неслыханная въ летописяхъ хореграфий, и остается удивляться выносливости и мужеству молоденькой Пильцъ, которая выдерживаетъ эту хореографическую пытку, обессиливая лишь по требованию либретто, а не на самомъ деле. 681

Die junge Frau beginnt den Tanz, der vier Minuten dauert. Das ist unglaublich in der Geschichte der Choreografie, und man kann sich nur wundern über die Ausdauer und den Mut der jungen Piltz, die diese Tanzfolter über sich ergehen lässt; entkräftet (ist sie) lediglich, weil es das Libretto vorgibt, nicht tatsächlich.

Und selbst Anatolij Lunačarskij, Mitherausgeber des Reformbandes Teatr. Kniga o novom teatre und nachmaliger sowjetischer Volkskommissar für Bildungswesen, wirkt begeistert von der Uraufführung, wenn er in der Sankt Petersburger Kunst- und Kulturzeitschrift Apollon Folgendes notiert:

Нижинскаго прежде всего приходится похвалить за то, что движение на сцене съ великой точностью и замечательнымъ искусствомъ подчинено талантливой звукописи Стравинскаго. Для того же, чтобы обрести ключъ къ особенностямъ примитивнаго жеста или стаднаго порыва - Нижинский обратился къ вышивкамъ, очень старымъ лубкамъ и вообще разнаго рода примитивной живописи. ${ }^{682}$

Nižinskij muss man zunächst dafür loben, dass die Bewegung auf der Bühne mit großer Genauigkeit und herausragender Gekonntheit dem talentvollen, musikalischen Stück von Stravinskij untergeordnet ist. Um allerdings den Schlüssel zu den Besonderheiten der primitiven Gesten oder der Impulse der Herde zu finden, wandte sich Nižinskij an Stickereien, sehr alte Lubki und im Allgemeinen an alle Arten von primitiven Gemälden.

Zwei Dinge hebt er hier an Musik und Tanz als besonders gelungen hervor:Zum einen, dass Nižinskij seine Choreografie in überzeugender Weise der Musik Stravinskijs „unterworfen“ habe; zum anderen, dass bei seinen primitiven

681 Valerian Svetlov: „Russkij Sezon” v” Pariže (ot našego korrespondenta). ,Svjaščennaja vesna'. Grandioznyj skandal" na pervom" predstavlenii baleta“, in: Peterburgskaja Gazeta, 23. Mai 1913 (julianischer Kalender), S. 14f., hier S. 15.

682 Anatolij LunAČARsKIJ: „Russkie spektakli v' Pariže“, in: Teatr i iskusstvo, Nr. 23, 9./22. Juni 1913, S. 486-488. Stanley Rabinowitz beschäftigte sich in einem Aufsatz mit insbesondere Lunačarskijs Ballets-Russes-Rezeption. Vgl. Stanley RABINowitz: „From the Other Shore: Russian Comment on Diaghilev's Ballets Russes“, in: Dance Research 27/1 (2009), S. 1-27. 
Gesten ein Einfluss russischer Lubki zu erkennen gewesen sei. ${ }^{683}$ Dies spezifiziert er einige Abschnitte später dann noch einmal wie folgt:

Но Стравинский и Нижинский [...] хотели воскресить примитивные пляски художественно, во всеоружии современной музыкально-оркестровой, балетной и декоративной техники. ${ }^{684}$

Aber Stravinskij und Nižinskij [...] wollten das Primitive der Tänze künstlerisch wiederbeleben, perfekt ausgerüstet mit moderner, musikalisch-orchestraler Ballett- und Bühnenausstattungstechnik.

Wie Minskij wertet auch Lunačarskij das dargestellte primitive Sujet des Balletts positiv und somit konträr zum Gros der Franzosen. Doch auch ihm geht es bei seinem Lob nicht um das Sujet selbst, sondern um die Art und Weise, wie Stravinskij und Nižinskij es auf die Bühne gebracht hatten: Sie hätten die primitiven Tänze mithilfe zeitgenössischer Orchester-, Ballettund Ausstattungstechnik in einer künstlerischen Form "wiederbelebt“. Lunačarskijs Wortwahl erinnert stark an Fuchs und jene von ihm geforderten neuen (Tanz-)Formen. Diese sollten ja gerade nicht auf altes Material zurückgreifen, sondern die primitiven Tänze in einer neuen künstlerischen Form wiedergeben und gleichzeitig die aus der Musik ausschwingenden Rhythmen widerspiegeln (Kapitel III.1.2.). Auch Sergej Volkonskijs Aussage erinnert ein wenig an Fuchs' Reformforderungen, wenn er in seiner Sacre-Rezension, die ebenfalls im Apollon erschien, die Art der Darstellung des Archaischen hervorhebt. Wie Lunačarskij ist er davon überzeugt, dass Stravinskij und Nižinskij etwas geschaffen hatten, das derart noch nie zuvor zu hören bzw. zu sehen gewesen war. Er begründet dies mit dem Argument, dass ihm die Bewegungen auf der Bühne intentionslos und naiv erschienen seien:

Архаичность въ движенияхъ-опасный элементъ. Редко ей верится на сцене она всегда кажеця чемъ-то деланымъ, исканымъ, нарочнымъ. Но я долженъ сказать, что здесь, съ перваго мгновения верилось, ни разу не было

683 Bei einem Lubok (Plural: Lubki) handelt es sich um Volksbilderbögen, die in Russland sehr populär waren. Sie erschienen seit circa Mitte des 17. Jahrhunderts als Holzschnitte, später als Kupferstiche, Radierungen und Drucke. Allgemeine Informationen zum Lubok finden sich unter anderem bei Stephen M. Norris: A War of Images. Russian Popular Prints, Wartime Culture, and National Identity. 1812-1945, DeKalb 2006, S. 4-10; Jeffrey Brooks: When Russia Learned to Read. Literacy and Popular Literature. 1861-1917, Princeton 1985, S. 62-67.

684 Lunačarskij, „Russkie spektakli v’ Pariže“. 
,нарочно؛. Я долженъ сказать, что въ первый разъ я поверилъ наивности на сцене. ${ }^{685}$

Das Archaische ist ein gefährliches Element bei Bewegungen. Selten glaubt man ihm auf der Bühne, es scheint immerzu etwas Hergestelltes, Gesuchtes, Absichtliches zu sein. Aber ich muss sagen, dass es hier vom ersten Moment an glaubhaft war, kein einziges Mal erschien es gewollt. Ich muss gestehen, dass ich erstmals der Naivität auf der Bühne Glauben geschenkt habe.

Auch hier lassen sich Analogien zu Fuchs ausmachen. Dieser hatte ja als Beispiel für die von ihm geforderte Tanzform den Schlaftanz der Magdeleine genannt, deren Bewegungen aufgrund von Hypnose aus dem unbewussten Inneren heraus entstanden waren. ${ }^{686}$

Es scheint also tatsächlich so, wie zu Anfang von Minskij skizziert: Sowohl französische als auch russische Kritiker erkannten im Sacre eine veränderte Ästhetik der Ballets Russes und machten diese am primitiven Sujet fest. Dessen jeweilige Bewertung fiel dann jedoch gegensätzlich aus: Während die Franzosen die archaischen Darstellungen im Sacre oft kritisierten und mitunter als fremd und/oder zu authentisch empfanden, beurteilten die Russen sie als positiv, und zwar weil die Choreografie der Musik untergeordnet schien und ihnen die Bewegungen eben nicht archaisch vorkamen, sondern unbewusst bzw. naiv und damit artifiziell.

Dass die russischen Rezensenten damit genau jene Tanzform beschrieben, deren Schaffung Fuchs in seiner Reformschrift Der Tanz gefordert hatte und die Stravinskij und Nižinskij umzusetzen geplant hatten, spricht für sich. Lediglich der dritte Reformpunkt, Gemeinschaftsrausch, war offenbar keinem der russischen Kritiker aufgefallen - ebensowenig wie jene mechanistische Ästhetik, die Minskij (in Bezug auf die Bewegungen der Tänzer) beschrieben hatte. War die Uraufführung des Sacre etwa schlicht kein rauschhaftes Gemeinschaftserlebnis gewesen? Und hatten Stravinskij und Nižinskij in diesem Punkt einfach nicht reüssiert?

2.3 Gemeinschaftsrausch und mechanistische Anklänge in der primitivistischen Sacre-Rezeption

„Primitivisme! Primitivisme!“687 Mit diesem Ausruf endet ein Abschnitt, in dem Jean Perros - wenngleich mit spürbarer Ermüdung - geschildert hatte,

685 Sergej VolkonskiJ: „Ptica i Čelovek“, in: Apollon 6 (1913), S. 39-43.

686 Vgl. Fuchs, „Der Tanz“, S. 21 sowie Kapitel III.1.2.1.

687 Jean Perros: „Opinions. Après les Ballets Russes“, in: La Critique Indépendante, 15. Juni 1913, S. 1, Sp. 1-3, hier Sp. 2. 
was die russische Ballettkompanie dem Pariser Publikum auch 1913 wieder geboten hatte:

Cette année encore, les fameux danseurs russes sont revenus, et avec eux, leurs costumiers, leurs accessoiristes, leurs décorateurs et dessinateurs, leurs metteurs en scène. [...] les Russes étaient venus et nous voyions enfin la lumière. Ils nous enseignaient la jeunesse, la candeur et la vérité. Ils nous offraient leur âme innocente, leur sensibilité jeune, leurs sentiments ingénus. Leur simplicité, leur ardeur, leur dévotion en face de la nature, voilà ce qui expliquait leur art et le rendait admirable. Ils étaient instinctifs comme des enfants. Ils ne raisonnaient pas leur vie, ils se laissaient aller à l'impulsion de leurs sens et tout ce qu'ils faisaient, tout ce qu'ils voyaient, tout ce qu'ils disaient portait la marque éblouissante du génie. ${ }^{688}$

Perros' Beitrag kann wohl als repräsentativ für jene positiv besetzte primitivistische Wahrnehmung der Ballets-Russes-Werke in Frankreich gesehen werden, die Minskij kritisiert hatte und die 1913 mit einem Mal ins Negative kippte. Und so ist durchaus nachvollziehbar, dass der Sacre sowohl in der Musik- als auch in der Tanzwissenschaft eine besondere Rolle einnimmt, wenn sich Forscher beider Disziplinen mit dem Phänomen des Primitivismus zu Beginn des 20. Jahrhunderts auseinandersetzen (Kapitel I.2.). Eine wichtige Rolle nimmt hierbei Jacques Rivières ausführlicher Sacre-Essay vom 13. November 1913 ein. ${ }^{689}$ Die Tanzwissenschaft hat ihn schon oft als einen der wichtigsten zeitgenössischen Beiträge über Nižinskijs Choreografie bezeichnet; ${ }^{690}$ Alexander Schwan macht darin „den ersten ausführlichen Kommentar zu Le Sacre du Printemps [aus], dessen Reflexionen über das Verhältnis von Tanz, Modernismus und die Denkfigur des ,Primitiven` wegweisend für die Tanzmoderne werden sollen “691. Taruskin hat bezüglich der primitivistischen Interpretation der Ballets-Russes-Werke einmal darauf hingewiesen, dass französische Kritiker damals dazu tendierten, in den Ballets Russes jene kreativen Bestrebungen erfüllt zu sehen, die sie sich selbst für ihre

688 Ebd., S. 1, Sp. 1f.

689 Vgl. Rivière, „Le Sacre du Printemps“', 1. November 1913. Eine ausführliche Analyse des Aufsatzes findet sich unter anderem bei Kennel, Bodies, Statues, and Machines, S. 236-252.

69 o Vgl. unter anderem Acocella, The Reception of Diaghilev's Ballets Russes, S. 35o; Kirstein, Nijinsky Dancing, S. 144; Hodson, Nijinsky's Crime Against Grace, S. xi; André LePECKI: "Am ruhenden Punkt der kreisenden Welt‘. Die vibrierende Mikroskopie der Ruhe“, in: ReMembering the Body. Körper-Bilder in Bewegung, hg. von Gabriele BRANDSTETTER und Hortensia VöLCKe RS, Ostfildern-Ruit 20oo, S. 334-366, hier S. 340-442; Sarah Kennel, Bodies, Statues and Machines, S. 236.

691 Schwan, „Queer Stupidity“, S. 70. 
eigene nationale Kultur erhofften. ${ }^{692}$ Und so sah er in Rivières primitivistisch geprägter Stravinskij-Eloge eher eine Anleitung für jene Literatur, die sich jener für Frankreich gewünscht hätte. ${ }^{693}$

Allein folgende Beschreibung Rivières klingt verblüffend deutlich nach dem dritten Reformpunkt Gemeinschaftsrausch, den Stravinskij und Nižinskij im Sacre umzusetzen gedachten:

Voici le sentiment devant nous désigné, fixé, représenté [...] Rien deplus émouvant que cette image physique des passions de lâme. C'est bien autre chose que leur expression par le langage articulé. Non pas profondeur plus grande, notation de détails en elles et de finesses que la parole ne pourrait atteindre. Mais par cette figure sensible nous sommes conduits plus près d'elles, nous sommes mis en leur présence d'une facon plus immédiate, nous les contemplons avant l'arrivée du langage, avant que ne s'empresse autour d'elles la foule innombrable et nuancée, mais bavarde, des mots. Pas besoin de traduire; ce n'est points un signe d'où il faille passer à la chose. Mais dans la nuit de l'intelligence, nous assistons; nous sommes là avec notre corps, et c'est lui qui comprend. Une certaine disposition, une certaine reconnaissance par l'intérieure... Chaque geste du danseur est comme un mot qui me rassemblerait. Si quelquefois il me paraît étrange, ce n'est qu'aux yeux de ma pensée; car d'emblée il se rencontre avec mes membres, avec le fonds de mon organisme dans une harmonie basse, pleine et parfaite. De même que la musique faisait entrer en nous son récit ,par gros morceaux faciles', c'est ainsi que nous considérons cette danse extravagante avec je ne sais quelle crédulité grossière et dans une intimité qui ,passe toute parole‘. Nous sommes devant elle comme les enfants à Guignol: ils n'ont pas besoin qu',on leur explique; mais ils rient, ils tremblent, ils comprennent à mésure. ${ }^{694}$

Ähnlich wie Lunačarskij und Volkonskij, die in der Choreografie eine gewisse Naivität zu erkennen glaubten, sieht auch Rivière das Innere der Tänzer nach außen gekehrt, wenn er ihre Bewegungen als physisches Bild ihrer Seele beschreibt. Was den Gemeinschaftsrausch angeht, erweist sich dann aber als ungleich interessanter, wenn er schildert, welchen Eindruck die auf der Bühne ausgeführten Bewegungen auf die Zuschauer gemacht hätten: Der Tanz wirke wie eine physische Sprache, die Rivière tiefsinniger, nuancierter und unmittelbarer erschien als ihr gesprochenes Pendant. Anders als die gesprochene sei diese physische Sprache auch nicht durch den Geist, sondern durch den Körper zu verstehen und brauche derart auch keinerlei Übersetzung: Selbst

\footnotetext{
692 Vgl. Taruskin, Stravinsky and the Russian Traditions, Bd. 2, S. 989.

693 Vgl. ebd., S. 988-994. Kennel macht ebenfalls darauf aufmerksam, dass der Sacre in Frankreich durch die Linse eines primitivistischen Diskurses gesehen wurde, der bereits seit der Jahrhundertwende existierte. Vgl. Kennel, Bodies, Statues, and Machines, S. 16; dies., „Primitivism, Popular Dance, and the Parisian Avant-Garde“, S. 114f.

694 Rivière, „,Le Sacre du Printemps“', 1. November 1913, S. 724 f.
} 
wenn der Geist einmal die dargebotenen Gesten als fremd oder sonderbar empfinde, absorbiere sie der gesamte Organismus mit all seinen Gliedmaßen sofort. Wie die Musik verstehe man derart das Bühnengeschehen in einer naiven und intimen Weise, die jedes Wort überflüssig mache. Schließlich vergleicht Rivière jenes physische vorsprachliche Erlebnis der Zuschauer und Zuhörer bei der Sacre-Premiere noch mit dem Erlebnis von Kindern, die vor (einem) Marionetten(-) oder Handpuppen(-Theater) stehen: Diesen Kindern müsse man nämlich nichts erklären, sie würden dennoch lachen, erschaudern und genau richtig verstehen.

Jenes körperlich empfundene Erschaudern und Verstehen, mit dem Rivière das Erlebnis der Zuschauer bzw. Zuhörer des Sacre beschreibt, deutet unmissverständlich auf den von Fuchs intendierten Gemeinschaftsrausch hin. Denn genau dies hatte er sich gewünscht: Das Theaterpublikum sollte durch den neuen Tanz in das rauschhafte Bühnengeschehen integriert und so zu einer gesteigerten Körperlichkeit erzogen werden - und damit schließlich zu einer neuen Kultur.

Nicht nur russische Kritiker, sondern auch einige französische Premierenbesucher scheinen also nolens volens erkannt zu haben, was 1913 auf der Bühne des Théâtre des Champs-Élysées geschehen war. Denn, wenn auch nicht bewusst, es beschreiben doch Anwesende beider Provenienz alle drei Reformforderungen, die Stravinskij und Nižinskij im Sacre umgesetzt hatten. Dennoch: Minskij scheint bislang der Einzige von ihnen zu sein, der in den Bewegungen der Tänzer eine wie auch immer geartete mechanistische Ästhetik zu erkennen vorgab. Rivières Vergleich der Zuschauer mit dem Publikum eines Marionettentheaters lässt allerdings aufhorchen: Vermittelten die dargebotenen Bewegungen der Tänzer etwa tatsächlich den Eindruck fremdgeleiteter Marionetten? Und wenn ja: Hatten andere Ähnliches beobachtet?

Liest man die französische Sacre-Berichterstattung vor dem Hintergrund von Minskij und Rivière, stößt man gleich mehrfach auf die von ihnen verwendeten Chiffren fürs Mechanische: den Automaten, die Puppe und/oder die Marionette. So schreibt beispielsweise Maurice Touchards in La Nouvelle Revue folgenden Absatz:

Cette cohue moutonnière, ces groupements peureux, ces piétinements, ces gestes maniaques de bête en cage, ces paniques soudaines, cet automatisme guignolesques sont, je le veux bien, le propre d'une humanité mal degrossie, puisqu'on en retrouve de nos jours des vestiges chez telle peuplade inculte. ${ }^{695}$

695 Maurice Touchard: „Ballets Russes et Français“, in: La Nouvelle Revue, 1. Juli 1913, ediert in: Bullard, The First Performance, Bd. 3, S. 173-179, hier S. 173. 
Touchard erweckt hier ganz den Eindruck, als empfinde er "guignolesque [also quasi (hand-)puppenartige] Automatismen" und Eigentümlichkeiten eines „unzivilisierten Volksstammes" als vergleichbar.

Auch bei Jean Chantavoine findet sich diese ungewöhnliche Gleichsetzung von Mechanischem und Archaischem, wenn er den Sacre in der französischen Illustrierten Excelsior rezensiert:

La choréographie veut évoquer sans doute la barbarie des âges primitifs et les gestes rituels d'une sauvagerie superstitieuse: ce sont de petits trépignements, des hochements de tête, des frémissements mécaniques où se combinent l'archaïsme du ,Faune' (encore!) et les pitreries guignolesques de ,Petrouchka'. $\mathrm{Au}$ second acte, la victime désignée gardant pendant dix minutes, avec une immobilité parfaite, une pose contournée qu'elle abandonne pour une danse incohérante. ${ }^{696}$

Zwar gibt er sich sehr überzeugt in der Annahme, dass Nižinskij durch die Choreografie die „Barbarei der Urzeit“ sowie „rituelle Gesten einer abergläubischen Wildheit" evozieren wollte, rekurriert dann aber, um dem Leser die tatsächlich ausgeführten Bewegungen auf der Bühne näherzubringen, auf das Bild des Mechanischen oder Puppenhaften und beschreibt eine der Bewegungen beispielsweise als "mechanisches Zittern“, das ihm wie eine Kombination aus Archaismen und puppenhaftem Klamauk erschien.

In der Theaterzeitschrift Comodia gibt auch Gustave de Pawlowski zu verstehen, dass ihm der Bewegungsstil im Sacre automatenartig vorgekommen sei:

Quelques gestes amusants, nouveaux, justes, suffisent à évoquer des peuplades barbares; il est inutile de les répeter trop longuement. [...] Au surplus, si l'idée générale de cet ouvrage nous paraît un peu faible, il n'en est pas moins vrai que par le soin avec lequel on le régla, par l'accord des gestes et de la musique, une sorte de stylisation étrange et nouvelle se dégage, un style que j'appellerai volontiers le style des mouvements réflexes, ou, si vous voulez, de l'automacité. ${ }^{697}$

Wie die russischen Kritiker Lunačarskij und Volkonskij, die ja in ihrer Rezension insbesondere die Kontrolle der unbewussten Bewegungen durch die Musik positiv hervorgehoben hatten, macht auch Pawlowski gerade am Zusammenspiel von Musik und Tanz jenen neuen Stil fest, den er beschreibt. Wie die beiden Russen beobachtete also auch er, dass die Bewegungen von

696 Jean Chantavoine: „Au Théatre des Champs-Élysées. ,Le Sacre du Printemps“隹: Excelsior, 3o. Mai 1913, S. 6.

697 Gustave DE PAwlowski: „Au Théâtre des Champs-Élysées. ,Le Sacre du printemps‘. Ballet en deux actes de M. Igor Stravinsky“, in: Comœedia, 31. Mai 1913, S. 1f., hier S. 2. 
der Musik geleitet und reflexartig ausgeführt wurden. Am Ende geht er dann allerdings noch einen Schritt weiter und vergleicht jene unbewussten Bewegungen mit denjenigen eines Automaten und merkt zusätzlich noch an, dass die Gesten der Tänzer in ihrer amüsanten Neuartigkeit genau richtig seien, um beim Publikum das Bild „primitiver Volksstämme“ hervorzurufen. Pawlowski sah im Sacre also nicht etwa ein tatsächliches Bild solcher Stämme vermittelt, sondern ging vielmehr davon aus, dass die von ihm beschriebenen automatenhaften Gesten der Tänzer beim Publikum ein solches evozieren würden. ${ }^{698}$ Einige Abschnitte später führt er dies noch weiter aus:

Il vous est arrivé sans doute d'être pris, dans une fête foraine, par cette sorte de vertige qui émane de la cacophonie orchestrale et de l'absurdité des gestes contradictoires que l'on remarque dans chaque boutique foraine. Lair que joue l'orgue des chevaux de bois n'est pas le même que celui des montagnes russes, la sirène de la machine à vapeur hurle sans se soucier des fanfares de victoire qui éclatent dans le tir, l'éclair de magnésium du photographe éclate pour son compte sans égard pour les coups de carabine ou les sonneries du jeu de massacre. Un général russe en sucre, juché sur un orgue, tape sur un triangle avec de petits gestes saccadés, d'autre automates, plus loin, se secouent, frénétiques, c'est un charivari intense dont se dégage cependant une étrange impression générale d'harmonie. C'est cette même impression que nous ressentonts devant ces gestes saccadés d'automates préhistoriques, devant ces attitudes spontanées et irraisonnées que nous offre ,Le Sacre du printemps', et tout cela, malgré les dissonances, donne une impression d'automaticité animale, de reflexes convulsifs d'un style très précis, d'un genre très délimite. Et n'est-ce poit tout justement cette impression d'animalité, de reflexes instinctifs que voulaient nous donner les auteurs? ${ }^{699}$

Ähnlich wie Rivière beschreibt Pawlowski das Rezeptionserlebnis als ein besonders intensives. Durch die „cacophonie orchestrale" und die „absurdité des gestes contradictoires" falle man in eine Art Taumel - einen Taumel, den er dann ausgerechnet mit dem Besuch eines Jahrmarkts vergleicht, wobei er erneut auf maschinenhafte und mechanische Bilder zurückgreift: Pferdekarusell

698 Auch Louis Laloy hatte das Gefühl, dass die dargestellten Tänze nicht primitiven Tänzen aus Russland entsprachen. Er geht davon aus, dass sich Nižinskij zwar möglicherweise an solchen orientiert, aus ihnen dann aber mechanische Bewegungen abgeleitet hatte: „M. Nijinsky n'a su que réunir, comme en une encyclopédie, des attitudes copiées un peu partout, depuis l'Afrique centrale jusqu'aux rivages samoyèdes, et de ces attitudes il n'a déduit que des mouvements mécaniques. S'il eût observé ces sauvages qu'il se donnait pour modèles, au lieu de feuilleter des traités d'ethnographie, il eût reconnu en leurs danses les plus désordonnées une sorte de grâce, et c'est cette grâce qu'il fallait s'attacher à reproduire." Vgl. Laloy, „La Musique“, S. 162.

699 De Pawlowski, „Au Théâtre des Champs-Élysées“, S. 2. 
und Achterbahnen, die Sirene der Dampfmaschine und der Magnesiumblitz des Fotografen, ein russischer General aus Zucker, der mit ruckartigen Gesten auf eine Triangel schlägt, sowie Automaten, die sich frenetisch schütteln. Sie alle dienen Pawlowski dazu, dem Leser jene „automaticité animale“ näherzubringen, die er in den auf der Bühne präsentierten „gestes saccadés d'automates préhistoriques“" zu erkennen glaubte.

In Pawlowskis oxymoronartiger Verschränkung archaischer und mechanischer Bilder wird nun noch deutlicher, was bereits bei Touchard und Chantavoine beobachtet werden konnte: Entweder empfanden die Rezensenten keinen allzu großen Unterschied zwischen den Gebärden „primitiver Volksstämme“ und den Bewegungen fremdgeleiteter Automaten, oder sie konnten sich schlicht nicht entscheiden, was von beidem denn nun zu sehen war: Glichen die „primitiven“ Gesten „(hand-)puppenartigen Automatismen", oder sah man hier fremdgeleitete Automaten, die sich reflexartig im Gewand „unzivilisierter Stämme“ bewegten?

Vielleicht lieferte Jacques-Émile Blanche (im Dezember 1913) in der Revue de Paris eine Antwort darauf. Er konnte sich nämlich auch ein halbes Jahr nach der skandalumwobenen Sacre-Premiere immer noch nicht erklären, warum Teile des Publikums auf die Darstellung eines so abscheulichen, archaischen Rituals wie des Opfertanzes im zweiten Akt derart belustigt reagiert hatten:

Que dire du second acte? L'entrée des vieillards-ours, puis la danse sacrale de l'Élue, après un prélude qui nous ramène encore en pleine campagne crépitante d'insectes, le second acte, beaucoup plus déconcertant pour l'oreille que n'était le premier, me parut simplement terrifiant. Que des spectateurs, même non prévenus, aient ri, au lieu d'être saisis d'une sorte d'angoisse, demeure inexplicable. L'on pouvait, à la fin, être furieux, on pouvait se colleter de loge à loge, s'insulter comme on le fit, soit! Mais pourquoi ces plaisanteries, ces quolibets de collégiens, pendant que se célébraient su la scène les rites funèbres de Demoiselle Élue?700

Eine Antwort auf diese Frage findet er beim französischen Philosophen und späteren Nobelpreisträger Henri-Louis Bergson. Über dessen Aufsatz Le Rire ${ }^{701}$ hatte er nämlich zuvor geschrieben:

M. Henri Bergson, dans son ,Essai sur le Rire', propose une célèbre explication de ce phénomène spécial à l'homme. Selon lui, l'une des plus fréquantes causes du rire, c'est le cas où un de nos semblables, devant nous rompant l'harmonie du

700 Blanche, „Un bilan artistique de 1913“, S. 517-534.

701 Vgl. Henri Bergson: Le Rire. Essai sur la signification du comique, Paris 1900. 
corps, par accident, par infirmité, prend l'aspect d'un automate, semble perdre contrôle sur lui-même. ${ }^{702}$

Der Sacre - so spezifiziert Blanche - „[déclenche] un rire irrépressible chez les spectateurs ${ }^{4703}$. Und deshalb würde Bergson auf seine Frage wohl Folgendes antworten: „Irrépressible rire, en face d'un automate passant du repos à une sorte de délire réglé et mécanique.“704

Auf die eigenartige Verschränkung von primitivistischen und mechanistischen Bildern in den Rezensionen zu Nižinskijs Sacre-Choreografie hat schon die amerikanische Kunsthistorikerin Sarah Kennel verwiesen. ${ }^{705}$ Sie sieht in Nižinskijs Choreografie zugleich den Wunsch als auch das Scheitern artikuliert, durch den Tanz zu körperlichen und kulturellen Ursprüngen zurückzukehren:

While the ballet tapped an entrenched set of discourses concering the category of the ,primitive', ,Sacre' exeeded its established visual and metaphorical boundaries by incorporating signs of the modern and mechanical. Although the ballet manifested all of the signs of the ,primitive' in its costumes, scenery, and narrative, the work nevertheless failed to yield the primary characteristics of what had come to signify as the ,primitive', particulary in dance: that is, the characteristics of spontaneity, freedom, naiveté, unhindered expression. All that had traditionally revealed the ,primitive' (and thus the antithesis of the modern) in dance was here reversed or negated by Nijinsky's conscientious stylisation of gesture and mechanisation of movement that verged on what one critic called ,automaticity. ${ }^{706}$

Das Ballett sei also vor allem im Tanz darin gescheitert, die vornehmlichen Wesenszüge des Primitiven auszustellen. Was hier wie eine Niederlage klingt, muss jedoch als Erfolg gewertet werden, wenn dieses Scheitern beabsichtigt war - und alles deutet darauf hin. Zwar lassen es die Quellen aufseiten der Produktion nicht zu, eine eindeutige Aussage darüber zu treffen, ob Stravinskij und Nižinskij für den Sacre eine Ästhetik des Mechanischen intendierten. Ihre Beschäftigung mit den Theaterreformtheorien der Zeit und insbesondere mit den Schriften Craigs und Fuchs' weist allerdings eindeutig darauf hin, dass sich Komponist wie Choreograf vor und während ihrer Arbeit an jenem epochalen Werk mit mechanischen und fremdgeleiteten Bewegungsabläufen auseinandergesetzt und außerdem mit dem Gedanken gespielt hatten, diese

\footnotetext{
702 Blanche, „Un bilan artistique de 1913“, S. 529.

703 Ebd.

704 Ebd., S. 533 .

705 Vgl. Kennel, Bodies, Statues, and Machines, S. 226-236.

706 Kennel, „Primitivism, Popular Dance, and the Parisian Avant-Garde“, S. 17. Vgl. auch Kennel, Bodies, Statues, and Machines, S. 232.
} 
mithilfe der Musik zu steuern. Kritiker sowohl aus Russland als auch aus Frankreich erkannten im Sacre jene drei Reformpunkte, die Stravinskij und Nižinskij zwischen 1911 und 1913 immer wieder diskutiert hatten: die Kontrolle der Bewegungen durch die Musik, die quasi unter Hypnose ausgeführten Gesten der Tänzer sowie den Gemeinschaftsrausch, der das Publikum spätestens in der Danse sacrale erfasste. Dass Rezensenten beider Provenienz dabei auf eine Ästhetik des Mechanischen verweisen, scheint nur konsequent. Denn durch die von Craig inspirierte und von Stravinskij und Nižinskij intendierte Kontrolle der Musik sind die von Fuchs geforderten unbewusst agierenden Subjekte nicht mehr von fremdgeleiteten (und unbelebten) Objekten zu unterscheiden. Die eigenartige Verschränkung von Primitivismus und Modernismus, die die Kritiker in Musik wie Choreografie des Sacre immer wieder beschrieben haben, muss also zwingend auch damit erklärt werden, dass der Komponist Ideen und Ideengebern der ,Theaterreform um 19oo' begegnet war. Zentrale Forderungen dieser Bewegung fanden am Premierenabend des Sacre den Weg von Deutschland über Russland nach Paris - ins Théâtre des Champs-Élysées. 